\title{
Arterial Function and Structure in Experimental Hypertension
}

Citation for published version (APA):

Lemkens, P. (2018). Arterial Function and Structure in Experimental Hypertension: Effects of NEP/ECE Inhibition. [Doctoral Thesis, Maastricht University]. Datawyse / Universitaire Pers Maastricht. https://doi.org/10.26481/dis.20181128pl

Document status and date:

Published: 01/01/2018

DOI:

10.26481/dis.20181128pl

Document Version:

Publisher's PDF, also known as Version of record

\section{Please check the document version of this publication:}

- A submitted manuscript is the version of the article upon submission and before peer-review. There can be important differences between the submitted version and the official published version of record.

People interested in the research are advised to contact the author for the final version of the publication, or visit the DOI to the publisher's website.

- The final author version and the galley proof are versions of the publication after peer review.

- The final published version features the final layout of the paper including the volume, issue and page numbers.

Link to publication

\footnotetext{
General rights rights.

- You may freely distribute the URL identifying the publication in the public portal. please follow below link for the End User Agreement:

www.umlib.nl/taverne-license

Take down policy

If you believe that this document breaches copyright please contact us at:

repository@maastrichtuniversity.nl

providing details and we will investigate your claim.
}

Copyright and moral rights for the publications made accessible in the public portal are retained by the authors and/or other copyright owners and it is a condition of accessing publications that users recognise and abide by the legal requirements associated with these

- Users may download and print one copy of any publication from the public portal for the purpose of private study or research.

- You may not further distribute the material or use it for any profit-making activity or commercial gain

If the publication is distributed under the terms of Article $25 \mathrm{fa}$ of the Dutch Copyright Act, indicated by the "Taverne" license above, 


\section{Arterial Function and Structure in Experimental Hypertension. Effects of NEP/ECE Inhibition}





\section{Arterial Function and Structure in Experimental Hypertension Effects of NEP/ECE Inhibition}


The studies presented in this thesis were financially supported by Dutch Top Institute Pharma projects: T2-108 (metalloproteases and novel targets in endothelial dysfunction) and T2-301 (renin-angiotensin system blockade beyond angiotensin II) and were performed within the Cardiovascular Research Institute Maastricht (CARIM).

Copyright (C) Pieter Lemkens 2018

ISBN 9789463801270

Printed by: Datawyse 


\title{
Arterial Function and Structure in Experimental Hypertension. Effects of $N E P / E C E$ Inhibition
}

\author{
PROEFSCHRIFT \\ ter verkerijging van de graad van doctor \\ aan de Universiteit Maastricht, \\ op gezag van Rector Magnificius, Prof. dr. Rianne M. Letschert, \\ volgens het besluit van het college van Decanen, \\ in het openbaar te verdedigen \\ op woensdag 28 November 2018 om 14.00 uur
}

door

Pieter Lemkens

Geboren op 31 December 1980 in Lewven 


\section{Promotor:}

Prof. dr. J.G.R. De Mey

Co-promotor:

Dr. P.M.H. Schiffers

Beoordelingscommissie:

Prof. dr. A. Bast (voorzitter)

Dr. W.M. Blankesteijn

Prof. dr. A.H.J. Danser (Erasmus University, Rotterdam)

Prof. dr. D. Henrion (University of Angers, Angers, France)

Dr. A.J.H.M. Houben 


\section{Table of contents}

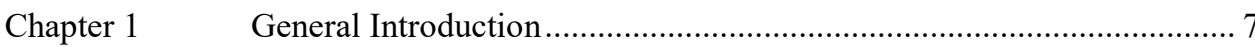

Chapter 2 Thrombospondin-1 in early Flow-Related Remodeling of

Mesenteric Arteries from Young Normotensive and

Spontaneously Hypertensive Rats

Chapter 3 ET -receptor Antagonists or Allosteric Modulators?

Chapter 4 Contractile Myo-Endothelial Coupling Involving

Endothelin-1 in Resistance Arteries from DOCA-Salt

Hypertensive Rats

Chapter 5 Impaired Flow-Induced Arterial Remodeling In DOCA-

Salt Hypertensive Rats

Chapter 6 Dual NEP/ECE Inhibition Improves Endothelial

Function in Mesenteric Resistance Arteries of Young

SHR

Chapter 7 Dual NEP/ECE Inhibition Improves Endothelial

Function in Mesenteric Resistance Arteries of 32 week

old SHR

Chapter 8

General Discussion 153

Chapter 9

Summary. 169

Chapter 10

Samenvatting 173

Appendix

Valorisatie addendum 178

Dankwoord 180

Curriculum Vitae 182

List of publications 183 



\section{Chapter 1}

General Introduction 


\section{Introduction}

\section{Hypertension and its Importance}

Hypertension or high blood pressure affects approximately 1 billion individuals worldwide. About $95 \%$ of patients with high blood pressure are considered to be suffering from primary or essential hypertension, since no specific cause has been identified for their condition [1]. High blood pressure is associated with an increased risk for mortality and morbidity from cardiovascular diseases, end-stage renal diseases and cerebrovascular events. The benefit of reducing blood pressure by anti-hypertensive treatment on risk reduction has been amply demonstrated by a large number of randomized clinical trials [2-10]. Despite progress in recent years in the prevention, detection, and treatment of high blood pressure (BP), hypertension remains an important public health challenge. Aging of the population and the upward trend in obesity, diabetes and high dietary salt intake predict continued increases in the total number of patients suffering from hypertension. Despite availability of more than 75 antihypertensive drugs in several classes, BP control in the general population remains inadequate. Although the proportions of hypertensive patients treated and controlled markedly increased during the past decade it appears that $1 / 3$ of the hypertensive patients are not being treated and that in another $1 / 4$, treatment failed to lower blood pressure.

\section{Blood pressure control}

Blood pressure is a reflection of the amount of blood pumped by the heart per minute (cardiac output) and the ease with which the blood flows through the peripheral vasculature (vascular resistance). Because in most forms of chronic hypertension cardiac output is within a normal range, the hemodynamic hallmark of hypertension lies within an increased peripheral resistance [11]. The basic relationship between arterial pressure, cardiac output and total peripheral resistance (TPR) is given by:

$$
\mathrm{MAP}=\mathrm{CO} \cdot \mathrm{TPR}
$$

where $\mathrm{CO}$ is cardiac output and MAP is mean arterial pressure.

Total vascular resistance can be approximated by Poisseuille's law for a vascular network:

$$
\mathrm{R}=\frac{1}{\mathrm{~N}} \cdot \frac{8 \eta \mathrm{L}}{\pi \mathrm{r}^{4}}
$$

where $\mathrm{N}$ is the number of vessels involved, $\mathrm{r}$ the radius of the vessels $(\mathrm{m}), \mathrm{L}$ the length of the vessels $(\mathrm{m})$ and $\eta$ is the viscosity of the blood (N.s $\left./ \mathrm{m}^{2}\right)$. Since the radius is 
expressed in the fourth power in the equation, vascular resistance and pressure are markedly affected by relative small changes in vessel lumen diameter.

The relationship MAP $=\mathrm{CO} * \mathrm{TPR}$ states the basic determinants of arterial pressure and provides a framework for understanding the influences of various factors that control pressure and that are of importance for hypertension.

\section{Resistance artery structure}

Resistance-sized arteries consist of three distinct layers separated by two elastic laminae (Figure 1.1). The endothelium or the tunica intima lines the inside of a blood vessel, forming a barrier between the blood stream and the vascular smooth muscle cell layer, the tunica media. Both layers are separated by the lamina elastica interna. The outer layer or the tunica adventitia is separated from the tunica media by the lamina elastica externa. Between the tunica media and the tunica adventitia nerve fibers are found. These are both afferent sensorimotor and efferent sympathetic (e.g. [12]).

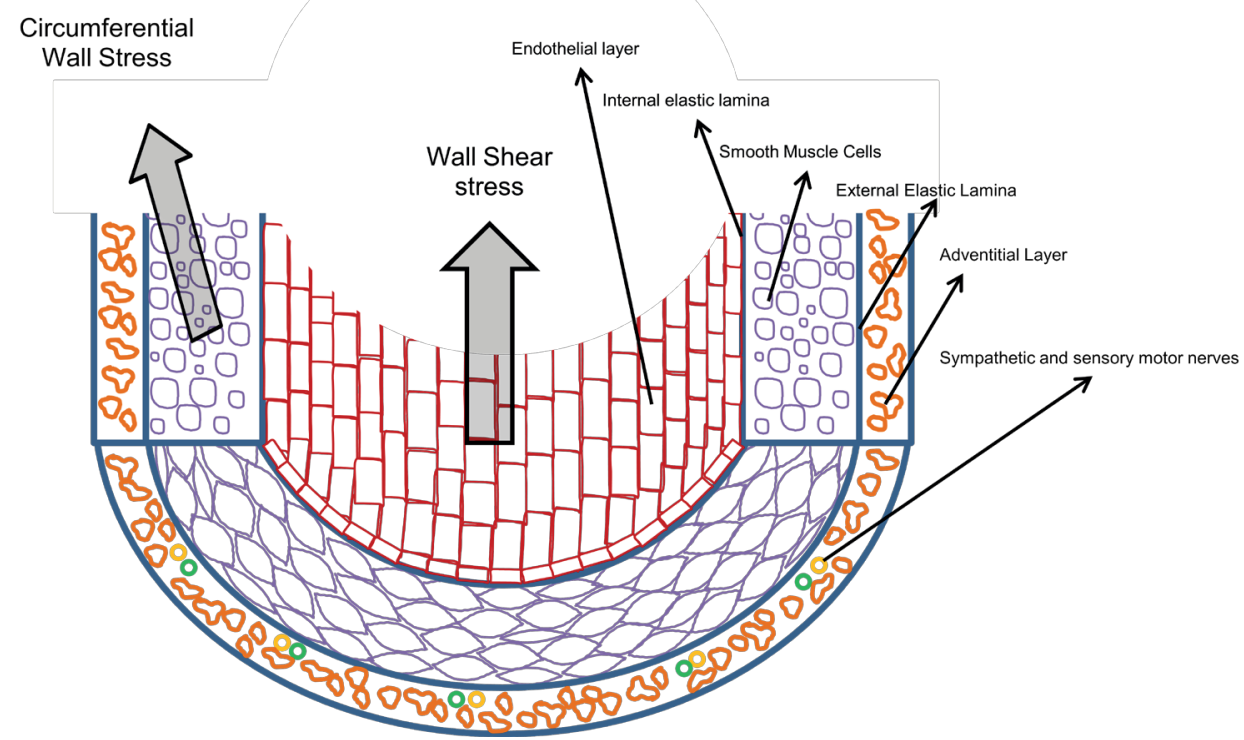

Figure 1.1: Schematic overview of the structure of resistance arteries and the hemodynamic forces which they are exposed to.

\section{Mathematic relation between hemodynamic forces and arterial wall structure}

Arteries are continuously exposed to the pulsatile mechanical forces resulting from the blood pressure and blood flow. Blood pressure causes tangential forces on the vessel 
wall, known as circumferential wall stress (CWS), that affect the cellular and extracellular matrix components of the entire arterial wall. This CWS is defined by the law of Laplace:

$$
\mathrm{CWS}=\frac{\mathrm{TP} \cdot \mathrm{r}}{\mathrm{Wt}}
$$

where TP is transmural pressure $\left(\mathrm{N} / \mathrm{m}^{2}\right), \mathrm{r}$ is lumen radius $(\mathrm{m})$ and $\mathrm{Wt}$ is wall thickness (m) of the vessel wall. Vascular smooth muscle cells are known to be the sensor of this force and translate this into biochemical signals.

Blood flow, on the other hand, is sensed by the endothelium as a frictional force of the streaming blood. This dragging force on the endothelium, called wall shear stress (WSS), is defined by the law of Pousseuille:

$$
\text { WSS }=\frac{4 \cdot \eta \cdot Q}{\pi \cdot r^{3}}
$$

where $\eta$ is the blood viscosity, $\mathrm{Q}$ is the blood velocity, and $\mathrm{r}$ is the lumen radius of the vessel.

Acute changes in pressure and flow result in transient adjustments of the vascular wall lumen diameter, mediated by myogenic contractile responses or release of paracrine vasoactive factors that aim to restore CWS and WSS. An acute increase in blood pressure causes narrowing or constriction of the artery (myogenic tone) [13], while an acute rise in blood flow results in widening or dilatation of the vessel (flow-induced dilatation) [14]. On the other hand, chronic changes in blood pressure and flow result in structural adaptations (remodeling) of the arterial wall (diameter and wall mass changes) to normalize CWS and WSS [15-17]. Many cardiovascular diseases are characterized by arterial remodeling, alterations in shape, composition and function. For instance, hypertension is characterized by absolute or relative wall thickening in small resistance arteries resulting in smaller lumen diameters and thus increased total peripheral resistance [18].

\section{Pathogenesis of hypertension}

Important information about the pathogenesis of hypertension has been derived from studies in man, but also through the development of experimental models of hypertension, primarily in rodents (Table 1.1). In almost all clinical and experimental forms of hypertension, blood pressure is maintained by elevated peripheral vascular resistance. Five main theories have been proposed in this respect: (1) hyperactivity of the sympathetic nervous system, (2) changes in kidney function, (3) vascular smooth muscle hyperreactivity, (4) endothelial dysfunction and (5) arterial remodeling. In this thesis the focus will be on the latter three aspects (Figure 1.2). Other factors which can 
broadly be classified as genetic and environmental, contribute as risk factors [19]. These include diabetes, obesity, high dietary salt intake, stress, heredity and aging.

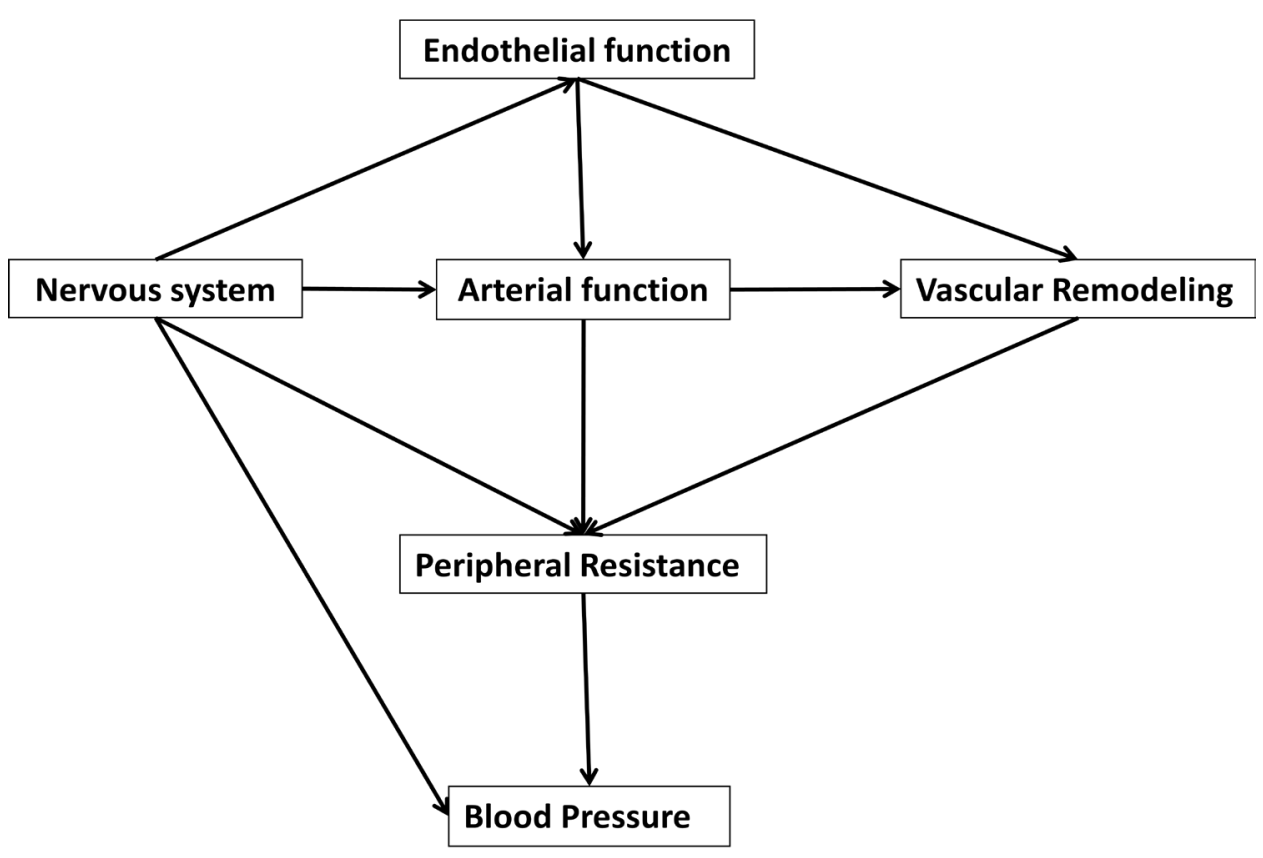

Figure 1.2: Possible interactions of arterial structures and peripheral resistance/blood pressure.

Hyperactivity of the sympathetic nervous system could have many consequences that ultimately lead to high blood pressure. These include increased release of noradrenaline from peripheral nerve endings activating adrenoceptors on blood vessels, the release of catecholamines from the adrenal medulla, the release of renin from juxtaglomular cells and the subsequent multiple actions of angiotensin II [20].

There is an important role for the kidney in the initiation of increased vascular resistance as observed in hypertension. The two main mechanisms that are believed to be involved are: (i) impaired salt and water excretion and (ii) increased renin secretion. If urine excretion is impaired, blood pressure will rise and thereby restore urine output at the expense of hypertension [21]. This shift in renal function could be the result of impaired nephrogenesis during early developmental stages [22], a genetic abnormality of the kidney function, an increased sympathetic nervous system activity or the actions of angiotensin II and aldosterone. Renin dependent hypertension in man is associated with some forms of secondary hypertension i.e. renin secreting tumors and renal artery stenosis [23]. Animal models of an altered RAS system are the $2 \mathrm{~K}-1 \mathrm{C}$ and $1 \mathrm{~K}-1 \mathrm{C}$ rat models of hypertension (Table 1.1). In these models, the RAS is involved in the initiation of high blood pressure by the acute vasopressor action of angiotensin II (Table 
1.1) [24]. The mechanisms that maintain the elevated blood pressure in the chronic phase may involve sodium and water retention and structural vascular changes [11].

\begin{tabular}{ccc}
\hline Species & Model & References \\
\hline Rat & Goldblatt 1K-1C & {$[25]$} \\
\hline Rat & Goldblatt 2K-1C & {$[25]$} \\
\hline Rat & Aortic coarctation & {$[23]$} \\
\hline Rat & Transgenic Ren & {$[26]$} \\
\hline Rat & Dahl-sensitive & {$[27]$} \\
\hline Rat & DOCA-salt & {$[28]$} \\
\hline Rat & SHR & {$[30]$} \\
\hline Rat & Chronic L-NAME infusion & {$[31]$} \\
\hline Rat & Chronic Ang-II infusion &
\end{tabular}

Table 1.1: Rat experimental models of hypertension. $1 \mathrm{~K}-1 \mathrm{C}=$ one kidney one clip, $2 \mathrm{~K}-1 \mathrm{C}=$ two kidney one clip; SHR, spontaneously hypertensive rat.

\section{Vascular function and structure in the development of hypertension}

\section{Endothelial-dysfunction and arterial tone (flow/pressure), acute effects}

Functional changes in vascular smooth muscle cells have been described to contribute in the development of hypertension. There is evidence in the literature indicating that arteries from SHR have an increased sensitivity to contractile substances. This increased sensitivity is suggested to be a result of an altered receptor affinity for particular agonists (e.g. noradrenaline, serotonin and angiotensin-II), an increase in the density of the receptors for these stimuli or an alteration in control of the contractile machinery within the arterial smooth muscle cells.

It is now well established that endothelial cells are important regulators of cardiovascular function [32-34]. First of all endothelial cells form a barrier between the blood stream and the vascular smooth muscle cells. This position explains the pivotal role of the endothelium as a sensor of WSS and the importance of the endothelium in the initiation of inflammatory processes. Moreover endothelial cells can produce vasoactive factors (relaxing, e.g. nitric oxide [33], EDHF [35], prostacyclin [36, 37], and contracting, e.g. prostanoids [37], endothelin-1 [38], ...), that can inhibit or stimulate contractile reactivity of vascular smooth muscle. Under physiological conditions, endothelium-derived relaxing factors (EDRF) appear to dominate over endothelium-derived contracting factors (EDCF). In a variety of experimental models of hypertension there is an imbalance between EDRF and EDCF favoring the latter [35, 
37, 39-43]. This imbalance may be important in the pathogenesis of hypertension and its cardiovascular complications (Figure 1.3).
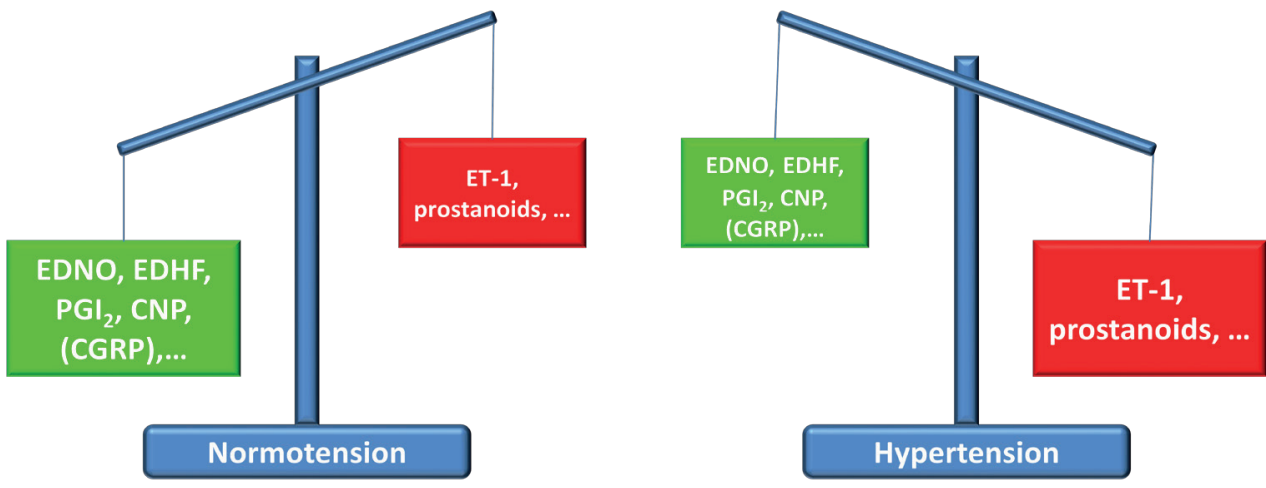

Figure 1.3: Balance between (endothelium derived) relaxing factors (EDRFs) and (endothelium derived) vasoconsticting factors (EDCFs). The picture on the left shows an example of a "healthy" balance. The picture on the right shows an example of a disbalance between EDRFs and EDCFs in pathological conditions.

Traditionally, interaction between the endothelial and vascular smooth muscle cells was considered to be a one way communication. Over the years, more and more evidence emerged proving that the communication can go both ways. Several studies show the existence of heterocellular myoendothelial junctions [44-47]. Through these gapjunctions, current, ions and small second messengers can diffuse from endothelial cells to vascular smooth muscle cells and vice versa. For instance, conductance of endothelium derived hyperpolarizing factor occurs through these myoendothelial gapjunctions [48, 49]. Even during vasoconstriction, a signal can originate in the vascular smooth muscle cells and prompt the endothelium to synthesize endothelium derived vasoactive factors $[49,50]$.

At the abluminal side of the medial layer sensory-motor nerves (SMN) and sympathetic nerves [12] have the ability to produce and secrete vasoactive factors such as NO, neuropeptide Y (NPY), substance P, ATP, noradrenaline (NA) and calcitonin-gene related peptide (CGRP) [12, 51]. These factors can influence the balance depicted in Figure 1.3. Thus nerves in the adventitial layer can influence arterial function and possibly compensate for or contribute to endothelial dysfunction in hypertension.

\section{Endothelial-dysfunction and arterial structure, long term effects}

Last but not least, vascular structure by itself can also participate in the resistance defect, as observed in hypertension. The importance of structural changes is demonstrated by: (i) the observation that different vascular beds in essential hypertension, and animal models of hypertension (SHR) show a higher flow resistance 
under conditions of maximal dilatation induced pharmacologically or by reactive hyperemia, (ii) the presence of structural alterations in blood vessels prior to the development of hypertension and (iii) the effects of antihypertensive therapy on vascular structure in essential and experimental models of hypertension. There is also some evidence that both the sympathetic nervous system and the endothelium may be involved in the regulation of vascular structure by trophic influences on the vascular smooth muscle [52-57].

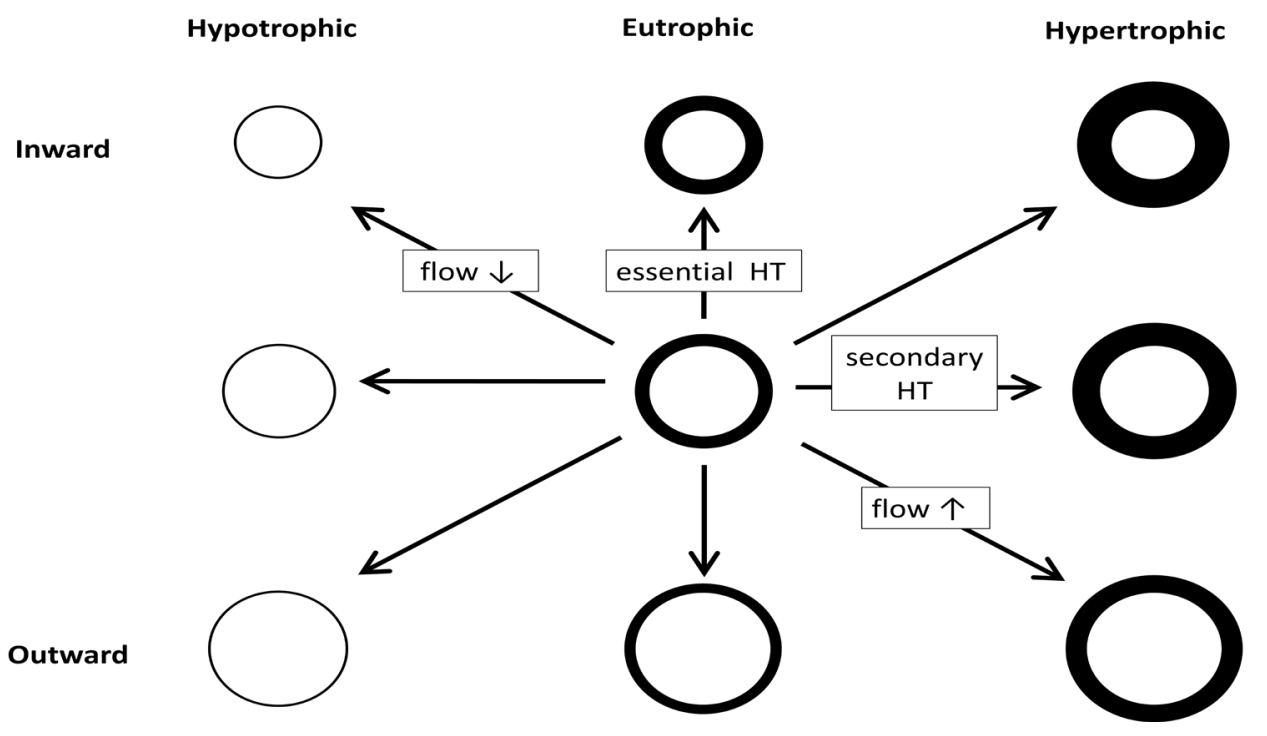

Figure 1.4: Arterial remodeling events (adapted from ref [17]) as a result of chronic changes in wall shear stress/circumferential wall stress

Bakker and colleagues stated that structural remodeling, caused by a decrease as well as an increase in flow, is facilitated by inflammation. Vascular tone on the other hand is a crucial determinant for the direction of the remodeling response [58]. In both parts of this process the endothelium plays a central role. This also means that endothelial dysfunction could have a serious impact on peripheral resistance, not only acutely but also chronically through vascular remodeling. In hypertensive humans as well as experimental hypertension, remodeling of resistance arteries is observed [15, 59-64]. Resistance artery remodeling in hypertension can in most instances be characterized by an increase in wall to lumen ratio (Figure 1.4). In essential hypertension, arterial remodeling is usually described as inward and eutrophic; i.e. resulting from rearrangement of the medial material around a smaller diameter [15]. In this case the increase in wall to lumen ratio is mainly caused by a decrease of the lumen diameter. The arterial changes in secondary hypertension, on the other hand, are mainly hypertrophic in nature and involve smooth muscle cell hypertrophy and/or hyperplasia 
$[15,16]$. The main contributor to the increased wall to lumen diameter in these models is hypertrophy (Figure 1.4).

To study the effects of changes in blood flow on resistance artery structure, experimental models were designed to impose flow changes in vascular beds. Blood flow-modifying surgery in the mesenteric bed is often used to impose such conditions. These conditions are created by distal ligation of alternate first-order mesenteric arteries chronically exposing these arteries to low blood flow (LF). The patent arteries between these then had a compensatory increased blood flow (HF) (Figure 1.5) [16, 65-72].

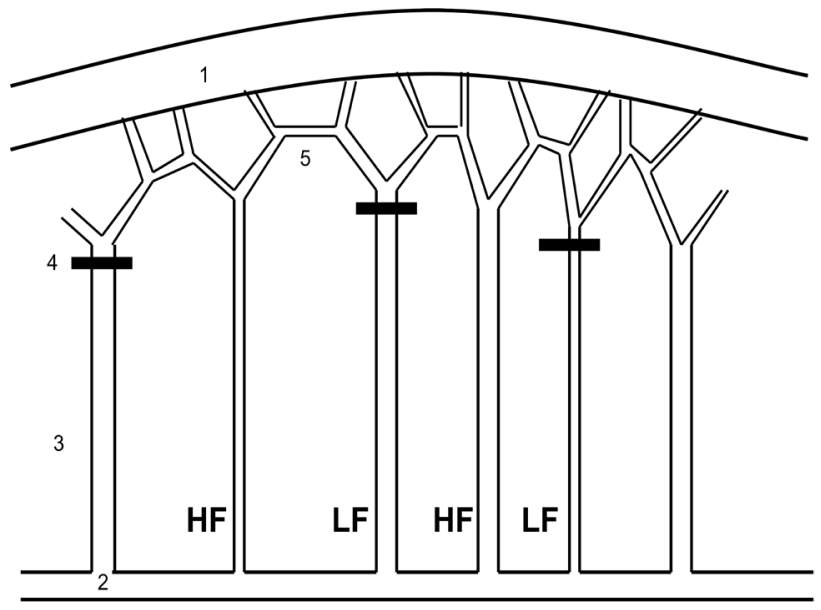

Figure 1.5: Schematic representation of the applied ligation model. 1: Ileum, 2: superior mesenteric artery, 3: First order branch, 4: ligation, 5: collateral. Low flow (LF) and high flow (HF) arteries are shown on the figure, normal flow (NF) arteries are harvested from a distal part of the mesentery. Figure adapted from [72]

In young healthy animals the remodeling response to prolonged increases in flow is outward hypertrophic remodeling, while a decrease in flow leads to inward hypotrophic remodeling [16, 68, 70, 72-74]. In hypertensive animals the situation is more complicated. Resistance-sized arteries have already changed structurally in relation to the hypertension. Moreover hypertension is often accompanied by endothelial dysfunction which can have a major influence on the ability of these arteries to react to changes in blood flow.

Only few studies exist investigating flow-induced arterial remodeling in relation to hypertension. Bouvet et al. showed that obese Zucker rats showed an outward remodeling response in response to high flow to the same proportions as lean rats. They did however not develop (additional) hypertrophy [75]. Gao et al. applied the same model in young WKY and SHR. They observed an impaired outward remodeling response and marked hypertrophy in SHR [76]. These authors did not investigate the effects of a decrease in flow. Ceiler et al. observed that flow-induced remodeling is insensitive to chronic L-NAME induced hypertension [70]. This questions the direct relationship between flow-induced vasodilatation and flow-induced arterial remodeling, that is frequently proposed by others $[77,78]$. 


\section{Treatment of Hypertension (in relation to above items)}

The main goal of current anti-hypertensive treatment is focused on blood pressure reduction. Because peripheral resistance is the main contributor to established high blood pressure, the aim could be considered tackling the symptoms and not the cause of the pathology. In this light it might be equally important to not only lower blood pressure but also to attempt to ameliorate structural and functional changes in arteries contributing to the peripheral resistance. In other words it might be equally important to reverse arterial structure and normalize (arterial) endothelial function. Table 1.2 summarizes current knowledge about effects of antihypertensive treatments on arterial structure and function.

\begin{tabular}{ccccc}
\hline & $\begin{array}{c}\text { Blood } \\
\text { Pressure }\end{array}$ & $\begin{array}{c}\text { Arterial } \\
\text { structure }\end{array}$ & $\begin{array}{c}\text { Arterial } \\
\text { function }\end{array}$ & References \\
\hline Alpha blockers & $\downarrow$ & $?$ & $+/-$ & {$[79]$} \\
\hline Beta-blockers & $\downarrow$ & - & $+/-$ & {$[80]$} \\
\hline Ca channel antagonists & $\downarrow$ & + & $+/-$ & {$[81]$} \\
\hline Diuretics & $\downarrow$ & $+/-$ & - & {$[82]$} \\
\hline Vasodilators/NO & & & & {$[83]$} \\
DONORS & $\downarrow$ & $?$ & $?$ & {$[84]$} \\
\hline Aldosterone antagonists & $\downarrow$ & + & $+/-$ & {$[85]$} \\
\hline ACE inhibitors & $\downarrow$ & ++ & + & {$[85]$} \\
\hline ARBs & $\downarrow$ & + & + & {$[86]$} \\
\hline Renin inhibitors & $\downarrow$ & $?$ & + & {$[87]$} \\
\hline ERA & $\downarrow$ & $(+)$ & + & {$[88]$} \\
\hline NEP/ECE inhibitors & $\leftrightarrow$ & $?$ & $?$ & \\
\hline
\end{tabular}

Table 1.2: overview of current therapies. $\mathrm{ACE}=$ angiontensin converting enzyme, $\mathrm{ARB}=$ angiotensin receptor blockers, ERA $=$ endothelin receptor antagonists, $\mathrm{NEP}=$ neutral endopeptidase, $\mathrm{ECE}=$ endothelin converting enzyme.

\section{Endothelin-1, Endothelin-1 receptors and endothelin receptor antagonists}

The endothelium-derived contractile factor endothelin-1 (ET1), as identified and characterised by Yanagisawa in 1988, is a very potent vasoconstrictor, has mitogenic effects on vascular smooth muscle cells and promotes fibrosis [38, 89-91]. An up regulation of the ET1 system has been linked to numerous pathologies, including moderate to severe hypertension, salt-sensitive hypertension and experimental models like the Dahl salt-sensitive rat and DOCA-salt hypertension [92-95] and genetic hypertension models like the spontaneously hypertensive rat (SHR) [96]. 
ET1 can bind to Endothelin ${ }_{\mathrm{A}}\left(\mathrm{ET}_{\mathrm{A}}\right)$ and Endothelin $\mathrm{B}_{\mathrm{B}}\left(\mathrm{ET}_{\mathrm{B})}\right.$ receptors, both present in the vasculature, thereby mediating vasoconstriction $\left(\mathrm{ET}_{\mathrm{A}}\right)$ and counteracting the effects of $\mathrm{ET}_{\mathrm{A}}$, by endothelium dependent vasodilation and clearance of ET1 through binding to the $\mathrm{ET}_{\mathrm{B}}$ receptor [97-101]. Whenever the $\mathrm{ET}_{\mathrm{A}}$ receptor activation by ET1 becomes dominant and in consequence is not in equilibrium with EDRF's, i.e. endothelial dysfunction (Figure 1.2), cardiovascular problems can arise. The development of ET receptor antagonists, selective for $\mathrm{ET}_{\mathrm{A}}$ or non-selective against $\mathrm{ET}_{\mathrm{A}}$ and $\mathrm{ET}_{\mathrm{B}}$, therefore became the next step to encounter the development of primary hypertension and other cardiovascular diseases, in addition to well known clinically approved antihypertensive drugs.

In time, endothelin receptor antagonists appeared to have less efficacy in cardiovascular conditions like primary hypertension, but have major beneficial effects in treating pulmonary arterial hypertension (bosentan and ambrisentan) $[102,103]$. Future research is needed to resolve the complex pharmacology of $\mathrm{ET}_{\mathrm{A}}$ receptors. To elaborate further on the pharmacological opportunities to treat primary hypertension, in the context of this system, also the enzymes involved producing/degrading ET1, are of great of interest.

\section{Functions of the metalloproteases endothelin converting enzyme (ECE) and neutral endopeptidase (NEP)}

Neutral endopeptidase (NEP) and endothelin converting enzyme (ECE) are structurally similar metalloproteases. They are both involved in the production and in the breakdown of several vasoactive peptides like, bradykinin, Ang I, Ang II, natriuretic peptides (ANP,BNP and CNP), substance $\mathrm{P}, \mathrm{CGRP}$ (a functional antagonist of $\mathrm{ET}_{\mathrm{A}}$ receptors) and ET1 (Figure 1.6). Furthermore, NEP and ECE are pivotal in the biosynthesis of ET1. ET1, a major EDCF, can be formed through cleavage of big-ET1 by endothelin-converting enzyme (ECE). Alternatively big-ET1 can be hydrolyzed by chymase or MMP-2 to form ET1 (1-31) or ET1 (1-32), respectively. These intermediates can then be further processed into ET1 (1-21) by neutral endopeptidase (NEP) [104-106]. 


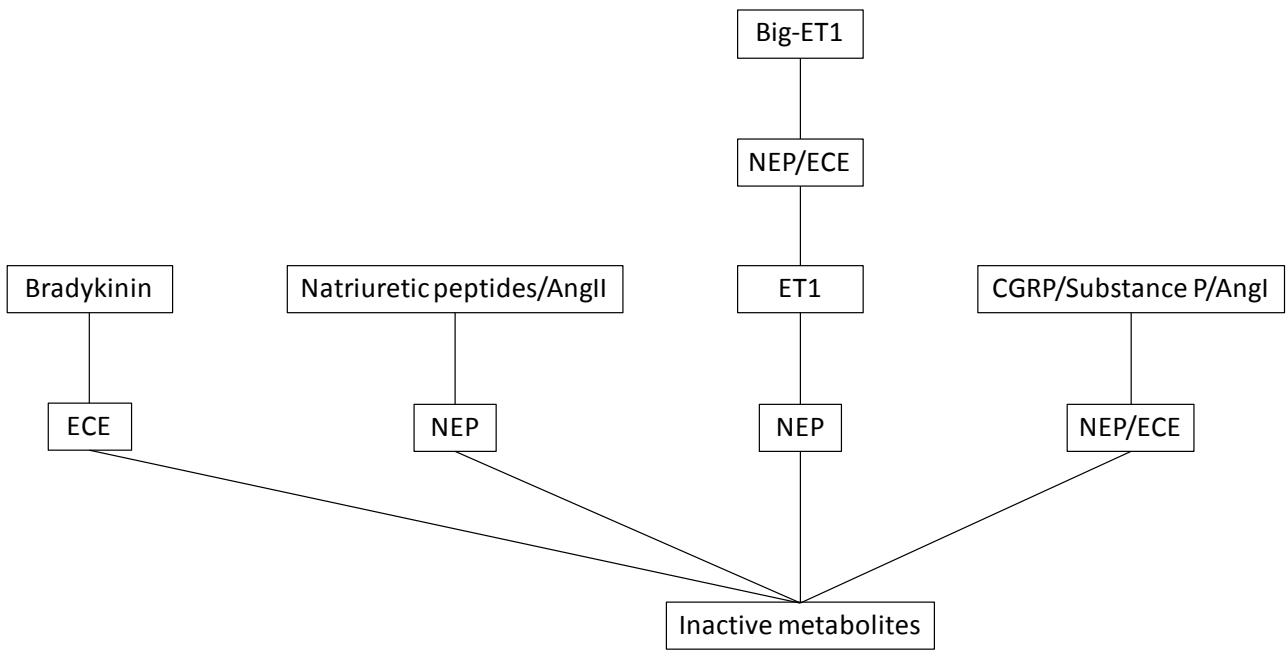

Figure 1.6: Possible involvement of NEP and ECE in the metabolism of vasoactive compounds

Inhibition of ECE, NEP or ECE/NEP will therefore influence blood and tissue levels of ET1 (and other vasoactive peptides (Figure 1.6) and will have physiological consequences as discussed next.

\section{ECE-inhibition}

Although preclinical studies with selective ECE-inhibition show some promise (e.g. Martin [107]), selective ECE inhibitors have not emerged into clinical applications. Moreover, several studies indicate that a reduction in ECE activity leads to accumulation of amyloid $\beta$-peptide, which is associated with neurotoxicity early in progression of Alzheimer's disease [108-111].

\section{NEP-inhibition}

Candoxatril was the first potent, orally available NEP inhibitor. Although effective in preventing the breakdown of ANP, BNP and CNP [112] and thus prolonging their cardiovascular effects, Candoxatril's effects on BP in hypertensive patients were not clinically meaningful [113]. One study even reported BP elevations among normotensive patients who were given candoxatril [114] which was likely to be contributed to increased Ang II [115] and endothelin-1 [116] activity as a consequence of neprilysin inhibition.

\section{ECE/NEP-inhibition}

SLV306 (daglutril) is an orally active, mixed enzyme inhibitor of both ECE and NEP. It is a pro-drug being converted in vivo to the active metabolite, $\mathrm{KC}-12615$. 
The effect of a SLV306 has been tested in volunteers in a randomized, double-blind trial. Following oral administration of three increasing doses of SLV306, big ET1 was infused into healthy volunteers. SLV306 dose-dependently attenuated the rise in blood pressure after big ET1 infusion and a significant increase in circulating big ET1 levels compared with placebo was observed, indicating that SLV306 was inhibiting an increasing proportion of endogenous ECE activity. Plasma ANP concentrations also significantly increased which is consistent with systemic NEP inhibition [117].

Parvanova et al. (2013) tested the efficacy of SLV306 in patients with type 2 diabetes mellitus who had albuminuria and were already receiving the angiotensin receptor antagonist losartan, together with up to two additional anti-hypertensive drugs. The authors showed for the first time that the combination decreased ambulatory blood pressure (particularly for systolic hypertension) in this patient group which is often resistant to treatment. These promising findings give reason to further investigate the beneficial cardiovascular effect of dual ECE/NEP inhibition in hypertension [118].

\section{Goal of this thesis}

It is well established that endothelial dysfunction and arterial remodeling contribute to the pathophysiology of hypertension. Whether hypertension affects the ability to respond to imposed changes in shear stress and circumferential wall stress is poorly characterized. Therefore we aimed to (i) characterize the nature of the endothelial dysfunction and the impact on vascular remodeling in rat models of hypertension and (ii) establish dual NEP/ECE inhibition as a treatment option with added value in hypertension.

To this end we first elaborate on the peculiar molecular pharmacology of the $\mathrm{ET}_{\mathrm{A}}$ receptor (Chapter 3)

Secondly we investigated the nature of the endothelial dysfunction in a genetic (Chapter 2, 6 and 7) and a non-genetic (Chapter 4 and 5) rat model of hypertension.

Next we investigated whether endothelial dysfunction altered the ability of arteries to respond to imposed shear stress changes (Chapter 2, 5, and 6).

Thirdly we investigated whether chronic NEP/ECE-inhibition improved endothelial function and arterial remodeling in genetic and non-genetic hypertension (Chapter 5, 6 and 7). Finally we discuss our observations in relation to earlier observations made within this topic (Chapter 8). 


\section{References}

[1] Chobanian AV, Bakris GL, Black HR, et al. Seventh report of the Joint National Committee on Prevention, Detection, Evaluation, and Treatment of High Blood Pressure. Hypertension 2003; 42: 1206-52.

[2] Major cardiovascular events in hypertensive patients randomized to doxazosin vs chlorthalidone: the antihypertensive and lipid-lowering treatment to prevent heart attack trial (ALLHAT). ALLHAT Collaborative Research Group. JAMA 2000; 283: 1967-75.

[3] Cohn JN, Archibald DG, Ziesche S, et al. Effect of vasodilator therapy on mortality in chronic congestive heart failure. Results of a Veterans Administration Cooperative Study. N Engl J Med 1986; 314: 1547-52.

[4] Kostis JB, Davis BR, Cutler J, et al. Prevention of heart failure by antihypertensive drug treatment in older persons with isolated systolic hypertension. SHEP Cooperative Research Group. JAMA 1997; 278: 212-6.

[5] Hansson L, Lindholm LH, Ekbom T, et al. Randomised trial of old and new antihypertensive drugs in elderly patients: cardiovascular mortality and morbidity the Swedish Trial in Old Patients with Hypertension-2 study. Lancet 1999; 354: 1751-6.

[6] de Leeuw PW, Ruilope LM, Palmer CR, et al. Clinical significance of renal function in hypertensive patients at high risk: results from the INSIGHT trial. Arch Intern Med 2004; 164: 2459-64.

[7] Staessen JA, Fagard R, Thijs L, et al. Randomised double-blind comparison of placebo and active treatment for older patients with isolated systolic hypertension. The Systolic Hypertension in Europe (Syst-Eur) Trial Investigators. Lancet 1997; 350: 757-64.

[8] Wang JG, Staessen JA, Heagerty AM. Ongoing trials: what should we expect after ALLHAT? Curr Hypertens Rep 2003; 5: 340-5.

[9] Collins R, Peto R, MacMahon S, et al. Blood pressure, stroke, and coronary heart disease. Part 2, Short-term reductions in blood pressure: overview of randomised drug trials in their epidemiological context. Lancet 1990; 335: 827-38.

[10] Liebson PR, Grandits GA, Dianzumba S, et al. Comparison of five antihypertensive monotherapies and placebo for change in left ventricular mass in patients receiving nutritional-hygienic therapy in the Treatment of Mild Hypertension Study (TOMHS). Circulation 1995; 91: 698-706.

[11] Folkow B. Physiological aspects of primary hypertension. Physiol Rev 1982; 62: 347-504.

[12] De Mey JG, Megens R, Fazzi GE. Functional antagonism between endogenous neuropeptide $\mathrm{Y}$ and calcitonin gene-related peptide in mesenteric resistance arteries. J Pharmacol Exp Ther 2008; 324: 930-7.

[13] Folkow B. Description of the Myogenic Hypothesis. Circ Res 1964; 15: SUPPL:279-87.

[14] Rubanyi GM, Romero JC, Vanhoutte PM. Flow-induced release of endothelium-derived relaxing factor. Am J Physiol 1986; 250: H1145-9. 
[15] Heagerty AM, Aalkjaer C, Bund SJ, Korsgaard N, Mulvany MJ. Small artery structure in hypertension. Dual processes of remodeling and growth. Hypertension 1993; 21: 391-7.

[16] Buus CL, Pourageaud F, Fazzi GE, et al. Smooth muscle cell changes during flow-related remodeling of rat mesenteric resistance arteries. Circ Res 2001; 89: $180-6$.

[17] Mulvany MJ, Baumbach GL, Aalkjaer C, et al. Vascular remodeling. Hypertension 1996; 28: 505-6.

[18] Mulvany MJ. Structure and function of small arteries in hypertension. J Hypertens Suppl 1990; 8: S225-32.

[19] Laurenzi M, Mancini M, Menotti A, et al. Multiple risk factors in hypertension: results from the Gubbio study. J Hypertens Suppl 1990; 8: S712.

[20] Shepherd JT. Franz Volhard lecture. Increased systemic vascular resistance and primary hypertension: the expanding complexity. J Hypertens Suppl 1990; 8: S15-27.

[21] Guyton AC. Blood pressure control--special role of the kidneys and body fluids. Science 1991; 252: 1813-6.

[22] Sanders MW, Fazzi GE, Janssen GM, Blanco CE, De Mey JG. High sodium intake increases blood pressure and alters renal function in intrauterine growthretarded rats. Hypertension 2005; 46: 71-5.

[23] Goldblatt H, Lynch J, Hanzal RF, Summerville WW. Studies on Experimental Hypertension : I. The Production of Persistent Elevation of Systolic Blood Pressure by Means of Renal Ischemia. J Exp Med 1934; 59: 347-79.

[24] Bing RF, Russell GI, Swales JD, Thurston H. Effect of 12-hour infusions of saralasin or captopril on blood pressure in hypertensive conscious rats. Relationship to plasma renin, duration of hypertension, and effect of unclipping. J Lab Clin Med 1981; 98: 302-10.

[25] Flohr H, Breull W, Dahners HW, et al. Regional distribution of vascular resistance in two models of experimental renovascular hypertension. Pflugers Arch 1976; 362: 157-64.

[26] Mullins JJ, Peters J, Ganten D. Fulminant hypertension in transgenic rats harbouring the mouse Ren-2 gene. Nature 1990; 344: 541-4.

[27] Dahl LK, Knudsen KD, Heine M, Leitl G. Effects of chronic excess salt ingestion. Genetic influence on the development of salt hypertension in parabiotic rats: evidence for a humoral factor. J Exp Med 1967; 126: 687-99.

[28] Selye H, Hall CE, Rowley EM. Malignant Hypertension Produced by Treatment with Desoxycorticosterone Acetate and Sodium Chloride. Can Med Assoc J 1943; 49: 88-92.

[29] Okamoto K, Aoki K. Development of a strain of spontaneously hypertensive rats. Jpn Circ J 1963; 27: 282-93.

[30] Ribeiro MO, Antunes E, de Nucci G, Lovisolo SM, Zatz R. Chronic inhibition of nitric oxide synthesis. A new model of arterial hypertension. Hypertension 1992; 20: 298-303.

[31] Mandel MJ, Sapirstein LA. Effect of angiotensin infusion on regional blood flow and regional vascular resistance in the rat. Circ Res 1962; 10: 807-16.

[32] De Mey JG, Vanhoutte PM. Heterogeneous behavior of the canine arterial and venous wall. Importance of the endothelium. Circ Res 1982; 51: 439-47. 
[33] Palmer RM, Ferrige AG, Moncada S. Nitric oxide release accounts for the biological activity of endothelium-derived relaxing factor. Nature 1987; 327: 524-6.

[34] Furchgott RF, Zawadzki JV. The obligatory role of endothelial cells in the relaxation of arterial smooth muscle by acetylcholine. Nature 1980; 288: 373 6.

[35] Furchgott RF, Vanhoutte PM. Endothelium-derived relaxing and contracting factors. FASEB J 1989; 3: 2007-18.

[36] Moncada S, Gryglewski R, Bunting S, Vane JR. An enzyme isolated from arteries transforms prostaglandin endoperoxides to an unstable substance that inhibits platelet aggregation. Nature 1976; 263: 663-5.

[37] Gluais P, Lonchampt M, Morrow JD, Vanhoutte PM, Feletou M.

Acetylcholine-induced endothelium-dependent contractions in the SHR aorta: the Janus face of prostacyclin. Br J Pharmacol 2005; 146: 834-45.

[38] Yanagisawa M, Kurihara H, Kimura S, et al. A novel potent vasoconstrictor peptide produced by vascular endothelial cells. Nature 1988; 332: 411-5.

[39] Matsumoto T, Kakami M, Noguchi E, Kobayashi T, Kamata K. Imbalance between endothelium-derived relaxing and contracting factors in mesenteric arteries from aged OLETF rats, a model of Type 2 diabetes. Am J Physiol Heart Circ Physiol 2007; 293: H1480-90.

[40] Rubanyi GM. Endothelium-derived relaxing and contracting factors. J Cell Biochem 1991; 46: 27-36.

[41] Vanhoutte PM, Eber B. Endothelium-derived relaxing and contracting factors. Wien Klin Wochenschr 1991; 103: 405-11.

[42] Feletou M, Verbeuren TJ, Vanhoutte PM. Endothelium-dependent contractions in SHR: a tale of prostanoid TP and IP receptors. Br J Pharmacol 2009; 156: 563-74.

[43] Feletou M, Vanhoutte PM. Endothelial dysfunction: a multifaceted disorder (The Wiggers Award Lecture). Am J Physiol Heart Circ Physiol 2006; 291 : H985-1002.

[44] Xia J, Little TL, Duling BR. Cellular pathways of the conducted electrical response in arterioles of hamster cheek pouch in vitro. Am J Physiol 1995; 269: H2031-8.

[45] Segal SS, Duling BR. Conduction of vasomotor responses in arterioles: a role for cell-to-cell coupling? Am J Physiol 1989; 256: H838-45.

[46] Little TL, Xia J, Duling BR. Dye tracers define differential endothelial and smooth muscle coupling patterns within the arteriolar wall. Circ Res 1995; 76: 498-504.

[47] Xia J, Duling BR. Electromechanical coupling and the conducted vasomotor response. Am J Physiol 1995; 269: H2022-30.

[48] Dora KA, Doyle MP, Duling BR. Elevation of intracellular calcium in smooth muscle causes endothelial cell generation of NO in arterioles. Proc Natl Acad Sci U S A 1997; 94: 6529-34.

[49] Hilgers RH, De Mey JG. Myoendothelial coupling in the mesenteric arterial bed; segmental differences and interplay between nitric oxide and endothelin1. Br J Pharmacol 2009; 156: 1239-47. 
[50] Dora KA, Hinton JM, Walker SD, Garland CJ. An indirect influence of phenylephrine on the release of endothelium-derived vasodilators in rat small mesenteric artery. Br J Pharmacol 2000; 129: 381-7.

[51] Brain SD, Grant AD. Vascular actions of calcitonin gene-related peptide and adrenomedullin. Physiol Rev 2004; 84: 903-34.

[52] Chamley JH, Campbell GR. Trophic influences of sympathetic nerves and cyclic AMP on differentiation and proliferation of isolated smooth muscle cells in culture. Cell Tissue Res 1975; 161: 497-510.

[53] Li JS, Schiffrin EL. Effect of chronic treatment of adult spontaneously hypertensive rats with an endothelin receptor antagonist. Hypertension 1995; 25: 495-500.

[54] Schiffrin EL. The endothelium and control of blood vessel function in health and disease. Clin Invest Med 1994; 17: 602-20.

[55] Moncada S, Higgs A. The L-arginine-nitric oxide pathway. N Engl J Med 1993; 329: 2002-12.

[56] Barton M, d'Uscio LV, Shaw S, et al. ET(A) receptor blockade prevents increased tissue endothelin-1, vascular hypertrophy, and endothelial dysfunction in salt-sensitive hypertension. Hypertension 1998; 31: 499-504.

[57] Leung JW, Wong WT, Koon HW, et al. Transgenic Mice Over-Expressing ET-1 in the Endothelial Cells Develop Systemic Hypertension with Altered Vascular Reactivity. PLoS One 2011; 6: e26994.

[58] Bakker EN, Matlung HL, Bonta P, et al. Blood flow-dependent arterial remodelling is facilitated by inflammation but directed by vascular tone. Cardiovasc Res 2008; 78: 341-8.

[59] Mulvany MJ. Small Artery Remodelling in Hypertension. Basic Clin Pharmacol Toxicol 2011.

[60] Mulvany MJ. Small artery remodelling in hypertension: causes, consequences and therapeutic implications. Med Biol Eng Comput 2008; 46: 461-7.

[61] Schiffrin EL. Remodeling of resistance arteries in essential hypertension and effects of antihypertensive treatment. Am J Hypertens 2004; 17: 1192-200.

[62] Li JS, Lariviere R, Schiffrin EL. Effect of a nonselective endothelin antagonist on vascular remodeling in deoxycorticosterone acetate-salt hypertensive rats. Evidence for a role of endothelin in vascular hypertrophy. Hypertension 1994; 24: 183-8.

[63] Agabiti-Rosei E, Heagerty AM, Rizzoni D. Effects of antihypertensive treatment on small artery remodelling. J Hypertens 2009; 27: 1107-14.

[64] Rehman A, Schiffrin EL. Vascular effects of antihypertensive drug therapy. Curr Hypertens Rep 2010; 12: 226-32.

[65] Tuttle JL, Nachreiner RD, Bhuller AS, et al. Shear level influences resistance artery remodeling: wall dimensions, cell density, and eNOS expression. Am J Physiol Heart Circ Physiol 2001; 281: H1380-9.

[66] Tuttle JL, Sanders BM, Burkhart HM, et al. Impaired collateral artery development in spontaneously hypertensive rats. Microcirculation 2002; 9: 343-51.

[67] Tulis DA, Unthank JL, Prewitt RL. Flow-induced arterial remodeling in rat mesenteric vasculature. Am J Physiol 1998; 274: H874-82. 
[68] Pourageaud F, De Mey JG. Structural properties of rat mesenteric small arteries after 4-wk exposure to elevated or reduced blood flow. Am J Physiol 1997; 273: H1699-706.

[69] Loufrani L, Levy BI, Henrion D. Defect in microvascular adaptation to chronic changes in blood flow in mice lacking the gene encoding for dystrophin. Circ Res 2002; 91: 1183-9.

[70] Ceiler DL, De Mey JG. Chronic N(G)-nitro-L-arginine methyl ester treatment does not prevent flow-induced remodeling in mesenteric feed arteries and arcading arterioles. Arterioscler Thromb Vasc Biol 2000; 20: 2057-63.

[71] Loufrani L, Li Z, Levy BI, Paulin D, Henrion D. Excessive microvascular adaptation to changes in blood flow in mice lacking gene encoding for desmin. Arterioscler Thromb Vasc Biol 2002; 22: 1579-84.

[72] Pourageaud F, De Mey JG. Vasomotor responses in chronically hyperperfused and hypoperfused rat mesenteric arteries. Am J Physiol 1998; 274: H1301-7.

[73] Unthank JL, Fath SW, Burkhart HM, Miller SC, Dalsing MC. Wall remodeling during luminal expansion of mesenteric arterial collaterals in the rat. Circ Res 1996; 79: 1015-23.

[74] Unthank JL, Nixon JC, Burkhart HM, Fath SW, Dalsing MC. Early collateral and microvascular adaptations to intestinal artery occlusion in rat. Am J Physiol 1996; 271: H914-23.

[75] Bouvet C, Belin de Chantemele E, Guihot AL, et al. Flow-induced remodeling in resistance arteries from obese Zucker rats is associated with endothelial dysfunction. Hypertension 2007; 50: 248-54.

[76] Gao YJ, Yang LF, Stead S, Lee RM. Flow-induced vascular remodeling in the mesenteric artery of spontaneously hypertensive rats. Can J Physiol Pharmacol 2008; 86: 737-44.

[77] Guzman RJ, Abe K, Zarins CK. Flow-induced arterial enlargement is inhibited by suppression of nitric oxide synthase activity in vivo. Surgery 1997; 122: 273-9; discussion 9-80.

[78] Tronc F, Wassef M, Esposito B, et al. Role of NO in flow-induced remodeling of the rabbit common carotid artery. Arterioscler Thromb Vasc Biol 1996; 16: 1256-62.

[79] Rossitto G, Kamath G, Messerli FH. Q: Should alpha-blockers ever be used as antihypertensive drugs? Cleve Clin J Med 2010; 77: 884-8.

[80] De Caterina AR, Leone AM. The role of Beta-blockers as first-line therapy in hypertension. Curr Atheroscler Rep 2011; 13: 147-53.

[81] Kreutz R. Olmesartan/amlodipine: a review of its use in the management of hypertension. Vasc Health Risk Manag 2011; 7: 183-92.

[82] Al Badarin FJ, Abuannadi MA, Lavie CJ, O'Keefe JH. Evidence-based diuretic therapy for improving cardiovascular prognosis in systemic hypertension. Am J Cardiol 2011; 107: 1178-84.

[83] Kandler MR, Mah GT, Tejani AM, Stabler SN. Hydralazine for essential hypertension. Cochrane Database Syst Rev 2010: CD004934.

[84] Batterink J, Stabler SN, Tejani AM, Fowkes CT. Spironolactone for hypertension. Cochrane Database Syst Rev 2010: CD008169.

[85] Ruilope LM, Segura J. ARBs and ACEis together in the treatment of hypertension and its complications? current practical recommendations. Expert Opin Pharmacother 2010; 11: 2619-23. 
[86] Morganti A, Lonati C. Aliskiren: the first direct renin inhibitor available for clinical use. J Nephrol 2011.

[87] Mathier MA, Ishizawar D. Bosentan. Expert Opin Pharmacother 2010; 11: 1023-34.

[88] Kalk P, Sharkovska Y, Kashina E, et al. Endothelin-converting enzyme/neutral endopeptidase inhibitor SLV338 prevents hypertensive cardiac remodeling in a blood pressure-independent manner. Hypertension 2011; 57: 755-63.

[89] Donckier JE, Michel L, Van Beneden R, Delos M, Havaux X. Increased expression of endothelin-1 and its mitogenic receptor ETA in human papillary thyroid carcinoma. Clin Endocrinol (Oxf) 2003; 59: 354-60.

[90] Boldrini L, Pistolesi S, Gisfredi S, et al. Expression of endothelin 1 and its angiogenic role in meningiomas. Virchows Arch 2006; 449: 546-53.

[91] Amiri F, Virdis A, Neves MF, et al. Endothelium-restricted overexpression of human endothelin-1 causes vascular remodeling and endothelial dysfunction. Circulation 2004; 110: 2233-40.

[92] Schiffrin EL, Lariviere R, Li JS, Sventek P, Touyz RM. Endothelin-1 gene expression and vascular hypertrophy in DOCA-salt hypertension compared to spontaneously hypertensive rats. Clin Exp Pharmacol Physiol Suppl 1995; 22: S188-90.

[93] Schiffrin EL, Lariviere R, Li JS, Sventek P, Touyz RM. Deoxycorticosterone acetate plus salt induces overexpression of vascular endothelin-1 and severe vascular hypertrophy in spontaneously hypertensive rats. Hypertension 1995; 25: 769-73.

[94] Hynynen MM, Khalil RA. The vascular endothelin system in hypertension-recent patents and discoveries. Recent Pat Cardiovasc Drug Discov 2006; 1: 95-108.

[95] Dhaun N, Goddard J, Kohan DE, et al. Role of endothelin-1 in clinical hypertension: 20 years on. Hypertension 2008; 52: 452-9.

[96] Montagnani M, Vulpis V, Nazzaro P, et al. Endothelin-1-receptor-mediated responses in resistance vessels of young and adult spontaneously hypertensive rats. J Hypertens 2000; 18: 893-900.

[97] Barton M, Yanagisawa M. Endothelin: 20 years from discovery to therapy. Can J Physiol Pharmacol 2008; 86: 485-98.

[98] Masaki T. Historical review: Endothelin. Trends Pharmacol Sci 2004; 25: 21924.

[99] Fukuroda T, Fujikawa T, Ozaki S, et al. Clearance of circulating endothelin-1 by ETB receptors in rats. Biochem Biophys Res Commun 1994; 199: 1461-5.

[100] Johnstrom P, Fryer TD, Richards HK, et al. Positron emission tomography using 18F-labelled endothelin-1 reveals prevention of binding to cardiac receptors owing to tissue-specific clearance by ET B receptors in vivo. Br J Pharmacol 2005; 144: 115-22.

[101] Schneider MP, Boesen EI, Pollock DM. Contrasting actions of endothelin ET(A) and ET(B) receptors in cardiovascular disease. Annu Rev Pharmacol Toxicol 2007; 47: 731-59.

[102] Nelissen J, Lemkens P, Sann H, et al. Pharmacokinetic and pharmacodynamic properties of SOL1: a novel dual inhibitor of neutral endopeptidase and endothelin converting enzyme. Life Sci 2012; 91: 587-92. 
[103] Abassi ZA, Tate JE, Golomb E, Keiser HR. Role of neutral endopeptidase in the metabolism of endothelin. Hypertension 1992; 20: 89-95.

[104] Sawamura T, Kimura S, Shinmi O, et al. Purification and characterization of putative endothelin converting enzyme in bovine adrenal medulla: evidence for a cathepsin D-like enzyme. Biochem Biophys Res Commun 1990; 168: 12306.

[105] Nakano A, Kishi F, Minami K, et al. Selective conversion of big endothelins to tracheal smooth muscle-constricting 31-amino acid-length endothelins by chymase from human mast cells. J Immunol 1997; 159: 1987-92.

[106] Fernandez-Patron C, Radomski MW, Davidge ST. Vascular matrix metalloproteinase-2 cleaves big endothelin-1 yielding a novel vasoconstrictor. Circ Res 1999; 85: 906-11.

[107] Martin P, Tzanidis A, Stein-Oakley A, Krum H. Effect of a highly selective endothelin-converting enzyme inhibitor on cardiac remodeling in rats after myocardial infarction. J Cardiovasc Pharmacol 2000; 36: S367-70.

[108] Eckman EA, Adams SK, Troendle FJ, et al. Regulation of steady-state betaamyloid levels in the brain by neprilysin and endothelin-converting enzyme but not angiotensin-converting enzyme. J Biol Chem 2006; 281: 30471-8.

[109] Eckman EA, Reed DK, Eckman CB. Degradation of the Alzheimer's amyloid beta peptide by endothelin-converting enzyme. J Biol Chem 2001; 276: 245408.

[110] Eckman EA, Watson M, Marlow L, Sambamurti K, Eckman CB. Alzheimer's disease beta-amyloid peptide is increased in mice deficient in endothelinconverting enzyme. J Biol Chem 2003; 278: 2081-4.

[111] Pacheco-Quinto J, Eckman EA. Endothelin-converting enzymes degrade intracellular beta-amyloid produced within the endosomal/lysosomal pathway and autophagosomes. J Biol Chem 2013; 288: 5606-15.

[112] Lang CC, Motwani J, Coutie WJ, Struthers AD. Influence of candoxatril on plasma brain natriuretic peptide in heart failure. Lancet 1991; 338: 255.

[113] Bevan EG, Connell JM, Doyle J, et al. Candoxatril, a neutral endopeptidase inhibitor: efficacy and tolerability in essential hypertension. J Hypertens 1992; 10: $607-13$

[114] Ando S, Rahman MA, Butler GC, Senn BL, Floras JS. Comparison of candoxatril and atrial natriuretic factor in healthy men. Effects on hemodynamics, sympathetic activity, heart rate variability, and endothelin. Hypertension 1995; 26: 1160-6.

[115] Richards AM, Wittert GA, Crozier IG, et al. Chronic inhibition of endopeptidase 24.11 in essential hypertension: evidence for enhanced atrial natriuretic peptide and angiotensin II. J Hypertens 1993; 11: 407-16.

[116] Ferro CJ, Spratt JC, Haynes WG, Webb DJ. Inhibition of neutral endopeptidase causes vasoconstriction of human resistance vessels in vivo. Circulation 1998; 97: 2323-30.

[117] Seed A, Kuc RE, Maguire JJ, et al. The dual endothelin converting enzyme/neutral endopeptidase inhibitor SLV-306 (daglutril), inhibits systemic conversion of big endothelin-1 in humans. Life Sci 2012; 91: 743-8.

[118] Parvanova A, van der Meer IM, Iliev I, et al. Effect on blood pressure of combined inhibition of endothelin-converting enzyme and neutral endopeptidase with daglutril in patients with type 2 diabetes who have 
General Introduction

albuminuria: a randomised, crossover, double-blind, placebo-controlled trial. Lancet Diabetes Endocrinol 2013; 1: 19-27. 



\section{Chapter 2 \\ Thrombospondin-1 in Early Flow-Related Remodeling of Mesenteric Arteries from Young Normotensive and Spontaneously Hypertensive Rats}

P. Lemkens, G.E.M. Boari, G.E. Fazzi, G.M.J. Janssen, J.E. Murphy-Ullrich, P.M.H. Schiffers and J.G.R. De Mey Open Cardiovasc Med J. 2012;6:50-9 


\section{Abstract}

We tested the hypotheses that TSP1 participates in the initiation of remodeling of small muscular arteries in response to altered blood flow and that the N-terminal domain of TSP1 (hepI) can reverse the pathological inward remodeling of resistance arteries from SHR.

We measured (1) changes in gene/protein expression in MA of 6 week old WKY and SHR exposed to either increased (+ $100 \%)$ or reduced blood flow $(-90 \%)$ for 24-40 hours and (2) structural changes in MA of 12 week old SHR exposed for 3 days to hepI in organ culture.

In both HF and LF of WKY, mRNA expression of eNOS, sGC $\alpha 1$ and PKG1 $\beta$ were significantly reduced $(\mathrm{p}<0.05)$, whereas mRNA of TSP1 was markedly increased $(\mathrm{p}<$ 0.05). In MA of young SHR, similar results were obtained except that eNOS mRNA was not reduced in LF. Expression of TSP1 protein was significantly increased in LF of young WKY and SHR ( $<<0.05)$. Exposure of MA of 12 week old SHR to hepI (1 $\mu \mathrm{mol} / \mathrm{L})$ resulted in a rapid lumen diameter increase $(+12 \pm 2 \%$ after 3 days $)$ without alteration in vascular reactivity, distensibility, media surface area or cell number.

These are the first observations of reduced gene expression of eNOS/sGC/PKG and increased expression of TSP1 at the initiation of arterial remodeling in young WKY and SHR, irrespective of its outward or inward outcome. Furthermore, a fragment of TSP1 rapidly and directly reversed pathological inward arterial remodeling of SHR in vitro. 


\section{Introduction}

In small muscular arteries of young normotensive rats, an increase in blood flow leads to an increase in lumen diameter that normalizes wall shear stress. The acute response consists of a reduction of the contractile activity of the vascular smooth muscle cells [13]. The response to a chronic increase in blood flow involves increases of the structural lumen diameter and of the arterial wall mass [4-7]. Flow-induced vasodilatation and remodeling are both endothelium-dependent $[4,8,9]$. In conditions of reduced blood flow, acute vasoconstriction and inward hypotrophic arterial remodeling are observed $[6,10]$. There is strong evidence that an increase in shear stress can stimulate the activity and expression of NO-synthase in the endothelium [9, 11-13]. The roles of NO and its main receptor soluble guanylyl cyclase (sGC) in flow-related arterial remodeling are less clear.

We previously demonstrated dedifferentiation and increased turnover of smooth muscle cells (SMC) during flow-induced remodeling of small arteries [14]. This contrasts to the inhibitory effects of NO on SMC dedifferentiation and proliferation $[15,16]$. In a RNA microarray analysis we observed that flow-related arterial structural changes were preceded by altered expression of a large number of genes involved in differentiation and proliferation of SMC [17]. This was in turn preceded by a rapid and transient change in the expression of a small number of genes including that for the $82 \mathrm{kDa}$ subunit of $\mathrm{sGC}$ (sGCa1, downregulated) and that for thrombospondin-1 (TSP1, upregulated) [18]. The cGMP produced by sGC, stimulates protein kinase G (PKG), which is known to inhibit the expression of TSP1 in rat vascular smooth muscle cells [19]. A sequence from the N-terminal heparin-binding domain of TSP1 stimulates focal adhesion disassembly and increases cell migration through binding to a receptor cocomplex of calreticulin-LRP1 [20-22]. These findings suggest that the eNOS/sGC/PKG system would be downregulated at the transition from flow-induced vasodilatation to flow-induced remodeling, leading to increased TSP1 expression and matrix metalloproteinase 2 (MMP-2) activation, and thereby stimulation of a de-adhesive state facilitating reorganization of the arterial wall material [10, 20, 23-25].

Flow-induced remodeling of small arteries is impaired by high blood pressure [26-28]. This might contribute to reduced collateralization and arteriogenesis in ischemia and to the increased vascular resistance that characterizes hypertension. There is convincing evidence in spontaneously hypertensive rats (SHR) and in human essential hypertension, that the extent of inward eutrophic remodeling of resistance arteries is of pathogenic significance [24, 29] and actually correlates with the incidence of life threatening events [30]. Hence, pharmacological interventions that stimulate outward remodeling could offer a therapeutic benefit.

The goal of this study was twofold. First, we tested the hypothesis that the eNOS/sGC/PKG pathway is downregulated and that gene and protein expression of 
TSP1 are upregulated early (24-40 hours) after the induction of flow-related arterial remodeling in vivo. We used 6 week old WKY and 6 weeks old pre-hypertensive SHR rats to study differences in molecular and functional outcomes after alterations in blood flow. Secondly, we tested the hypothesis that a peptide mimetic of TSP1 (hepI) which induces cellular de-adhesion [19-22] can directly reverse the inward remodeling of resistance arteries of 12 week old SHR. For these purposes we used rat mesenteric small muscular arteries that were exposed to (1) altered blood flow in vivo or to (2) hepI during arterial organ culture at constant pressure and flow.

\section{Material and Methods}

\section{Animals}

Male normotensive Wistar-Kyoto rats (WKY) and Spontaneously Hypertensive rats (SHR) were obtained from Charles River (Maastricht, the Netherlands). All animals were housed separately and had free access to standard food (SRMA-1210; Hope Farms, Woerden, the Netherlands) and tap water. All experiments were conducted according to institutional guidelines. This investigation conforms to the Guide for Care and Use of Laboratory Animals as published by the US National Institutes of Health (NIH Publication No.85-23, revised 1996), and all experimental protocols were approved by the Animal Ethics Committee of the Maastricht University.

\section{MA Ligation model}

Small mesenteric arteries (MA) of 6 week old WKY $(n=27)$ and SHR $(n=27)$ were exposed to altered blood flow in vivo as described previously [6, 14, 17, 31]. Briefly, rats were anesthetized with isoflurane (Abbott, Kent, UK) and after laparotomy, local blood flow was reduced (LF) by distal ligation of three alternate second order MA branches. The MA between these had compensatory enhanced flow (HF). We previously observed in WKY that the blood flow averages $10 \%$ and $200 \%$ in LF and HF respectively when compared to second order MA outside of the surgical area (normal flow, NF) and that these interventions ultimately result in inward hypotrophic (LF) and outward hypertrophic arterial remodeling (HF), respectively [6, 14, 31]. Animals received buprenorphine $(0.05 \mathrm{mg} / \mathrm{kg}$, s.c.; Schering-Plough, Utrecht, Netherlands) as an analgesic at three time-points: before surgery, at the end of the day of surgery and the next morning.

\section{Gene expression (RT-PCR)}

At 24 hours after flow-modifying surgery, NF, HF and LF MA segments were isolated and pooled for each individual WKY and SHR rat $(n=9)$. To isolate RNA, Trizol reagent (Invitrogen, Leek, NL) in combination with RNeasy Mini Kit (Qiagen, Venlo, NL) was used. RNA (100 ng) was then used for first-strand cDNA synthesis with 
Ready-To-Go You-Prime First-Strand Beads (GE healthcare, Diegem, BE) and pd(N) 6 random hexamer primer (GE healthcare, Diegem, BE). Plasmids containing gene fragments of rat MMP2, TSP1 and cyclophilin were used as standard curves, while a pool of cDNA of all samples was used for standard curves for the eNOS, sGC $\alpha 1$ and PKG1 $\beta$ genes. Taqman RT-PCR for MMP2, TSP1 and cyclophilin was performed in an ABI Prism 7700 SDS cycler (Applied-biosystems, Bleiswijk, NL) in combination with the appropriate fluorogenic probes, primer and qPCR MasterMix (Eurogentec, Maastricht, NL). Taqman RT-PCR for eNOS, sGC $\alpha 1$, PKG1 $\beta$ and cyclophilin was performed in a MyiQ iCycler (Biorad, Zwijndrecht, NL) with primers and qPCR MasterMix containing the DNA intercalating dye, SYBR-green. Each PCR reaction was performed in duplicate wells using the following conditions, $10 \mathrm{~min}$ at $95^{\circ} \mathrm{C}$, followed by a total of 40 cycles of $15 \mathrm{~s}$ at $95^{\circ} \mathrm{C}$ and $1 \mathrm{~min}$ at $60^{\circ} \mathrm{C}\left(15 \mathrm{~s}\right.$ at $95^{\circ} \mathrm{C}$ and $30 \mathrm{~s}$ at $58^{\circ} \mathrm{C}$ for SYBR-green). Gene expression levels were normalized to the house-keeping gene cyclophilin in each sample.

\section{Contractile and relaxing reactivity}

To evaluate consequences of altered gene expression for vasomotor control, $2 \mathrm{~mm}$ arterial segments were harvested at $24(n=4)$ and at 32 hours $(n=8)$ after flow modifying surgery in 6 week old WKY and SHR. Preparations were mounted in a $5 \mathrm{ml}$ organ chamber (Danish Myotechnology, Aarhus, DK) filled with Krebs Ringer bicarbonate solution $\left(\mathrm{KRB} ; 37^{\circ} \mathrm{C} ; 95 \% \mathrm{O}_{2} / 5 \% \mathrm{CO}_{2}\right)$ between an isometric force transducer and a displacement device. Their diameter was set at $90 \%$ of that of the resting vessel at a transmural pressure of $100 \mathrm{mmHg}$. Effects of the endothelium-dependent vasodilator acetylcholine, the NO-donor Na-nitroprusside and of the non-selective NOS-inhibitor $\mathrm{N}^{\omega}$-L-nitro arginine methyl ester (L-NAME) were evaluated in the presence of 3 $\mu \mathrm{mol} / \mathrm{L}$ indomethacin during contractions induced by an equiosmotic KRB solution containing $40 \mathrm{mmol} / \mathrm{L} \mathrm{K} \mathrm{K}^{+}$. These steps were taken to rule out influences of prostaglandins and endothelium-derived hyperpolarizing factors. Because depolarizing high $\mathrm{K}^{+}$buffer can stimulate release of neurotransmitters from peri-arterial nerves, experiments were initiated after exposure of the arteries to phenoxybenzamine (1 $\mu \mathrm{mol} / \mathrm{L}, 10 \mathrm{~min})$ and capsaicin $(1 \mu \mathrm{mol} / \mathrm{L}, 20 \mathrm{~min})$ which irreversibly block $\alpha$ adrenoceptors and peri-arterial sensorimotor nerves, respectively [32].

\section{Protein expression}

Protein levels were investigated in view of discrepancies between mRNA levels on the one hand and vasomotor responses on the other hand. At 32 hours and at 40 hours after flow-modifying surgery, NF, HF and LF MA segments ( $n=9$, each group) were isolated and pooled from $3 \mathrm{WKY}$ and $3 \mathrm{SHR}$ rats and snap-frozen in liquid nitrogen. Pooled arteries were crunched at $-80^{\circ} \mathrm{C}$ and resuspended in ice cold RIPA buffer $(50 \mathrm{mM} \mathrm{HCl}$ $\mathrm{pH} 7.4,150 \mathrm{mM} \mathrm{NaCl}, 1 \% \mathrm{NP}-40,0.25 \%$ Na-deoxycholate and $1 \mathrm{mM}$ EDTA) containing protease and phosphatase-inhibitors (1mM PMSF, $1 \mathrm{mM} \mathrm{NaVO}$, $1 \mathrm{mM}$ 
$\mathrm{NaF}, 1 \mu \mathrm{g} / \mathrm{ml}$ aprotinin, $1 \mu \mathrm{g} / \mathrm{ml}$ pepstatin and $1 \mu \mathrm{g} / \mathrm{ml}$ leupeptin) to extract total protein. The lysates were cleared by centrifugation. Protein content of the lysates was determined with the BCA method [33]. Lysates were subsequently run on a criterion bis/tris gradient gel, and blotted to a nitrocellulose membrane. Membranes were blocked with 1:1 oddysey blocking buffer:PBS and were subsequently incubated with antibodies diluted in 1:1 oddysey blocking buffer:PBS against: eNOS (BD Transduction Laboratories, Franklin Lakes, USA, 1:2500), sGC $\alpha 1$ (Santa Cruz, Santa Cruz, USA 1:2000), PKG1 $\beta$ (Biovision, Zurich, CH, 1:500), MMP2 (Santa Cruz, Santa Cruz, USA $1: 500$, detecting the pro $(72 \mathrm{kDa})$ - and the active $(62 \mathrm{kDa})$ form of MMP2) and TSP1 (Abcam, Cambridge, USA, 1:500). Primary antibodies were detected with secondary antibodies labeled with the near infrared dye IRdye800 and visualized with an odyssey detection system. TSP1 antibody was detected with secondary antibodies labeled with biotin. Biotin was subsequently detected with IRdye800 labeled streptavidin. Protein expression levels were normalized to the house-keeping protein GAPDH in each run.

\section{Arterial organ culture}

To investigate whether hepI could reverse inward arterial remodeling in hypertension, we used MA segments of 12 week old SHR in organ culture as described by Bakker et al. $[10,34]$. The vessels were mounted on two glass micropipettes in a stainless steel organ chamber. Vessels were pressurized at $80 \mathrm{mmHg}$ (no flow) and incubated in Hanks balanced salt solution (HBSS) for $60 \mathrm{~min}$ at $37^{\circ} \mathrm{C}$, before baseline measurements of diameter and reactivity were obtained. Thereafter the vessels were exposed intraluminally as well as extra-luminally to culture medium (Leibovitz $(n=6)$ or $5 \%$ dFCS$\operatorname{DMEM}(\mathrm{n}=6))$ with or without $1 \mu \mathrm{mol} / \mathrm{L}$ hepI for 3 days. The parallel experiments with Leibovitz and 5\% dFCS in DMEM yielded quantitatively identical results. The data were pooled for subsequent analysis.

At the start of the experiments and at daily intervals, passive pressure-diameter (P/D) curves were constructed [13]. The culture medium was replaced by $\mathrm{Ca}^{2+}$-free HBSS containing $10 \mu \mathrm{mol} / \mathrm{L} \mathrm{Na-nitroprusside} \mathrm{to} \mathrm{inactivate} \mathrm{arterial} \mathrm{smooth} \mathrm{muscle} \mathrm{tone.} \mathrm{The}$ cannulated arterial segments were pressurized using a feedback controlled pressure source (Living Systems Instrumentation, Burlington, USA) and placed on the stage of an invertoscope (Nikon TMS, Abingdon, USA) equipped with a video camera (Stemmer) and a digital device (LSI) for recording of lumen diameter. Intra-arterial pressure was increased in $10 \mathrm{mmHg}$ steps from 20 to $120 \mathrm{mmHg}$. After each step, the vessel was allowed to equilibrate until a stable diameter was reached ( 2 minutes). Findings were expressed as percentage change from vessel diameter on day 0 at 80 $\mathrm{mmHg}$. From the P/D relationships arterial distensibility was calculated by the following formula: $\mathrm{DC}=(1 / \Delta \mathrm{P}) *\left(\Delta \mathrm{D} / \mathrm{D}_{\mathrm{n}-1}\right) * 100(\mathrm{DC}=$ distensibility, $\mathrm{P}=$ intraluminal pressure, $\mathrm{D}=$ diameter at a given intraluminal pressure). After the highest pressure was reached, pressure was returned to $80 \mathrm{mmHg}$ and the HBSS-solution was replaced by culture medium with or without $1.0 \mu \mathrm{mol} / \mathrm{L}$ hepI. 
On day 0 and day 3 of the culture period the viability of the vessels was verified by recording diameter changes at $80 \mathrm{mmHg}$ in response to $1 \mu \mathrm{mol} / \mathrm{L}$ serotonin, $10 \mu \mathrm{mol} / \mathrm{L}$ phenylephrine and $1 \mu \mathrm{mol} / \mathrm{L}$ acetylcholine in HBSS. Finally the vessels were fixed in neutral buffered formalin at $80 \mathrm{mmHg}$ and $37^{\circ} \mathrm{C}$ and stored in $70 \%$ ethanol.

\section{Histology and morphometry}

Fixed vessels were embedded in paraffin and cross-sections $(4 \mu \mathrm{m})$ were stained with Lawson's solution (Boom, Meppel, the Netherlands) to visualize the internal and external elastic laminae. Cross-sectional area (mCSA), thickness, cellular density of the tunica media, and the lumen diameter were determined as previously described $[6,13$, $14,17,26,31]$.

\section{Solutions, culture media and drugs}

Leibovitz medium (Invitrogen, Leek, NL) was supplemented with $1 \mathrm{mg} / \mathrm{mL}$ albumine (Sigma Aldrich, Zwijndrecht, NL), $20 \mathrm{mg} / \mathrm{mL}$ ciprofloxacin (Bayer, Leverkusen, DE), $100 \mathrm{U} / \mathrm{mL}$ penicillin, $100 \mu \mathrm{g} / \mathrm{mL}$ streptomycin and $2.5 \mathrm{U} / \mathrm{mL}$ amphotericin $\mathrm{B}$ (Invitrogen, Leek, NL). DMEM (Invitrogen, Leek, NL) was supplemented with $2.5 \mathrm{mM}$ glutamine, $100 \mathrm{IU} / \mathrm{mL}$ penicillin, $100 \mu \mathrm{g} / \mathrm{mL}$ streptomycin and $5 \%$ dialyzed fetal-calf serum. All pharmacological agents were purchased from Sigma Aldrich, (Zwijndrecht, NL). The hepI peptide (ELTGAARKGSGRRLVKGPD) was synthesized by Anaspec Inc (San Jose, USA) and purified by HPLC [21]. The peptide was confirmed to be $>95 \%$ pure by HPLC and mass spectrometry.

\section{Statistical analysis}

Results are expressed as means \pm SEM. Statistical significance of differences between groups was evaluated by analysis of variance (ANOVA for consecutive measurements for pressure-diameter curves) or 1-way ANOVA followed by Bonferroni or paired t-test (SPSS 11.5). A value of $\mathrm{P}<0.05$ was considered significant.

\section{Results}

\section{Gene expression under basal conditions}

Figure 2.1 illustrates expression of genes encoding protein kinase $G$ (PKG) and candidate modulators and targets of this enzyme in mesenteric small arteries of 6 week old WKY and SHR rats. In control arteries with normal flow (NF), mRNA levels were high for sGC $\alpha 1$ and PKG1 $\beta$, intermediate for eNOS, and low for MMP2 and TSP1. Although expression of eNOS tended to be smaller in NF of SHR, the expression levels of all five genes did not differ significantly between NF arteries of 6 weeks old SHR and WKY rats. 
Changes in gene expression in MA exposed for 24 hours to altered blood flow in vivo are summarized in Figure 2.1. Consistent with earlier RNA microarray observations $[17,18]$, the expression of sGC $\alpha 1$ was significantly reduced and that of TSP1 was markedly increased in arteries from WKY rats exposed to high blood flow (HF). Surprisingly, the findings were very similar in vessels exposed to increased (HF) or reduced (LF) blood flow. In both HF and LF arteries of WKY rats, the expression of eNOS, sGC $\alpha 1$ and PKG1 $\beta$ was significantly reduced, whereas TSP1 was markedly increased and MMP2 was not appreciably altered. In HF of SHR, qualitatively and quantitatively similar findings were obtained, except that there was a less marked downregulation of eNOS possibly due to the already reduced basal levels. Also in arteries of SHR exposed to reduced blood flow (LF), largely similar results were obtained, with the exception that eNOS and TSP1 expression were affected to a lesser extent. Collectively these results indicate that either an increase or a decrease in blood flow both lead to a concurrent reduction of eNOS, sGC $\alpha 1$ and PKG1 $\beta$ and to a marked increase of TSP1 mRNA levels within 24 hours in rat mesenteric small muscular arteries. 
e-NOS

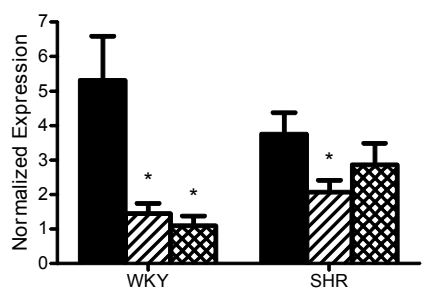

PKG1b

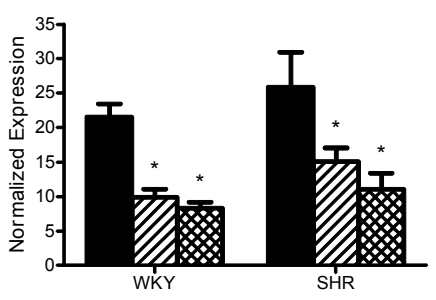

MMP2

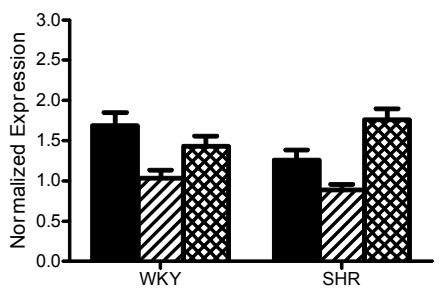

sGCa 1

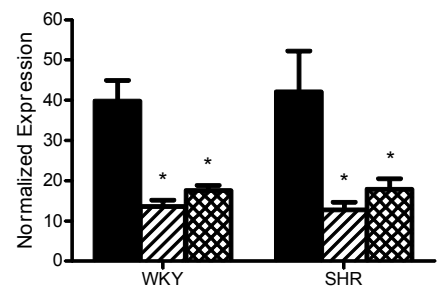

TSP1

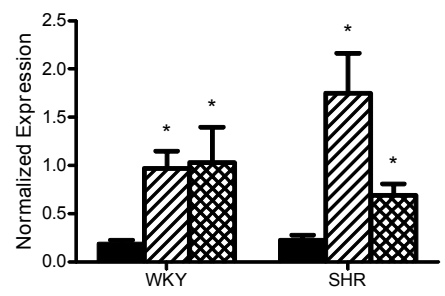

Figure 2.1: mRNA expressions of eNOS, sGCa1, PKG1及, TSP1 and MMP2 in mesenteric small arteries exposed to normal blood flow (NF, black bars) or for 24 hours to increased blood flow (HF, hatched bars) or reduced blood flow (LF, crosshatched bars) in 6 week old Wistar Kyoto (WKY) rats and Spontaneously Hypertensive rats (SHR) in vivo, normalized to the housekeeping gene cyclophylin. Results are expressed as the mean $\pm \operatorname{SEM}(n=6)$. * $p<0.05$ versus NF. 

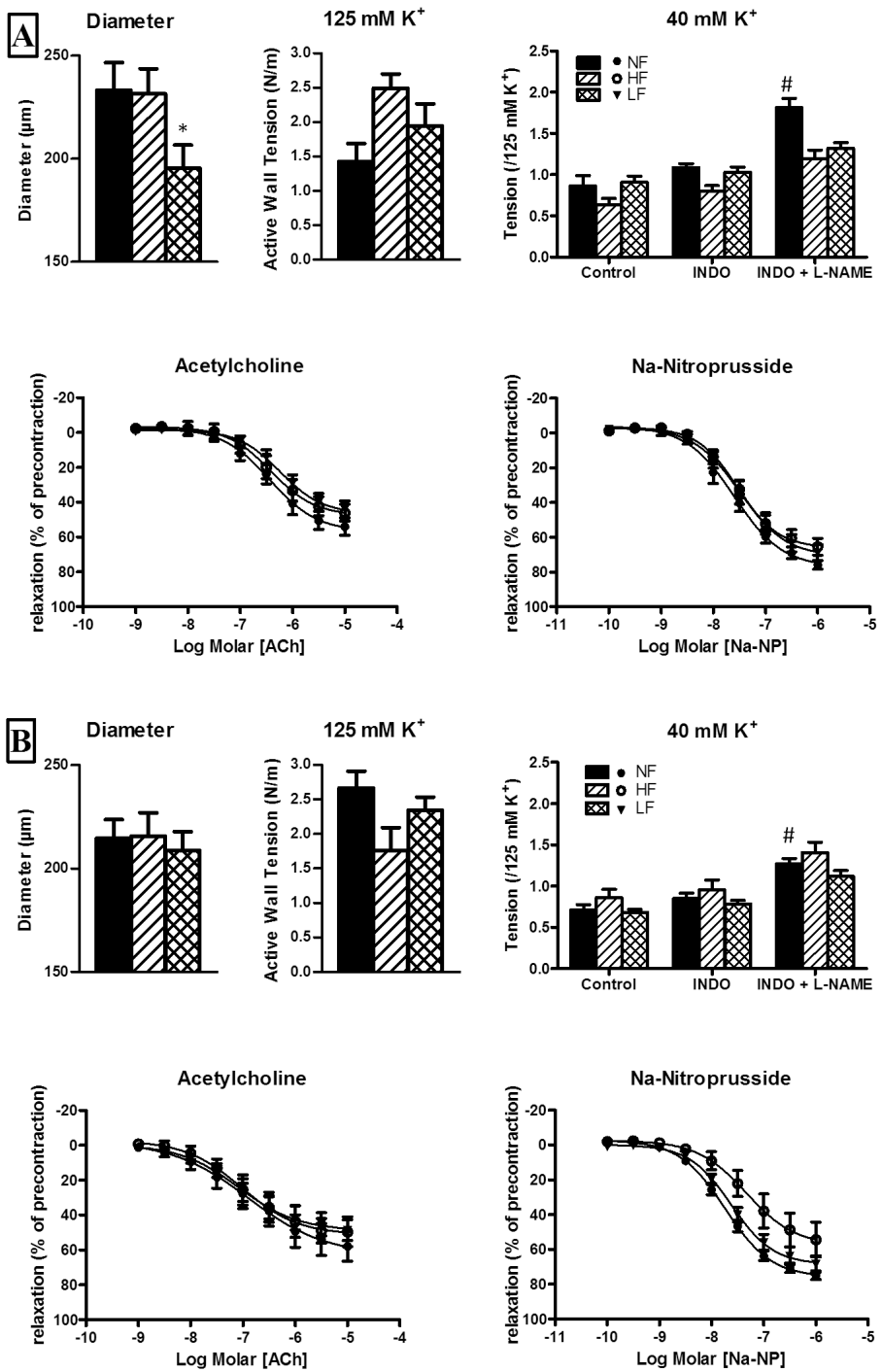

Figure 2.2: In vitro contractile reactivity of mesenteric small arteries of 6 week old WKY rats (panel A) and SHR rats (panel B) exposed to normal flow (black bars) or for 32 hours to increased (hatched bars) or reduced blood flow (cross-hatched bars). Means \pm SEM $(n=8-11)$. Normalized diameter and maximal contraction in response to $125 \mathrm{mmol} / \mathrm{L} \mathrm{K}_{+}$(top left) and the effect of indomethacin and $L_{-}$ NAME on contractile responses to $40 \mathrm{mmol} / \mathrm{L} K_{+}$(top right) are shown along with the relaxing responses to acetylcholine during $K^{+}$-induced contraction in the presence of indomethacin (bottom left) and the relaxing responses to Na-nitroprusside during $K^{+-i n d u c e d ~ c o n t r a c t i o n ~ i n ~ t h e ~ p r e s e n c e ~ o f ~}$ indomethacin and L-NAME (bottom right) for NF (closed circle), HF (open circle) and LF (closed triangle). * $p<0.05$ versus NF; \#p<0.05 INDO versus INDO + L-NAME. 

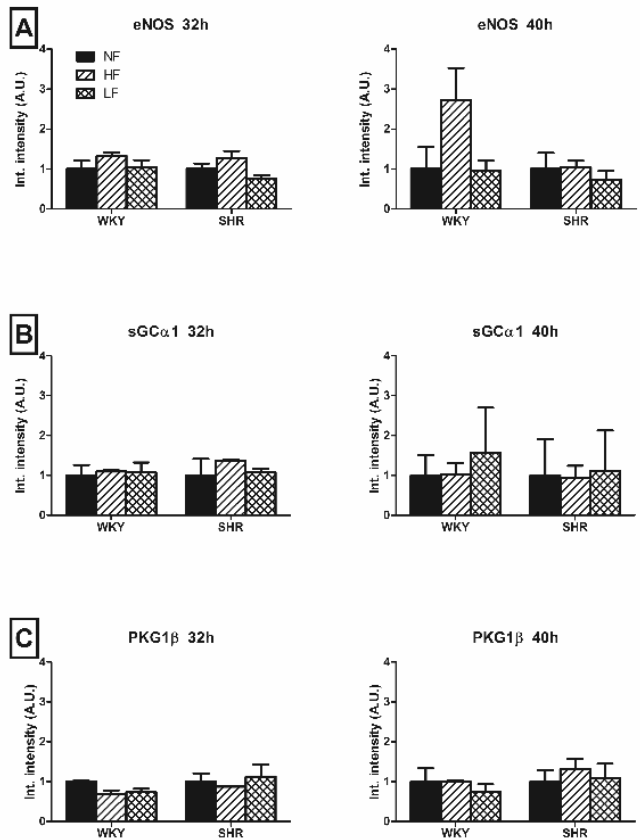

Figure 2.3: Changes in protein expression of eNOS (A), sGCa1 (B), PKG1及 (C), MMP2 (pro/act, D/E) and TSP1 (F), in mesenteric small arteries exposed for 32 and 40 hours to normal (black bars), increased (hatched bars) or reduced (crosshatched bars) blood flow in 6
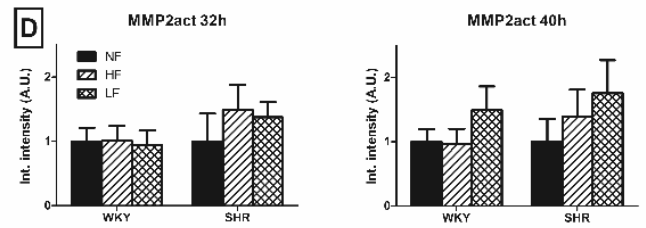
week old WKY and SHR rats in vivo. Means $\pm \operatorname{SEM}(n=6) .{ }^{*} p<0.05$ versus NF.
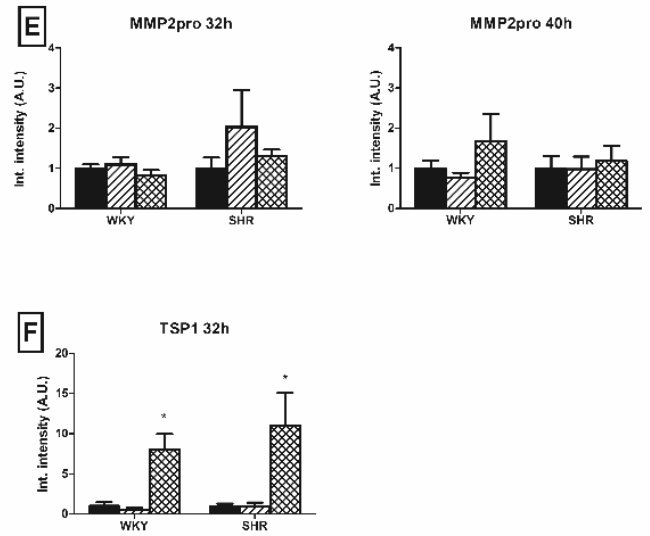


\section{Vasomotor responses}

To evaluate potential functional consequences of the observed downregulation of the $\mathrm{NO} / \mathrm{sGC} / \mathrm{PKG}$ pathway, we recorded arterial contractile reactivity in vitro in MA of 6 week old WKY and SHR rats. At 24 hours after flow-modifying surgery there were no statistically significant differences between NF, HF or LF arteries $(n=4-6$, data not shown). Because changes in the abundance and activity of proteins lag behind changes in mRNA expression, functional analyses were repeated at 32 hours after altered blood flow in vivo. These results are summarized in Figure $2.2 \mathrm{~A}$ ). These findings indicate that the marked and concurrent reductions of the mRNA levels for eNOS, sGC $\alpha 1$ and PKG1 $\beta$ were not accompanied by remodeling in WKY. Similar results were obtained in SHR, as shown Figure 2.2 B. In contrast to WKY, the diameter of SHR LF arteries did not differ from that of NF and HF arteries.

\section{Altered protein expression during initiation of flow-related arterial remodeling in vivo}

Figure 2.3 summarizes changes in protein expression in MA exposed for 32 (left panel) and 40 hours (right panel) to altered blood flow in vivo. These time-points were chosen to allow

protein synthesis to occur and are based on the 24 hour gene expression experiments and the earlier observation that in low flow conditions specifically, the inward remodeling response manifests within 2 days [14]. In both HF and LF arteries of WKY and SHR rats, the protein levels of eNOS, sGC $\alpha 1$, PKG1 $\beta$ and MMP2 (pro/act) were not significantly altered after 32 and 40 hours of flow modifying surgery (Figure 2.3 AE). Protein expression for TSP1 was significantly increased in LF arteries of both WKY and SHR (Figure $2.3 \mathrm{~F}$ ). After 40 hours of exposure to LF, protein expression of TSP1 was below threshold in NF, HF and LF arteries.

\section{Arterial structural effects of the hepI sequence of TSP1}

To evaluate structural consequences of upregulated TSP1 mRNA and protein expression, isolated arteries were exposed to hepI under constant conditions of pressure (80 $\mathrm{mmHg}$ ) and flow (no flow) in vitro. These experiments were deliberately performed in arteries of 12 week old SHR that display an inward eutrophic remodeling which contributes to the increased peripheral resistance and blood pressure [24, 29]. In the untreated arteries, the diameter at $80 \mathrm{mmHg}$ and the relationship between passive diameter and transmural pressure did not change during the 3 day culture period (Figure 2.4). The presence of $1 \mu \mathrm{mol} / \mathrm{L}$ hepI, however, resulted in an increase of the diameter at $80 \mathrm{mmHg}$ and in an upward shift of the pressure-diameter curves $(\mathrm{p}<0.05$ for day 1 , day 2 and day 3)(Figure 2.4). Arterial structural diameter was increased by $7.5 \pm 1.9 \%$ within 24 hours and increased further to $+12.6 \pm 2.4 \%$ after 3 days (Figure 2.4). Exposure to hepI did not modify calculated distensibility (Figure 2.4), general arterial 
histology (not shown), and did not result in statistically significant changes in media cross sectional area $\left(13693 \pm 4043 \mu \mathrm{m}^{2}\right.$ versus $\left.12881 \pm 3182 \mu \mathrm{m}^{2}\right)$ or cell number $(52 \pm$ 11 versus $54 \pm 8$ nuclear profiles/section) indicating that the hepI-induced outward remodeling was eutrophic in nature.
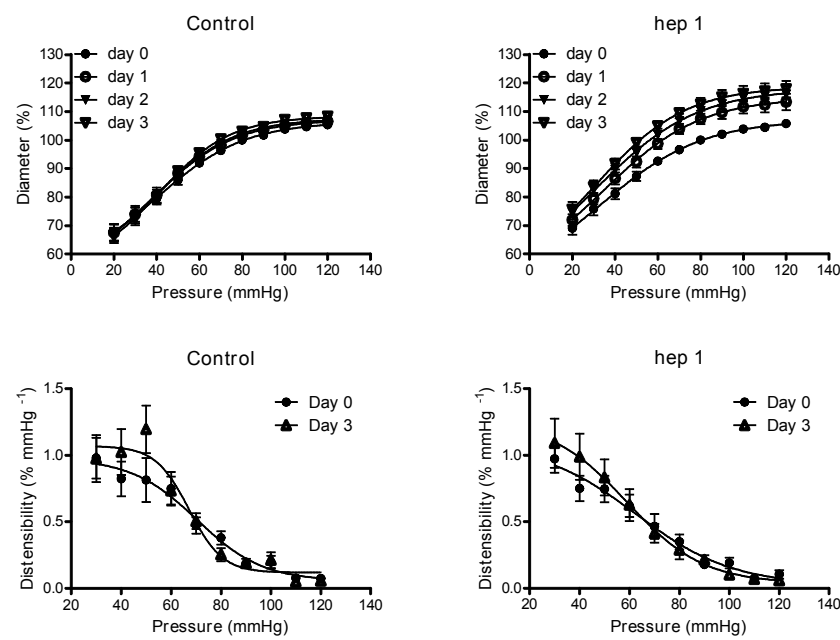

Figure 2.4: Effects of time (control, top left) and $1 \pm \mathrm{mol} / \mathrm{L}$ hepI (hepI, top right) on passive pressurediameter relationships in mesenteric small arteries (MA) of 12 week old SHR during organ culture. Calculated distensibility for control MA (day 0 and day 3, bottom left) and hepI treated MA (day 0 and day 3 , bottom right). Values are shown as means $\pm \operatorname{SEM}(n=12)$. Closed circle, day 0 ; open circle, day 1 ; closed triangle, day 2 ; open triangle, day 3 . * $p<0.05$, versus day 0 .

In an additional set of experiments we tested whether hepI displayed vasomotor effects. Contractile responses of freshly isolated arteries to $25 \mathrm{mmol} / \mathrm{L} \mathrm{K}^{+}$were reduced by acetylcholine and enhanced by indomethacin and L-NAME indicating intact endothelium. Depolarization-induced contractions were not modified by $0.0001-1.0$ $\mu \mathrm{mol} / \mathrm{L}$ hepI indicating that hepI does not display major acute vasomotor effects. After 3 days in vitro, $1 \mu \mathrm{mol} / \mathrm{L}$ serotonin and $10 \mu \mathrm{mol} / \mathrm{L}$ phenylephrine reduced arterial diameter to $45 \pm 4 \%$ and $47 \pm 3 \%$ of baseline, respectively, in untreated vessels and to $44 \pm 3 \%$ and $46 \pm 4 \%$ of baseline, respectively, in arteries that had been exposed to hepI. Moreover, $1 \mu \mathrm{mol} / \mathrm{L}$ acetylcholine reversed the serotonin-induced constriction by $66 \pm 5 \%$ in untreated vessels and by $63 \pm 5 \%$ in hepI treated arteries. These findings indicate that exposure to hepI for three days did not adversely affect vasoconstriction or endothelium-dependent vasodilatation. 


\section{Discussion}

We demonstrate for the first time i) rapid and concurrent downregulation of eNOS, sGC and PKG mRNA and upregulation of TSP1 mRNA expressions at the initiation of flowrelated remodeling and ii) a direct effect of the calreticulin/LRP1 binding sequence of TSP1 on the structural lumen diameter in small muscular arteries of the rat. That the latter was observed in the narrowed arteries of SHR rats, suggests a therapeutic potential for the pathways involved.

In arteries, wall shear stress and circumferential wall stress are homeostatically controlled by vasomotor and structural changes of lumen diameter and wall thickness $[6,9,35]$. The transition from the acute vasomotor responses to the chronic structural responses is poorly understood. Here we concentrated on subacute effects of altered local blood flow in the interconnected arterial trees of the mesenteric vascular bed. In this system of young rats, increased and reduced blood flow ultimately lead to outward hypertrophic and inward hypotrophic remodeling, respectively [5-7, 14, 17, 18, 27, 28, $31]$. Both structural responses involve marked changes in gene expression and in cellular turnover and differentiation $[14,17]$ which are preceded by a rapid and transient transcriptional response of a comparatively small number of genes [18]. The latter candidate initiators of remodeling might be a target for interventions aimed at improved collateralization in ischemia and reversal of the adverse structural narrowing of resistance arteries in hypertension. We focussed on changes occurring within 24 hours in a cell-cell signaling and signal transduction system that was shown to be involved in flow-induced vasodilatation [9, 11-13], vascular smooth muscle cell de-differentiation and proliferation $[15,16]$ and in the expression of a modulator of cellular adhesion and extracellular matrix, such as TSP1 [19, 22].

The wall shear stress resulting from blood flow can alter the activity and expression of type III NOS (eNOS) in the endothelium [9, 11, 12]. The main NO-receptor in vascular smooth muscle is the heterodimeric soluble guanylyl cyclase sGC $\alpha 1 \beta 1$ [36-38]. The cGMP produced by this enzyme stimulates protein kinases, in the vascular wall primarily PKG1 $\beta$ [36-38], which inhibit vasoconstriction, dedifferentiation and expression of TSP1 in vascular smooth muscle $[19,22]$. In this study we confirmed several earlier findings like (i) inhibitory effects of low blood flow on the mRNA expression of eNOS $[9,12]$ and (ii) association between reduced mRNA expression of PKG and increased mRNA expression of TSP1 [19, 22]. The overall picture of our observations is, however, unexpected. Reduced mRNA expression of eNOS was accompanied by reduced mRNA expression of $s G C \alpha 1$ and PKG1 $\beta$, which is not observed in eNOS-deficient mice [36, 37, 39, 40]. The mRNA expression of both sGC $\alpha 1$ and of PKG1 $\beta$ was reduced, although in a variety of vascular SMC culture models a negative feedback interaction between these effectors has been demonstrated [41]. Most surprising is that concurrent down regulation of eNOS, sGC $\alpha 1$ and PKG1 $\beta$ gene expressions were observed in vessels exposed to reduced blood flow and in vessels 
exposed to increased blood flow. This was found in two strains of rats (WKY and SHR). The finding suggests a general response to an altered hemodynamic microenvironment that prepares the tissue for adequate structural changes aimed at restoring stresses independent from the direction of the initiating change. This may be required to initiate cellular de-differentiation, de-adhesion and turnover and extracellular matrix reorganization that take part in both outward hypertrophic remodeling and in inward hypotrophic remodeling.

In addition, we studied protein expression and vasomotor responses to monitor turnover and activity of eNOS/sGC/PKG pathway components in response to altered blood flow in vivo. Protein expression of TSP1 was increased in LF MA of both WKY and SHR at 32 hours after flow modifying surgery. However, no statistically significant changes in the protein levels of the other proteins and in vasomotor responses to NO-synthase blockade, an endothelium dependent vasodilator and an NO-donor were observed after 32 or 40 hours exposure of rat arteries to altered blood flow.

Although shear stress can at least transiently stimulate activity and expression of eNOS $[9,11,12]$, there is no consensus on the precise role of eNOS in flow-induced arterial remodeling. Caveolin-mediated activation of eNOS seems to be required for the inward remodeling of ligated carotid arteries in mice [42]. In a rabbit carotid artery A-V fistula model, chronic L-NAME treatment inhibits outward remodeling and the contribution of NO can be attributed to stimulation of MMP9 [43]. Chronic L-NAME does, however, not impair inward and outward remodeling of mesenteric small arteries in the rat model that we used here [31]. In this rat mesenteric model, doubling of blood flow does not result in increased expression of eNOS after 2 or 7 days, whereas a four fold increase in blood flow leads to a significant increase in eNOS at these time points [44]. In a similar mouse mesenteric model, Dumont et al. [7] observed increased expression of eNOS and activity of MMP9 at 4 days that contributed to the structural outcome. Differences between species, arteries and extent of blood flow alterations may contribute to these divergent findings. TSP1, as already mentioned, is a large matricellular protein with many functions, particularly the ability of the hepI sequence of TSP1 to signal cellular de-adhesion [22]. This sequence of TSP1 binds to the receptor co-complex of calreticulin/LRP1 and stimulates focal adhesion disassembly and increased cell migration $[20,22,45,46]$. To evaluate a possible contribution of TSP1 to small artery remodeling arteries were exposed to the hepI peptide mimetic in vitro [19].

As described by Bakker et al [34, 47], rat mesenteric small arteries could be maintained for 72 hours in arterial organ culture at constant pressure and in the absence of flow without noticeable alterations in viability of the smooth muscle and endothelium. In this static in vitro setting the arterial diameter did not change while narrowing of LF arteries developed within 40 hours in vivo (present study and [14]). This indicates that the absence of flow is in itself not a potent stimulus for inward remodeling. Administration of hepI in vitro resulted in a diameter increase and in an upward shift of the pressure- 
diameter relationship within 24 hours. The $12 \%$ increase in lumen diameter observed with hepI in vitro is comparable to the diameter response to doubling of blood flow in vivo [14, 17, 31]. HepI-induced outward remodeling was not accompanied by changes in wall mass or vasomotor control. Although TSP1 was upregulated in vessels exposed to increased or reduced blood flow in vivo, exogenous hepI caused outward, but not inward arterial remodeling. The role of vasomotor responses in arterial remodeling may help explain this paradox. Prolonged vasoconstriction has been shown to reorganize cell-matrix interactions [23] and to lead to a narrower arterial lumen (inward remodeling) in vitro $[10,48]$. We now propose that TSP1 expressed in response to a change in shear stress can lead to an intermediate de-adhesive state [20] and that the levels of transmural pressure and vasoconstrictor/vasodilator tone will determine the outward or inward nature of the resulting arterial structural change. A distending pressure, but no vasomotor tone was present during culture allowing the Hep-1 induced de-adhesive state to result in outward arterial remodeling. That 3 days of exposure to Hep-1 increased diameter without altering arterial distensibility contributes to the suggestion that the remodeling resulted from a de-adhesive state rather than from major changes in the extracellular matrices.

Effects of altered blood flow on the mRNA's and proteins investigated were largely similar in 6 week old WKY and SHR. This suggests that the pathways investigated are not likely involved in the inward remodeling of resistance arteries that contributes to the elevated total peripheral vascular resistance and blood pressure in SHR [24, 29, 30]. Despite this limited pathophysiological relevance, hepI, that lacks apparent vasomotor effects was found to rapidly and directly reverse inward arterial remodeling of mesenteric resistance arteries of the hypertensive 12 week old SHR. This strengthens the proposal that small artery structure is a directly amenable pharmaco-therapeutic target. 


\section{Acknowledgements}

Parts of this work were financed by the European Vascular Genomics Network (http://www.evgn.org) supported by the European Community's sixth Framework Programme (contract LSHM-CT-2003-503254), a travel grant from the Italian Society for Hypertension to GB and by a grant from the Dutch Top Institute Pharma (T2-108; metalloproteases and novel targets in endothelial dysfunction). 


\section{References}

[1] Smiesko V, Lang DJ, Johnson PC. Dilator response of rat mesenteric arcading arterioles to increased blood flow velocity. Am J Physiol 1989; 257: H195865 .

[2] Bevan JA, Laher I. Pressure and flow-dependent vascular tone. FASEB J 1991; 5: 2267-73.

[3] Bevan JA, Henrion D. Pharmacological implications of the flow-dependence of vascular smooth muscle tone. Annu Rev Pharmacol Toxicol 1994; 34: 17390 .

[4] Langille BL, O'Donnell F. Reductions in arterial diameter produced by chronic decreases in blood flow are endothelium-dependent. Science 1986; 231: 405-7.

[5] Unthank JL, Fath SW, Burkhart HM, Miller SC, Dalsing MC. Wall remodeling during luminal expansion of mesenteric arterial collaterals in the rat. Circ Res 1996; 79: 1015-23.

[6] Pourageaud F, De Mey JG. Structural properties of rat mesenteric small arteries after 4-wk exposure to elevated or reduced blood flow. Am J Physiol 1997; 273: H1699-706.

[7] Dumont O, Loufrani L, Henrion D. Key role of the NO-pathway and matrix metalloprotease-9 in high blood flow-induced remodeling of rat resistance arteries. Arterioscler Thromb Vasc Biol 2007; 27: 317-24.

[8] Tohda K, Masuda H, Kawamura K, Shozawa T. Difference in dilatation between endothelium-preserved and -desquamated segments in the flowloaded rat common carotid artery. Arterioscler Thromb 1992; 12: 519-28.

[9] Davies PF. Flow-mediated endothelial mechanotransduction. Physiol Rev 1995; 75: 519-60.

[10] Bakker EN, Buus CL, VanBavel E, Mulvany MJ. Activation of resistance arteries with endothelin-1: from vasoconstriction to functional adaptation and remodeling. J Vasc Res 2004; 41: 174-82.

[11] Dimmeler S, Fleming I, Fisslthaler B, et al. Activation of nitric oxide synthase in endothelial cells by Akt-dependent phosphorylation. Nature 1999; 399: 6015.

[12] Fleming I, Busse R. Molecular mechanisms involved in the regulation of the endothelial nitric oxide synthase. Am J Physiol Regul Integr Comp Physiol 2003; 284: R1-12.

[13] Hilgers RH, Bergaya S, Schiffers PM, et al. Uterine artery structural and functional changes during pregnancy in tissue kallikrein-deficient mice. Arterioscler Thromb Vasc Biol 2003; 23: 1826-32.

[14] Buus CL, Pourageaud F, Fazzi GE, et al. Smooth muscle cell changes during flow-related remodeling of rat mesenteric resistance arteries. Circ Res 2001; 89: $180-6$.

[15] Cornwell TL, Arnold E, Boerth NJ, Lincoln TM. Inhibition of smooth muscle cell growth by nitric oxide and activation of cAMP-dependent protein kinase by cGMP. Am J Physiol 1994; 267: C1405-13.

[16] Lincoln TM, Wu X, Sellak H, Dey N, Choi CS. Regulation of vascular smooth muscle cell phenotype by cyclic GMP and cyclic GMP-dependent protein kinase. Front Biosci 2006; 11: 356-67. 
[17] Wesselman JP, Kuijs R, Hermans JJ, et al. Role of the Rhoa/Rho kinase system in flow-related remodeling of rat mesenteric small arteries in vivo. $\mathrm{J}$ Vasc Res 2004; 41: 277-90.

[18] De Mey JG, Schiffers PM, Hilgers RH, Sanders MM. Toward functional genomics of flow-induced outward remodeling of resistance arteries. Am J Physiol Heart Circ Physiol 2005; 288: H1022-7.

[19] Dey NB, Boerth NJ, Murphy-Ullrich JE, et al. Cyclic GMP-dependent protein kinase inhibits osteopontin and thrombospondin production in rat aortic smooth muscle cells. Circ Res 1998; 82: 139-46.

[20] Murphy-Ullrich JE. The de-adhesive activity of matricellular proteins: is intermediate cell adhesion an adaptive state? J Clin Invest 2001; 107: 785-90.

[21] Murphy-Ullrich JE, Gurusiddappa S, Frazier WA, Hook M. Heparin-binding peptides from thrombospondins 1 and 2 contain focal adhesion-labilizing activity. J Biol Chem 1993; 268: 26784-9.

[22] Murphy-Ullrich JE, Pallero MA, Boerth N, et al. Cyclic GMP-dependent protein kinase is required for thrombospondin and tenascin mediated focal adhesion disassembly. J Cell Sci 1996; 109 ( Pt 10): 2499-508.

[23] Martinez-Lemus LA, Hill MA, Meininger GA. The plastic nature of the vascular wall: a continuum of remodeling events contributing to control of arteriolar diameter and structure. Physiology (Bethesda) 2009; 24: 45-57.

[24] Mulvany MJ, Baumbach GL, Aalkjaer C, et al. Vascular remodeling. Hypertension 1996; 28: 505-6.

[25] Lee T, Esemuede N, Sumpio BE, Gahtan V. Thrombospondin-1 induces matrix metalloproteinase-2 activation in vascular smooth muscle cells. J Vasc Surg 2003; 38: 147-54.

[26] van der Heijden OW, Essers YP, Simkens LH, et al. Aging blunts remodeling of the uterine artery during murine pregnancy. J Soc Gynecol Investig 2004; 11: 304-10.

[27] Tuttle JL, Hahn TL, Sanders BM, et al. Impaired collateral development in mature rats. Am J Physiol Heart Circ Physiol 2002; 283: H146-55.

[28] Tuttle JL, Sanders BM, Burkhart HM, et al. Impaired collateral artery development in spontaneously hypertensive rats. Microcirculation 2002; 9: 343-51.

[29] Mulvany MJ. Small artery remodeling and significance in the development of hypertension. News Physiol Sci 2002; 17: 105-9.

[30] Rizzoni D, Porteri E, Boari GE, et al. Prognostic significance of small-artery structure in hypertension. Circulation 2003; 108: 2230-5.

[31] Ceiler DL, De Mey JG. Chronic N(G)-nitro-L-arginine methyl ester treatment does not prevent flow-induced remodeling in mesenteric feed arteries and arcading arterioles. Arterioscler Thromb Vasc Biol 2000; 20: 2057-63.

[32] De Mey JG, Megens R, Fazzi GE. Functional antagonism between endogenous neuropeptide $\mathrm{Y}$ and calcitonin gene-related peptide in mesenteric resistance arteries. J Pharmacol Exp Ther 2008; 324: 930-7.

[33] Smith PK, Krohn RI, Hermanson GT, et al. Measurement of protein using bicinchoninic acid. Anal Biochem 1985; 150: 76-85.

[34] Bakker EN, van Der Meulen ET, Spaan JA, VanBavel E. Organoid culture of cannulated rat resistance arteries: effect of serum factors on vasoactivity and remodeling. Am J Physiol Heart Circ Physiol 2000; 278: H1233-40. 
[35] Langille BL. Morphologic responses of endothelium to shear stress: reorganization of the adherens junction. Microcirculation 2001; 8: 195-206.

[36] Pilz RB, Casteel DE. Regulation of gene expression by cyclic GMP. Circ Res 2003; 93: 1034-46.

[37] Feil R, Lohmann SM, de Jonge H, Walter U, Hofmann F. Cyclic GMPdependent protein kinases and the cardiovascular system: insights from genetically modified mice. Circ Res 2003; 93: 907-16.

[38] Friebe A, Koesling D. Regulation of nitric oxide-sensitive guanylyl cyclase. Circ Res 2003; 93: 96-105.

[39] Li D, Laubach VE, Johns RA. Upregulation of lung soluble guanylate cyclase during chronic hypoxia is prevented by deletion of eNOS. Am J Physiol Lung Cell Mol Physiol 2001; 281: L369-76.

[40] Brandes RP, Kim D, Schmitz-Winnenthal FH, et al. Increased nitrovasodilator sensitivity in endothelial nitric oxide synthase knockout mice: role of soluble guanylyl cyclase. Hypertension 2000; 35: 231-6.

[41] Browner NC, Dey NB, Bloch KD, Lincoln TM. Regulation of cGMPdependent protein kinase expression by soluble guanylyl cyclase in vascular smooth muscle cells. J Biol Chem 2004; 279: 46631-6.

[42] Yu J, Bergaya S, Murata T, et al. Direct evidence for the role of caveolin-1 and caveolae in mechanotransduction and remodeling of blood vessels. J Clin Invest 2006; 116: 1284-91.

[43] Tronc F, Wassef M, Esposito B, et al. Role of NO in flow-induced remodeling of the rabbit common carotid artery. Arterioscler Thromb Vasc Biol 1996; 16: 1256-62.

[44] Tuttle JL, Nachreiner RD, Bhuller AS, et al. Shear level influences resistance artery remodeling: wall dimensions, cell density, and eNOS expression. Am J Physiol Heart Circ Physiol 2001; 281: H1380-9.

[45] Orr AW, Elzie CA, Kucik DF, Murphy-Ullrich JE. Thrombospondin signaling through the calreticulin/LDL receptor-related protein co-complex stimulates random and directed cell migration. J Cell Sci 2003; 116: 2917-27.

[46] Orr AW, Pedraza CE, Pallero MA, et al. Low density lipoprotein receptorrelated protein is a calreticulin coreceptor that signals focal adhesion disassembly. J Cell Biol 2003; 161: 1179-89.

[47] Bakker EN, Buus CL, Spaan JA, et al. Small artery remodeling depends on tissue-type transglutaminase. Circ Res 2005; 96: 119-26.

[48] Bouvet C, Gilbert LA, Girardot D, deBlois D, Moreau P. Different involvement of extracellular matrix components in small and large arteries during chronic NO synthase inhibition. Hypertension 2005; 45: 432-7. 


\section{Chapter 3 $\mathrm{ET}_{\mathrm{A}}$-receptor Antagonists or Allosteric Modulators?}

Jo G.R. De Mey, Matthijs G. Compeer, Pieter Lemkens, Merlijn J.P.M.T. Meens

Trends Pharmacol Sci. 2011 Jun;32(6):345-51 


\begin{abstract}
The paracrine signaling peptide endothelin-1 (ET1) is involved in cardiovascular diseases, cancer and chronic pain. It acts on class A G-protein-coupled receptors (GPCRs) but displays atypical pharmacology. It binds tightly to ET receptor type A $\left(\mathrm{ET}_{\mathrm{A}}\right)$ and causes longlasting effects. In resistance arteries, the long-lasting contractile effects can only be partly and reversibly relaxed by low-molecular-weight $\mathrm{ET}_{\mathrm{A}}$ antagonists (ERAs). However, the neuropeptide calcitonin-generelated peptide selectively terminates binding of ET1 to $\mathrm{ET}_{\mathrm{A}}$. We propose that ET1 binds polyvalently to $\mathrm{ET}_{\mathrm{A}}$ and that ERAs and the physiological antagonist allosterically reduce $\mathrm{ET}_{\mathrm{A}}$ functions. Combining the two-state model and the two-domain model of GPCR function and considering receptor activation beyond agonist binding might lead to better antiendothelinergic drugs. Future studies could lead to compounds that discriminate between $\mathrm{ET}_{\mathrm{A}}$-mediated effects of the endogenous isopeptides ET1, ET2 and ET3 and that become more effective when the activity of the endogenous endothelin system is elevated.
\end{abstract}


$\mathrm{ET}_{\mathrm{A}}$-receptor Antagonists or Allosteric Modulators?

\section{Introduction}

We predicted the existence of endothelium-derived contractile factors (EDCFs) in 1982 [1]. In 1988, one of these EDCFs was identified as the 21-amino-acid bicyclic peptide endothelin-1 (ET1), which causes sustained and long-lasting vasoconstrictor and vasopressor effects [2]. The endothelin system in mammals includes three 21 -aminoacid bicyclic signaling peptides (ET1, ET2 and ET3), the enzymes involved in their synthesis and degradation (endothelin-converting enzymes and, to a lesser extent, chymase and neutral endopetidase) and two G-protein-coupled receptors (GPCRs, ET and $\mathrm{ET}_{\mathrm{B}}$ ) [3-5]. These GPCRs are involved in embryonic development and cardiovascular homeostasis, and in the pathogenesis of cardiovascular and renal diseases, diabetes, cancers and chronic pain [6-10]. Prolonged $\mathrm{ET}_{\mathrm{A}}$ stimulation causes vasospasm, inflammation, oxidative stress, and cell growth and proliferation. In blood vessels, endothelial $\mathrm{ET}_{\mathrm{B}} \mathrm{s}$ counteract these deleterious effects of $\mathrm{ET}_{\mathrm{A}}$ [11] and scavenge ET1 from the circulation $[12,13]$. There is ongoing debate on the therapeutic effects of selective $\mathrm{ET}_{\mathrm{A}}$ versus mixed $\mathrm{ET}_{\mathrm{A}}$ and $\mathrm{ET}_{\mathrm{B}}$ antagonists [8]. Here we focus on the peculiar molecular pharmacology of $\mathrm{ET}_{\mathrm{A}}$.

Based on its amino acid sequence, $\mathrm{ET}_{\mathrm{A}}$ is a class A GPCR [5, 14]. Compared with the well-known rhodopsin, $\beta$-adrenoceptor, adenosine and muscarinic members of this family [15], it displays atypical pharmacological properties. Most notably, agonistinduced effects of $\mathrm{ET}_{\mathrm{A}}$ stimulation persist for several hours and are little affected by desensitization, tachyphylaxis or tolerance $[2,4,16]$. In this article, we discuss the mechanisms and consequences of long-lasting ET1-induced $\mathrm{ET}_{\mathrm{A}}$-mediated effects.

\section{ETA-mediated signaling}

GPCRs are flexible seven-transmembrane (7TM) proteins that can isomerize between inactive and active conformations.Binding of the endogenous agonist to its orthosteric binding site on the GPCR promotes transition of the receptor from an inactive to an active state that can interact with intracellular proteins involved in signal transduction [17] such as GTP-binding regulatory proteins and arrestins. Activated $\mathrm{ET}_{\mathrm{A}}$ can bind both low-molecular-weight monomeric G proteins (Ras and Rho) and heterotrimeric G proteins. Several subtypes of $\mathrm{G} \alpha$ subunits can be activated. This promiscuity explains stimulation of various signal transduction pathways. These include calcium influx, phospholipase $\mathrm{C} \beta$, phospholipase $\mathrm{D}$, protein kinase $\mathrm{C}(\mathrm{PKC})$, mitogen-activated protein kinases (MAPKs), $\mathrm{Ca}^{2+} /$ calmodulin-dependent kinases and, at a higher level of complexity, stimulation of vasospasm, oxidative stress, inflammation and cellular proliferation [18]. Whether G $\beta \gamma$ subunits contribute to signaling (as is the case for several other GPCRs [19]) has not been investigated yet. $\mathrm{ET}_{\mathrm{A}}$ can be phosphorylated by G-receptor kinases (GRKs) and subsequently bind arrestins [20-22]. Arrestin-mediated signaling, which is increasingly recognized for other GPCRs [15], has also been demonstrated for $\mathrm{ET}_{\mathrm{A}}$ [9]. It was originally proposed that activated $\mathrm{G}$ proteins, GRK- 
mediated phosphorylation and arrestin binding cause desensitization, tachyphylaxis, internalization and tolerance of GPCRs [15]. However, because $\mathrm{ET}_{\mathrm{A}}$-mediated vasopressor responses persist for a long time, chronically activated $\mathrm{ET}_{\mathrm{A}}$ seems to be little affected by these negative feedback mechanisms. This might involve tight binding of endothelins to $\mathrm{ET}_{\mathrm{A}}[4,16]$. The molecular mechanisms of ongoing signaling by activated $\mathrm{ET}_{\mathrm{A}}$, however, remain to be established. Candidates include (i) inhibition of GRK activity by nitrosylation [23], (ii) G-protein-independent arrestin-mediated signaling [9] and (iii) rapid recycling of internalized $\mathrm{ET}_{\mathrm{A}}$ [24] in tissue and in in vivo systems where the long-lasting effects of ET1 are most prominent.

\section{Agonist binding}

$\mathrm{ET}_{\mathrm{A}}$ activation is promoted by binding of the endogenous peptidergic agonists to their orthosteric binding site on the receptor. ET1 and ET2 (Trp6-Leu7-ET1) bind with equal high affinity to $\mathrm{ET}_{\mathrm{A}}$, whereas the third endogenous isopeptide ET3 (Thr2-Phe4-Thr5Tyr6-Lys7-Tyr14-ET1) binds with considerably less affinity [3, 5]. This agonistreceptor binding is not influenced by GTP, which reduces the affinity of many GPCRs for their agonists. Truncation, amidation or extension of the C-terminal Trp21 of ET1 abolishes binding. The linear analogue 4Ala-ET1 (in which both disulfide bonds are absent due to replacement of all four cysteine residues by alanine) does not bind to $\mathrm{ET}_{\mathrm{A}}$. These observations indicate that the C-terminal tail, selected amino acids in the Nterminal loop and both disulfide bonds are all required for polyvalent binding of endogenous peptides to $\mathrm{ET}_{\mathrm{A}}[16,25,26]$. The orthosteric binding site of $\mathrm{ET}_{\mathrm{A}}$ would thus contain more than one functional domain. Studies using site-directed mutagenesis, chimeric receptors and photoaffinity labeling indicate that these orthosteric binding domains are located between TM helices 1, 2, 3 and 7, and between TMs 4, 5 and 6 of $\mathrm{ET}_{\mathrm{A}}$, respectively [25, 27-30]. Hilal-Dandan et al. proposed that the ultimate polyvalent ET1-ET $\mathrm{A}_{\mathrm{A}}$ complex is preceded by one or more transitory conformations [31]. However, the equilibrium dissociation constants and the structure-affinity relationships of these intermediates have not been defined. Results of binding studies using intact radioactively labeled ET1 provide information about the kinetics of the formation of the ultimate complex and include the influences of receptor activation on agonist affinity $[32,33]$. The rate of association between ET1 and $\mathrm{ET}_{\mathrm{A}}$ is comparable to that for angiotensin II (another potent vasoactive peptide) acting on the AT1a GPCR. The rate of dissociation $\left(0.0005 \mathrm{~min}^{-1}\right)$ is, however, 100 times slower. As a result, complexes composed of radioactively labeled ET1 and $\mathrm{ET}_{\mathrm{A}}$ cannot be dissociated by cold agonists, and their half-life ranges from 7 to $77 \mathrm{~h}[4]$. ET1 thus binds tightly to $\mathrm{ET}_{\mathrm{A}}$.

\section{Model of receptor binding and activation}

It has been proposed that $\mathrm{ET}_{\mathrm{A}} \mathrm{S}$ display an inactive conformation $(\mathrm{R})$ or an active conformation $\left(R^{*}\right)$ that can bind one or more $G$ proteins $(G)$ and other effector proteins (Figure 3.1a). An orthosteric agonist (e.g. ET1) binds sequentially and polyvalently to $\mathrm{R}$ 
and promotes its activation ( $\mathrm{R} ! \mathrm{R}^{*}$ conversion). A first transitory complex (R-et) is a prerequisite for subsequent formation of the quasi-irreversible R-ET complex (Figure 3.1b). Although R-et binding and G-R*-et function might exhibit typical class A GPCR behavior, R-ET binding and G-R*-ET function do not. The initial transitory complexes might exhibit dynamic equilibrium and susceptibility to desensitization and tolerance. By contrast, the ultimate complexes are tight and their effects are long-lasting and persistent (Figure 3.1b). Figure 3.1c,d illustrates the effects of a neutral competitive antagonist and an allosteric modulator in this situation, respectively. Recent work by our research team revealed functional observations [16] that, in combination with earlier structure-affinity relationships [25, 34], suggest roles for different parts of the agonist molecule and different domains of $\mathrm{ET}_{\mathrm{A}}$ in (i) the dynamic interaction,

(a)

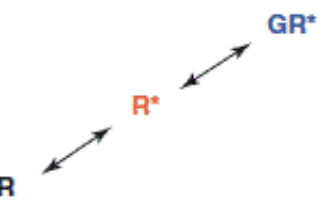

(b)

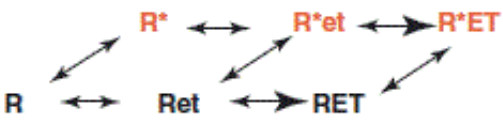

(c)

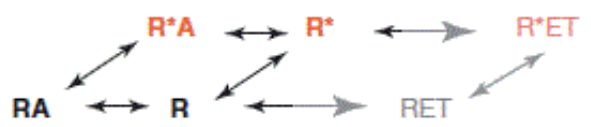

(d)

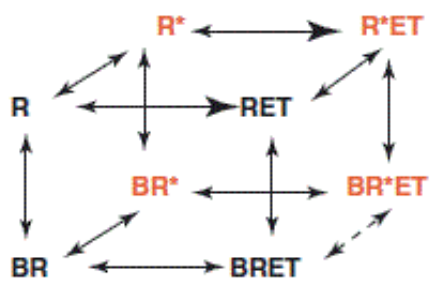

Figure 3.1: Activation, agonist binding and modulation of $\mathbf{E T}_{\mathrm{A}}$. (a) The receptor occurs in an inactive conformation $(R)$ or in an active conformation $\left(R^{*}\right)$ that can bind one or more signaling molecules $(G)$. (b) Sequential binding of an endothelin isopeptide to the receptor resulting in the formation of a tight complex (RET) that promotes receptor activation. (c) An orthosteric ligand (A, e.g. a neutral competitive antagonist) hinders binding of the endothelin isopeptide. (d) An allosteric ligand (B) can modulate the affinity of the receptor for the orthosteric agonist and can modulate receptor activation. An ideal allosteric inhibitor would promote dissociation of preexisting RET complexes and/or promote the transition from activated $\left(R^{*}\right)$ to inactive receptors $(R)$. Thick arrows indicate the formation of slowly dissociating complexes. Grey arrows indicate reduced apparent affinity due to competitive antagonism. 
(ii) ultimate tight binding and (iii) activation of the receptor. We therefore propose that ET1 consists of two functional parts (Figure 3.2). One part of the agonist would be responsible for association with $\mathrm{ET}_{\mathrm{A}}$. This would concentrate another part of the agonist at another domain of the receptor, which could then bind tightly and activate the receptor. For various other endogenous peptides that act on class B GPCRs, the reported structure-activity relationships are in line with the presence of distinct 'address' and 'message' domains [35-38]. For ET1, such detailed information is not available yet, but structural analyses indicate a flexibility of the agonist molecule [25] that might be essential for the two parts of the agonist to interact sequentially with $\mathrm{ET}_{\mathrm{A}}$ (Figure 3.2). In the event that ET1 consists of functional parts separated by a hinge region [25], the orthosteric binding site of $\mathrm{ET}_{\mathrm{A}}$ contains at least two functional domains (Figure 3.2). This suggestion is supported by studies using engineered receptors and photoaffinity labeling [27-30, 34].

(a)

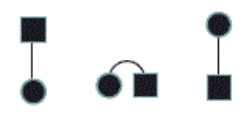

(b)

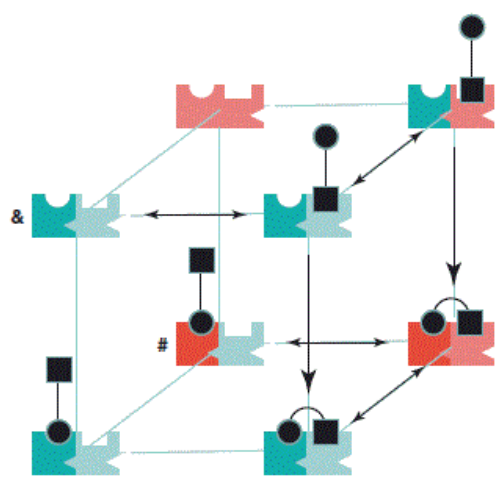

Figure 3.2: Two-domain and two-state model of $\mathbf{E T}_{\mathrm{A}}$ function. (a) The agonist molecule (e.g. ET1) is flexible and is composed of two functional parts separated by a hinge region. (b) The orthosteric site of the receptor contains two binding domains and exists in inactive (blue) or active (reddish) conformations. The arrows (black) indicate preferred reactions, with the thickest ones representing the formation of a tight complex. The conformations of the receptor on the left-hand side can be acted on by low-molecular-weight ERA, which can modulate the agonist affinity and/or efficacy of the receptor. $\&$ and \# indicate proposed conformations that, when acted on by low-molecular-weight ERA, display (i) reduced sensitivity to ET1 and (ii) partial and reversible reduction of long-lasting effects initiated by ET1, respectively.

During the past decade, it became increasingly clear that the affinity and efficacy of small agonists acting on the orthosteric binding site of a GPCR can be modulated by ligands that bind to a topographically distinct (allosteric) binding site on the same GPCR molecule [33, 39-42]. This allosteric modulation involves cooperativity between the affinity and efficacy of the distinct ligands acting on their distinct binding sites. In our opinion, a large agonist molecule such as ET1 that consists of two parts and that 
acts on two orthosteric binding domains of a receptor engages similar cooperativity between the orthosteric binding domains (Figure 3.2); in other words, endothelins might be considered as endogenous bitopic agonists [43] of at least $\mathrm{ET}_{\mathrm{A}}$.

\section{Long-lasting agonism}

Conditions of dynamic equilibrium govern most classical and modern theories of molecular pharmacology [44]. These conditions do not easily apply to $\mathrm{ET}_{\mathrm{A}}$ in view of the slow dissociation of the agonist-receptor complex [4, 31, 45, 46]. Hence, reported affinity measures (e.g. the 'equilibrium' dissociation constant $\mathrm{Kd}$ ) must be regarded as approximations. When the dissociation rate constant of the agonist-receptor complex $(\mathrm{k}-1)$ is considerably less than its association rate constant $(\mathrm{k}+1)$, very low concentrations of agonist can act locally with high potency because $\mathrm{Kd}=\mathrm{k}-1 / \mathrm{k}+1$ [47]. This is an effective mechanism for a paracrine mediator. However, conditions of dynamic equilibrium become hard to establish in routine experimental settings such as ligand-binding and concentration-response studies. Not only is the agonist concentration a crucial factor, but the duration and history of agonist exposure also become determining factors that influence binding and effects [4, 16]. Figure 3.3 illustrates this for ET1-ET induced contractile responses in isolated arteries. Over time, the concentration-response curve shifts to the left; the agonist seems to become more potent. Moreover, the response persists if the organ chamber content is flushed and free (unbound) agonist is no longer available. The halflife of the response is $>20$ min (compared to $<1 \mathrm{~min}$ for the classical vasoconstrictor agonist noradrenaline) [16]. In theory, both the tightness of agonist-receptor complexes ( $\mathrm{R}^{*}$-ET and R-ET in Figure 3.1 ) and the slow reversibility of receptor activation (slow conversion of $R^{*}$ to $R$ in Figure 3.1) can contribute to such long-lasting agonism. However, using fluorescently labeled ET1 in the same functional assay system, we established that the contractile response and binding of the agonist to the cell membrane of smooth muscle cells in the intact arterial wall were maintained for $>20 \mathrm{~min}$ in the absence of the free ligand [16]. Moreover, intravenous bolus administration of ET1 in vivo causes a long-lasting increase in blood pressure $[2,48]$ despite the short half-life of the peptide in circulation $(\mathrm{T} 1 / 2<1.5 \mathrm{~min})$ as a result of its scavenging by 


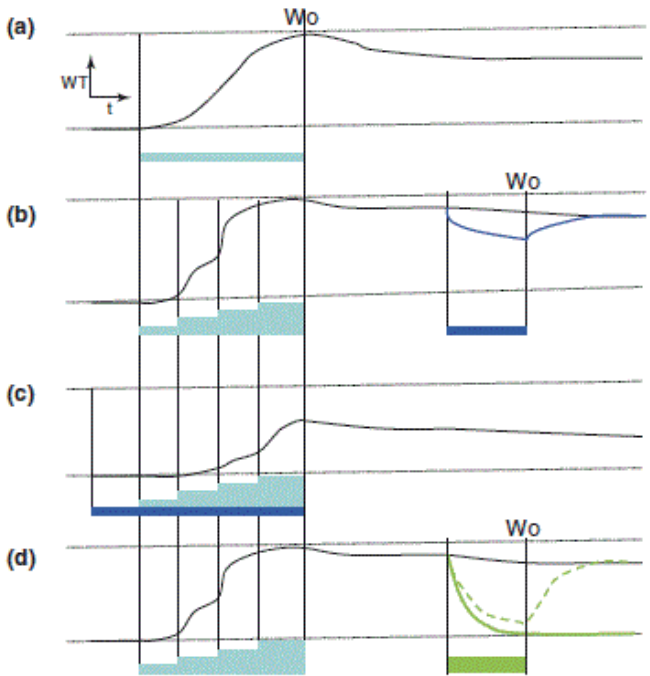

Figure 3.3: Long-lasting agonism of ET1. Idealized tracings of wall tension (WT) versus time (t) recorded in four isolated arterial segments as detailed in [16,61]. The presence of vasoactive compounds is indicated by the colored horizontal bars, with their thickness representing the concentration. At washout (Wo), free (unbound) compounds were flushed from the organ chamber. (a) Over time, a low concentration of ET1 (light blue) causes strong vasoconstriction that persists after Wo. (b) Vasoconstrictor responses to increasing concentrations of ET1 resulting in a response that persists in

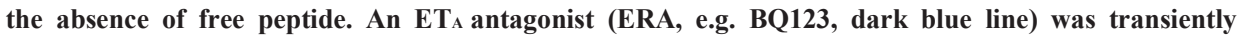
applied on top of the long-lasting contraction. (c) The presence of an ERA (e.g. BQ123, dark blue line) shifts the ET1 concentration-response curve to higher concentrations. The same compound causes a small and transient reduction in the vasoconstrictor response that had been initiated by ET1 (b). (d) Arterial contractile responses initiated by ET1 are transiently relaxed by a functional antagonist (dashed green line, e.g. acetylcholine that causes release of endothelium-derived relaxing factors) but can be reversed by a putative indirect allosteric inhibitor (full green line, e.g. exogenous or endogenously released CGRP).

the lungs and its elimination by the kidneys $[12,13]$. These in vitro arterial contractile responses to ET1 and the in vivo vasopressor effects of ET1 can be prevented by prior application of a selective $\mathrm{ET}_{\mathrm{A}}$ antagonist (ERA). In summary, ET1 binds tightly to $\mathrm{ET}_{\mathrm{A}}$ and consequently causes long-lasting cardiovascular effects not only in vitro, but also in vivo.

\section{ERAs}

Antagonists are still frequently seen as agents that can occupy an orthosteric binding site without altering the activation of the receptor [17], in other words, as neutral competitive antagonists. According to the International Union of Basic and Clinical Pharmacology (IUPHAR), however, 'an antagonist is a drug that reduces the action of another drug, generally an agonist' [47]. An antagonist can thus be a chemical 
antagonist, a functional antagonist, a physiological antagonist, a neutral competitive antagonist, an inverse agonist and a negative allosteric modulator. In most ligandbinding and functional experiments, the latter three cannot be discriminated unless the allosteric inhibitory effect is only moderate [47]. Soon after the discovery of ET1 and the cloning of its $\mathrm{ET}_{\mathrm{A}}$ and $\mathrm{ET}_{\mathrm{B}}$ receptors, low-molecular-weight compounds were identified that can prevent the binding and effects of radioactively labeled ET1 [3, 5, 6, 8]. Initially, these ERAs resulted from screening efforts (e.g. BQ123 [39, 49] and bosentan [50]). Subsequently, rational drug design focused on the C-terminal hexapeptide that is common to all endogenous ET isopeptides was applied [51]. Today, several classes of peptidergic, nonpeptidergic, hydrophilic, lipophilic and orally active ERAs are available [52]. Some of these do not discriminate between ET receptor subtypes, whereas others display selectivity for either $\mathrm{ET}_{\mathrm{A}}$ or $\mathrm{ET}_{\mathrm{B}}$. One ERA, bosentan (Tracleer1), is registered worldwide for application in pulmonary hypertension. Several others are in advanced clinical development $[6,8,52]$. The literature on these agents tends to suggest that all ERAs act as neutral competitive antagonists. However, ERAs can prevent agonist binding, but do not reverse established agonist- receptor complexes in membrane preparations [31, 45] or in tissue [16]. This adds evidence of the tight nature of the agonist-receptor complexes. As a result, certain ERAs prevent responses to ET1 but do not influence responses that were initiated by the peptide [53]. Surprisingly, in most cases ERAs not only prevent but also reduce (albeit to a smaller extent) ET1-induced effects in vitro and in vivo [48, 54]. We recently reported such a situation in isolated resistance arteries using a non-selective ERA, the pyrimidine sulfonamide bosentan, and three $\mathrm{ET}_{\mathrm{A}}$-selective ERAs, the cyclic pentapeptide BQ123, the pyrazole SB234551 and the butenolide PD156707 [16]. For all four compounds, we observed partial and reversible relaxation of the contractions during and after exposure to ET1 (Figure 3.3). This was not accompanied by reversal of the binding of fluorescently labeled ET1 [16]. Effects of different ERAs differ in the same test system (e.g. FR139317 vs BQ123, bosentan, PD156707 and SB234551 in rat mesenteric arteries $[16,53])$ and different effects were obtained with the same ERA in different preparations (e.g. PD156707 in rat mesenteric arteries and human mammary arteries $[16,55])$. Interpretation of the effects of ERAs will thus have to include their system dependence, which ranks among the criteria for allosteric modulation. Two mechanisms can explain the actions of ERAs on $\mathrm{ET}_{\mathrm{A}}$. The low-molecular-weight compounds either (i) compete at only one of the orthosteric binding domains of $\mathrm{ET}_{\mathrm{A}}$ or (ii) bind at a distinct allosteric site that modulates the affinity and efficacy of the orthosteric domains (Figures 3.1c,d and 3.2). In the first model [16], ERAs and ET1 compete at a domain on $\mathrm{ET}_{\mathrm{A}}$ that would correspond to R-et in Figure 3.1, which is a prerequisite for irreversible binding of ET1 at another domain (represented by R-ET in Figure 3.1). Binding at this domain can modulate the activation triggered by the occupied second domain. In this view, ERAs can act as either neutral competitive antagonists or inverse agonists on the orthosteric domain, depending on whether the orthosteric domains display cooperativity for receptor activation. The notion that low-molecular-weight ERAs bind to an orthosteric domain is suggested by observations that at least some of them (e.g. BQ123 
and $\mathrm{ABT}-627$ ) promote internalization of $\mathrm{ET}_{\mathrm{A}}[56,57]$. In the second model, ERAs act as allosteric inhibitors, reducing the affinity and/or efficacy of the orthosteric binding domains within the orthosteric binding site (Figure 3.1d). Molecular modeling studies indicate that the binding site of some ERAs does not fully coincide with the ET1 binding domains $[27,30]$. It has been proposed that the binding site of some ERAs is located somewhat deeper in the cleft between TMs 1, 2, 3 and 7 of the ET $\mathrm{A}_{\mathrm{A}}$. If the ERA and ET1 binding sites partly overlap, then the two models are not mutually exclusive. Furthermore, both models might not equally apply to distinct classes of ERAs. This remains to be established. There is currently no nomenclature in pharmacology that discriminates between antagonists that bind to either (i) one of two orthosteric binding domains or (ii) an allosteric binding site that is topographically distinct from both of the two orthosteric binding domains.

\section{Allosteric inhibitors}

In general, candidate drugs that bind to a GPCR at a site that is distinct (allosteric site) from the binding site of the endogenous agonist (orthosteric site) are attracting increasing attention [39, 41, 58]. Allosteric modulators display saturability of their effect, probe dependence, differential effects on the affinity and efficacy of orthosteric ligands, and system dependence $[39,41,58]$. In 2000, it was reported that the effects of salicylates on $\mathrm{ET}_{\mathrm{A}}$ meet some of these criteria $[45,46]$. In addition, they promoted the dissociation of ET1-ET $\mathrm{A}_{\mathrm{A}}$, and thus accelerated the fading of vasoconstrictor responses initiated by ET1 and enhanced the inhibitory effects of the prototype ERA BQ123 [45, 46]. Important criteria of allosteric modulation such as probe (or agonist) dependence and the saturability of effects were not addressed. The structure-activity relationship for salicylates differs from that of their best-known target (cyclooxygensases) and millimolar rather than micromolar concentrations of the compounds are required for their proposed allosteric effect on $\mathrm{ET}_{\mathrm{A}}$. It is therefore not likely that allosteric modulation of $\mathrm{ET}_{\mathrm{A}}$ function contributes to therapeutic effects of these aspirin-like compounds in patients. These observations suggest the existence of an allosteric modifier site on $\mathrm{ET}_{\mathrm{A}}$ that recognizes salicylate-like molecules.

\section{Physiological antagonism}

Tight receptor binding and long-lasting agonism by an endogenous signaling molecule such as ET1 are not compatible with homeostatic control of cardiovascular function in vivo. We therefore evaluated candidate endogenous counterbalancing mechanisms for specific inhibition of ET1 receptor function [16].We tested whether one or more vasodilator compounds that can be produced in blood vessels could terminate arterial contractile responses initiated by ET1. Agents were either exogenously administered to isolated arteries or were endogenously released using accepted stimuli that act indirectly, such as acetylcholine and capsaicin [16, 59-61]. Both endothelium-derived relaxing factors and vasodilator neuropeptides were considered. In the endothelium, 
nitric oxide (NO) (i) inhibits the synthesis and release of ET1 and (ii) is produced in response to ET1 acting on endothelial $\mathrm{ET}_{\mathrm{B}}[11,62]$. Endothelium-derived $\mathrm{NO}$ and hyperpolarizing factor relax the contractile responses of arterial smooth muscle to $\mathrm{ET}_{\mathrm{A}}$ stimulation [16, 61, 63]. Endothelium-derived relaxing factors can thus be important functional antagonists of ET1 responses. It has been reported that this is also the case in human conductance and resistance coronary arteries [64]. However, in contrast to consequences of ET1- induced signaling, ET1-ET $\mathrm{A}_{\mathrm{A}}$ interaction does not seem to be modified by endothelium-derived relaxing factors. The endothelium-dependent vasodilator acetylcholine did not promote dissociation of ET1-ET $\mathrm{E}_{\mathrm{A}}$ complexes (Figure 3.3) [16], and NOS and COX inhibition did not modify the potency of contractile responses to ET1 and their irreversibility $[16,61]$. In the kidneys, sensorimotor nerves counterbalance effects of ET1 through release of one of their neurotransmitters, calcitonin-gene-related peptide (CGRP) [65]. In rat mesenteric arteries, stimuli of periarterial sensorimotor nerves and exogenous CGRP relax contractile responses to ET1 more potently than responses to other vasoconstrictors [61]. CGRP receptor stimulation by both exogenous and endogenously released neuropeptide promotes dissociation of arterial smooth muscle ET1-ET $\mathrm{A}_{\mathrm{A}}$ complexes [16]. Because CGRP acts on its own heterotrimeric GPCR [38] and not directly on $\mathrm{ET}_{\mathrm{A}}$, these observations illustrate crosstalk between peptidergic GPCRs that results in reduced affinity (increased rate of dissociation) of one of them $\left(\mathrm{ET}_{\mathrm{A}}\right)$ for its endogenous agonist (ET1), which represents indirect allosteric modulation (Figures 3.3 and 3.4). The signal transduction involved in this CGRP-ET $\mathrm{A}_{\mathrm{A}}$ crosstalk differs from the mechanisms underlying the general vasodilator effects of CGRP [66]. It does not involve adenylyl cyclase, cAMP, NO or activation of ATP-sensitive $\mathrm{K}^{+}$channels [16]. Whether it is due to (i) direct interaction between the two types of receptors, (ii) a receptor-activity modifying protein or (iii) an as yet unknown second messenger could be addressed in cells that express both types of receptors and in membrane preparations of these cells. It remains to be established whether CGRP-ET $\mathrm{E}_{\mathrm{A}}$ crosstalk is an incidental oddity of the rat mesenteric artery or if it also applies to other vascular beds and other species and if it is sufficiently widespread and powerful to result in systemic cardiovascular effects. Nevertheless, it illustrates the potential for allosteric mechanisms triggered not only by exogenous compounds (e.g. salicylates), but also by endogenous systems (e.g. CGRP) (Figure 3.4). It is noteworthy in this respect that peri-arterial sensorimotor nerves are acted on by active ingredients of chili peppers, mustard, wasabi and garlic $[67,68]$. These stimulate TRP channels on the nerves, which leads to release of neuropeptides (including CGRP). Some of the health benefits associated with consumption of these foods might involve an indirect (through CGRP) but selective anti-endothelinergic component. 


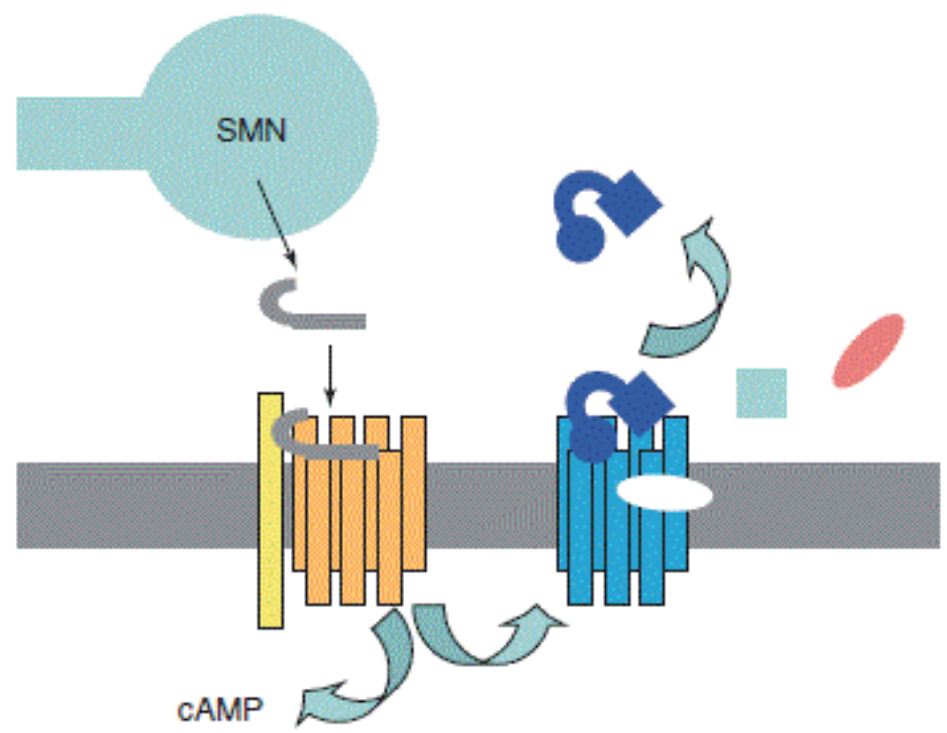

Figure 3.4 Modulation of ET $\mathrm{A}_{\mathrm{A}}$ function by exogenous compounds and endogenous systems. On the cell membrane (grey) of vascular smooth muscle cells in the arterial wall, the function (affinity and efficacy) of $\mathrm{ET}_{\mathrm{A}}$ receptors (blue 7TM structure) can be modulated by an orthosteric ligand [e.g. a competitive antagonist (light blue square) with a structure that resembles part of the endogenous endothelinergic agonist (dark blue, bitopic structure)]. An exogenous allosteric inhibitor is represented by the pink ellipsoid. In addition, perivascular sensorimotor nerves (SMNs) can be stimulated to release the neuropeptide CGRP (grey bent line) that acts on postjunctional CGRP receptors [calcitonin receptorlike receptor (CRLR), orange 7TM; RAMP1, yellow TM structure] that (i) cause cAMP-dependent

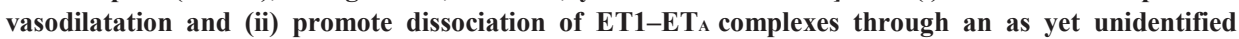
mechanism

\section{Concluding remarks}

Some of the clinical trials of putative neutral competitive ERAs have been less successful than anticipated $[6,8,11]$. This might be because of underestimation of the complexity of the molecular pharmacology of $\mathrm{ET}_{\mathrm{A}}$. To resolve this, it will be necessary to define the signaling mechanisms during the long-lasting effects resulting from $\mathrm{ET}_{\mathrm{A}}$ stimulation. G-protein-independent arrestin-mediated signaling is worth considering $[69,70]$. In the meantime, it might be informative to combine models elaborated for GPCRs that are acted on by small agonists (e.g. two-state, cubic ternary complex, allosteric ternary complex and allosteric ternary two-state models [32, 33, 39, 41-43]) with models elaborated for GPCRs that are acted on by high-molecular-weight peptides (e.g. two-domain model $[35,36,38])$. Testing of reversing or curative effects of putative antagonists should take into consideration that ET1 dissociates only slowly from ETA. Renewed interest in structure-activity relationships of endothelins and their receptors might focus on (i) potentially distinct address and message domains and (ii) both affinity and efficacy, including those for recruitment of arrestin. It is also worth considering currently available and future ERAs and physiological antagonists of ETA 
as negative allosteric modulators. The criteria of allosterism that should be addressed $[39,41,42]$ include at least distinct effects on agonist affinity and efficacy, saturability and the probe (or agonist) dependence of these effects. Although challenging, these approaches could result (at least in theory) in drugs that become more effective the more the endogenous ET system is activated and in drugs that can discriminate between the ETA-mediated effects of the distinct endogenous endothelins ET1, ET2 and ET3 [39, $41,42]$. Because a prominent feature of ETA pharmacology is tight binding of endogenous agonists, particular attention to the rate of dissociation and to the residence time of the agonist on the receptor is required. Several excellent reviews have recently examined various techniques that can be used to study aspects of drug-target binding $[71,72]$. The reported roles of ETA in a broad variety of diseases [6-9] and our recent finding that endogenously released CGRP and CGRP receptor activation can act as endogenous indirect negative allosteric modulators of ETA function [4, 16, 61] should provide motivation to investigate these issues. 
Chapter 3

\section{Acknowledgements}

The authors' research is performed within the framework of the Dutch Top Institute Pharma, projects T2-108 (metalloproteases and novel targets in endothelial dysfunction) and T2-301 (renin-angiotensin system blockade beyond angiotensin II). 
$\mathrm{ET}_{\mathrm{A}}$-receptor Antagonists or Allosteric Modulators?

\section{References}

[1] De Mey JG, Claeys M, Vanhoutte PM. Endothelium-dependent inhibitory effects of acetylcholine, adenosine triphosphate, thrombin and arachidonic acid in the canine femoral artery. J Pharmacol Exp Ther 1982; 222: 166-73.

[2] Yanagisawa M, Kurihara H, Kimura S, et al. A novel potent vasoconstrictor peptide produced by vascular endothelial cells. Nature 1988; 332: 411-5.

[3] Davenport AP. International Union of Pharmacology. XXIX. Update on endothelin receptor nomenclature. Pharmacol Rev 2002; 54: 219-26.

[4] De Mey JGR, Compeer MG, Meens MJ. Endothelin-1, an Endogenous Irreversible Agonist in Search of an Allosteric Inhibitor. Mol Cell Pharmacol 2009; 1: 246.

[5] Masaki T. Historical review: Endothelin. Trends Pharmacol Sci 2004; 25: 21924.

[6] Hynynen MM, Khalil RA. The vascular endothelin system in hypertension-recent patents and discoveries. Recent Pat Cardiovasc Drug Discov 2006; 1 : 95-108.

[7] Khodorova A, Montmayeur JP, Strichartz G. Endothelin receptors and pain. J Pain 2009; 10: 4-28.

[8] Kirkby NS, Hadoke PW, Bagnall AJ, Webb DJ. The endothelin system as a therapeutic target in cardiovascular disease: great expectations or bleak house? Br J Pharmacol 2008; 153: 1105-19.

[9] Rosano L, Spinella F, Bagnato A. The importance of endothelin axis in initiation, progression, and therapy of ovarian cancer. Am J Physiol Regul Integr Comp Physiol 2010; 299: R395-404.

[10] Yanagisawa H, Hammer RE, Richardson JA, et al. Role of Endothelin$1 /$ Endothelin-A receptor-mediated signaling pathway in the aortic arch patterning in mice. J Clin Invest 1998; 102: 22-33.

[11] Schneider MP, Boesen EI, Pollock DM. Contrasting actions of endothelin ET(A) and ET(B) receptors in cardiovascular disease. Annu Rev Pharmacol Toxicol 2007; 47: 731-59.

[12] Fukuroda T, Fujikawa T, Ozaki S, et al. Clearance of circulating endothelin-1 by ETB receptors in rats. Biochem Biophys Res Commun 1994; 199: 1461-5.

[13] Johnstrom P, Fryer TD, Richards HK, et al. Positron emission tomography using 18F-labelled endothelin-1 reveals prevention of binding to cardiac receptors owing to tissue-specific clearance by ET B receptors in vivo. Br J Pharmacol 2005; 144: 115-22.

[14] Lin HY, Kaji EH, Winkel GK, Ives HE, Lodish HF. Cloning and functional expression of a vascular smooth muscle endothelin 1 receptor. Proc Natl Acad Sci U S A 1991; 88: 3185-9.

[15] Lefkowitz RJ. Historical review: a brief history and personal retrospective of seven-transmembrane receptors. Trends Pharmacol Sci 2004; 25: 413-22.

[16] Meens MJ, Compeer MG, Hackeng TM, et al. Stimuli of sensory-motor nerves terminate arterial contractile effects of endothelin-1 by CGRP and dissociation of ET-1/ET(A)-receptor complexes. PLoS One 2010; 5: e10917.

[17] Deupi X, Kobilka BK. Energy landscapes as a tool to integrate GPCR structure, dynamics, and function. Physiology (Bethesda) 2010; 25: 293-303. 
[18] Ivey ME, Osman N, Little PJ. Endothelin-1 signalling in vascular smooth muscle: pathways controlling cellular functions associated with atherosclerosis. Atherosclerosis 2008; 199: 237-47.

[19] Smrcka AV, Lehmann DM, Dessal AL. G protein betagamma subunits as targets for small molecule therapeutic development. Comb Chem High Throughput Screen 2008; 11: 382-95.

[20] Bremnes T, Paasche JD, Mehlum A, et al. Regulation and intracellular trafficking pathways of the endothelin receptors. J Biol Chem 2000; 275 : 17596-604.

[21] Freedman NJ, Ament AS, Oppermann M, et al. Phosphorylation and desensitization of human endothelin A and B receptors. Evidence for $G$ protein-coupled receptor kinase specificity. J Biol Chem 1997; 272: 17734-43.

[22] Morris GE, Nelson CP, Standen NB, Challiss RA, Willets JM. Endothelin signalling in arterial smooth muscle is tightly regulated by $\mathrm{G}$ protein-coupled receptor kinase 2. Cardiovasc Res 2010; 85: 424-33.

[23] Whalen EJ, Foster MW, Matsumoto A, et al. Regulation of beta-adrenergic receptor signaling by S-nitrosylation of G-protein-coupled receptor kinase 2. Cell 2007; 129: 511-22.

[24] Gregan B, Jurgensen J, Papsdorf G, et al. Ligand-dependent differences in the internalization of endothelin A and endothelin B receptor heterodimers. J Biol Chem 2004; 279: 27679-87.

[25] Lattig J, Oksche A, Beyermann M, Rosenthal W, Krause G. Structural determinants for selective recognition of peptide ligands for endothelin receptor subtypes ETA and ETB. J Pept Sci 2009; 15: 479-91.

[26] Sakamoto A, Yanagisawa M, Sakurai T, et al. The ligand-receptor interactions of the endothelin systems are mediated by distinct "message" and "address" domains. J Cardiovasc Pharmacol 1993; 22 Suppl 8: S113-6.

[27] Breu V, Hashido K, Broger C, et al. Separable binding sites for the natural agonist endothelin-1 and the non-peptide antagonist bosentan on human endothelin-A receptors. Eur J Biochem 1995; 231: 266-70.

[28] Masaki T, Ninomiya H, Sakamoto A, Okamoto Y. Structural basis of the function of endothelin receptor. Mol Cell Biochem 1999; 190: 153-6.

[29] Orry AJ, Wallace BA. Modeling and docking the endothelin G-protein-coupled receptor. Biophys J 2000; 79: 3083-94.

[30] Webb ML, Patel PS, Rose PM, et al. Mutational analysis of the endothelin type A receptor (ETA): interactions and model of selective ETA antagonist BMS182874 with putative ETA receptor binding cavity. Biochemistry 1996; 35: 2548-56.

[31] Hilal-Dandan R, Villegas S, Gonzalez A, Brunton LL. The quasi-irreversible nature of endothelin binding and $\mathrm{G}$ protein-linked signaling in cardiac myocytes. J Pharmacol Exp Ther 1997; 281: 267-73.

[32] Leff P. The two-state model of receptor activation. Trends Pharmacol Sci 1995; 16: 89-97.

[33] Hall DA. Modeling the functional effects of allosteric modulators at pharmacological receptors: an extension of the two-state model of receptor activation. Mol Pharmacol 2000; 58: 1412-23.

[34] Sakamoto A, Yanagisawa M, Sawamura T, et al. Distinct subdomains of human endothelin receptors determine their selectivity to endothelinA- 
selective antagonist and endothelinB-selective agonists. J Biol Chem 1993; 268: 8547-53.

[35] Hoare SR. Mechanisms of peptide and nonpeptide ligand binding to Class B G-protein-coupled receptors. Drug Discov Today 2005; 10: 417-27.

[36] Hoare SR. Allosteric modulators of class B G-protein-coupled receptors. Curr Neuropharmacol 2007; 5: 168-79.

[37] Conner AC, Hay DL, Howitt SG, et al. Interaction of calcitonin-gene-related peptide with its receptors. Biochem Soc Trans 2002; 30: 451-5.

[38] Conner AC, Simms J, Barwell J, Wheatley M, Poyner DR. Ligand binding and activation of the CGRP receptor. Biochem Soc Trans 2007; 35: 729-32.

[39] Christopoulos A, Kenakin T. G protein-coupled receptor allosterism and complexing. Pharmacol Rev 2002; 54: 323-74.

[40] Conn PJ, Christopoulos A, Lindsley CW. Allosteric modulators of GPCRs: a novel approach for the treatment of CNS disorders. Nat Rev Drug Discov 2009; 8: 41-54.

[41] Keov P, Sexton PM, Christopoulos A. Allosteric modulation of G proteincoupled receptors: a pharmacological perspective. Neuropharmacology 2011; 60: 24-35.

[42] Kenakin T, Miller LJ. Seven transmembrane receptors as shapeshifting proteins: the impact of allosteric modulation and functional selectivity on new drug discovery. Pharmacol Rev 2010; 62: 265-304.

[43] Valant C, Sexton PM, Christopoulos A. Orthosteric/allosteric bitopic ligands: going hybrid at GPCRs. Mol Interv 2009; 9: 125-35.

[44] Kenakin T. Principles: receptor theory in pharmacology. Trends Pharmacol Sci 2004; 25: 186-92.

[45] Talbodec A, Berkane N, Blandin V, et al. Aspirin and sodium salicylate inhibit endothelin ETA receptors by an allosteric type of mechanism. Mol Pharmacol 2000; 57: 797-804.

[46] Blandin V, Vigne P, Breittmayer JP, Frelin C. Allosteric inhibition of endothelin ETA receptors by 3, 5-dibromosalicylic acid. Mol Pharmacol 2000; 58: 1461-9.

[47] Neubig RR, Spedding M, Kenakin T, Christopoulos A. International Union of Pharmacology Committee on Receptor Nomenclature and Drug Classification. XXXVIII. Update on terms and symbols in quantitative pharmacology.

Pharmacol Rev 2003; 55: 597-606.

[48] Warner TD, Allcock GH, Vane JR. Reversal of established responses to endothelin-1 in vivo and in vitro by the endothelin receptor antagonists, BQ123 and PD 145065. Br J Pharmacol 1994; 112: 207-13.

[49] Ihara M, Noguchi K, Saeki T, et al. Biological profiles of highly potent novel endothelin antagonists selective for the ETA receptor. Life Sci 1992; 50: 24755.

[50] Clozel M, Breu V, Gray GA, et al. Pharmacological characterization of bosentan, a new potent orally active nonpeptide endothelin receptor antagonist. J Pharmacol Exp Ther 1994; 270: 228-35.

[51] Doherty AM, Cody WL, DePue PL, et al. Structure-activity relationships of Cterminal endothelin hexapeptide antagonists. J Med Chem 1993; 36: 2585-94.

[52] Palmer MJ. Endothelin receptor antagonists: status and learning 20 years on. Prog Med Chem 2009; 47: 203-37. 
[53] Adner M, Shankley N, Edvinsson L. Evidence that ET-1, but not ET-3 and $\mathrm{S} 6 \mathrm{~b}, \mathrm{ET}(\mathrm{A})$-receptor mediated contractions in isolated rat mesenteric arteries are modulated by co-activation of ET(B) receptors. Br J Pharmacol 2001; 133: 927-35.

[54] Sabaa N, de Franceschi L, Bonnin P, et al. Endothelin receptor antagonism prevents hypoxia-induced mortality and morbidity in a mouse model of sicklecell disease. J Clin Invest 2008; 118: 1924-33.

[55] Maguire JJ, Kuc RE, Davenport AP. Affinity and selectivity of PD156707, a novel nonpeptide endothelin antagonist, for human ET(A) and ET(B) receptors. J Pharmacol Exp Ther 1997; 280: 1102-8.

[56] Bhowmick N, Narayan P, Puett D. The endothelin subtype A receptor undergoes agonist- and antagonist-mediated internalization in the absence of signaling. Endocrinology 1998; 139: 3185-92.

[57] Chiou WJ, Wessale JL, von Geldern T, Opgenorth TJ, Wu-Wong JR. 'Irreversible' endothelin-1 binding does not prohibit ABT-627 from reversing endothelin-1-induced effects. J Cardiovasc Pharmacol 2000; 36: S48-52.

[58] Christopoulos A. Allosteric binding sites on cell-surface receptors: novel targets for drug discovery. Nat Rev Drug Discov 2002; 1: 198-210.

[59] De Mey JG, Vanhoutte PM. Heterogeneous behavior of the canine arterial and venous wall. Importance of the endothelium. Circ Res 1982; 51: 439-47.

[60] De Mey JG, Megens R, Fazzi GE. Functional antagonism between endogenous neuropeptide $\mathrm{Y}$ and calcitonin gene-related peptide in mesenteric resistance arteries. J Pharmacol Exp Ther 2008; 324: 930-7.

[61] Meens MJ, Fazzi GE, van Zandvoort MA, De Mey JG. Calcitonin gene-related peptide selectively relaxes contractile responses to endothelin-1 in rat mesenteric resistance arteries. J Pharmacol Exp Ther 2009; 331: 87-95.

[62] Boulanger C, Hendrickson H, Lorenz RR, Vanhoutte PM. Release of different relaxing factors by cultured porcine endothelial cells. Circ Res 1989; 64: 10708.

[63] Nakashima M, Vanhoutte PM. Endothelin-1 and -3 cause endotheliumdependent hyperpolarization in the rat mesenteric artery. Am J Physiol 1993; 265: H2137-41.

[64] Wiley KE, Davenport AP. Physiological antagonism of endothelin-1 in human conductance and resistance coronary artery. Br J Pharmacol 2001; 133: 568-74.

[65] Wang Y, Wang DH. Prevention of endothelin-1-induced increases in blood pressure: role of endogenous CGRP. Am J Physiol Heart Circ Physiol 2004; 287: H1868-74.

[66] Brain SD, Grant AD. Vascular actions of calcitonin gene-related peptide and adrenomedullin. Physiol Rev 2004; 84: 903-34.

[67] Bautista DM, Movahed P, Hinman A, et al. Pungent products from garlic activate the sensory ion channel TRPA1. Proc Natl Acad Sci U S A 2005; 102: 12248-52.

[68] Caterina MJ, Schumacher MA, Tominaga M, et al. The capsaicin receptor: a heat-activated ion channel in the pain pathway. Nature 1997; 389: 816-24.

[69] Luttrell LM, Gesty-Palmer D. Beyond desensitization: physiological relevance of arrestin-dependent signaling. Pharmacol Rev 2010; 62: 305-30. 
[70] Rajagopal S, Rajagopal K, Lefkowitz RJ. Teaching old receptors new tricks: biasing seven-transmembrane receptors. Nat Rev Drug Discov 2010; 9: 37386.

[71] Copeland RA, Pompliano DL, Meek TD. Drug-target residence time and its implications for lead optimization. Nat Rev Drug Discov 2006; 5: 730-9.

[72] Packeu A, Wennerberg M, Balendran A, Vauquelin G. Estimation of the dissociation rate of unlabelled ligand-receptor complexes by a 'two-step' competition binding approach. Br J Pharmacol 2010; 161: 1311-28. 



\section{Chapter 4 \\ Contractile Myo-Endothelial Coupling Involving Endothelin-1 in Resistance Arteries from DOCA- Salt Hypertensive Rats}

P. Lemkens, J. Nelissen, M.J.P.M.T Meens, G.P.J. Bost, B.J.A. Janssen, P.M.H. Schiffers, J.G.R. De Mey 


\begin{abstract}
In resistance-sized arteries, the smooth muscle can influence release of vasoactive factors by the endothelium. We tested the hypothesis that in resistance arteries of DOCA-salt hypertensive rats this myo-endothelial coupling triggers release of contractile quantities of endothelin-1 (ET1). In male Wistar rats, one kidney was removed and the animals were given drinking water containing $1 \% \mathrm{NaCl}$ and $0.2 \% \mathrm{KCl}$ after implantation with a pellet with deoxy-corticosterone (DOCA salt hypertensive rats, HT) or without DOCA (normotensive rats, NT). 6 weeks later, mesenteric small arteries were isolated and their ET1 content was determined by radioimmunoassay or their contractile and relaxing responses were recorded by wire myography in presence of 10 $\mu \mathrm{M}$ indomethacin after desensitization of sensorimotor nerves with capsaicin. Blood pressure was increased in DOCA (HT) rats. In HT arteries, ET1 content was not altered but could be selectively increased by high $\mathrm{K}^{+}$buffer and this was prevented by NEP/ECE-inhibitors (10 $\mu \mathrm{M}$ phosphoramidon or $10 \mu \mathrm{M}$ SOL1). Endotheliumdependent relaxing responses to acetylcholine in absence and presence of the NOSinhibitor L-NAME or high $\mathrm{K}^{+}$did not differ between HT and NT arteries and were not modified by NEP/ECE-inhibitor or ET-receptor antagonist ( $1 \mu \mathrm{M}$ bosentan). L-NAME caused an endothelium-dependent increase of contractile responses to $11-40 \mathrm{mM} \mathrm{K}^{+}$in both HT and NT arteries. In HT but not NT arteries, bosentan reduced contractile responses to high $\mathrm{K}^{+}$in absence and presence of L-NAME. This was endotheliumdependent and tended to be sensitive to NEP/ECE inhibition. We conclude that in resistance arteries of rats with DOCA-salt hypertension, endothelium-dependent relaxations are not modified but a contractile myo-endothelial coupling involving ET1 can be unmasked.
\end{abstract}




\section{Introduction}

The endothelium influences underlying arterial smooth muscle by release of relaxing factors, release of contractile factors and, especially in small muscular resistance-sized arteries, via heterocellular gapjunctions [1-6]. These can participate in non-NOmediated endothelium-dependent relaxation and endothelium-dependent smooth muscle hyperpolarization $(\mathrm{EDH})$. Through these junctions the smooth muscle can, however, also in turn activate the endothelium [7-9]. In a recent study of this myo-endothelial coupling in rat mesenteric resistance arteries, we observed that selective arterial smooth stimulation causes release of endothelium-derived NO and of the endothelium-derived contractile factor endothelin-1 (ET1) when NO-synthases (NOS) are inhibited [8].

Endothelial dysfunction in cardiovascular diseases is frequently defined as a reduction of the vasodilatation in response to direct stimulation of the endothelium with acetylcholine (ACh) [1, 10]. It is often attributed to reduced bioavailability of endothelium-derived NO (EDNO). In large conduit arteries of spontaneously hypertensive rats (SHR) there seems also to be a role for endothelium-derived contractile cyclo-oxygenase products [11]. In these SHR, diabetes and aging, not only EDNO but also EDH is reduced in resistance arteries of at least some vascular beds. Although ET1 is clearly involved in the inflammatory aspects of DOCA-salt hypertension in the rat and ET1 function is upregulated when the bioavailability of EDNO is reduced, the contribution of this endothelium-derived contractile peptide to endothelial dysfunction is unclear [12-14].

In this study we tested the hypothesis that resistance artery responses to arterial smooth muscle stimulation involve endothelium-derived ET1 in an experimental animal model of hypertension. Because rat mesenteric resistance arteries have been observed to contain heterocellular gap-junctions that participate in endothelium-dependent reactivity and because the endothelin system is activated in DOCA-salt hypertensive rats, we studied these tissues from this experimental animal model. We determined changes in arterial ET1 content and the effects of inhibition of metalloproteases (enzymes that are involved in the synthesis of ET1) and of ET-receptor antagonism on arterial reactivity. 


\section{Material and Methods}

\section{Animals, model and surgery}

10 week old Wistar rats (Charles River, Maastricht, the Netherlands) were used in all experiments, which were performed in accordance with the ethical committee for animal welfare of the Maastricht University.

All animals were anesthetized with isoflurane (1-4\%) and the left kidney was removed. After a 1 week recovery period, a pellet containing deoxy-corticosterone acetate (DOCA, $100 \mathrm{mg}$, Sigma Aldrich, Zwijndrecht, the Netherlands) or a control silicon pellet was implanted subcutaneously. All animals were given high-salt drinking water $(1 \% \mathrm{NaCl}$ and $0.2 \% \mathrm{KCl})$ for 6 weeks after DOCA/control-pellet implantation. In total, 13 normotensive rats (NT) and 14 DOCA-salt hypertensive rats (HT) were investigated.

Intra-arterial blood pressure was measured in conscious unrestrained rats via a heparinized $(5 \mathrm{U} / \mathrm{ml})$ indwelling polyethylene catheter that was introduced into the left femoral artery 2 days before measurement. The arterial catheter was connected to a pressure transducer (Micro Switch $150 \mathrm{PC}$ ) and its output was sampled at $2.5 \mathrm{kHz}$. Mean arterial pressure (MAP) was calculated using the IDEEQ data-acquisition system (instrument services, Maastricht University, the Netherlands). Animals were euthanized by isoflurane $(>4 \%)$.

\section{Physiological solutions and drugs}

The Krebs Ringer bicarbonate-buffered physiological salt solution (KRB) that was continuously aerated with $95 \% \mathrm{O} 2 / 5 \% \mathrm{CO}_{2}$ and maintained at $37^{\circ} \mathrm{C}$ contained (in $\mathrm{mM}$ ): 118.5 NaCl, 4.7 KCl, 2.5 $\mathrm{CaCl}_{2}, 1.2 \mathrm{MgSO} 4,1.2 \mathrm{KH} 2 \mathrm{PO} 4,25.0 \mathrm{NaHCO}_{3}$ and 5.5 glucose. Bosentan (BOS) was obtained from Actelion Pharmaceuticals (Basel, Switzerland) and was dissolved in DMSO. Phophoramidon (PRD) was obtained from Sigma Aldrich (Zwijndrecht, The Netherlands) and dissolved in DMSO. Capsaicin and indomethacin (INDO) were purchased from Sigma Aldrich (Zwijndrecht, the Netherlands) and dissolved in ethanol. Acetylcholine (ACh), noradrenaline (NA), phenylephrine (PHE), thrombin and the nitric oxide synthase inhibitor N $\omega$-nitro-Larginine (L-NAME) were all purchased from Sigma Aldrich (Zwijndrecht, the Netherlands) and dissolved in $\mathrm{KRB}$. High $\mathrm{K}^{+}-\mathrm{KRB}$ solution was $\mathrm{KRB}$ in which all $\mathrm{NaCl}$ was replaced by $\mathrm{KCl}$. Solutions containing $10-40 \mathrm{mM} \mathrm{K}{ }^{+}$were prepared by mixing appropriate volumes of $\mathrm{KRB}$ and $\mathrm{K}^{+}-\mathrm{KRB}$.

The dual NEP/ECE inhibitor SOL1 (2-\{[1-(\{[(3S)-1-(carboxymethyl-2-oxo-2,3,4,5tetrahydro-1H-1-benzazepin-3-yl]amino carbonyl)cyclopentyl]methyl\}-4-[[3-

methylamino) propyl](methyl)amino]-4-oxobutanoic acid; Abbott) effectively inhibits big-ET1 to ET1 conversion in vivo at a dose of $3 \mu \mathrm{mol} / \mathrm{kg}$ i.v [15]. 


\section{Arterial ET1 content}

Mesenteric arterial trees containing $1^{\text {st }}$ to $4^{\text {th }}$ order side branches were isolated and subsequently incubated for 30 minutes at $37^{\circ} \mathrm{C}$ in $500 \mu \mathrm{KRB}$ buffer in absence or presence of the dual NEP/ECE inhibitors phosphoramidon $(10 \mu \mathrm{M})$ or SOL1 $(10 \mu \mathrm{M})$. Arteries were then stimulated for 3 hours at $37^{\circ} \mathrm{C}$ by adding $5 \mathrm{U} / \mathrm{ml}$ thrombin [16]. A different set of arterial branches was incubated for 30 minutes at $37^{\circ} \mathrm{C}$ in $500 \mu 1 \mathrm{KRB}$ or high potassium $\mathrm{K}^{+}$-KRB buffer $\left(125 \mathrm{mM} \mathrm{K}^{+}\right)$in the absence or presence of the nitric oxide synthase inhibitor L-NAME $(100 \mu \mathrm{M})$, phosphoramidon $(10 \mu \mathrm{M})$ or SOL1 (10 $\mu \mathrm{M})$. The arteries were then snap-frozen and protein was extracted from homogenized arteries in $1 \mathrm{M}$ acetic acid at $100{ }^{\circ} \mathrm{C}$ for 15 minutes. The homogenate was then centrifuged at $14000 \mathrm{~g}$ for 15 minutes at $4{ }^{\circ} \mathrm{C}$. The supernatant was applied to SepPak C18 cartridges (Waters, the Netherlands) and the eluate was dried in a centrifugal concentrator. The dried sample was reconstituted in assay buffer for radioimmunoassay. ET1 levels were measured by a commercially available radiommunoassay kit (S2024, Bachem, Basel, Switzerland) and were normalized to total protein concentration as determined using the BCA-method.

\section{Wire Myography}

Third order mesenteric resistance artery segments $(2 \mathrm{~mm}$ long) were isolated and mounted in wire myographs for the recording of isometric tension development [17]. From part of the arterial segments the endothelium was mechanically removed by sliding a horse hair through the lumen of the vessel. Each experiment started by progressively stretching the arterial segment to the diameter at which the largest contractile response to $10 \mu \mathrm{M}$ NA could be obtained (optimal diameter). To prevent the peri-arterial sensorimotor nerves from releasing vasodilator neurotransmitters such as calcitonin gene-related peptide (CGRP), all arterial segments were exposed to capsaicin (1 $\mu \mathrm{M}$, during $20 \mathrm{~min}$ ) [18, 19]. To avoid influences of contractile and relaxing cyclooxygenase products, all experiments were performed in the continuous presence of indomethacin $(1 \mu \mathrm{M})$. Contractile responses to increasing concentrations of $\mathrm{K}^{+}$(5.9-40 $\mathrm{mM})$ and PHE $(0.16-20 \mu \mathrm{M})$ and relaxing responses to increasing concentrations of ACh $(0.01-10 \mu \mathrm{M})$ during these contractions, were recorded. These contractile and relaxing concentration-response curves were constructed in the absence and presence of nitric oxide synthase inhibition (L-NAME, $100 \mu \mathrm{M}$ ), dual NEP/ECE inhibition (phosphoramidon, $10 \mu \mathrm{M}$ ) and ET-receptor antagonism (bosentan, $1 \mu \mathrm{M}$ ).

\section{Statistical analysis}

Radio-immuno-assay results are shown as mean \pm SEM. Significance of the differences between the different groups was determined by ANOVA. Contractile responses were expressed as a percentage of the maximal response to NA prior to the administration of any pharmacological inhibitor. Relaxing responses were expressed as percentage of the level of precontraction. Individual concentration-response curves were fitted to a non- 
Chapter 4

linear sigmoid regression curve (Graphpad Prism 5.0). Sensitivity $\left(\mathrm{pEC}_{50}\right)$ and maximal effect $\left(E_{\max }\right)$ are shown as mean \pm SEM. One-way ANOVA was used to compare $\mathrm{pEC}_{50}$ and Emax. A Bonferroni post-test was used to compare multiple groups. A $P$ value $<0.05$ was considered statistically significant. 


\section{Results}

\section{General characteristics}

Mean arterial blood pressure was markedly increased (173 \pm 3 versus $114 \pm 3 \mathrm{mmHg}, \mathrm{P}$ $<0.001)$ while body weight ( $338 \pm 8$ versus $368 \pm 12 \mathrm{~g}$ ), optimal lumen diameter of mesenteric resistance arteries $(262 \pm 7$ versus $252 \pm 6 \mu \mathrm{m})$ and the maximal contractile response of these arteries to noradrenaline $(3.28 \pm 0.19$ versus $3.09 \pm 0.11 \mathrm{~N} / \mathrm{m})$ were not significantly modified in DOCA-salt treated rats compared to control rats.

\section{Arterial ET1 content}

The content of immunoreactive ET1 did not differ significantly between mesenteric arteries of DOCA-salt hypertensive rats (HT) and those of normotensive (NT) rats (16.9 \pm 2.1 versus $13.7 \pm 0.9 \mathrm{fmol} / \mathrm{mg}$ protein) (Figure 4.1). Presence of the metalloprotease inhibitors phosphoramidon or SOL1 $(10 \mu \mathrm{M})$ did not alter arterial ET1 content under basal conditions. Incubation with thrombin $(5 \mathrm{U} / \mathrm{ml})$ during 3 hours $)$ caused a two fold increase of the ET1 content in arteries from HT (to $24.4 \pm 1.2 \mathrm{fmol} / \mathrm{mg}$ protein, $\mathrm{P}<$ 0.05 ) and NT rats (to $26.1 \pm 1.1 \mathrm{fmol} / \mathrm{mg}$ protein, $\mathrm{P}<0.001$ ) and this was in both cases prevented by presence of phosphoramidon or SOL1 (Figure 4.1). Exposure to depolarizing buffer $\left(125 \mathrm{mM} \mathrm{K}{ }^{+}\right.$in exchange for $\mathrm{Na}^{+}$, during $30 \mathrm{~min}$ ) stimulated a marked increase of the ET1 content in arteries from HT rats (to $31.5 \pm 3.6 \mathrm{fmol} / \mathrm{mg}$ protein, $\mathrm{P}<0.05$ ) but not NT rats (to $12.5 \pm 0.3 \mathrm{fmol} / \mathrm{mg}$ protein, NS). This stimulation was prevented by phosphoramidon and SOL1 (Figure 4.1). Presence of $100 \mu \mathrm{M} \mathrm{L}-$ NAME did not modify basal arterial ET1 content and the observations after exposure to high $\mathrm{K}^{+}$in arteries of HT and NT rats (data not shown).
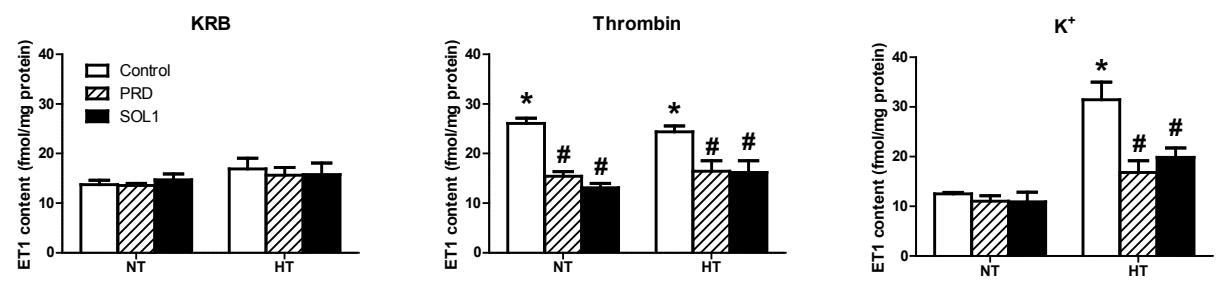

Figure 4.1: ET1 content in MA without stimulation (KRB, left panel), after stimulation with thrombin (middle panel) and after stimulation with $125 \mathrm{mM} \mathrm{K}$ (right panel). Effects of pretreatment with PRD (crosshatched) and SOL1 (black). Data shown as mean \pm SEM. *: $p<0.05$ non stimulated vs stimulated, \#: $\mathbf{p}<0.05$ no pretreatment vs pretreatment. 


\section{Endothelium-dependent relaxing responses to acetylcholine}

Relaxing responses to ACh $(0.01-10.0 \mu \mathrm{M})$ were investigated in mesenteric resistance arteries in the presence of $10 \mu \mathrm{M}$ indomethacin i) during contraction induced by $20 \mu \mathrm{M}$ phenylephrine, ii) during contraction induced by $40 \mathrm{mM} \mathrm{K}^{+}$and iii) during contraction induced by $20 \mu \mathrm{M}$ phenylephrine in the presence of $100 \mu \mathrm{M}$ L-NAME. The latter two have been attributed to endothelium-derived NO (EDNO) and endothelium-dependent hyperpolarization (EDH), respectively [8]. The sensitivity and maximal response to the three types of ACh-induced relaxation did not differ significantly between mesenteric resistance arteries of HT and NT rats (Figure 4.2 and Table 4.1). Moreover, presence of the ET-receptor antagonist bosentan $(1 \mu \mathrm{M})$ or of the NEP/ECE-inhibitor phosphoramidon $(10 \mu \mathrm{M})$ did not significantly modify the overall responses to ACh and the EDNO- or EDH-related components in resistance arteries of HT or NT rats (Figure 4.2 and Table 4.1). In denuded arteries of NT and NT rats, ACh failed to cause relaxation during either $\mathrm{K}^{+}$- or phenylephrine-induced contraction (data not shown).

\begin{tabular}{|c|c|c|c|c|c|c|}
\hline $\mathrm{pEC}_{50}$ & & EDNO & & & EDHF & \\
\hline & $\mathrm{CON}$ & BOS & PRD & $\mathrm{CON}$ & BOS & PRD \\
\hline NT & $6,74 \pm 0,17$ & $6,70 \pm 0,10$ & $6,78 \pm 0,15$ & $6,33 \pm 0,20$ & $6,22 \pm 0,24$ & $6,28 \pm 0,14$ \\
\hline HT & $6,81 \pm 0,11$ & $6,84 \pm 0,15$ & $6,86 \pm 0,16$ & $6,13 \pm 0,3$ & $6,20 \pm 0,19$ & $6,31 \pm 0,23$ \\
\hline $\mathrm{E}_{\max }$ & & EDNO & & & EDHF & \\
\hline & $\mathrm{CON}$ & BOS & PRD & $\mathrm{CON}$ & BOS & PRD \\
\hline NT & $50 \pm 6$ & $50 \pm 3$ & $57 \pm 6$ & $57 \pm 7$ & $61 \pm 5$ & $67 \pm 4$ \\
\hline HT & $66 \pm 5$ & $66 \pm 6$ & $64 \pm 7$ & $49 \pm 6$ & $61 \pm 7$ & $58 \pm 7$ \\
\hline
\end{tabular}

Table 4.1: Overview of $\mathrm{pEC}_{50}$ and $\mathrm{E}_{\max }$ values of $\mathrm{ACh}$-induced relaxations in $3 \mathrm{rd}$ order $\mathrm{MA}$ of NT and HT. In the absence and presence of BOS or PRD. Data are shown as mean \pm SEM. EDNO refers to ACh-induced relaxations after a potassium precontraction in the presence of INDO. EDHF refers to Ach-induced relaxations after a PHE precontraction in the presence of L-NAME and INDO. 

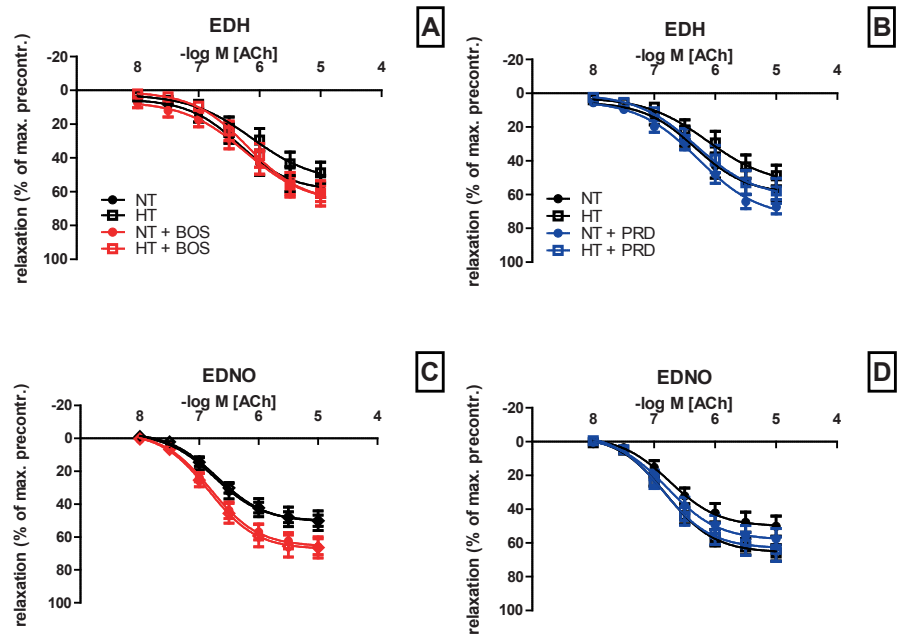

Figure 4.2: Panels $\mathrm{A}$ and $\mathrm{B}$ depict the response to increasing concentrations of $\mathrm{ACh}(0.01-10 \mu \mathrm{M})$ during a PHE $(20 \mu \mathrm{M})$ precontraction in presence of INDO $(1 \mu \mathrm{M})$ and L-NAME $(100 \mu \mathrm{M})$. EDHF-type responses were not significantly different in DOCA-salt hypertensive rats (HT, open squares) compared to normotensive rats (NT, closed circles). No effect of acute bosentan (BOS, in red) or phosphoramidon (PRD, in blue) administration was observed. Panels $C$ and $D$ depict the response to increasing concentrations of $\mathrm{ACh}(0.001-10 \mu \mathrm{M})$ during a $\mathrm{K}^{+}$-induced $(40 \mathrm{mM})$ precontraction in presence of INDO $(1 \mu \mathrm{M})$. EDNO-type responses were not significantly different in DOCA-salt hypertensive rats (HT, open squares) compared to normotensive rats (NT, closed dots). No effect of acute BOS (in red) or PRD (in blue) administration was observed. Data are shown as mean $\pm \mathrm{SEM}$.

\section{Endothelium-dependent responses to smooth muscle stimulation}

Contractile responses to phenylephrine $(0.15-20 \mu \mathrm{M})$ were compared in mesenteric resistance arteries of HT and NT rats in the continuous presence of $10 \mu \mathrm{M}$ indomethacin and the effects of NOS-inhibition, NEP/ECE inhibition, ET-receptor antagonism, and of mechanical removal of the endothelium were evaluated. Maximal responses to the $\alpha_{1}$ adrenoceptor agonist did not differ between HT and NT rats and were not significantly modified by either intervention in arteries from both types of rats (Figure 4.3). Sensitivity to phenylephrine was significantly smaller in intact arteries of HT compared to NT (Figure 4.3). In arteries of HT rats, the sensitivity to phenylephrine was not significantly modified by L-NAME, phosphoramidon or bosentan (Figure 4.3). In arteries of NT, however, L-NAME and denudation significantly increased the sensitivity to phenylephrine and the effect of L-NAME was absent in denuded arteries and in the presence of bosentan although it was not prevented by phosphoramidon (Figure 4.3). 

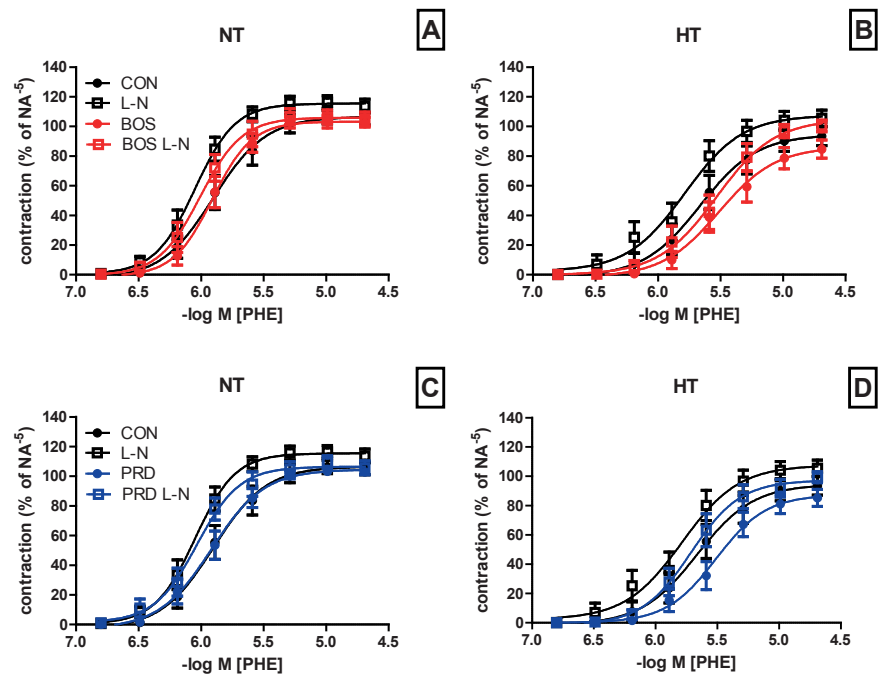

c

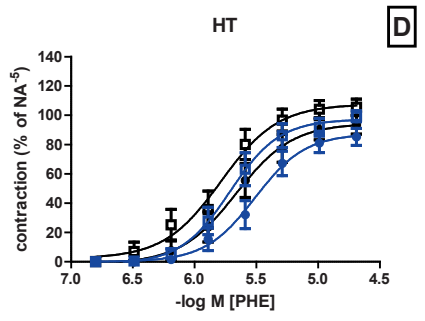

Figure 4.3: Contractile responses to increasing concentrations of PHE in the presence of INDO (closed dots) in NT $(A+C)$ and HT (B + D) MA. Open squares depict the effect of L-NAME. The effect of acute BOS or PRD administration is shown in red and in blue, respectively. Data shown as mean \pm SEM.

Using similar conditions we also compared arterial contractile effects of $\mathrm{K}^{+}$(5.9 to 40 $\mathrm{mM}$; Figure 4.4). Responses to the depolarizing solutions did not differ between intact and denuded arteries of HT and NT rats (Figure 4.4 A-L). In arteries of NT rats, $\mathrm{K}^{+}-$ induced contractions were increased by L-NAME but not modified by phosphoramidon or bosentan (Fig. 4 A,C,E,G). The effect of L-NAME was endothelium-dependent and resistant to NEP/ECE-inhibiton and ET-receptor antagonism (Figure 4.4 A, C, E. G). Also in arteries of HT rats, L-NAME caused an endothelium-dependent increase of $\mathrm{K}^{+}$induced contractions (Fig 4 B,F). In these resistance arteries from DOCA-salt HT rats, however, bosentan and to a lesser extent phosphoramidon reduced $\mathrm{K}^{+}$-induced contractions in both the absence and presence of L-NAME (Figure 4.4 B, F). These effects of bosentan were endothelium-dependent (Figure 4.4 B, D, F, H) indicating a contribution of endothelium-derived ET1 to depolarization-induced contractile responses of resistance arteries of DOCA-salt HT rats. 

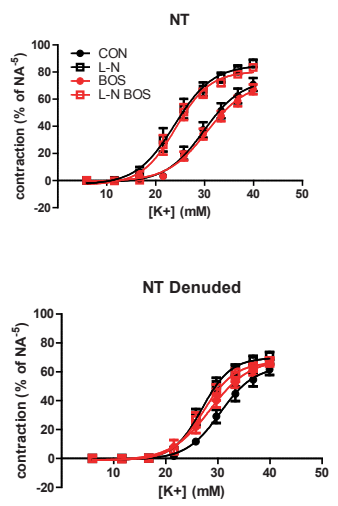

NT

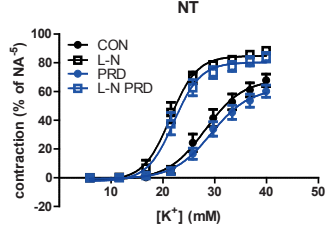

NT Denuded

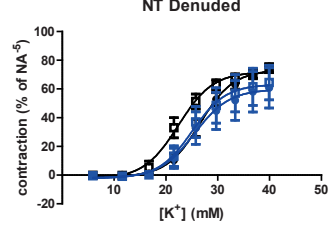

NT

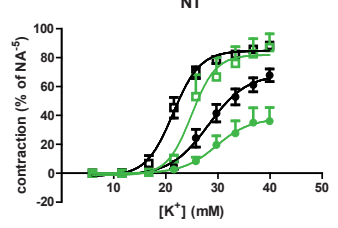

NT Denuded

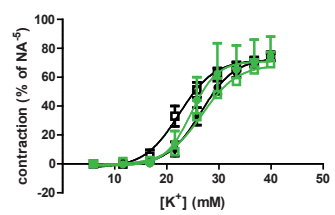

A

B

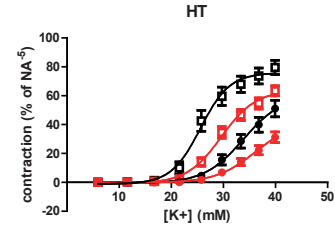

C

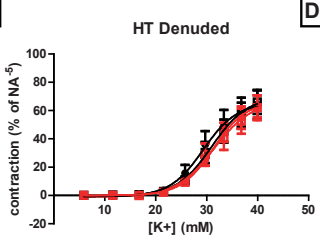

因

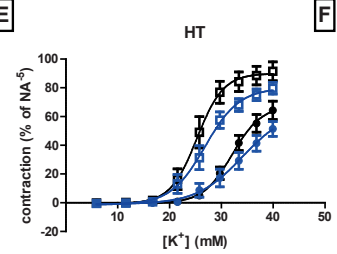

G

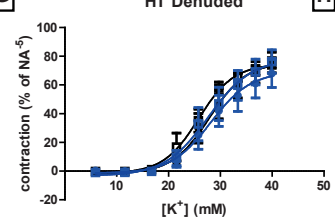

四

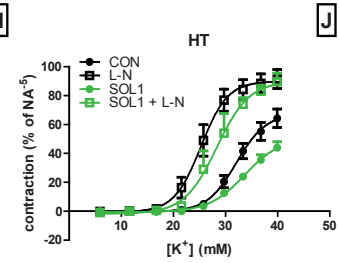

凡

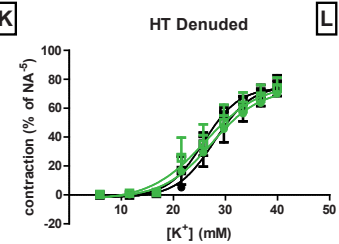

Figure 4.4: Contractile responses to increasing concentrations of $\mathrm{K}^{+}$in the presence of INDO (closed dots) in NT $(A-K)$ and HT (B - L) in intact (A + $\mathrm{B}, \mathbf{E}+\mathbf{F}, \mathbf{I}+\mathbf{J})$ and denuded $(\mathrm{C}+\mathrm{D}$, $\mathbf{G}+\mathbf{H}, \mathbf{K}+\mathbf{L})$ MA. Open squares depict the effect of L-NAME. The effect of BOS, PRD or SOL1 is shown in red, blue and green, respectively. $A$ inhibitory effect of BOS (B) on $\mathrm{K}^{+}$ induced contractions is observed in MA of HT. This effect is not observed in MA of NT (A) and denuded MA of HT (D). Data shown as mean \pm SEM. 


\section{Discussion}

With this work, we show that activating arterial smooth muscle by depolarizing buffer triggers the production and release of endothelin-1 in and from the endothelium in mesenteric resistance arteries of DOCA-salt hypertensive rats. These effects are observed on the level of protein content as well as functionally, and can be (partly) reversed by mechanical denudation, acute bosentan, acute phoshoramidon and acute SOL1 treatment. While SOL1 as well as phosphoramidon succeed in significantly reducing endothelin-1 production in vitro, NEP inhibition is not effective and dual NEP/ECE inhibition is slightly less effective than ET-receptor blockade on a functional level. Endothelium-dependent relaxing responses were not significantly altered in mesenteric resistance arteries of 6 weeks DOCA-salt hypertensive rats.

Endothelin-1 is not only a very potent vasoconstrictor [20, 21] but is also a proinflammatory agent, has mitogenic effect on vascular smooth muscle cells and promotes fibrosis [22-25]. An up regulation of the ET1 system has been linked to numerous pathologies including moderate to severe hypertension, salt-sensitive hypertension and experimental models like the Dahl salt-sensitive rat and DOCA-salt hypertension [2629].

We tested the hypotheses that in the mesenteric bed of DOCA-salt hypertensive rats, (i) activated arterial smooth muscle can stimulate the endotheliu $m$ to release ET1 which contributes to endothelial dysfunction and (ii) the endothelial dysfunction is mainly restricted to contractile rather than relaxing factors. To this end we (i) measured ET1 content in arteries of normotensive and DOCA-salt hypertensive rats and (ii) assessed acute vasomotor responses of arteries from normotensive and DOCA-salt hypertensive rats.

Thrombin is a well described stimulus for ET1 production and release from isolated arteries [16]. After a 3 hour incubation period with thrombin the ET1 levels in mesenteric arteries of both normotensive and DOCA-salt hypertensive rats were increased 2-fold. These results demonstrate the validity of the assay. A candidate indirect stimulus for endothelial ET1 production and release, depolarization with high $\mathrm{K}^{+}[8]$, significantly increased ET1 levels in arteries from DOCA-salt hypertensive rats. In normotensive controls however depolarization did not influence arterial ET1 content. This suggests that the contribution of ET1 to arterial function is altered in mesenteric arteries of DOCA-salt hypertensive rats.

To strengthen the validity of the radio-immuno assay and of our pharmacological tools we tested the ability of the dual NEP/ECE inhibitor phosphoramidon and SOL1 to prevent the production of ET1. Phosphoramidon as well as SOL1 significantly reduced the content of ET1 in mesenteric resistance arteries of both normotensive and DOCA- 
salt hypertensive rats, produced by thrombin stimulation and in DOCA-salt hypertensive rats produced by $\mathrm{K}^{+}$stimulation.

Endothelial dysfunction is often regarded as a phenomenon associated with hypertension, frequently caused by reduced NO bioavailability or blunted EDH responses. In this study, we do observe considerable increases in blood pressure, however we did not detect any significant differences in the EDNO component or the EDH component of the ACh-induced relaxation responses in mesenteric resistance arteries of DOCA-salt hypertensive rats. On the other hand, we observe a decreased effect of NO synthase inhibition on PHE induced contraction and increased effects of $\mathrm{NO}$ synthase inhibition on $\mathrm{K}^{+}$induced contractions. It is conceivable that reduced NO availability might be more pronounced in arteries with a bigger contribution of EDNO to stimulated endothelium-dependent relaxation like large conduit arteries [30].

Basic functional properties (optimal diameter, maximal pre-contraction) of third order mesenteric resistance were not altered by DOCA-salt hypertension, and as described above no classic endothelial dysfunction was observed, but earlier studies [31] showed that DOCA-salt hypertension is accompanied by severe arterial stiffening which could also be a considerable contributor to an increase in mean arterial pressure [32] .

We observed an inhibitory effect of an endothelin receptor antagonist on $\mathrm{K}^{+}$-induced stimulation of the arterial smooth muscle in DOCA salt hypertensive rats. A large portion of this effect could be mimicked by inhibiting ET1 production through NEP/ECE inhibition. NEP inhibition did not produce the same effects, suggesting that ECE activity is the major contributor to this effect. The effects of the ET-receptor antagonist as well as the effect of the dual NEP/ECE inhibitor are absent after mechanical removal of the endothelium. This implies that activating the arterial smooth muscle prompts (possibly through myo-endothelial gap junctions) the endothelium to produce and release ET1 which will further activate the arterial smooth muscle.

Bilateral communication between the arterial smooth muscle and the endothelium is not a new concept. Elevation of intracellular calcium in arterial smooth muscle induced the release of endothelium-derived vasodilators in rat mesenteric arteries, indicating a myoendothelial coupling [7, 9]. Hilgers and De Mey [8] observed that in twelve to sixteen week old normotensive WKY rats, inhibition of NO synthase during stimulation of arterial smooth muscle with Ca-channel activator (BaK8644), alpha1-agonist or periarterial nerve stimulation, enhances contraction by increased effect of endotheliumderived ET1. These effects could be prevented by uncouplers of gap-junctions suggesting a role for heterocellular gap junctions in this mechanism. These gap junctions could also serve as a gateway between the endothelium and the smooth muscle cells (and vice versa) in the myo-endothelial feedback mechanism we describe here. Probably due to the pathology in DOCA-salt hypertensive rats it is not necessary 
to inhibit nitric oxide synthase to uncover the enhancing effects of ET1 on contractions although the effect was further increased by NOS inhibition.

Because ET receptor blockade was more effective than either dual NEP/ECE inhibitor there could be a NEP/ECE independent pathway of ET1 production. The residual effect could also be due to ET1 precursor ET1 (1-32) which was described by FernandezPatron and colleagues to behave as an $\mathrm{ET}_{\mathrm{A}}$ receptor agonist [33]. Production of this precursor is probably not inhibited by NEP/ECE inhibition, because it is formed out of big-Endothelin (1-38) by vascular matrix metalloproteinase-2 (MMP-2, galatinase A). Another option is the existence of ET1 storage in Weibel Palade bodies which can provide an explanation for the difference between ET-receptor antagonism and NEP/ECE inhibition [21].

In conclusion we observed that a pronounced feedback mechanism exists stimulating ET1 release from the endothelium during $\mathrm{K}^{+}$- induced activation of vascular smooth muscle in DOCA-salt hypertensive rats. The effects of endogenous ET1 could be completely inhibited by mechanical removal of the endothelium and by the nonselective ET-receptor antagonist bosentan, and partly by inhibiting the synthesis pathways with the dual NEP/ECE inhibitors phosphoramidon and the novel compound SOL1. These observations emphasize the importance of the myo-endothelial coupling component of endothelium-dependent vasodilatation. 
Arterial Function in DOCA-salt Hypertension

Sources of funding:

This study was performed within the framework of the Dutch Top Institute Pharma project: T2-108; Metalloproteases and Novel Targets in Endothelial Dysfunction 


\section{References}

[1] Vanhoutte PM, Shimokawa H, Tang EH, Feletou M. Endothelial dysfunction and vascular disease. Acta Physiol (Oxf) 2009; 196: 193-222.

[2] Furchgott RF, Vanhoutte PM. Endothelium-derived relaxing and contracting factors. FASEB J 1989; 3: 2007-18.

[3] Xia J, Little TL, Duling BR. Cellular pathways of the conducted electrical response in arterioles of hamster cheek pouch in vitro. Am J Physiol 1995; 269: H2031-8.

[4] Segal SS, Duling BR. Conduction of vasomotor responses in arterioles: a role for cell-to-cell coupling? Am J Physiol 1989; 256: H838-45.

[5] Little TL, Xia J, Duling BR. Dye tracers define differential endothelial and smooth muscle coupling patterns within the arteriolar wall. Circ Res 1995; 76: 498-504.

[6] Xia J, Duling BR. Electromechanical coupling and the conducted vasomotor response. Am J Physiol 1995; 269: H2022-30.

[7] Dora KA, Doyle MP, Duling BR. Elevation of intracellular calcium in smooth muscle causes endothelial cell generation of NO in arterioles. Proc Natl Acad Sci U S A 1997; 94: 6529-34.

[8] Hilgers RH, De Mey JG. Myoendothelial coupling in the mesenteric arterial bed; segmental differences and interplay between nitric oxide and endothelin1. Br J Pharmacol 2009; 156: 1239-47.

[9] Dora KA, Hinton JM, Walker SD, Garland CJ. An indirect influence of phenylephrine on the release of endothelium-derived vasodilators in rat small mesenteric artery. Br J Pharmacol 2000; 129: 381-7.

[10] Tang EH, Vanhoutte PM. Endothelial dysfunction: a strategic target in the treatment of hypertension? Pflugers Arch 2010; 459: 995-1004.

[11] Gluais P, Lonchampt M, Morrow JD, Vanhoutte PM, Feletou M. Acetylcholine-induced endothelium-dependent contractions in the SHR aorta: the Janus face of prostacyclin. Br J Pharmacol 2005; 146: 834-45.

[12] Cordellini S, Carvalho MH, Scivoletto R, Fortes ZB, Nigro D. Indirect evidence for an endothelium-derived contracting factor release in aorta of deoxycorticosterone acetate-salt hypertensive rats. J Hypertens 1990; 8: 53-60.

[13] Schiffrin EL. Vascular endothelin in hypertension. Vascul Pharmacol 2005; 43: 19-29.

[14] Bourque SL, Davidge ST, Adams MA. The interaction between endothelin-1 and nitric oxide in the vasculature: new perspectives. Am J Physiol Regul Integr Comp Physiol 2011; 300: R1288-95.

[15] Nelissen J, Lemkens P, Sann H, et al. Pharmacokinetic and pharmacodynamic properties of SOL1: a novel dual inhibitor of neutral endopeptidase and endothelin converting enzyme. Life Sci 2012; 91: 587-92.

[16] Boulanger C, Luscher TF. Release of endothelin from the porcine aorta. Inhibition by endothelium-derived nitric oxide. J Clin Invest 1990; 85: 587-90.

[17] Hilgers RH, Todd J, Jr., Webb RC. Regional heterogeneity in acetylcholineinduced relaxation in rat vascular bed: role of calcium-activated $\mathrm{K}^{+}$channels. Am J Physiol Heart Circ Physiol 2006; 291: H216-22. 
[18] Wang Y, Wang DH. Prevention of endothelin-1-induced increases in blood pressure: role of endogenous CGRP. Am J Physiol Heart Circ Physiol 2004; 287: H1868-74.

[19] De Mey JG, Megens R, Fazzi GE. Functional antagonism between endogenous neuropeptide $\mathrm{Y}$ and calcitonin gene-related peptide in mesenteric resistance arteries. J Pharmacol Exp Ther 2008; 324: 930-7.

[20] Yanagisawa M, Kurihara H, Kimura S, et al. A novel potent vasoconstrictor peptide produced by vascular endothelial cells. Nature 1988; 332: 411-5.

[21] Davenport AP, Hyndman KA, Dhaun N, et al. Endothelin. Pharmacol Rev 2016; 68: 357-418.

[22] Donckier JE, Michel L, Van Beneden R, Delos M, Havaux X. Increased expression of endothelin-1 and its mitogenic receptor ETA in human papillary thyroid carcinoma. Clin Endocrinol (Oxf) 2003; 59: 354-60.

[23] Ammarguellat F, Larouche I, Schiffrin EL. Myocardial fibrosis in DOCA-salt hypertensive rats: effect of endothelin ET(A) receptor antagonism. Circulation 2001; 103: 319-24.

[24] Saleh MA, Boesen EI, Pollock JS, Savin VJ, Pollock DM. Endothelin-1 increases glomerular permeability and inflammation independent of blood pressure in the rat. Hypertension 2010; 56: 942-9.

[25] Boldrini L, Pistolesi S, Gisfredi S, et al. Expression of endothelin 1 and its angiogenic role in meningiomas. Virchows Arch 2006; 449: 546-53.

[26] Schiffrin EL, Lariviere R, Li JS, Sventek P, Touyz RM. Endothelin-1 gene expression and vascular hypertrophy in DOCA-salt hypertension compared to spontaneously hypertensive rats. Clin Exp Pharmacol Physiol Suppl 1995; 22: S188-90.

[27] Schiffrin EL, Lariviere R, Li JS, Sventek P, Touyz RM. Deoxycorticosterone acetate plus salt induces overexpression of vascular endothelin-1 and severe vascular hypertrophy in spontaneously hypertensive rats. Hypertension 1995; 25: 769-73.

[28] Hynynen MM, Khalil RA. The vascular endothelin system in hypertension-recent patents and discoveries. Recent Pat Cardiovasc Drug Discov 2006; 1 : 95-108.

[29] Dhaun N, Goddard J, Kohan DE, et al. Role of endothelin-1 in clinical hypertension: 20 years on. Hypertension 2008; 52: 452-9.

[30] Shimokawa H, Yasutake H, Fujii K, et al. The importance of the hyperpolarizing mechanism increases as the vessel size decreases in endothelium-dependent relaxations in rat mesenteric circulation. J Cardiovasc Pharmacol 1996; 28: 703-11.

[31] Leibovitz E, Ebrahimian T, Paradis P, Schiffrin EL. Aldosterone induces arterial stiffness in absence of oxidative stress and endothelial dysfunction. $\mathrm{J}$ Hypertens 2009; 27: 2192-200.

[32] Harvey A, Montezano AC, Lopes RA, Rios F, Touyz RM. Vascular Fibrosis in Aging and Hypertension: Molecular Mechanisms and Clinical Implications. Can J Cardiol 2016; 32: 659-68.

[33] Fernandez-Patron C, Radomski MW, Davidge ST. Vascular matrix metalloproteinase-2 cleaves big endothelin-1 yielding a novel vasoconstrictor. Circ Res 1999; 85: 906-11. 



\section{Chapter 5 Impaired Flow-Induced Arterial Remodeling In DOCA-Salt Hypertensive Rats}

P. Lemkens, J. Nelissen, M.J.P.M.T Meens, G.E. Fazzi, G.J.M. Janssen, J.J.M. Debets,

B. Janssen, P.M.H. Schiffers, J.G.R. De Mey.

Hypertens Res, 2012 Nov;35(11):1093-101 


\title{
Chapter 5
}

\begin{abstract}
Arteries from young healthy animals respond to chronic changes in blood flow and blood pressure by structural remodeling. We tested whether the ability to respond to decreased $(-90 \%)$ or increased $(+100 \%)$ blood flow is impaired during development of DOCA-salt hypertension in rats, a model for an upregulated endothelin-1 system. Mesenteric small arteries (MrA) were exposed to low (LF) or high blood flow (HF) for 4 or 7 weeks. Bioavailability of vasoactive peptides was modified by chronic treatment of the rats with the dual NEP/ECE inhibitor SOL1.
\end{abstract}

After 3 and 6 weeks of hypertension, MrA showed hypertrophic arterial remodeling (3: media cross sectional area (mCSA): $10 \pm 1.10^{3}$ to $17 \pm 2.10^{3} \mu \mathrm{m}^{2} ; 6: 13 \pm 2.10^{3} \mu \mathrm{m}^{2}$ to 24 $\pm 3.10^{3} \mu \mathrm{m}^{2}$ ). After 3 but not 6 weeks of hypertension, the arterial diameter was increased (Ø: $385 \pm 13$ to $463 \pm 14 \mu \mathrm{m}$ ). SOL1 reduced hypertrophy after 3 weeks of hypertension (mCSA: $6.10^{3} \pm 1.10^{3} \mu \mathrm{m}^{2}$ ).

Diameter of HF arteries of normotensive rats increased (Ø: $463 \pm 22 \mu \mathrm{m}$ ) but no expansion occurred in HF arteries of hypertensive rats (Ø: $471 \pm 16 \mu \mathrm{m})$. .MrA from SOL1 treated hypertensive rats did show a significant diameter increase (Ø: $419 \pm 13$ to $475 \pm 16 \mu \mathrm{m})$. Arteries exposed to LF, showed inward remodeling in normotensive and hypertensive rats (mean $\varnothing$ between 235 and $290 \mu \mathrm{m}$ ), and infiltration of monocyte/macrophages. SOL1 treatment did not affect arterial diameter of LF arteries but reduced infiltration of monocyte/macrophages.

We show for the first time that flow-induced remodeling is impaired during development of DOCA-salt hypertension and that this can be prevented by chronic NEP/ECE inhibition. 


\section{Introduction}

Blood flow is an important regulator of vascular function and structure. An acute alteration in blood flow initially leads to a change in vasomotor tone which modifies the arterial diameter in order to normalize wall shear stress. When the increase in blood flow is sustained, arteries can structurally remodel to restore normal values of wall shear stress and circumferential wall stress [1]. Both flow-mediated dilatation and flowmediated remodeling are endothelium-dependent processes [2, 3]. Structural remodeling of the arterial wall in response to hemodynamic changes can occur under both physiological and pathological conditions, for example in the uterine vascular bed during pregnancy and in hypertension, respectively [4-6].

Because in established hypertension cardiac output is within the normal range, the increased blood pressure is mainly due to increased vascular resistance [7]. This is associated with an increased wall to lumen ratio in the systemic resistance arteries. In essential hypertension, this arterial remodeling is usually described as inward and eutrophic; i.e. resulting from rearrangement of the medial material around a smaller diameter [8]. The arterial changes in secondary and experimental hypertension, on the other hand, are mainly hypertrophic in nature and involve smooth muscle cell hypertrophy and/or hyperplasia [8, 9]. Remodeling of the vascular wall in hypertension is also associated with changes in the composition of the extracellular matrix leading to increased stiffness [10].

While anti-hypertensive therapy is mainly focused on lowering the blood pressure, preventing or reversing the arterial structural changes might be more beneficial for the morbidity and mortality of hypertensive patients [11]. Angiotensin II is thought to play an important role in the pathological alterations in the vascular wall, as is supported by the partial reversal of these alterations by chronic treatment with inhibitors of angiotensin-converting enzyme or antagonists of AT1-receptors [12, 13]. Endothelin-1 (ET1), another vasoactive peptide might also be involved in the arterial structural changes in pathophysiological conditions. Apart from being a potent vasoconstrictor, ET1 is also a potent growth promoting and pro-inflammatory agent [14-18]. Production of ET1 is reported to be increased in salt-dependent models of hypertension like DOCA (deoxycorticosterone acetate)-salt induced hypertension, a model showing pronounced endothelial dysfunction [19] and arterial hypertrophy [20, 21]. ET1 can be formed through cleavage of big-ET1 by endothelin-converting enzyme (ECE). Alternatively big-ET1 can be hydrolyzed by chymase or MMP2 to form ET1 (1-31) or ET1 (1-32), respectively. Both are further processed into ET1 by neutral endopeptidase (NEP) [2224]. Thus a dual inhibitor of NEP and ECE reduces ET1 production by inhibiting all three pathways [25]. Recently Kalk et al. [26] reported that the dual NEP/ECE inhibitor SLV338 reduces smooth muscle hypertrophy, interstitial fibrosis and perivascular fibrosis in the 2 kidney one clip model, partly by suppression of TGF- $\beta 1$ expression. 
Here we tested the hypotheses that (1) flow-induced remodeling of resistance arteries is reduced during the development of DOCA-salt hypertension and that (2) treatment with a dual NEP/ECE inhibitor has beneficial effects on flow-induced arterial remodeling in this setting.

\section{Methods}

\section{Animals, model and surgery}

10 week old Wistar rats (Charles River, Maastricht, the Netherlands) were used in all experiments which were performed in accordance with the ethical committee for animal welfare of the Maastricht University.

All animals were anesthetized with isoflurane (1-4\%) and the left kidney was removed. Blood flow-modifying surgery was performed in the animals by distal ligation of alternate first-order mesenteric arteries to create arteries chronically exposed to low blood flow (LF). The patent arteries between these then had a compensatory increased blood flow (HF). Arteries from a distant part of the intestine were considered control arteries exposed to normal flow (NF) [9, 27]. After a 1 week recovery period, a DOCA pellet (100 mg, Sigma Aldrich, Zwijndrecht, the Netherlands) ( $\mathrm{n}=28)$ or a control silicon pellet $(\mathrm{n}=29)$ was implanted subcutaneously. All animals were given high-salt drinking water $(1 \% \mathrm{NaCl}$ and $0.2 \% \mathrm{KCl})$. In total, 16 normotensive rats and 14 hypertensive rats were investigated after 3 weeks and 13 normotensive and 14 hypertensive rats after 6 weeks.

Intra-arterial blood pressure was measured in conscious unrestrained rats via a heparinized $(5 \mathrm{U} / \mathrm{ml})$ indwelling polyethylene catheter that was introduced into the left femoral artery 2 days before measurement. The arterial catheter was connected to a pressure transducer (Micro Switch $150 \mathrm{PC}$ ) and its output was sampled at $2.5 \mathrm{kHz}$. Mean arterial pressure (MAP) was calculated using the IDEEQ data-acquisition system (Instrument Services, Maastricht University, The Netherlands).

Preliminary dose-finding experiments were carried out to identify appropriate doses of the dual NEP/ECE inhibitor SOL1 (2-\{[1-(\{[(3S)-1-(carboxymethyl-2-oxo-2,3,4,5tetrahydro-1H-1-benzazepin-3-yl]amino carbonyl)cyclopentyl]methyl\}-4-[[3-

methylamino)propyl](methyl)amino]-4-oxobutanoic acid; Abbott [25]). A dose of 50 $\mathrm{mg} / \mathrm{kg} /$ day drastically decreased urinary ET1 content (from $32.89 \pm 3.91$ to $1.35 \pm 0.25$ $\mathrm{pg} / \mathrm{ml} \mathrm{p}<0.001)$ in DOCA-salt hypertensive rats $(\mathrm{n}=3)$. Animals were randomly assigned to the treatment groups $(\mathrm{n}=7)$. Osmotic minipumps (2ml4, Alzet, Cupertino, CA, USA) were implanted subcutaneously, simultaneously with the DOCA pellet, for chronic continuous drug treatment over the next 3 weeks. The vehicle group received osmotic minipumps containing a saline solution for the same period of time. 


\section{Determination of arterial remodeling}

3 or 6 weeks after the induction of hypertension, animals were euthanized with isoflurane ( $>4 \%)$ and arteries exposed in vivo to high flow (HF) or low flow (LF) conditions were isolated. Arteries located outside the region of ligation were used as normal flow controls (NF). Arteries were mounted on two glass micropipettes in an organ chamber filled with $\mathrm{Ca}^{2+}$-free Krebs Ringer solution $(144 \mathrm{mM} \mathrm{NaCl}, 4.7 \mathrm{mM}$ $\mathrm{KCl}, 1.2 \mathrm{mM} \mathrm{MgSO}_{4}, 1.2 \mathrm{mM} \mathrm{KH}_{2} \mathrm{PO}_{4}, 14.9 \mathrm{mM}$ HEPES, and $5.5 \mathrm{mM}$ glucose; $\mathrm{pH}$ 7.4). $10 \mu \mathrm{M}$ Na-nitroprusside (SNP, Sigma Aldrich, Zwijndrecht, The Netherlands) was added to ensure maximal vasodilatation. A pressure-diameter relationship was established by recording the lumen diameter while gradually increasing the distending pressure (20-120 $\mathrm{mmHg}, 10 \mathrm{mmHg}$ steps). After the experiment, vessels were fixed at $80 \mathrm{mmHg}$ in $4 \%$ phosphate buffered formaldehyde solution for 1 hour and stored in $70 \%$ ethanol.

Arterial distensibility was calculated by: $\mathrm{DC}=(1 / \Delta \mathrm{P}) *\left(\Delta \mathrm{D} / \mathrm{D}_{\mathrm{n}-1}\right) * 100$ with $\mathrm{DC}=$ distensibility, $\mathrm{P}=$ intraluminal pressure and $\mathrm{D}=$ measured diameter [28]. A linear regression was performed on the pressure-distensibility curves between 20 and 80 $\mathrm{mmHg}$ for every artery considered and the slope was calculated as an index of arterial stiffness.

\section{Histological analyses}

Fixed vessels were embedded in paraffin and cross-sections $(4 \mu \mathrm{m})$ were stained with Lawson's solution (Boom, Meppel, The Netherlands). Media cross-sectional area (mCSA) was determined from the circumferences of the internal and external elastic laminae. The average number of nuclear profiles in the media was determined by counting on haematoxylin-eosin stained cross-sections (\# nuclei). The elastin density was determined in 4 areas of the media and 4 areas of the adventitia in every vessel using Leica Qwin software. Measurements were averaged for every layer individually in every vessel. Elastin content was calculated as percentage elastin positive area per total area. To stain collagen, cross-sections were deparaffinized and incubated in phosphomolybdenic acid $(0.2 \%)$ for 5 minutes, followed by incubation with Sirius red. After washing with $0.1 \mathrm{M} \mathrm{HCl}$ for 2 minutes, sections were dehydrated and protected with coverslips. The content of collagen in the media and adventitia was quantified as described as for elastin.

To identify smooth muscle cells and monocyte/macrophages, immunoperoxidase staining was performed with primary monoclonal antibodies directed against smooth muscle $\alpha$-actin and rat monocyte/macrophages, respectively (ASMA (A-2547) and CD68 (ED-1) [29] (Sigma Aldrich, Zwijndrecht, The Netherlands, dilution 1:5000). After incubation with these monoclonal antibodies, the sections were incubated with peroxidase-conjugated rabbit anti-mouse immunoglobulins (Dako, Enschede, the Netherlands). Visualization was performed with DAB as a substrate. 
Chapter 5

\section{Statistical analysis}

Results are expressed as means \pm SEM. Statistical significance of differences between groups was evaluated by analysis of variance (ANOVA for consecutive measurements for pressure-diameter curves) or 1-way ANOVA followed by Bonferroni or paired t-test (graphpad 5.0). A value of $\mathrm{P}<0.05$ was considered statistically significant.

\section{Results}

\section{General characteristics}

In normotensive rats, body weight and mean arterial pressure (MAP) did not change significantly between 14 and 17 weeks of age (Table 5.1). DOCA-salt treatment did not modify body weight but increased MAP after 3 weeks and even more after 6 weeks (Table 5.1). Administration of the dual NEP/ECE inhibitor SOL1 (50 mg/kg.day) to DOCA-salt rats during 3 weeks did not modify body weight but attenuated the increase in MAP (Table 5.1).

\begin{tabular}{|c|c|c|c|c|c|}
\hline \multirow[b]{2}{*}{$\begin{array}{c}\text { General } \\
\text { characteristics }\end{array}$} & \multicolumn{3}{|c|}{3 weeks } & \multicolumn{2}{|c|}{6 weeks } \\
\hline & NT & HT & $\mathrm{HT}+\mathrm{SOL} 1$ & NT & HT \\
\hline Body Weight (g) & $353 \pm 6$ & $331 \pm 6$ & $359 \pm 9$ & $368 \pm 12$ & $338 \pm 8$ \\
\hline MAP (mmHg) & $118 \pm 2$ & $150 \pm 5 * * *$ & $136 \pm 2 \&$ & $114 \pm 3$ & $173 \pm 3 * * *$ \\
\hline \multicolumn{6}{|l|}{ Diameter $(\mu \mathrm{m})$} \\
\hline Normal Flow & $385 \pm 13$ & $452 \pm 12 *$ & $419 \pm 13$ & $414 \pm 20$ & $451 \pm 12$ \\
\hline High Flow & $\begin{array}{c}463 \pm 22 \\
\text { \#\#\# }\end{array}$ & $471 \pm 16$ & $475 \pm 16 \#$ & $455 \pm 21$ & $486 \pm 12$ \\
\hline Low Flow & $\begin{array}{c}270 \pm 10 \\
\text { \#\#\# }\end{array}$ & $\begin{array}{c}290 \pm 14 \\
\# \# \#\end{array}$ & $253 \pm 6$ \#\#\# & $\begin{array}{c}265 \pm 14 \\
\text { \#\#\# }\end{array}$ & $\begin{array}{c}265 \pm 14 \\
\text { \#\#\# }\end{array}$ \\
\hline \multicolumn{6}{|l|}{$\begin{array}{c}\operatorname{mCSA}\left(10^{3}\right. \\
\left.\mu \mathrm{m}^{2}\right)\end{array}$} \\
\hline Normal Flow & $10 \pm 1$ & $16 \pm 1 * *$ & $14 \pm 2$ & $13 \pm 2$ & $24 \pm 3 * *$ \\
\hline High Flow & $15 \pm 2 \#$ & $16 \pm 1$ & $14 \pm 2$ & $14 \pm 1$ & $21 \pm 2$ \\
\hline Low Flow & $11 \pm 3$ & $12 \pm 2 \#$ & $7 \pm 1 \&$ & $11 \pm 3$ & $16 \pm 2$ \\
\hline \multicolumn{6}{|l|}{$\begin{array}{c}\text { \# nuclear } \\
\text { profiles (media) }\end{array}$} \\
\hline Normal Flow & $45 \pm 3$ & $58 \pm 4$ & $42 \pm 3 \&$ & $49 \pm 5$ & $66 \pm 7$ \\
\hline High Flow & $56 \pm 3 \#$ & $53 \pm 5$ & $45 \pm 4$ & $41 \pm 3$ & $53 \pm 4$ \\
\hline Low Flow & $65 \pm 8 \#$ & $57 \pm 9$ & $42 \pm 4$ & $40 \pm 4$ & $90 \pm 13$ \\
\hline
\end{tabular}




\begin{tabular}{|c|c|c|c|c|c|}
\hline $\begin{array}{l}\text { stiffness factor } \\
\left(\mathrm{mmHg}^{-2}\right)\end{array}$ & & & & & \\
\hline Normal Flow & $\begin{array}{c}-0,034 \pm \\
0,002\end{array}$ & $\begin{array}{c}-0,022 \pm \\
0,002 * * *\end{array}$ & $\begin{array}{c}-0,021 \pm \\
0.002\end{array}$ & $\begin{array}{c}-0,031 \pm \\
0,002\end{array}$ & $\begin{array}{c}-0,016 \pm \\
0,002 * * *\end{array}$ \\
\hline High Flow & $\begin{array}{c}-0,031 \pm \\
0,002\end{array}$ & $\begin{array}{c}-0,018 \pm \\
0,002 * * *\end{array}$ & $\begin{array}{c}-0,019 \pm \\
0,002\end{array}$ & $\begin{array}{c}-0,027 \pm \\
0,003\end{array}$ & $\begin{array}{l}-0,017 \pm \\
0,002 * *\end{array}$ \\
\hline Low Flow & $\begin{array}{c}-0,003 \pm \\
0,001 \text { \#\#\# }\end{array}$ & $\begin{array}{c}-0,004 \pm \\
0,001 \text { \#\#\# }\end{array}$ & $\begin{array}{c}-0,002 \pm \\
0.001 \text { \#\#\# }\end{array}$ & $\begin{array}{c}-0,006 \pm \\
0,001 \text { \#\#\# }\end{array}$ & $\begin{array}{c}-0,001 \pm \\
0,001 \text { \#\#\# }\end{array}$ \\
\hline \multicolumn{6}{|l|}{$\begin{array}{l}\text { elastin/collagen } \\
\text { ratio }\end{array}$} \\
\hline Normal Flow & $2,7 \pm 0,8$ & $1,3 \pm 0,5$ & $0,8 \pm 0,5$ & $5,7 \pm 2,3$ & $1,8 \pm 0,3$ \\
\hline High Flow & $2,1 \pm 0,5$ & $2.0 \pm 0,7$ & $3,5 \pm 1,2$ & $2,74 \pm 0,6$ & $1,8 \pm 0,5$ \\
\hline Low Flow & $9,1 \pm 6,3$ & $1,3 \pm 0,4$ & $2,8 \pm 1,1$ & $4,0 \pm 0,9$ & $6.0 \pm 3.0 \#$ \\
\hline \multicolumn{6}{|l|}{$\begin{array}{c}\% \text { ED-1 positive } \\
\text { area }\end{array}$} \\
\hline Normal Flow & $0,02 \pm 0,01$ & $0,17 \pm 0,11$ & $0.08 \pm 0.02$ & $0,03 \pm 0,01$ & $0,02 \pm 0,01$ \\
\hline High Flow & $0,03 \pm 0,01$ & $0,29 \pm 0,11$ & $0.11 \pm 0.05$ & $0,01 \pm 0,01$ & $0,03 \pm 0,01$ \\
\hline Low Flow & $\begin{array}{c}1,24 \pm 0,56 \\
\#\end{array}$ & $\begin{array}{c}5.89 \pm 3.10 \\
\# \#\end{array}$ & $\begin{array}{c}0.24 \pm 0.09 \\
\&\end{array}$ & $0,38 \pm 0,23$ & $\begin{array}{c}1,41 \pm 0,63 \\
\#\end{array}$ \\
\hline
\end{tabular}

Table 5.1: General animal characteristics and overview of structural parameters. Data are shown as mean \pm SEM. *: $\mathbf{p}<\mathbf{0 . 0 5}, * *: \mathbf{p}<0.01, * * *: \mathbf{p}<0.001$ NT versus HT; \#: $\mathbf{p}<\mathbf{0 . 0 5}$, \#\#: $\mathbf{p}<0.001$ versus NF, \&: p < 0.05 HT versus HT + SOL1. NT: normotensive rats, HT: DOCA-salt hypertensive rats.

In normotensive rats, the size of mesenteric small arteries (MrA) tended to increase between 14 and 17 weeks of age (Figure 5.1 A,B and Figure 5.2). The increases in lumen diameter (Ø: $385 \pm 13$ to $414 \pm 20 \mu \mathrm{m})$, media cross sectional area (mCSA: $10 \pm$ 1 to $13 \pm 210^{3} \mu \mathrm{m}^{2}$ ) and in the number of nuclear profiles per medial section (\# nuclei: $45 \pm 3$ to $49 \pm 5$ ) did, however, not reach statistical significance.

\section{Resistance artery remodeling in DOCA-salt hypertensive rats}

MrA diameter was significantly increased after 3 weeks of DOCA-salt hypertension (Ø: $385 \pm 13$ to $452 \pm 12 \mu \mathrm{m}, \mathrm{p}<0.05$; Figure 5.1 C and Figure 5.2 A). After 6 weeks of hypertension, MrA diameter tended to be increased (Ø: $414 \pm 20$ to $451 \pm 12 \mu \mathrm{m}$; Figure 5.1 D and Figure 5.1 B) but this was no longer statistically significant compared to arteries from age-matched normotensive rats. After both 3 and 6 weeks of DOCA-salt hypertension, significant media hypertrophy was observed (mCSA: 3 weeks: $10 \pm 1$ to $16 \pm 110^{3} \mu \mathrm{m}^{2}, \mathrm{p}<0.01$; 6 weeks: $13 \pm 2$ to $24 \pm 310^{3} \mu \mathrm{m}^{2}, \mathrm{p}<0.01$; Figure 5.2 C, D). This was accompanied by hyperplasia and by increased arterial wall stiffness. \# nuclei averaged $45 \pm 3$ and $58 \pm 4$ at 3 weeks (p < 0.05; Fig. 2 E) and $49 \pm 5$ and $66 \pm 7$ at 6 weeks (NS; Figure 5.2 F) and the stiffness factor averaged $-0.034 \pm 0.002$ and $-0.022 \pm$ $0.002 \mathrm{mmHg}^{-2}$ at 3 weeks (Figure $5.2 \mathrm{G}$ ) and $-0.031 \pm 0.002$ and $-0.016 \pm 0.002 \mathrm{mmHg}^{-2}$ at 6 weeks (Figure $5.2 \mathrm{H}$ ) in normotensive and hypertensive rats, respectively. The 
elastin to collagen ratio was, however, not significantly modified (Table 5.1) nor was there a significant increase in monocyte/macrophages in the tunica media of MrA from DOCA-salt hypertensive rats (Table 5.1).

3 Weeks treatment of DOCA-salt hypertensive rats with SOL1 tended to attenuate arterial outward remodeling (Ø: $419 \pm 13 \mu \mathrm{m}$, NS, Figure 5.1 E and Figure 5.2 A), but did not modify arterial hypertrophy (mCSA: $14 \pm 210^{3} \mu \mathrm{m}^{2}$, Figure $5.2 \mathrm{C}$ ), arterial stiffness $\left(-0.021 \pm 0.002 \mathrm{mmHg}^{-2}\right.$, Fig. $\left.2 \mathrm{G}\right)$ or elastin to collagen ratio $(0.81 \pm 0.47)$. Chronic treatment with the dual NEP/ECE inhibitor did, however, significantly reduce arterial hyperplasia (\# nuclei: $42 \pm 3, \mathrm{p}<0.05$ versus solvent treated DOCA-salt rats) (Figure 5.2 E).

\section{Flow-related arterial remodeling in normotensive rats}

Increased local blood flow (HF) during 4 weeks in normotensive rats, caused an upward shift of the pressure-diameter relationship (Fig. $1 \mathrm{~A})$ and significantly increased lumen diameter (Ø: to $463 \pm 22 \mu \mathrm{m}, \mathrm{p}<0.001$; Fig. $2 \mathrm{~A}$ ), medial mass (mCSA: to $15 \pm 210^{3}$ $\mu \mathrm{m}^{2}, \mathrm{p}<0.05$; Fig. $2 \mathrm{C}$ ) and cellularity at $80 \mathrm{mmHg}$ (\# nuclei: to $56 \pm 3$; Fig. $2 \mathrm{E}$ ) compared to vessels exposed to normal blood flow (NF). This is in line with the flowinduced outward hypertrophic remodeling reported before [9, 27, 30, 31]. It was, however, not accompanied by altered arterial wall stiffness (Figure $5.2 \mathrm{G}$ ), elastin to collagen ratio or macrophage count (Table 5.1). Surprisingly, after 7 weeks exposure to elevated blood flow, the outward remodeling (Figure 5.1 B) and the increases in lumen diameter (Ø: to $455 \pm 21 \mu \mathrm{m}$, NS, Figure 5.2 B), in medial mass (mCSA: to $14 \pm 110^{3}$ $\mu \mathrm{m}^{2}$, NS, Figure 5.2 D) and the hyperplasia (\#nuclei: to $41 \pm 3$, NS; Figure $5.2 \mathrm{~F}$ ) were no longer statistically significant compared to control (NF) arteries of the same normotensive rats. 


\section{3 weeks}
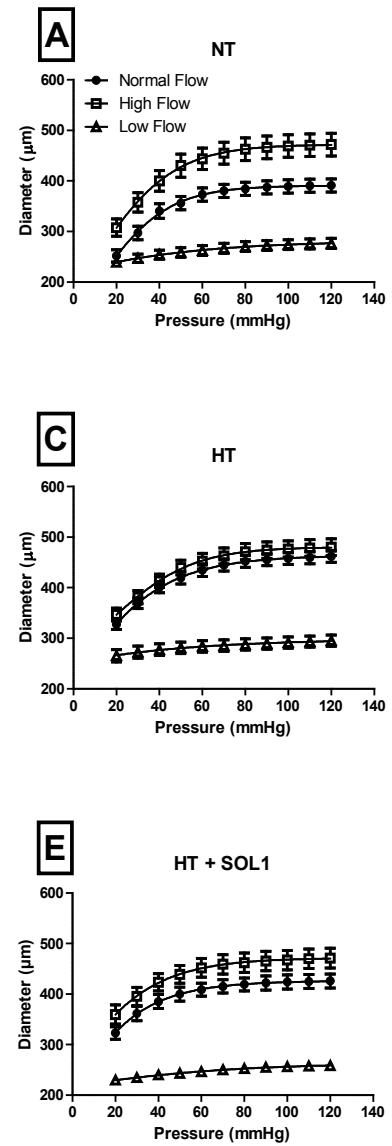

\section{6 weeks}
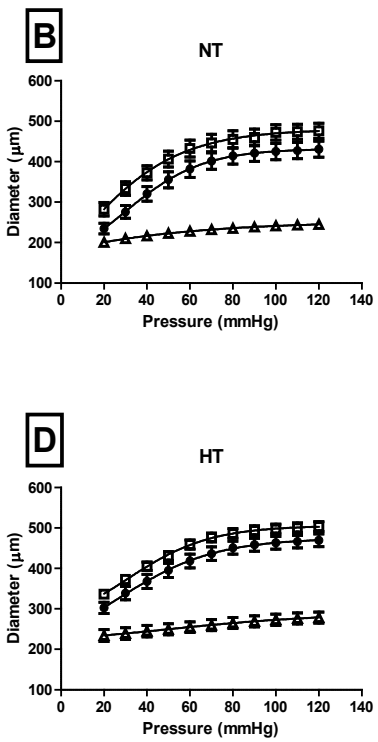

Figure 5.1: Relation between imposed pressure and diameter after 4 weeks of altered flow in mesenteric resistance arteries of (A) NT, (C) HT and (E) HT + SOL1: Relation between imposed pressure and diameter after 7 weeks of altered flow in mesenteric resistance arteries in (B) NT and (D) HT. 

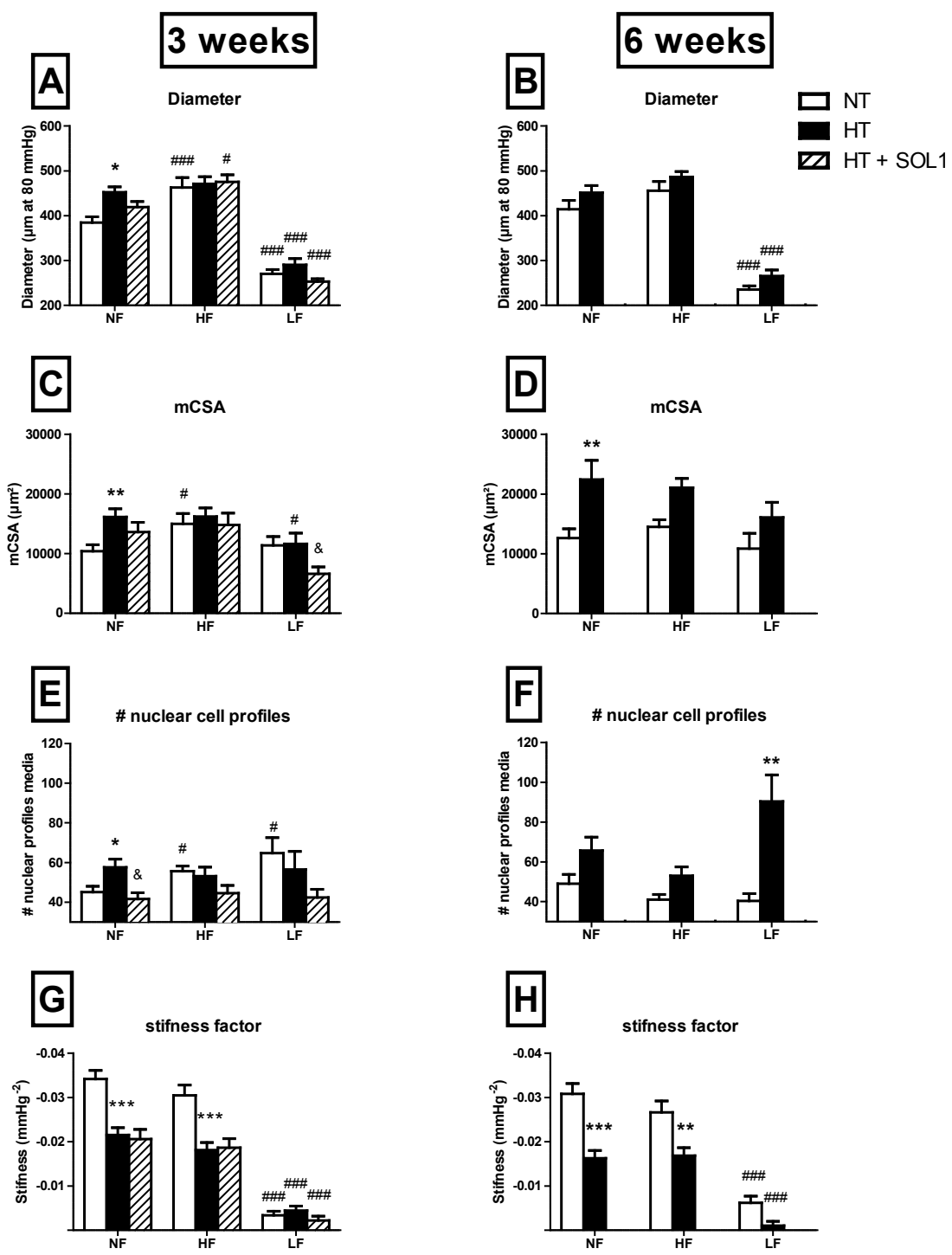

Figure 5.2: The lumen diameter as measured at $80 \mathrm{mmHg}$ after (A) 4 weeks (B) 7 weeks of altered blood flow. The Effect of altered blood flow on cross sectional area of the medial layer after (C) 4 weeks (D) 7 weeks. The effect of altered blood flow on the number of medial cells per cross section after (E) 4 weeks (F) 7 weeks. The effect of altered blood flow on the stiffness index after (G) 4 weeks (H) 7 weeks. Data are shown as mean \pm SEM.*: $p<0.05$ NT versus HT, \#: $p<0.05$ NF versus HF/LF, + : $p<0.05$ HT versus HT + SOL1.

Reduced local blood flow (LF) during both 4 and 7 weeks in normotensive rats, markedly reduced arterial diameter and markedly increased arterial wall stiffness 
(Figure 5.1 A,B, Figure 5.2 A,B,G,H) without significant changes in medial mass

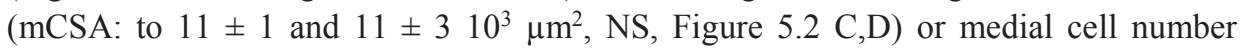
(\#nuclei: $40 \pm 4$ and $90 \pm 13$, after 4 and 7 weeks, respectively, NS, Figure 5.2 E,F). At 3 weeks an elevated number of ED-1-positive monocyte/macrophages was observed in the LF vessels of normotensive rats, but this was no longer statistically significant at the later time point (Table 5.1).

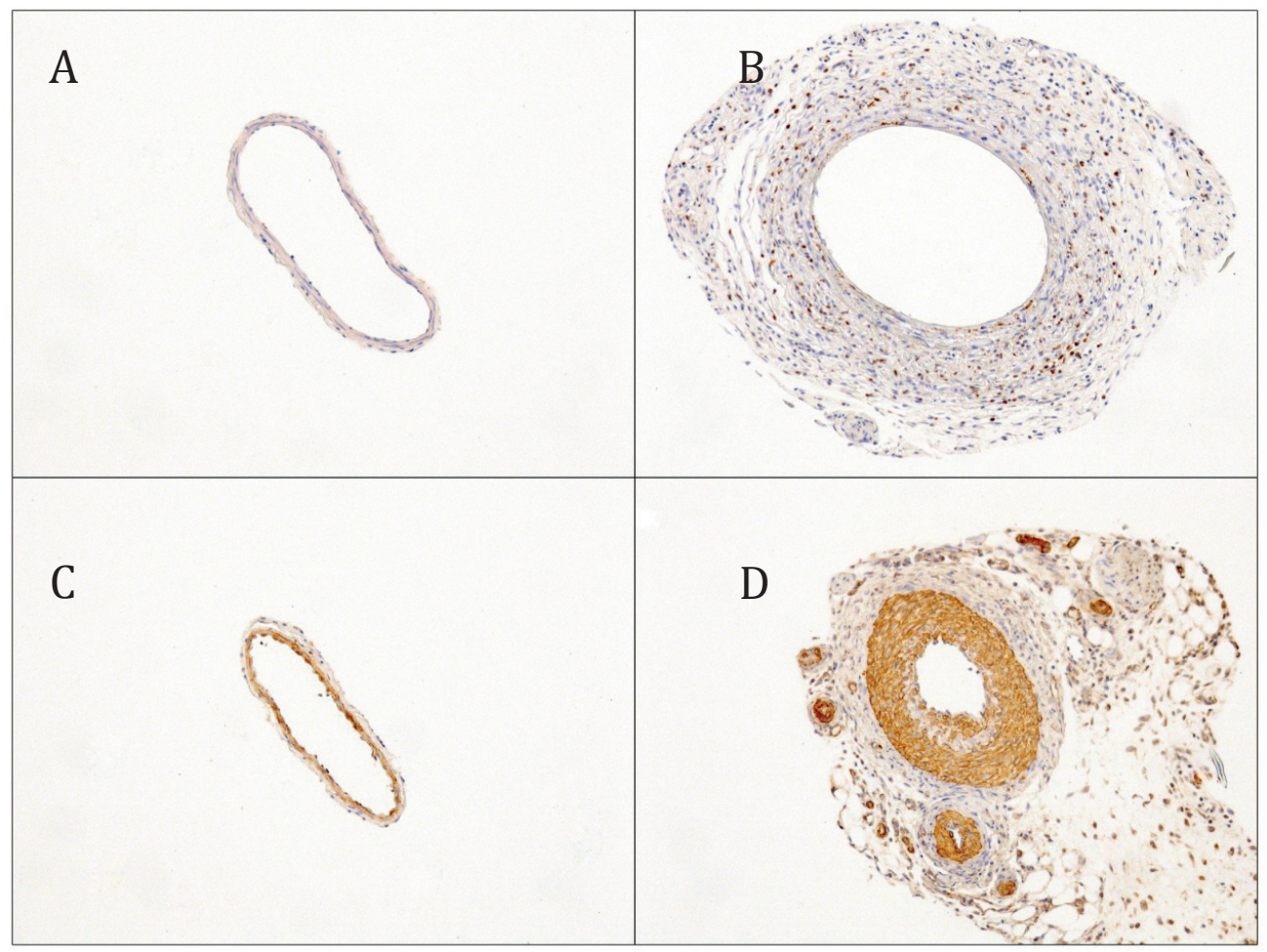

Figure 5.3: Cross sections of low flow arteries of normotensive rats stained for (A) ED-1, (C) alpha smooth muscle actin, and DOCA-salt hypertensive rats stained for (B) ED-1, (D) alpha smooth muscle actin.

\section{Flow-related arterial remodeling in DOCA-salt hypertensive rats}

In MrA of DOCA-salt hypertensive rats, no additional outward hypertrophic remodeling occurred in HF arteries after 4 weeks $(\varnothing: 452 \pm 12$ to $471 \pm 16 \mu \mathrm{m}, \mathrm{mCSA}: 16 \pm 1$ to 16 $\pm 110^{3} \mu \mathrm{m}^{2}$, \# nuclei: $53 \pm 4$ to $53 \pm 5$ ) (Figure 5.1 $\mathrm{C}$ and Figure 5.2 A,C,E) and after 7 weeks (Ø: $451 \pm 12$ to $486 \pm 12 \mu \mathrm{m}, \mathrm{mCSA}: 24 \pm 3$ to $21 \pm 210^{3} \mu \mathrm{m}^{2}$, \# nuclei: $66 \pm 7$ to $53 \pm 4$ ) (Figure $5.1 \mathrm{D}$ and Figure $5.2 \mathrm{~B}, \mathrm{D}, \mathrm{F}$ ). Flow-induced outward remodeling was however improved by 3 weeks treatment with SOL1 (Ø: from $419 \pm 13$ to $475 \pm 16 \mu \mathrm{m}$ $\mathrm{p}<0.05$; Figure 5.1 E and Figure 5.2 A) but no hypertrophy was found in HF arteries of 
DOCA-salt hypertensive rats treated with SOL1 (mCSA from $14 \pm 2$ to $14 \pm 210^{3} \mu \mathrm{m}^{2}$ ) (Figure 5.2 C).

While additional outward remodeling was blunted in DOCA-salt hypertensive rats, their LF arteries became markedly narrower (Figure 5.1 C,D, Figure 5.2 A,B) and stiffer (Figure $5.2 \mathrm{G}, \mathrm{H})$. Lumen diameter was reduced from $452 \pm 12$ to $290 \pm 14 \mu \mathrm{m}(\mathrm{p}<$ $0.001)$ and from $451 \pm 16$ to $265 \pm 14 \mu \mathrm{m}(\mathrm{p}<0.001)$ at 3 and 6 weeks of hypertension, respectively (Figure 5.2). Media mass was significantly reduced at 3 weeks (mCSA: 16 \pm 1 to $12 \pm 210^{3} \mu \mathrm{m}^{2}, \mathrm{p}<0.05$ ) but not at 6 weeks of hypertension (mCSA: $24 \pm 3$ to 16 $\pm 210^{3} \mu \mathrm{m}^{2}$, NS; Figure 5.2) a stage at which a marked increase in medial cell number was observed (Figure 5.2 F). Despite the marked stiffening, the elastin to collagen ratio was significantly increased (Table 5.1).

Chronic treatment of DOCA-salt hypertensive rats with the dual NEP/ECE inhibitor SOL1 further decreased the diameter of LF arteries (Ø: $253 \pm 6 \mu \mathrm{m})$ and significantly decreased their media cross sectional area (mCSA: $\left.7 \pm 110^{3} \mu \mathrm{m}^{2}, \mathrm{p}<0.05\right)$ and medial cell number (\# nuclei: $42 \pm 4$ ) but did not affect stiffness (Figure 5.2) or elastin/collagen (Table 5.1)

In an attempt to evaluate inflammation and characterize the nature of the hyperplastic changes we performed immunohistochemistry for ED-1 and smooth muscle $\alpha$-actin (ASMA) (Figure 5.3). Significant numbers of monocyte/macrophages in the tunica media were observed only in LF arteries (Table 5.1). In arteries of normotensive rats this was a transient response, while in arteries of DOCA-salt hypertensive rats this was still statistically significant at 6 weeks (Table 5.1). Treatment with SOL1 significantly reduced this index of inflammation (Table 5.1). ED-1 staining was also observed in the adventitia of LF arteries (Figure 5.3 B), but this could not be crisply quantified. ASMAstaining indicates that the vast majority of cells in the hyperplastic tunica media of the LF arteries of DOCA-salt hypertensive rats were still differentiated smooth muscle cells (Figure $5.3 \mathrm{D}$ ). Moreover, this approach revealed development of new blood vessels in this setting.

\section{Discussion}

The main findings of this study are that, in mesenteric resistance arteries of DOCA salt hypertensive rats, flow-induced outward remodeling is impaired. Moreover mesenteric resistance arteries of DOCA-salt hypertensive rats are hypertrophic and show a clear inflammatory component. These effects can partly be prevented by treatment with a dual NEP/ECE inhibitor.

DOCA-salt hypertension is a model of low renin/angiotensin but high ET1 levels which shows pronounced endothelial dysfunction [19] and arterial hypertrophy [20, 21]. Endothelin-1 is not only a potent vasoconstrictor [14] but is also a pro-inflammatory 
agent [17], has mitogenic effects on vascular smooth muscle cells [15], is proangiogenic [18] and promotes fibrosis [16]. An upregulation of the ET1 system has been linked to numerous pathologies including salt-sensitive hypertension [20, 21, 32 , 33]. Because of these functions the endothelin system might in large part contribute to the hypertrophy and the endothelial dysfunction observed in DOCA-salt hypertension. In an attempt to test this we (i) treated DOCA-salt hypertensive rats for three weeks with the NEP/ECE inhibitor SOL1 and (ii) studied the endothelium-dependent structural effects of imposed changes in blood flow in DOCA salt hypertensive rats.

In this study MrA's of DOCA-salt hypertensive rats showed hypertrophic arterial remodeling after 3 and 6 weeks. At 3 weeks of hypertension an increase in diameter was observed while at 6 weeks of hypertension diameter did not differ from that in arteries of normotensive rats which had increased as a result of development. Reports from other groups lean more to an unaltered or decreased arterial diameter [5, 21]. This discrepancy might be because of differences in strain and age of the rats and in other aspects of the protocols used to induce DOCA-salt hypertension. A possible explanation for the increase in diameter after 3 weeks of hypertension is that in this experimental model blood pressure rises in a much shorter timeframe than in genetic hypertension [8] and that mesenteric blood flow may increase during the first weeks of DOCA-salt hypertension [34]. While outward remodeling is generally not observed in models of hypertension, hypertrophic remodeling is often witnessed especially in models of non genetic hypertension and experimental hypertension. Also ET1 has been shown to contribute to the remodeling of large and small arteries in hypertension $[35,36]$. Hypertrophic remodeling rather than eutrophic remodeling of resistance arteries seems to occur in models associated with an upregulated endothelin system [5]. This is in line with the observation that chronic administration of the non- selective ET-receptor antagonist bosentan reduces the cross sectional area of the arterial media in DOCA-salt hypertensive rats [5]. In contract in mRen2 transgenic rats, a model of enhanced endogenous angiotensin II generation, inward eutrophic remodeling was observed and bosentan had no effects on arterial structure [37]. A dual ACE/NEP inhibitor and an ACE inhibitor on the other hand caused a significant regression of arteriolar structural changes [38-40]. Figure 5.4 shows a schematic overview of changes in arterial lumen diameter and medial mass in relation to hypertension (blue arrow) and age (purple arrow). 


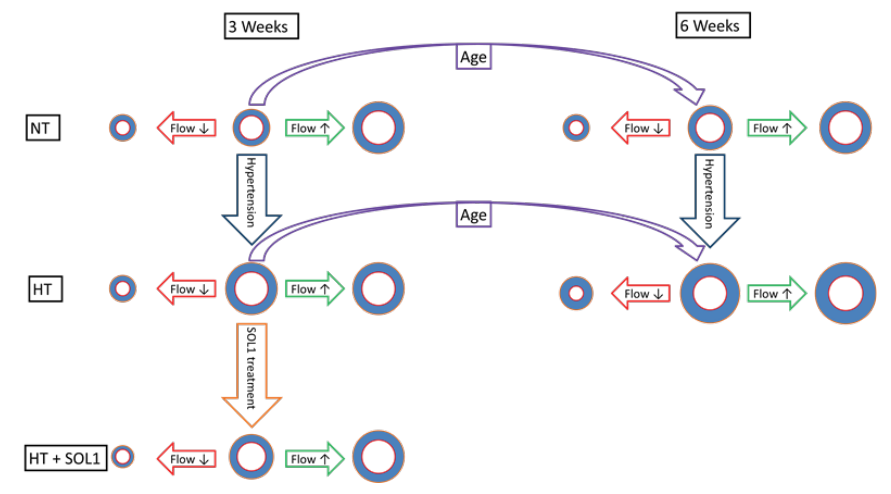

Figure 5.4: Schematic overview of changes in arterial lumen diameter and medial mass in relation to hypertension (blue arrow), imposed changes in flow (green arrow (high flow) and red arrow (low flow)), SOL1 treatment during hypertension (HT + SOL1: orange arrow) and age (purple arrow). NT: normotensive rats, HT: DOCA-salt hypertensive rats

In the present study, 3 week treatment of DOCA-salt hypertensive rats with the NEP/ECE inhibitor SOL1, tended to reduce the arterial diameter and -hypertrophy and significantly reduced the arterial hyperplasia. Whether this is due to reduction of the direct arterial effects of ET1 or indirectly to the reduction of blood pressure, however, remains to be established. To discriminate between the effects of blood pressure lowering and of modified levels of vasoactive peptides, future studies with vasodilator compounds in a setting similar to the one used here may be considered. Figure 5.4 shows a schematic overview of changes in arterial lumen diameter and medial mass in relation to SOL1 treatment during hypertension (orange arrow)

Pourageaud and De Mey showed that in 6 week old Wistar-Kyoto rats, elevated blood flow resulted in outward hypertrophic remodeling and reduced blood flow in inward hypotrophic remodeling 4 weeks after flow altering surgery [30]. Similar observations were made by our group and others [27, 30, 41, 42]. In the present study, we observed flow-induced outward hypertrophic remodeling but no hypotrophy in resistance arteries exposed to low blood flow in normotensive Wistar rats studied between 10 and 14 weeks of age. This is indicates dependence of flow-related arterial remodeling on rat age [43] and strain [44]. Unexpectedly, no significant differences in diameter and media mass were observed between control arteries and arteries exposed during 7 weeks to elevated blood flow in normotensive rats. This seems to be due to the growth and development of the control arteries during this period time. We speculate in this respect that the marked flow-induced remodeling of young arteries represents an accelerated developmental process [45].

In resistance arteries of DOCA-salt hypertensive rats, remodeling in response increased blood flow was blunted (see below) but structural responses to reduced blood flow were extensive. We observed a marked decrease in diameter that was, as in normotensive 
rats, not accompanied by a significant change in media mass. Unlike in normotensive rats, signs of marked and long lasting inflammation were observed such as extensive ED1 staining in tunica media and adventitia and sprouting of new vessels in the adventitial layer. The observation that in DOCA-salt hypertensive rats treated with SOL1, mesenteric arteries exposed to decreased flow were hypotrophic and lack the inflammatory component as well as the artery-like structures in the adventitia are in line with the mitogenic, proinflammatory and proangiogenic effects of ET1 $[15,17,18]$.

Flow-induced outward arterial remodeling did not occur in DOCA-salt hypertensive rats. This implies that the physiological response to an increase in flow, outward remodeling, is impaired in DOCA-salt hypertensive rats. This model of hypertension is described to show pronounced endothelial dysfunction [19] as evidenced by increased infiltration of inflammatory cells and reduced endothelium-dependent vasodilatation and increased endothelium-dependent vasoconstriction. Several studies indicate a strong interplay between endothelin-1 and endothelium derived nitric oxide [46]. Amiri et al. [35] showed that overexpressing the human prepoET1 gene in the endothelium in mice caused endothelial dysfunction and reduced NO bioavailability. Strong evidence indicates that endothelium-derived NO and other relaxing factors, can be released from the endothelium in response to increased shear stress mediating flow-induced vasodilatation [2, 3]. Endothelium-derived NO also plays a role in the arterial remodeling of large conduit arteries in response to a chronic increase in blood flow [47, 48]. In small resistance-sized arteries, the situation is less clear. Here NO is not the only endothelium-derived relaxing factor [49] and chronic pharmacological inhibition of NO-synthases does not inhibit flow-induced arterial remodeling [27]. In contrast to LNAME-induced hypertension, flow-induced remodeling was inhibited in DOCA-salt hypertensive rats. This indicates that in DOCA-salt hypertension endotheliumdependent remodeling of resistance arteries is blunted independently from classical endothelial dysfunction. Outward remodeling might be independent of endotheliumdependent vasodilatation. Alternatively, the endothelial dysfunction in DOCA-salt hypertension might not be restricted to reduced bioavailability of NO and upregulation of ET1, but also involve another endothelium-derived relaxing factor such as EDHF contributing to structural changes. Another possibility is that, due to the increase in diameter occurring during the development of the hypertension and due to the increased arterial stiffness, the dynamic range to respond to an imposed increase in flow might be considerably reduced in DOCA-salt hypertensive rats. Chronic SOL1 treatment during the development of DOCA-salt hypertension preserved the flow induced outward remodeling response. Thus NEP/ECE inhibition improves endothelium-dependent structural responses in mesenteric arteries of DOCA-salt hypertensive rats. Because a moderate inflammatory response seems necessary for the initiation of outward remodeling, the pharmacological effect is unlikely due to its anti-inflammatory consequences. The possible contributions of reduced blood pressure, reduced synthesis of ET1 and of improved non-NO-mediated relaxation, however, remain to be established. Figure 5.4 shows a schematic overview of changes in arterial lumen 


\section{Chapter 5}

diameter and medial mass in relation to an increase (green arrows) and a decrease (red arrows)

Our study has a number of limitations. The 3D-dissector technique is more accurate to determine changes in cell number and size, than the more rapid counting of nuclear profiles on hematoxylin-eosin stained tissue sections [9]. Additional measurement of local transmural pressure and of local blood flow at the various time points would have allowed to speculate on the extent to which normalization of wall stress and wall shear stress is impaired in mesenteric resistance arteries of DOCA-salt hypertensive rats.

In conclusion we observed in resistance arteries of DOCA-salt hypertensive rats, a selective reduction of flow-induced outward remodeling. This indicates that in this experimental model of hypertension, endothelial dysfunction is not limited to reduced endothelium-dependent vasodilatation. In addition some of our findings in arteries of both normotensive and hypertensive rats suggest that experimentally induced and developmental flow-induced arterial remodeling have the same upper limit. This should be taken into account when for instance vasodilator therapies are being proposed for reversal of inward arterial remodeling in essential hypertension [50]. 
Arterial Remodeling in DOCA-salt Hypertension

\section{Sources of funding:}

This study was performed within the framework of the Dutch Top Institute Pharma project: T2-108; Metalloproteases and Novel Targets in Endothelial Dysfunction 


\section{References}

[1] Martinez-Lemus LA, Hill MA, Meininger GA. The plastic nature of the vascular wall: a continuum of remodeling events contributing to control of arteriolar diameter and structure. Physiology (Bethesda) 2009; 24: 45-57.

[2] Bellien J, Iacob M, Gutierrez L, et al. Crucial role of NO and endotheliumderived hyperpolarizing factor in human sustained conduit artery flowmediated dilatation. Hypertension 2006; 48: 1088-94.

[3] Sun D, Huang A, Yan EH, et al. Reduced release of nitric oxide to shear stress in mesenteric arteries of aged rats. Am J Physiol Heart Circ Physiol 2004; 286: H2249-56.

[4] Hilgers RH, Schiffers PM, Aartsen WM, et al. Tissue angiotensin-converting enzyme in imposed and physiological flow-related arterial remodeling in mice. Arterioscler Thromb Vasc Biol 2004; 24: 892-7.

[5] Li JS, Lariviere R, Schiffrin EL. Effect of a nonselective endothelin antagonist on vascular remodeling in deoxycorticosterone acetate-salt hypertensive rats. Evidence for a role of endothelin in vascular hypertrophy. Hypertension 1994; 24: 183-8.

[6] Jaeckel M, Simon G. Altered structure and reduced distensibility of arteries in Dahl salt-sensitive rats. J Hypertens 2003; 21: 311-9.

[7] Folkow B. Physiological aspects of primary hypertension. Physiol Rev 1982; 62: 347-504.

[8] Heagerty AM, Aalkjaer C, Bund SJ, Korsgaard N, Mulvany MJ. Small artery structure in hypertension. Dual processes of remodeling and growth. Hypertension 1993; 21: 391-7.

[9] Buus CL, Pourageaud F, Fazzi GE, et al. Smooth muscle cell changes during flow-related remodeling of rat mesenteric resistance arteries. Circ Res 2001; 89: 180-6.

[10] Briones AM, Arribas SM, Salaices M. Role of extracellular matrix in vascular remodeling of hypertension. Curr Opin Nephrol Hypertens 2010; 19: 187-94.

[11] Rizzoni D, Muiesan ML, Porteri E, et al. Vascular remodeling, macro- and microvessels: therapeutic implications. Blood Press 2009; 18: 242-6.

[12] Rizzoni D, Porteri E, Piccoli A, et al. Effects of losartan and enalapril on small artery structure in hypertensive rats. Hypertension 1998; 32: 305-10.

[13] Schiffrin EL, Park JB, Intengan HD, Touyz RM. Correction of arterial structure and endothelial dysfunction in human essential hypertension by the angiotensin receptor antagonist losartan. Circulation 2000; 101: 1653-9.

[14] Yanagisawa M, Kurihara H, Kimura S, et al. A novel potent vasoconstrictor peptide produced by vascular endothelial cells. Nature 1988; 332: 411-5.

[15] Donckier JE, Michel L, Van Beneden R, Delos M, Havaux X. Increased expression of endothelin-1 and its mitogenic receptor ETA in human papillary thyroid carcinoma. Clin Endocrinol (Oxf) 2003; 59: 354-60.

[16] Ammarguellat F, Larouche I, Schiffrin EL. Myocardial fibrosis in DOCA-salt hypertensive rats: effect of endothelin ET(A) receptor antagonism. Circulation 2001; 103: 319-24. 
[17] Saleh MA, Boesen EI, Pollock JS, Savin VJ, Pollock DM. Endothelin-1 increases glomerular permeability and inflammation independent of blood pressure in the rat. Hypertension 2010; 56: 942-9.

[18] Boldrini L, Pistolesi S, Gisfredi S, et al. Expression of endothelin 1 and its angiogenic role in meningiomas. Virchows Arch 2006; 449: 546-53.

[19] Schiffrin EL. Vascular endothelin in hypertension. Vascul Pharmacol 2005; 43: 19-29.

[20] Schiffrin EL, Lariviere R, Li JS, Sventek P, Touyz RM. Deoxycorticosterone acetate plus salt induces overexpression of vascular endothelin-1 and severe vascular hypertrophy in spontaneously hypertensive rats. Hypertension 1995; 25: 769-73.

[21] Schiffrin EL, Lariviere R, Li JS, Sventek P, Touyz RM. Endothelin-1 gene expression and vascular hypertrophy in DOCA-salt hypertension compared to spontaneously hypertensive rats. Clin Exp Pharmacol Physiol Suppl 1995; 22: S188-90.

[22] Sawamura T, Kimura S, Shinmi O, et al. Purification and characterization of putative endothelin converting enzyme in bovine adrenal medulla: evidence for a cathepsin D-like enzyme. Biochem Biophys Res Commun 1990; 168: 12306.

[23] Nakano A, Kishi F, Minami K, et al. Selective conversion of big endothelins to tracheal smooth muscle-constricting 31-amino acid-length endothelins by chymase from human mast cells. J Immunol 1997; 159: 1987-92.

[24] Fernandez-Patron C, Radomski MW, Davidge ST. Vascular matrix metalloproteinase-2 cleaves big endothelin-1 yielding a novel vasoconstrictor. Circ Res 1999; 85: 906-11.

[25] Nelissen J, Lemkens P, Sann H, et al. Pharmacokinetic and Pharmacodynamic Properties of SOL1; a Novel Dual Inhibitor of Neutral Endopeptidase and Endothelin Converting Enzyme. Life sci 2012; in press.

[26] Kalk P, Sharkovska Y, Kashina E, et al. Endothelin-Converting Enzyme/Neutral Endopeptidase Inhibitor SLV338 Prevents Hypertensive Cardiac Remodeling in a Blood Pressure-Independent Manner. Hypertension 2011; 57: 755-63.

[27] Ceiler DL, De Mey JG. Chronic N(G)-nitro-L-arginine methyl ester treatment does not prevent flow-induced remodeling in mesenteric feed arteries and arcading arterioles. Arterioscler Thromb Vasc Biol 2000; 20: 2057-63.

[28] Ceiler DL, Nelissen-Vrancken HJ, Smits JF, De Mey JG. Pressure but not angiotensin II-induced increases in wall mass or tone influences static and dynamic aortic mechanics. J Hypertens 1999; 17: 1109-16.

[29] Dijkstra CD, Dopp EA, Joling P, Kraal G. The heterogeneity of mononuclear phagocytes in lymphoid organs: distinct macrophage subpopulations in the rat recognized by monoclonal antibodies ED1, ED2 and ED3. Immunology 1985; 54: 589-99.

[30] Pourageaud F, De Mey JG. Structural properties of rat mesenteric small arteries after 4-wk exposure to elevated or reduced blood flow. Am J Physiol 1997; 273: H1699-706.

[31] Unthank JL, Nixon JC, Burkhart HM, Fath SW, Dalsing MC. Early collateral and microvascular adaptations to intestinal artery occlusion in rat. Am J Physiol 1996; 271: H914-23. 
[32] Hynynen MM, Khalil RA. The vascular endothelin system in hypertension-recent patents and discoveries. Recent Pat Cardiovasc Drug Discov 2006; 1: 95-108.

[33] Dhaun N, Goddard J, Kohan DE, et al. Role of endothelin-1 in clinical hypertension: 20 years on. Hypertension 2008; 52: 452-9.

[34] Shimamoto H, Iriuchijima J. Hemodynamic characteristics of conscious deoxycorticosterone acetate hypertensive rats. Jpn J Physiol 1987; 37: 243-54.

[35] Amiri F, Virdis A, Neves MF, et al. Endothelium-restricted overexpression of human endothelin-1 causes vascular remodeling and endothelial dysfunction. Circulation 2004; 110: 2233-40.

[36] Fukuda G, Khan ZA, Barbin YP, et al. Endothelin-mediated remodeling in aortas of diabetic rats. Diabetes Metab Res Rev 2005; 21: 367-75.

[37] Rossi GP, Sacchetto A, Rizzoni D, et al. Blockade of angiotensin II type 1 receptor and not of endothelin receptor prevents hypertension and cardiovascular disease in transgenic (mREN2)27 rats via adrenocortical steroid-independent mechanisms. Arterioscler Thromb Vasc Biol 2000; 20: 949-56.

[38] Rossi GP, Bova S, Sacchetto A, et al. Comparative effects of the dual ACENEP inhibitor MDL-100,240 and ramipril on hypertension and cardiovascular disease in endogenous angiotensin II-dependent hypertension. Am J Hypertens 2002; 15: 181-8.

[39] Rossi GP, Cavallin M, Rizzoni D, et al. Dual ACE and NEP inhibitor MDL100,240 prevents and regresses severe angiotensin II-dependent hypertension partially through bradykinin type 2 receptor. J Hypertens 2002; 20: 1451-9.

[40] Rizzoni D, Rossi GP, Porteri E, et al. Bradykinin and matrix metalloproteinases are involved the structural alterations of rat small resistance arteries with inhibition of ACE and NEP. J Hypertens 2004; 22: 759-66.

[41] Tulis DA, Unthank JL, Prewitt RL. Flow-induced arterial remodeling in rat mesenteric vasculature. Am J Physiol 1998; 274: H874-82.

[42] Tuttle JL, Nachreiner RD, Bhuller AS, et al. Shear level influences resistance artery remodeling: wall dimensions, cell density, and eNOS expression. Am J Physiol Heart Circ Physiol 2001; 281: H1380-9.

[43] Miyashiro JK, Poppa V, Berk BC. Flow-induced vascular remodeling in the rat carotid artery diminishes with age. Circ Res 1997; 81: 311-9.

[44] Ibrahim J, Miyashiro JK, Berk BC. Shear stress is differentially regulated among inbred rat strains. Circ Res 2003; 92: 1001-9.

[45] Glagov S, Vito R, Giddens DP, Zarins CK. Micro-architecture and composition of artery walls: relationship to location, diameter and the distribution of mechanical stress. J Hypertens Suppl 1992; 10: S101-4.

[46] Hilgers RH, De Mey JG. Myoendothelial coupling in the mesenteric arterial bed; segmental differences and interplay between nitric oxide and endothelin1. Br J Pharmacol 2009; 156: 1239-47.

[47] Rudic RD, Shesely EG, Maeda N, et al. Direct evidence for the importance of endothelium-derived nitric oxide in vascular remodeling. J Clin Invest 1998; 101: 731-6.

[48] Tronc F, Wassef M, Esposito B, et al. Role of NO in flow-induced remodeling of the rabbit common carotid artery. Arterioscler Thromb Vasc Biol 1996; 16: 1256-62. 
[49] Shimokawa H, Yasutake H, Fujii K, et al. The importance of the hyperpolarizing mechanism increases as the vessel size decreases in endothelium-dependent relaxations in rat mesenteric circulation. J Cardiovasc Pharmacol 1996; 28: 703-11.

[50] Mulvany MJ. Small artery remodeling and significance in the development of hypertension. News Physiol Sci 2002; 17: 105-9. 



\section{Chapter 6 Dual NEP/ECE Inhibition Improves Endothelial Function in Mesenteric Resistance Arteries of Young SHR}

P. Lemkens, J. Nelissen, M.J.P.M.T Meens, B.J.A. Janssen, P.M.H. Schiffers, J.G.R. De Mey.

J Hypertens. 2012 Sep;30(9):1799-808 


\begin{abstract}
ET1 is a potent vasoconstrictor peptide with pro-mitogenic and pro-inflammatory properties and is therefore of interest in the development of endothelial dysfunction, endothelium dependent flow-related remodeling and hypertension-related remodeling. ET1 can be formed through cleavage of big-ET1 by endothelin converting enzyme (ECE) and neutral endopeptidase (NEP). We investigated whether the dual NEP/ECE inhibitor SOL1 improves resistance artery function and structure in 12 weeks old SHR and whether arterial structural responses to decreased $(-90 \%)$ or increased $(+100 \%)$ blood flow are impaired in young SHR. To this end two groups of SHR received chronic 4 week treatment at two different timepoints (4-8 weeks and 8-12 weeks) prior to the experiment. We compared in vitro effects of COX-inhibition (1 $\mu \mathrm{M}$ indomethacine), NOS-inhibition (100 $\mu \mathrm{M}$ L-NAME) and stimulation of the endothelium by $0.001-10 \mu \mathrm{M}$ acetylcholine $(\mathrm{ACh})$ in isolated $3^{\text {rd }}$ order mesenteric arteries (MA) of SHR and aged matched WKY. SOL1 had no effect on blood pressure in SHR or WKY. ACh caused biphasic effects in MA of SHR. The contractile component (EDCF) was (1) absent in WKY and (2) abolished by acute indomethacin administration or chronic SOL1 treatment. EDNO (endothelium derived nitric oxide) type responses did not differ in both strains and were not influenced by SOL1 treatment. EDHF (endothelium derived hyperpolarizing factor) -type responses were severely impaired in SHR compared to WKY and were normalized by chronic SOL1 treatment. In $1^{\text {st }}$ order MA, outward flow-induced remodeling was impaired in SHR. Chronic SOL1 treatment did not restore this response.
\end{abstract}

Thus chronic SOL1 treatment during the development of hypertension in SHR has no effect on blood pressure but improves several aspects of endothelium-dependent vasomotor responses but not-arterial remodeling. 


\section{Introduction}

The endothelium, can produce several vasoactive compounds that communicate with the underlying smooth muscle thus inducing vasomotor responses to control blood pressure and blood flow. Endothelium-derived vasoactive factors include the vasodilators nitric oxide (NO), endothelium-derived hyperpolarizing factors (EDHF) and prostacyclin, and the vasoconstrictors endoperoxides and endothelin-1 (ET1) [1, 2]. Endothelial dysfunction is classically described as an impairment of endotheliumdependent relaxing responses and an enhanced sensitivity to vasoconstrictors. In many forms of human and experimental hypertension, endothelial dysfunction and arterial remodeling are considered key players in the development and maintenance of high blood pressure $[1,3,4]$. A well described example of hypertension leading to an altered function of the endothelium is the spontaneously hypertensive rat (SHR), which shows decreased arterial relaxing responses to acetylcholine (ACh) and an increased production of an endothelium derived contractile factor (EDCF) in this case contractile prostaglandins [5].

Hypertension is also associated with remodeling of resistance sized arteries. In SHR, mesenteric resistance arteries display inward eutrophic remodeling attributed to reorganization of a normal arterial wall mass around a narrower lumen. This hypertension-related remodeling might contribute to the increased peripheral resistance observed in this model [6]. Chronic changes in blood flow can also cause arteries to remodel. Initially an alteration in blood flow causes a change in vasomotor tone which modifies the arterial diameter in order to normalize wall shear stress. When the increase in blood flow is sustained, arteries can structurally remodel to restore normal values of wall shear stress and circumferential wall stress [7]. Both the acute and the chronic response are endothelium-dependent processes $[8,9]$ and are thus likely to be affected by endothelial dysfunction. Studies from our group showed that during the development of hypertension in SHR, the levels of the endothelium-derived peptide ET1 are increased in several organs [10]. Apart from being a potent vasoconstrictor, ET1 is also a potent growth promoting and pro-inflammatory agent [11-15]. Because of these functions ET1 is of interest in the development of endothelial dysfunction, hypertension-related remodeling and flow-related remodeling. ET1 can be formed through cleavage of big-ET1 by endothelin converting enzyme (ECE). Alternatively big-ET1 can be hydrolyzed by chymase or matrix metalloproteinase 2 (MMP2) to form ET1 (1-31) or ET1 (1-32) respectively. Both are further processed into ET1 by neutral endopeptidase (NEP) [16-18]. Thus a dual NEP/ECE inhibitor, for example the novel compound SOL1, reduces ET1 production by inhibiting all three pathways [19]. Recently Kalk et al. [20] reported that the dual NEP/ECE inhibitor SLV338, an analogue of SOL1, reduced myocyte hypertrophy, interstitial fibrosis and perivascular fibrosis. 
We tested the hypotheses that chronic NEP/ECE inhibition improves (i) endothelial function of mesenteric resistance arteries of SHR and (ii) the ability of mesenteric resistance arteries of SHR to remodel in response to imposed flow changes. In previous studies from our group ET1 content was increased in heart and kidneys of SHR compared to WKY at 8 weeks of age and remained stable for the next four weeks. Therefore we treated one group between 4 and 8 weeks of age (to test if preventing the increase in ET1 content had beneficial effects) and another group between 8 and 12 weeks of age (to test if lowering ET1 content after an initial increase had beneficial effects).

\section{Materials and Methods}

\section{Animals, model and surgery}

12 week old spontaneously hypertensive rats (SHR) and age matched WKY normotensive controls (Charles River, Maastricht, The Netherlands) were used in all experiments, which were performed in accordance with the ethical committee for animal welfare of the Maastricht University.

All animals were anesthetized with isoflurane (1-4\%) and osmotic minipumps (Alzet, Cupertino, CA, USA) were implanted subcutaneously for chronic continuous drug treatment over the next 4 weeks Preliminary dose-finding experiments were carried out to identify appropriate doses of the dual NEP/ECE inhibitor SOL1 (2-\{[1-(\{[(3S)-1(carboxymethyl-2-oxo-2,3,4,5-tetrahydro-1H-1-benzazepin-3-

yl]amino carbonyl)cyclopentyl]methyl \}-4-[[3-methylamino)propyl](methyl)amino]-4oxobutanoic acid; Abbott). A dose of $50 \mathrm{mg} / \mathrm{kg} /$ day drastically decreased urinary ET1 content (from $32.89 \pm 3.91$ to $1.35 \pm 0.25 \mathrm{pg} / \mathrm{ml} \mathrm{p}<0.001$ ). We opted for 2 treatment regimes. The first regime consisted of a 4 week treatment before a peak in ET1 content is reached (4-8 weeks). Terminal experiments were performed at week 12. The second regime consisted of a 4 week after the peak in ET1 content (8-12 weeks). Animals were randomly assigned to a chronic treatment group $(n=6)$. The vehicle group received osmotic minipumps containing a saline solution for the same period of time. At week 8 , blood flow-modifying surgery was performed in the animals by distal ligation of alternate first-order mesenteric arteries to create arteries chronically exposed to low blood flow (LF). The patent arteries between these then had a compensatory increased blood flow (HF). Arteries from a distant part of the intestine were considered control arteries exposed to normal flow (NF) [21, 22]. The intra-arterial blood pressure was measured in conscious unrestrained state rats via a heparinized $(5 \mathrm{U} / \mathrm{ml})$ indwelling polyethylene catheter that was introduced into the left femoral artery 2 days before measurement. The arterial catheter was connected to a pressure transducer (Micro Switch 150 PC) and its output was sampled at $2.5 \mathrm{kHz}$. MAP was calculated using the IDEEQ data-acquisition system (instrument services, Maastricht University, The Netherlands). Animals were euthanized by isoflurane ( $>4 \%)$. 


\section{Physiological solutions and drugs}

The Krebs Ringer bicarbonate-buffered physiological salt solution (KRB) that was continuously aerated with $95 \% \mathrm{O}_{2} / 5 \% \mathrm{CO}_{2}$ and maintained at $37^{\circ} \mathrm{C}$ contained (in $\mathrm{mM}$ ): $118.5 \mathrm{NaCl}, 4.7 \mathrm{KCl}, 2.5 \mathrm{CaCl}_{2}, 1.2 \mathrm{MgSO}_{4}, 1.2 \mathrm{KH}_{2} \mathrm{PO}_{4}, 25.0 \mathrm{NaHCO}_{3}$ and 5.5 glucose. Capsaicin (CAPS) and indomethacin (INDO) were purchased from Sigma Aldrich (Zwijndrecht, the Netherlands) and dissolved in ethanol. Acetylcholine (ACh), noradrenaline (NA), phenylephrine (PHE) and the nitric oxide synthase inhibitor $\mathrm{N}^{\omega_{-}}$ nitro-L-arginine (L-NAME) were all purchased from Sigma Aldrich (Zwijndrecht, The Netherlands) and dissolved in KRB. High $\mathrm{K}^{+}-\mathrm{KRB}$ solution was $\mathrm{KRB}$ in which all $\mathrm{NaCl}$ was replaced by $\mathrm{KCl}$. Solutions containing $10-40 \mathrm{mM} \mathrm{K}^{+}$were prepared by mixing appropriate volumes of $\mathrm{KRB}$ and $\mathrm{K}^{+}-\mathrm{KRB}$.

\section{Wire Myography}

Third order mesenteric resistance arterial segments of approximately $2 \mathrm{~mm}$ in length were isolated and mounted in wire myographs for the recording of isometric force development [23]. Each experiment started by progressively stretching the arterial segment to the diameter at which the largest contractile response to $10 \mu \mathrm{M}$ NA could be obtained (optimal diameter). To prevent the sensory nerves from releasing calcitonin gene related peptide (CGRP) when stimulated during potassium induced depolarizations all arterial segments were exposed to capsaicin (1 $\mu \mathrm{M}$, during $20 \mathrm{~min})[24,25]$. Viability of the endothelium was tested by measuring ACh $(10 \mu \mathrm{M})$ induced relaxation during PHE induced contraction. Contractile responses to increasing concentrations of $\mathrm{K}^{+}$(5.9-40 $\left.\mathrm{mM}\right)$ and PHE $(0.16-20 \mu \mathrm{M})$ and relaxing responses to increasing concentrations of ACh $(0.001-10 \mu \mathrm{M})$ were recorded. The effects of nitric oxide synthase inhibition (L-NAME, $100 \mu \mathrm{M}$ ), cyclo-oxygenase inhibition (INDO, $1 \mu \mathrm{M}$ ) were evaluated.

\section{Determination of arterial remodeling}

$1^{\text {st }}$ order MA exposed to high flow (HF) or low flow (LF) conditions in vivo were isolated. Arteries located outside the region of ligation were used as normal flow controls (NF). Arteries were mounted on two glass micropipettes in an organ chamber filled with $\mathrm{Ca} 2^{+}$-free Krebs Ringer solution $(144 \mathrm{mM} \mathrm{NaCl}, 4.7 \mathrm{mM} \mathrm{KCl}, 1.2 \mathrm{mM}$ $\mathrm{MgSO}_{4}, 1.2 \mathrm{mM} \mathrm{KH} \mathrm{PO}_{4}, 14.9 \mathrm{mM}$ HEPES, and $5.5 \mathrm{mM}$ glucose; pH 7.4). $10 \mu \mathrm{M} \mathrm{Na}-$ nitroprusside (SNP, Sigma Aldrich, Zwijndrecht, the Netherlands) was added to ensure maximal vasodilatation. A pressure-diameter relationship was established by recording the lumen diameter while gradually increasing the distending pressure $(20-120 \mathrm{mmHg}$, $10 \mathrm{mmHg}$ steps). After the experiment, vessels were fixed at $80 \mathrm{mmHg}$ in $4 \%$ phosphate buffered formaldehyde solution for 1 hour and stored in $70 \%$ ethanol. 


\section{Histological analyses}

Fixed vessels were embedded in paraffin and cross-sections $(4 \mu \mathrm{m})$ were stained with Lawson's solution (Boom, Meppel, the Netherlands). Media cross-sectional area (mCSA) was determined from the circumferences of the internal and external elastic laminae. The average number of nuclear profiles in the media was determined by counting on haematoxylin-eosin stained cross-sections (\# nuclei).

\section{Statistical analysis}

Results are expressed as means \pm SEM. All contractile responses are represented as a percentage of the maximal NA response prior to the administration of any pharmacological inhibitor. Individual concentration-response curves were fitted to a non-linear sigmoid regression curve (Graphpad Prism 5.0). Sensitivity $\left(\mathrm{pEC}_{50}\right)$ and maximal effect $\left(\mathrm{E}_{\max }\right)$ are shown as mean \pm SEM. Statistical significance of differences between groups was evaluated by analysis of variance (ANOVA for consecutive measurements for pressure-diameter curves) or 1-way ANOVA (to compare $\mathrm{pEC}_{50}$ and $E_{\max }$ ) followed by Bonferroni post-test (graphpad 5.0). A value of $\mathrm{P}<0.05$ was considered statistically significant.

\section{Results}

\section{General characteristics}

Blood pressure of 12 week old SHR was significantly increased compared to WKY. Body weights of 12 week old SHR were significantly lower than age matched WKY. The treatments with SOL1 had no significant effect on either blood pressure or body weight of SHR and WKY (Table 6.1).

\begin{tabular}{|c|c|c|c|c|c|}
\hline \multirow{2}{*}{ Treatment } & & \multicolumn{2}{|c|}{$4-8$ weeks of age } & \multicolumn{2}{|c|}{$8-12$ weeks of age } \\
\hline & & Vehicle $(n=6)$ & SOL1 $(n=6)$ & Vehicle $(n=6)$ & SOL1 $(n=6)$ \\
\hline \multirow{2}{*}{ Body weight (g) } & WKY & $335 \pm 6$ & $331 \pm 4$ & $318 \pm 3$ & $307 \pm 8$ \\
\hline & SHR & $289 \pm 7 * * *$ & $288 \pm 7 * * *$ & $278 \pm 5 * * *$ & $277 \pm 8 *$ \\
\hline \multirow{2}{*}{ MAP (mmHg) } & WKY & $113 \pm 2$ & $102 \pm 2$ & $110 \pm 1$ & $108 \pm 1$ \\
\hline & SHR & $165 \pm 2 * * *$ & $160 \pm 4 * * *$ & $160 \pm 3 * * *$ & $165 \pm 2 * * *$ \\
\hline
\end{tabular}

Table 6.1: General characteristics of 12 week old rats. Data are shown as mean \pm SEM, *: $p<0.05$ WKY versus SHR, ***: $p<0.001$ WKY versus SHR

Optimal diameter and active tension are summarized in Table 6.2. Diameters of mesenteric resistance arteries of WKY and SHR were not significantly influenced by the 4-8 week SOL1 treatment. Active tension was slightly decreased in WKY and 
significantly decreased in SHR by the 4-8 week SOL1 treatment. The 8-12 week SOL1 treatment had no effect on diameter or active tension. $\mathrm{E}_{\max }$ values of the precontractions were comparable between different strains and treatment groups (Figure 6.1).

\begin{tabular}{|c|c|c|c|c|c|}
\hline \multirow[b]{2}{*}{ Treatment } & & \multicolumn{2}{|c|}{4 - 8 weeks of age } & \multicolumn{2}{|c|}{$8-12$ weeks of age } \\
\hline & & $\begin{array}{l}\text { Vehicle } \\
(n=6)\end{array}$ & $\begin{array}{l}\text { SOL1 } \\
(n=6)\end{array}$ & $\begin{array}{l}\text { Vehicle } \\
(\mathrm{n}=6)\end{array}$ & $\begin{array}{l}\text { SOL1 } \\
(n=6)\end{array}$ \\
\hline \multirow[t]{2}{*}{ Diameter $(\mu \mathrm{m})$} & $\begin{array}{c}\text { WK } \\
\mathrm{Y}\end{array}$ & $263 \pm 17$ & $233 \pm 8$ & $254 \pm 10$ & $246 \pm 10$ \\
\hline & SHR & $241 \pm 7$ & $233 \pm 8$ & $240 \pm 8$ & $240 \pm 5$ \\
\hline \multirow{2}{*}{$\begin{array}{l}\text { Active Tension } \\
\qquad(\mathrm{N} / \mathrm{m})\end{array}$} & $\begin{array}{c}\text { WK } \\
\mathrm{Y}\end{array}$ & $3.3 \pm 0.2$ & $2.8 \pm 0.3$ & $3.2 \pm 0.3$ & $3.2 \pm 0.3$ \\
\hline & SHR & $3.5 \pm 0.2$ & $2.7 \pm 0.3 *$ & $3.6 \pm 0.5$ & $3.5 \pm 0.3$ \\
\hline
\end{tabular}

Table 6.2: General characteristics of $3^{\text {rd }}$ order mesenteric resistance arteries. Optimal diameter and maximal tensions to $10 \mu \mathrm{M}$ noradrenaline. Data are shown as mean $\pm \mathrm{SEM}, *: p<0.05$ Vehicle versus SOL1

\section{Effects of Chronic NEP/ECE inhibition on acetylcholine induced EDCF responses in mesenteric arteries of WKY and SHR.}

To asses endothelium-dependent responses arteries were precontracted with PHE and exposed to increasing concentrations of ACh (0.001-10 $\mu \mathrm{M})$. In arteries of WKY, ACh caused concentration-dependent relaxations. In arteries of SHR, the muscarinic agonist caused biphasic responses; relaxation at low and contraction at high concentrations (Figure 6.2 A, B). No significant difference in $\mathrm{pEC}_{50}$ but a significant decrease in $\mathrm{E}_{\max }$ in SHR was observed. The EDCF component in the SHR was significantly inhibited by both 4-8 and 8-12 week SOL1 treatment (Figure 6.2 A, B, Table 6.3) which did not significantly influence $\mathrm{pEC}_{50}$.
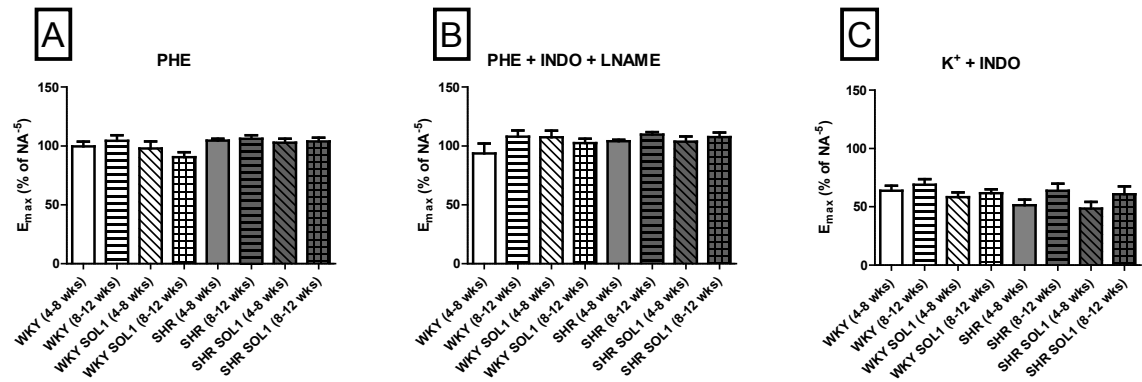

Figure 6.1: Maximal contraction in response to $20 \mu \mathrm{M}$ PHE (A), $20 \mu \mathrm{M}$ PHE in presence of INDO (1 $\mu M)$ and L-NAME $(100 \mu \mathrm{M})(B)$ and $40 \mathrm{mM} \mathrm{K} \mathrm{K}^{+}$in presence of INDO $(1 \mu \mathrm{M})(\mathrm{C})$. Contractions are shown as a percentage of a contraction with $10 \mu \mathrm{M}$ NA. Data are shown as mean $\pm \mathrm{SEM}$. 
Chapter 6

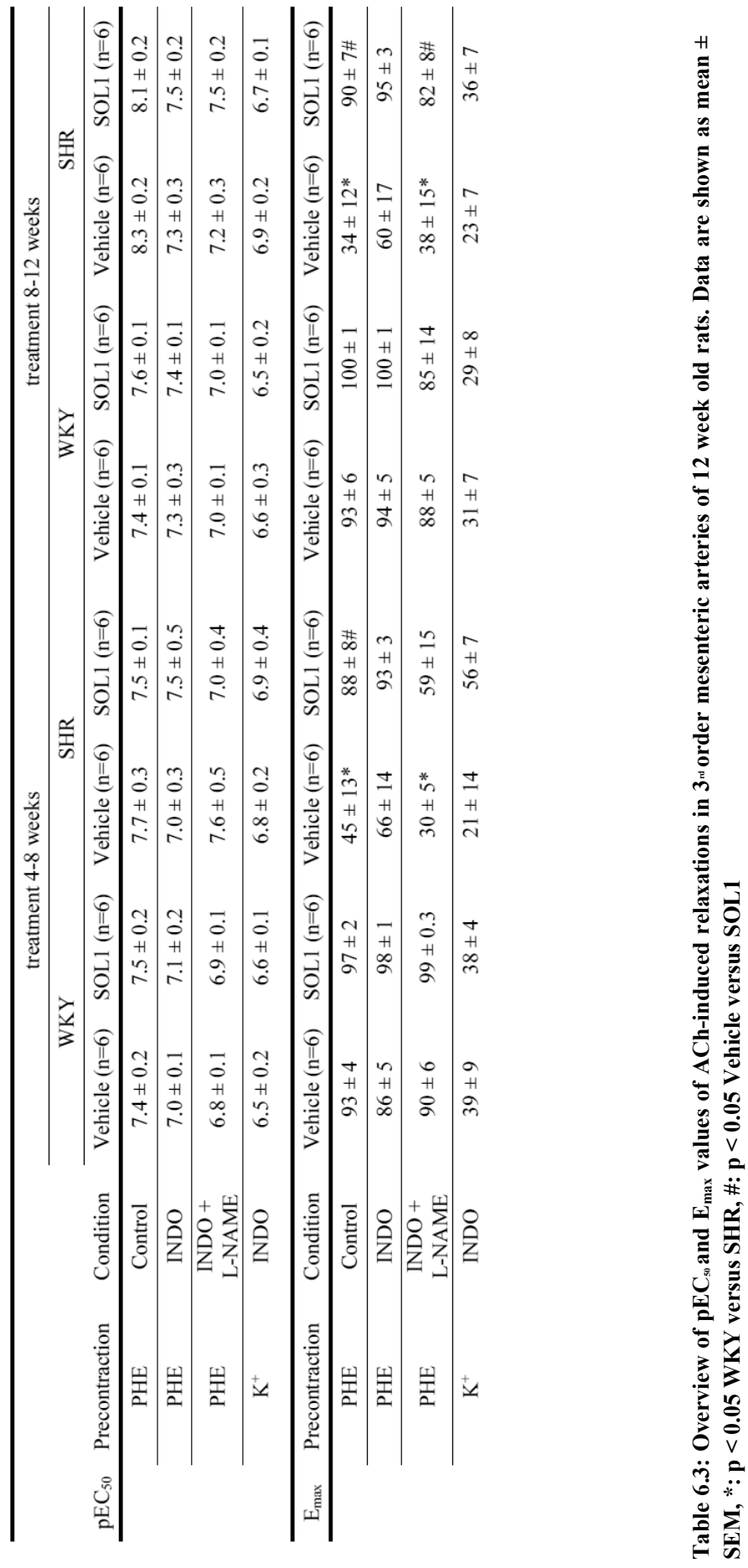




\section{Effects of Chronic NEP/ECE inhibition on acetylcholine induced EDHF responses in mesenteric arteries of WKY and SHR.}

To assess the contribution of EDHF to the ACh (0.001-10 $\mu \mathrm{M})$ induced relaxing response, arteries were precontracted with PHE $(20 \mu \mathrm{M})$ in presence of INDO (to prevent formation of vasodilator and vasoconstrictor prostaglandins) and L-NAME (to prevent involvement of NO). The remaining ACh induced response was considered EDHF.

$\mathrm{pEC}_{50}$ values did not differ significantly between WKY or SHR, treated or not treated, (Figure 6.2 C, D, Table 6.3). Maximal relaxation was impaired in SHR compared to WKY. The maximal EDHF response was significantly improved by the 8-12 week SOL1 treatment. The 4-8 week SOL1 treatment tended to increase the maximal EDHF response but this did not reach statistical significance.

Effects of Chronic NEP/ECE inhibition on acetylcholine induced EDNO responses in mesenteric arteries of WKY and SHR.

To investigate the contribution of nitric oxide in the ACh $(0.001-10 \mu \mathrm{M})$ induced relaxing response, arteries were precontracted with high potassium buffer in the presence of INDO (to prevent formation of vasodilator and vasoconstrictor prostaglandins). A high extracellular $\mathrm{K}^{+}$concentration effectively prevents EDHFrelated responses [26].The remaining $\mathrm{ACh}$ induced response was completely abolished in presence of L-NAME (relaxations between 0 and $3 \%$ of the maximal contraction) and was thus considered EDNO.

No significant differences of the $\mathrm{pEC}_{50}$ and $\mathrm{E}_{\max }$ of $\mathrm{ACh}$ were observed between WKY and SHR, and between treated and non treated animals when considering the contribution of $\mathrm{NO}$ to the ACh induced relaxing response (Figure 6.2 E, F, Table 6.3). 


\section{৫}

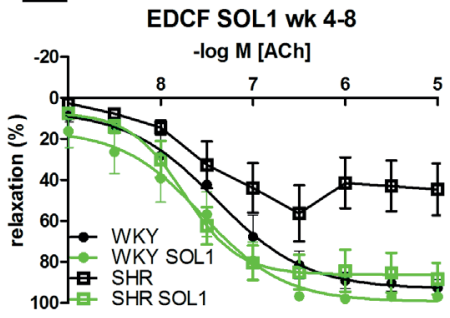

c

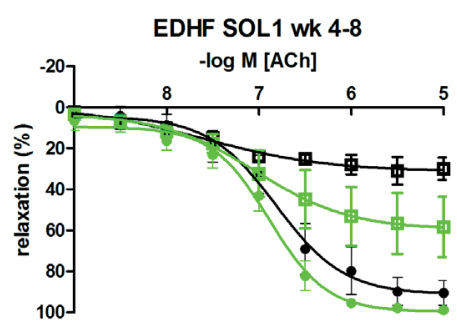

E

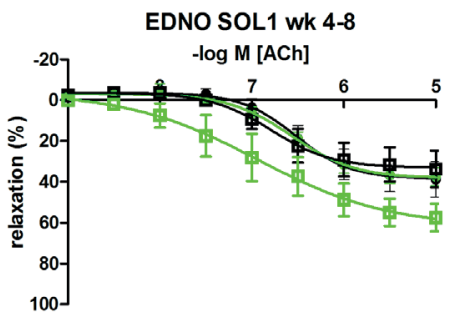

田

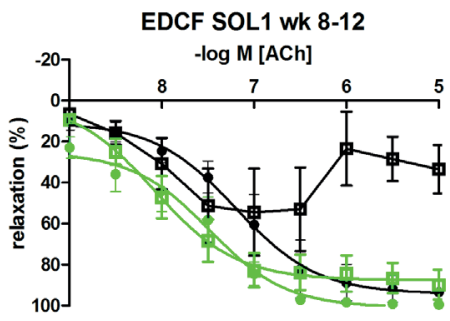

甲

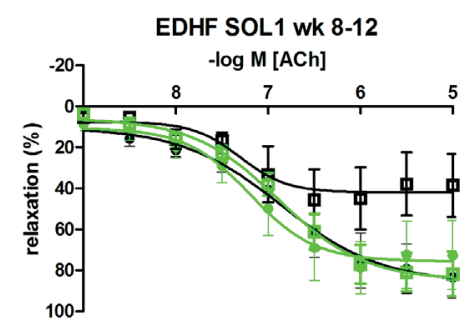

$F$

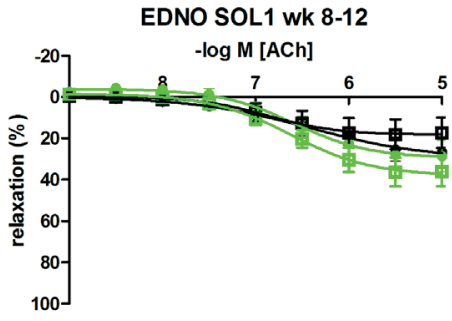

Figure 6.2: Acetylcholine-induced in 3rd order mesenteric arteries. The top panels depict the response to increasing concentrations of ACh (0.001-10 $\mu \mathrm{M})$ during a PHE $(20 \mu \mathrm{M})$ precontraction. The typical biphasic response is only observed in the SHR. The middle panels depict the response to increasing concentrations of $\mathrm{ACh}(0.001-10 \mu \mathrm{M})$ during a PHE $(20 \mu \mathrm{M})$ precontraction in presence of INDO (1 $\mu M)$ and L-NAME $(100 \mu \mathrm{M})$. These EDHF type responses are severely impaired in SHR, but partly restored by SOL1 treatment. The bottom panels depict the response to increasing concentrations of ACh $(0.001-10 \mu \mathrm{M})$ during a $\mathrm{K}^{+}$-induced $(40 \mathrm{mM})$ precontraction in presence of INDO $(1 \mu \mathrm{M})$. The closed circles depict WKY, the open squares depict SHR. The effects of SOL1 treatment are shown in green. Data are shown as mean \pm SEM 

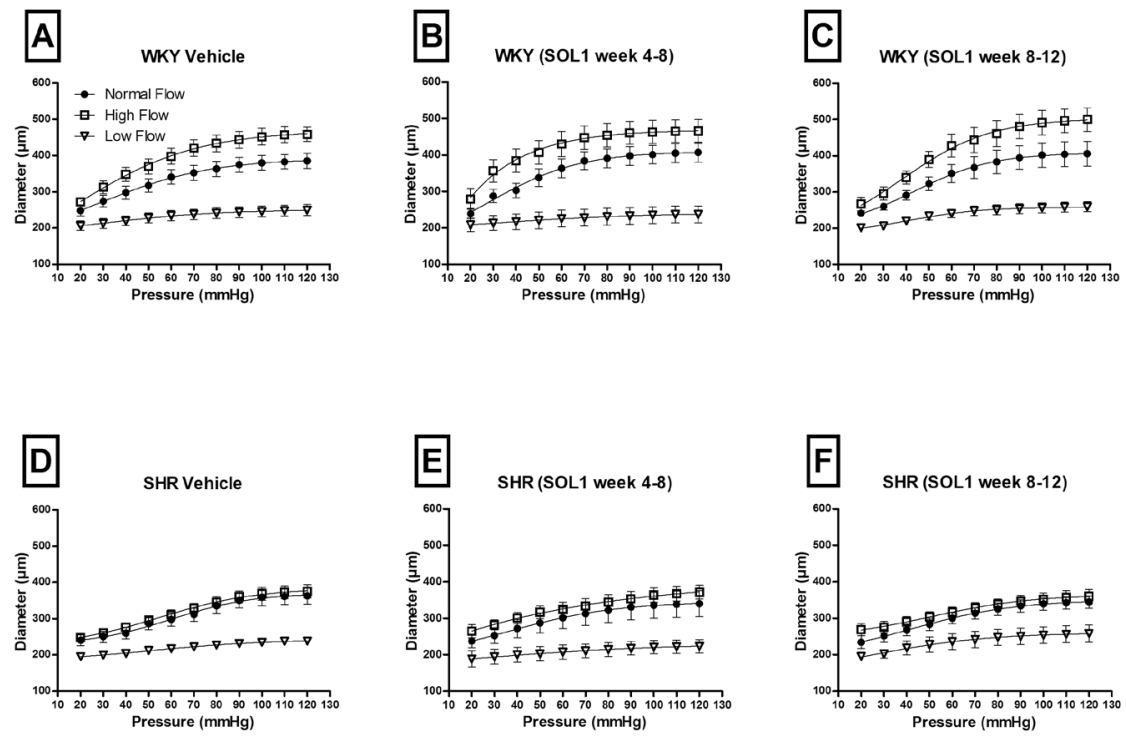

Figure 6.3: Relation between imposed pressure and diameter after 4 weeks of altered flow in mesenteric resistance arteries of (A) WKY, (B) WKY + SOL1 treatment from week 4-8 (C) WKY + SOL1 treatment from week 8-12: (D) SHR, (E) SHR + SOL1 treatment from week 4-8 (F) SHR + SOL1 treatment from week 8-12. Data are shown as mean \pm SEM.

\section{Mechanical and morphological properties of mesenteric resistance arteries of WKY and SHR, effects of NEP/ECE inhibition.}

Diameter of $1^{\text {st }}$ order mesenteric arteries of SHR was smaller than the diameter of WKY arteries although this did not reach significance (Figure 6.3 A, B, Figure 6.4 A). These arteries of SHR showed no significant hypertrophy or hyperplasia (Figure 6.4 B, C). 

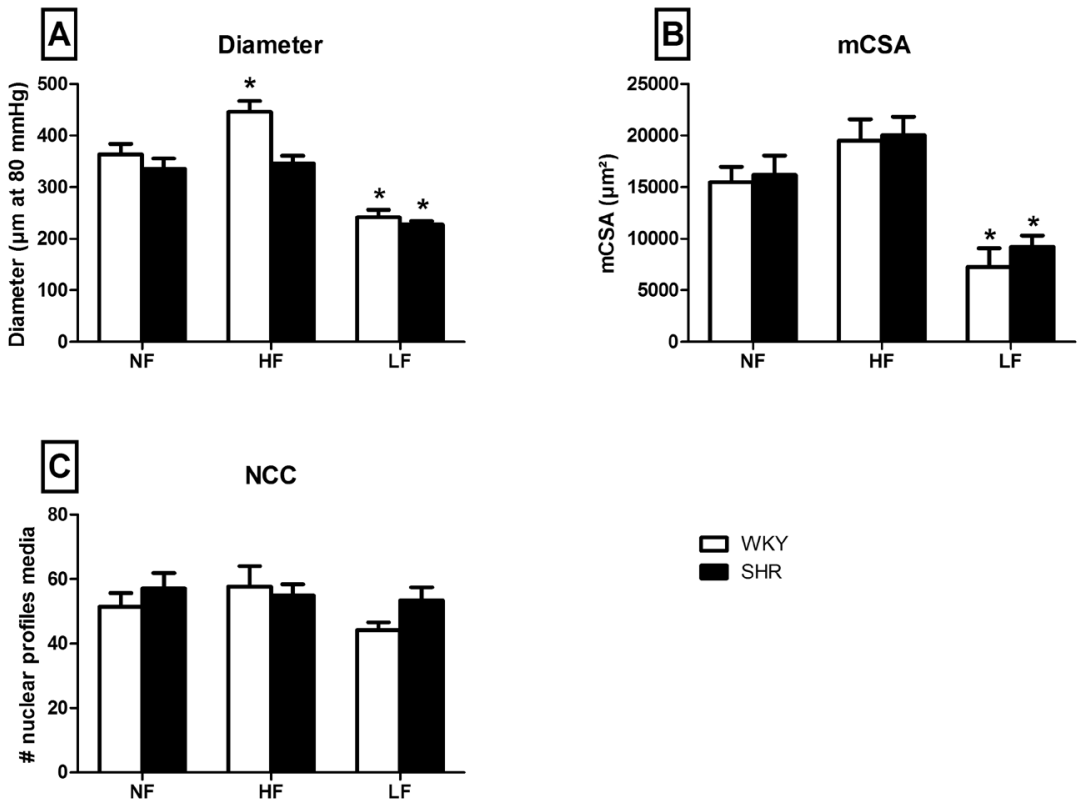

Figure 6.4: Effects of 4 weeks of altered blood flow on (A) lumen diameter (measured at $80 \mathrm{mmHg}$ ), (B) cross sectional area of the medial layer (mCSA), (C) the number of medial cells per cross section after 4 weeks (NCC) of $1^{\text {st }}$ order mesenteric arteries of WKY (open bars) and SHR (closed bars). Data are shown as mean \pm SEM. *: $p<0.05$ versus NF

An imposed increase in blood flow caused outward remodeling in MA of normotensive WKY (Figure 6.3 A, B, Figure 6.4 A) that was accompanied by modest hypertrophy and hyperplasia (Figure $6.4 \mathrm{~B}, \mathrm{C}$ ). An imposed decrease in blood flow caused significant inward remodeling (Figure 6.3 A, B, Figure 6.4 A). This response was accompanied by hypotrophy without a significant change in cellularity of the media (Figure $6.4 \mathrm{~B}, \mathrm{C}$ ). These observations in WKY are similar to earlier observations [21, $22,27,28]$.

In MA of SHR, outward remodeling in response to increased blood flow did not occur. Moreover no significant change in cross sectional area of the media or cellularity were observed. LF arteries in SHR showed an inward (Figure 6.3 A, B, Figure 6.4 A) hypotrophic remodeling response without a change in cellularity (Figure $4 \mathrm{~B}, \mathrm{C}$ ).

Neither a 4-8 week or an 8-12 week treatment with SOL1 significantly influenced arterial structure nor flow-induced arterial remodeling in WKY and the failure of the latter in SHR (Figure 6.3). 


\section{Discussion}

The main finding of this work is that NEP/ECE-inhibitor treatment normalizes endothelium-dependent vasodilatation in resistance arteries of SHR by reducing EDCF and improving EDHF, without noticeable effects on blood pressure, arterial structure or flow-induced remodeling.

In SHR the role of the renin-angiotensin system is well established [29]. A potential role of the endothelin system in the arterial functional and structural changes is, however, less clear [30]. Montagnani et al. reported that while there is no difference in ET1 induced contractions between 5 week old SHR and WKY, they noted a marked increase in ET1 induced contractile responses in 12 week old animals [31]. Furthermore, our group reported increased levels of endothelin-1 in several organs of 8 and 12 week old SHR [10]. This points to a transient upregulation of the endothelin system during the development of hypertension. ET1 is not only a very potent vasoconstrictor [11] but is also a pro-inflammatory agent [14], has mitogenic effects on vascular smooth muscle cells [12], is pro-angiogenic [15], pro-oxidant [32] and promotes fibrosis [13]. Moreover, endothelium restricted overexpression of ET1 caused vascular remodeling and endothelial dysfunction in the absence of a hemodynamic effect [32]. The prooxidant and pro-inflammatory functions might, at least in some forms of hypertension, be more important than the pressor effect. Because of the aforementioned functions, the endothelin system emerges as a potential target for normalizing functional and structural arterial properties associated with hypertension. We tested the hypothesis that ET1 contributes to the endothelial dysfunction, the arterial remodeling and the hypertension in 12 week old SHR. To evaluate this contribution we treated young SHR at two different timepoints (4-8 weeks and 8-12 weeks) with the dual NEP/ECE inhibitor SOL1 that effectively decreases big-ET1 to ET1 production [19]. This might be helpful in conditions where either the intravascular levels of ET1 and/or the vascular effects of the peptide are increased [31, 33, 34]. Moreover inhibiting NEP might have added beneficial value by chronically inhibiting the breakdown of other vasoactive peptides such as natriuretic peptides and calcitonin-gene related peptide [35-37]. We paid attention to two aspects of endothelium-dependent arterial function: acute vasomotor responses and chronic flow-related arterial remodeling.

SHR develop high blood pressure between week 4 and 10 of age [38]. In this study we observed that at 12 weeks of age, SHR show a clear upregulation of EDCF and an impairment of the EDHF-related arterial relaxation. It can be debated whether these endothelial dysfunctions are a cause or a consequence of the high blood pressure. Earlier reports suggest that abnormalities of the vasculature of both structure and function precede the development of hypertension and could thus well be of a genetic nature rather than a secondary effect of the high blood pressure [39, 40]. 
Chronic SOL1 treatment did not have an effect on blood pressure or body weight. This is in line with observations made by Kalk et al. who did not observe a blood pressure reduction with SLV338, a SOL1 analogue [20], in the 2-kidney 1-clip model. Similarly Sharkovska et al. did not observe a blood pressure reduction with SLV338 in rats chronically treated with L-NAME [41]. SOL1 treatment had minor to no effects on the diameter of $1^{\text {st }}$ and $3^{\text {rd }}$ order mesenteric resistance arteries, we do however see a trend to lower diameters in SHR compared to WKY.

To assess arterial and endothelial function and the effects of a chronic SOL1 treatment we investigated the functional properties of $3^{\text {rd }}$ order mesenteric resistance arteries in vitro.

Functional properties of resistance sized arteries are often altered in hypertension frequently attributed to a dysfunctional endothelium. Endothelial dysfunction is normally regarded as a reduced NO bioavailability or function, blunted EDHF responses and hypersensitivity to vasoconstrictors [42]. In SHR, specifically endothelium derived contractile factors (EDCF) are described as a manifestation of endothelial dysfunction. This contraction in response to stimulation of the artery with acetylcholine is fully inhibited by a cyclo-oxygenase inhibitor. In these 12 week old SHR the EDCF component is clearly observed. The prostanoids $\mathrm{PGH}_{2}, \mathrm{PGI}_{2}$ and thromboxane $\mathrm{A}_{2}$ $\left(\mathrm{TXA}_{2}\right)$ have been suggested to be responsible for increased vascular tone in hypertension [43]. Recently Spijkers et al. reported endothelium dependent contractions due to increased $\mathrm{TXA}_{2}$ release in arteries of SHR. Moreover they observed an increased expression of COX-1 in smooth muscle cells of SHR compared to WKY and an increased expression of $\mathrm{TXA}_{2}$-synthase and $\mathrm{iPLA}_{2}$ (substrate delivery to COX-1) in the endothelium of SHR compared to WKY $[44,45]$. In this study, the EDCF response was abolished by both regimens of treatment with the NEP/ECE inhibitor as well as by acute cyclo-oxygenase inhibition.

The hallmark of endothelial function is still considered to be vasorelaxation in response to the endothelium derived relaxing factors (EDRF), most notably endothelium derived nitric oxide (EDNO). In this study none of the treatments caused an improvement of the NO-induced relaxation compared to the vehicle group. This is in line with the observation that there is little to no alteration in NO production in this model [46-48].

Another EDRF, endothelium derived hyperpolarizing factor (EDHF) causes endothelial hyperpolarization with subsequent vascular smooth muscle cell hyperpolarization. The contribution of EDHF is most marked in small arteries [23, 49], In mesenteric resistance arteries this response is blocked by depolarization by high extracellular $\left[\mathrm{K}^{+}\right]$or inhibitors of endothelial small- and intermediate-conductance calcium-activated $\mathrm{K}^{+}$ channels $[23,26,50,51]$. In this study, the EDHF response evoked by ACh was clearly blunted in MA of 12 week old SHR. The 4-8 week SOL1 treatment improved EDHF responses but the 8-12 week SOL1 treatment completely normalized EDHF responses 
to the levels of normotensive WKY. The mechanisms by which the drug treatments reduced EDCF- and enhanced EDHF-related arterial reactivity may become the subject of future investigation. It is, however, noteworthy that this did not lead to a reduction in blood pressure nor can it be attributed to a blood pressure reduction.

That one can improve/normalize endothelial function in the absence of a blood pressure lowering effect is in line with findings that different classes of antihypertensive drugs can have distinct effects on vascular properties in experimental models and patients (e.g. $[52,53])$. Endothelial function has been proposed as an independent but amenable risk factor [54-59] and improving endothelial function has been reported to lead to more favorable prognosis. A therapy that significantly improves endothelial function might in this respect be of added value to reduce the complications of chronic high blood pressure.

With respect to endothelium-dependent arterial structural changes we observed impaired outward remodeling in response to increased flow in SHR. This is in line with earlier findings of Gao et al. [60]. Noteworthy is that while outward remodeling is impaired, inward remodeling in response to a flow decrease is comparable in WKY and SHR. The reduction in wall mass however was significantly larger in WKY. The lack of flow-related outward remodeling implies that the physiological response to an increase in flow, outward remodeling, is impaired. It is well established that the endothelium acts as a shear stress sensor in both flow induced dilatation and flow induced remodeling $[61,62]$. Therefore it is tempting to assume that both processes are closely related (e.g. chronic flow-induced vasodilatation eventually leads to flow-induced arterial outward remodeling). However, several observations argue against this causal relationship. For example, chronic vasodilator treatment does not uniformly lead to outward remodeling of resistance arteries in vivo [63]. Furthermore, while during arterial organ culture in vitro chronic vasoconstrictor administration can cause inward remodeling of resistance arteries, chronic vasodilator administration does not cause outward arterial remodeling [64-66]. Moreover, while there is strong evidence that endothelium derived NO is released from the endothelium in response to increased shear stress causing a flowmediated dilatation $[8,9]$ and early reports pointed to a role for endothelium derived NO in flow-induced remodeling, [67, 68] Ceiler et al. provided strong evidence for a NO-independent mechanism for flow-induced outward remodeling. They observed that flow-induced resistance artery remodeling is not modified by chronic L-NAME treatment [21]. Potential roles of alternative endothelium-derived signals such as EDHF, myoendothelial coupling and EDCF in arterial remodeling have hardly been considered. We observed that chronic treatment with SOL1 did not restore flow-induced outward arterial remodeling, although it normalized endothelium-dependent relaxation in general and EDHF and EDCF in particular. This suggests that the latter two mechanisms do not play a major role in arterial structural responses and adds proof to our earlier suggestion that endothelium-dependent vasodilatation and -remodeling may be largely unrelated mechanisms [69]. In conclusion chronic NEP/ECE inhibition has no effects on blood 
Chapter 6

pressure nor on structure and structural responses of mesenteric resistance arteries from young SHR but reversed endothelial dysfunction by reducing EDCF- and improving EDHF-related reactivity. 
Arterial function and structure in young SHR

\section{Sources of funding:}

This study was performed within the framework of the Dutch Top Institute Pharma project: T2-108; Metalloproteases and Novel Targets in Endothelial Dysfunction 


\section{References}

[1] Vanhoutte PM, Shimokawa H, Tang EH, Feletou M. Endothelial dysfunction and vascular disease. Acta Physiol (Oxf) 2009; 196: 193-222.

[2] Furchgott RF, Vanhoutte PM. Endothelium-derived relaxing and contracting factors. FASEB J 1989; 3: 2007-18.

[3] Tang EH, Vanhoutte PM. Endothelial dysfunction: a strategic target in the treatment of hypertension? Pflugers Arch 2010; 459: 995-1004.

[4] Heagerty AM, Aalkjaer C, Bund SJ, Korsgaard N, Mulvany MJ. Small artery structure in hypertension. Dual processes of remodeling and growth. Hypertension 1993; 21: 391-7.

[5] Gluais P, Lonchampt M, Morrow JD, Vanhoutte PM, Feletou M. Acetylcholine-induced endothelium-dependent contractions in the SHR aorta: the Janus face of prostacyclin. Br J Pharmacol 2005; 146: 834-45.

[6] Mulvany MJ. Resistance vessel growth and remodelling: cause or consequence in cardiovascular disease. J Hum Hypertens 1995; 9: 479-85.

[7] Martinez-Lemus LA, Hill MA, Meininger GA. The plastic nature of the vascular wall: a continuum of remodeling events contributing to control of arteriolar diameter and structure. Physiology (Bethesda) 2009; 24: 45-57.

[8] Bellien J, Iacob M, Gutierrez L, et al. Crucial role of NO and endotheliumderived hyperpolarizing factor in human sustained conduit artery flowmediated dilatation. Hypertension 2006; 48: 1088-94.

[9] Sun D, Huang A, Yan EH, et al. Reduced release of nitric oxide to shear stress in mesenteric arteries of aged rats. Am J Physiol Heart Circ Physiol 2004; 286: H2249-56.

[10] Nelissen J, Heijnen B, Lemkens P, et al. Endothelin-1 and Calcitonin GeneRelated Peptide contribute to the developing hypertension in young spontaneously hypertensive rats. The FASEB Journal 2011; 25: 823.2.

[11] Yanagisawa M, Kurihara H, Kimura S, et al. A novel potent vasoconstrictor peptide produced by vascular endothelial cells. Nature 1988; 332: 411-5.

[12] Donckier JE, Michel L, Van Beneden R, Delos M, Havaux X. Increased expression of endothelin-1 and its mitogenic receptor ETA in human papillary thyroid carcinoma. Clin Endocrinol (Oxf) 2003; 59: 354-60.

[13] Ammarguellat F, Larouche I, Schiffrin EL. Myocardial fibrosis in DOCA-salt hypertensive rats: effect of endothelin ET(A) receptor antagonism. Circulation 2001; 103: 319-24.

[14] Saleh MA, Boesen EI, Pollock JS, Savin VJ, Pollock DM. Endothelin-1 increases glomerular permeability and inflammation independent of blood pressure in the rat. Hypertension 2010; 56: 942-9.

[15] Boldrini L, Pistolesi S, Gisfredi S, et al. Expression of endothelin 1 and its angiogenic role in meningiomas. Virchows Arch 2006; 449: 546-53.

[16] Sawamura T, Kimura S, Shinmi O, et al. Purification and characterization of putative endothelin converting enzyme in bovine adrenal medulla: evidence for a cathepsin D-like enzyme. Biochem Biophys Res Commun 1990; 168: 12306. 
[17] Nakano A, Kishi F, Minami K, et al. Selective conversion of big endothelins to tracheal smooth muscle-constricting 31-amino acid-length endothelins by chymase from human mast cells. J Immunol 1997; 159: 1987-92.

[18] Fernandez-Patron C, Radomski MW, Davidge ST. Vascular matrix metalloproteinase-2 cleaves big endothelin-1 yielding a novel vasoconstrictor. Circ Res 1999; 85: 906-11.

[19] Nelissen J, Lemkens P, Sann H, et al. Pharmacokinetic and pharmacodynamic properties of SOL1: A novel dual inhibitor of neutral endopeptidase and endothelin converting enzyme. Life Sci 2012.

[20] Kalk P, Sharkovska Y, Kashina E, et al. Endothelin-Converting Enzyme/Neutral Endopeptidase Inhibitor SLV338 Prevents Hypertensive Cardiac Remodeling in a Blood Pressure-Independent Manner. Hypertension 2011; 57: 755-63.

[21] Ceiler DL, De Mey JG. Chronic N(G)-nitro-L-arginine methyl ester treatment does not prevent flow-induced remodeling in mesenteric feed arteries and arcading arterioles. Arterioscler Thromb Vasc Biol 2000; 20: 2057-63.

[22] Buus CL, Pourageaud F, Fazzi GE, et al. Smooth muscle cell changes during flow-related remodeling of rat mesenteric resistance arteries. Circ Res 2001; 89: 180-6.

[23] Hilgers RH, Todd J, Jr., Webb RC. Regional heterogeneity in acetylcholineinduced relaxation in rat vascular bed: role of calcium-activated $\mathrm{K}+$ channels. Am J Physiol Heart Circ Physiol 2006; 291: H216-22.

[24] Wang Y, Wang DH. Prevention of endothelin-1-induced increases in blood pressure: role of endogenous CGRP. Am J Physiol Heart Circ Physiol 2004; 287: H1868-74.

[25] De Mey JG, Megens R, Fazzi GE. Functional antagonism between endogenous neuropeptide $\mathrm{Y}$ and calcitonin gene-related peptide in mesenteric resistance arteries. J Pharmacol Exp Ther 2008; 324: 930-7.

[26] Adeagbo AS, Triggle CR. Varying extracellular [K+]: a functional approach to separating EDHF- and EDNO-related mechanisms in perfused rat mesenteric arterial bed. J Cardiovasc Pharmacol 1993; 21: 423-9.

[27] Pourageaud F, De Mey JG. Structural properties of rat mesenteric small arteries after 4-wk exposure to elevated or reduced blood flow. Am J Physiol 1997; 273: H1699-706.

[28] Unthank JL, Nixon JC, Burkhart HM, Fath SW, Dalsing MC. Early collateral and microvascular adaptations to intestinal artery occlusion in rat. Am J Physiol 1996; 271: H914-23.

[29] Rizzoni D, Porteri E, Piccoli A, et al. Effects of losartan and enalapril on small artery structure in hypertensive rats. Hypertension 1998; 32: 305-10.

[30] Schiffrin EL. Vascular endothelin in hypertension. Vascul Pharmacol 2005; 43: 19-29.

[31] Montagnani M, Vulpis V, Nazzaro P, et al. Endothelin-1-receptor-mediated responses in resistance vessels of young and adult spontaneously hypertensive rats. J Hypertens 2000; 18: 893-900.

[32] Amiri F, Virdis A, Neves MF, et al. Endothelium-restricted overexpression of human endothelin-1 causes vascular remodeling and endothelial dysfunction. Circulation 2004; 110: 2233-40. 
[33] Touyz RM, Lariviere R, Schiffrin EL. Endothelin receptor subtypes in mesenteric vascular smooth muscle cells of spontaneously hypertensive rats. Can J Physiol Pharmacol 1995; 73: 1262-73.

[34] Dohi Y, Hahn AW, Boulanger CM, Buhler FR, Luscher TF. Endothelin stimulated by angiotensin II augments contractility of spontaneously hypertensive rat resistance arteries. Hypertension 1992; 19: 131-7.

[35] Kenny AJ, Bourne A, Ingram J. Hydrolysis of human and pig brain natriuretic peptides, urodilatin, C-type natriuretic peptide and some C-receptor ligands by endopeptidase-24.11. Biochem J 1993; 291 ( Pt 1): 83-8.

[36] Yandle TG, Brennan SO, Espiner EA, Nicholls MG, Richards AM. Endopeptidase-24.11 in human plasma degrades atrial natriuretic factor (ANF) to ANF(99-105/106-126). Peptides 1989; 10: 891-4.

[37] Katayama M, Nadel JA, Bunnett NW, et al. Catabolism of calcitonin generelated peptide and substance $\mathrm{P}$ by neutral endopeptidase. Peptides 1991; 12: 563-7.

[38] Harrap SB, Mirakian C, Datodi SR, Lever AF. Blood pressure and lifespan following brief ACE inhibitor treatment in young spontaneously hypertensive rats. Clin Exp Pharmacol Physiol 1994; 21: 125-7.

[39] Mulvany MJ. Resistance vessel abnormalities in spontaneously hypertensive rats. J Cardiovasc Pharmacol 1984; 6 Suppl 4: S656-65.

[40] Fu-Xiang D, Jameson M, Skopec J, Diederich A, Diederich D. Endothelial dysfunction of resistance arteries of spontaneously hypertensive rats. $\mathrm{J}$ Cardiovasc Pharmacol 1992; 20 Suppl 12: S190-2.

[41] Sharkovska Y, Kalk P, von Websky K, et al. Renoprotective effects of combined endothelin-converting enzyme/neutral endopeptidase inhibitor SLV338 in acute and chronic experimental renal damage. Clin Lab 2011; 57 : 507-15.

[42] Singh M, Mensah GA, Bakris G. Pathogenesis and clinical physiology of hypertension. Cardiol Clin 2010; 28: 545-59.

[43] Feletou M, Verbeuren TJ, Vanhoutte PM. Endothelium-dependent contractions in SHR: a tale of prostanoid TP and IP receptors. Br J Pharmacol 2009; 156: 563-74.

[44] Spijkers LJ, Janssen BJ, Nelissen J, et al. Antihypertensive treatment differentially affects vascular sphingolipid biology in spontaneously hypertensive rats. PLoS One 2011; 6: e29222.

[45] Spijkers LJ, van den Akker RF, Janssen BJ, et al. Hypertension is associated with marked alterations in sphingolipid biology: a potential role for ceramide. PLoS One 2011; 6: e21817.

[46] Luscher TF, Vanhoutte PM. Endothelium-dependent contractions to acetylcholine in the aorta of the spontaneously hypertensive rat. Hypertension 1986; 8: 344-8.

[47] Hoeffner U, Vanhoutte PM. Increases in flow reduce the release of endothelium-derived relaxing factor in the aorta of normotensive and spontaneously hypertensive rats. Am J Hypertens 1989; 2: 762-7.

[48] Yang D, Feletou M, Levens N, Zhang JN, Vanhoutte PM. A diffusible substance(s) mediates endothelium-dependent contractions in the aorta of SHR. Hypertension 2003; 41: 143-8. 
[49] Parsons SJ, Hill A, Waldron GJ, Plane F, Garland CJ. The relative importance of nitric oxide and nitric oxide-independent mechanisms in acetylcholineevoked dilatation of the rat mesenteric bed. Br J Pharmacol 1994; 113: 1275 80 .

[50] Hilgers RH, Janssen GM, Fazzi GE, De Mey JG. Twenty-four-hour exposure to altered blood flow modifies endothelial $\mathrm{Ca} 2+$-activated $\mathrm{K}+$ channels in rat mesenteric arteries. J Pharmacol Exp Ther 2010; 333: 210-7.

[51] Edwards G, Dora KA, Gardener MJ, Garland CJ, Weston AH. K+ is an endothelium-derived hyperpolarizing factor in rat arteries. Nature 1998; 396: 269-72.

[52] Ghiadoni L, Magagna A, Versari D, et al. Different effect of antihypertensive drugs on conduit artery endothelial function. Hypertension 2003; 41: 1281-6.

[53] Rehman A, Schiffrin EL. Vascular effects of antihypertensive drug therapy. Curr Hypertens Rep 2010; 12: 226-32.

[54] Agabiti-Rosei E, Porteri E, Rizzoni D. Arterial stiffness, hypertension, and rational use of nebivolol. Vasc Health Risk Manag 2009; 5: 353-60.

[55] Kitta Y, Obata JE, Nakamura T, et al. Persistent impairment of endothelial vasomotor function has a negative impact on outcome in patients with coronary artery disease. J Am Coll Cardiol 2009; 53: 323-30.

[56] Modena MG, Bonetti L, Coppi F, Bursi F, Rossi R. Prognostic role of reversible endothelial dysfunction in hypertensive postmenopausal women. $\mathrm{J}$ Am Coll Cardiol 2002; 40: 505-10.

[57] Bonetti PO, Lerman LO, Lerman A. Endothelial dysfunction: a marker of atherosclerotic risk. Arterioscler Thromb Vasc Biol 2003; 23: 168-75.

[58] Taddei S, Virdis A, Ghiadoni L, Sudano I, Salvetti A. Effects of antihypertensive drugs on endothelial dysfunction: clinical implications. Drugs 2002; 62: 265-84.

[59] Versari D, Daghini E, Virdis A, Ghiadoni L, Taddei S. Endothelial dysfunction as a target for prevention of cardiovascular disease. Diabetes Care 2009; 32 Suppl 2: S314-21.

[60] Gao YJ, Yang LF, Stead S, Lee RM. Flow-induced vascular remodeling in the mesenteric artery of spontaneously hypertensive rats. Can J Physiol Pharmacol 2008; 86: 737-44.

[61] Langille BL. Arterial remodeling: relation to hemodynamics. Can J Physiol Pharmacol 1996; 74: 834-41.

[62] Davies PF. Flow-mediated endothelial mechanotransduction. Physiol Rev 1995; 75: 519-60.

[63] Mulvany MJ. Small artery remodeling and significance in the development of hypertension. News Physiol Sci 2002; 17: 105-9.

[64] Bakker EN, van der Meulen ET, van den Berg BM, et al. Inward remodeling follows chronic vasoconstriction in isolated resistance arteries. J Vasc Res 2002; 39: 12-20.

[65] Bakker EN, Sorop O, Spaan JA, VanBavel E. Remodeling of resistance arteries in organoid culture is modulated by pressure and pressure pulsation and depends on vasomotion. Am J Physiol Heart Circ Physiol 2004; 286: H2052-6.

[66] Martinez-Lemus LA, Hill MA, Bolz SS, Pohl U, Meininger GA. Acute mechanoadaptation of vascular smooth muscle cells in response to continuous 
Chapter 6

arteriolar vasoconstriction: implications for functional remodeling. FASEB J 2004; 18: 708-10.

[67] Rudic RD, Shesely EG, Maeda N, et al. Direct evidence for the importance of endothelium-derived nitric oxide in vascular remodeling. J Clin Invest 1998; 101: 731-6.

[68] Tronc F, Wassef M, Esposito B, et al. Role of NO in flow-induced remodeling of the rabbit common carotid artery. Arterioscler Thromb Vasc Biol 1996; 16: 1256-62.

[69] De Mey JG, Schiffers PM, Hilgers RH, Sanders MM. Toward functional genomics of flow-induced outward remodeling of resistance arteries. Am J Physiol Heart Circ Physiol 2005; 288: H1022-7. 


\section{Chapter 7}

\section{Dual NEP/ECE Inhibition Improves Endothelial Function in Mesenteric Resistance Arteries of 32 week old SHR}

P. Lemkens, L. Spijkers, M. Meens, J. Nelissen, B. Janssen, S. Peters, P.M.H. Schiffers, JGR De Mey Hypertens Res. 2017 Mar 16. 


\begin{abstract}
Endothelin 1 (ET1), a potent vasoconstrictor, pro-mitogenic and pro-inflammatory peptide, may promote development of endothelial dysfunction and arterial remodeling. ET1 can be formed through cleavage of big-ET1 by endothelin converting enzyme (ECE) or neutral endopeptidase (NEP). We investigated whether chronic treatment with the novel dual NEP/ECE inhibitor SOL1 improves functional and structural properties of resistance-sized arteries of 32 week old male spontaneously hypertensive rats (SHR). SHR received chronic 4 week treatment with SOL1, losartan or hydralazine. We then compared effects of NOS-inhibition (100 $\mu \mathrm{M}$ L-NAME), blockade of $\mathrm{ET}_{\mathrm{A}^{-}}$and $\mathrm{ET}_{\mathrm{B}^{-}}$ receptors $(10 \mu \mathrm{M}$ bosentan) and stimulation of the endothelium with $0.001-10 \mu \mathrm{M}$ acetylcholine $(\mathrm{ACh})$ in isolated $3^{\text {rd }}$ order mesenteric resistance arteries. Losartan and hydralazine significantly lowered blood pressure. Losartan decreased the media to lumen ratio of resistance arteries. L-NAME (1) increased arterial contractile responses to $\mathrm{K}^{+}(5.9-40 \mathrm{mM})$ in the losartan, SOL1 and vehicle groups and (2) increased the sensitivity to phenylephrine (PHE) $(0.16-20 \mu \mathrm{M})$ in the SOL1 but not losartan, hydralazine or vehicle group. Relaxing responses to $\mathrm{ACh}$ in absence or presence of LNAME during contractions induced by either $10 \mu \mathrm{M}$ PHE or $40 \mathrm{mM} \mathrm{K}^{+}$were not altered by any in vivo treatment. Acute treatment with bosentan did however significantly improve maximal relaxing responses involving endothelium-derived nitric oxide and -hyperpolarizing factors in the SOL1 but not losartan, hydralazine or vehicle groups.
\end{abstract}

Thus, chronic inhibition of NEP/ECE improved basal endothelial function but did not alter blood pressure, resistance artery structure and stimulated endothelium-dependent relaxing responses in 32 week old SHR. 


\section{Introduction}

The endothelium can produce vasoactive compounds which influence the underlying layer of smooth muscle cells modulating vasomotor responses to control blood pressure and local blood flow. Endothelium-derived vasoactive factors include vasodilators such as nitric oxide (NO), endothelium-derived hyperpolarizing factors (EDHF) and prostacyclin but also vasoconstrictors such as endoperoxides and endothelin-1 (ET1).[1, 2] Endothelial dysfunction is classically described as i) an impairment of endotheliumdependent relaxing responses and ii) an enhanced sensitivity to vasoconstrictors. In many forms of human and experimental hypertension, endothelial dysfunction and arterial remodeling are considered key players in development and maintenance of high blood pressure.[3-5] In spontaneously hypertensive rats (SHR) a well-described manifestation of endothelial dysfunction is an increased production of endotheliumderived contractile factors (EDCF).[6]

Drug-intervention studies showed that some anti-hypertensive treatments, for instance with angiotensin $\mathrm{AT}_{1}$ receptor antagonists not only lower blood pressure but also cause an improvement of endothelial function and regression of structural changes in resistance arteries.[7, 8] Other anti-hypertensive treatments, for instance the selective $\beta_{1}$-adrenoceptor antagonist atenolol succeed in lowering blood pressure but do not reverse the structural changes or the endothelial dysfunction associated with hypertension. In other words, for reversing adverse effects associated with hypertension, lowering blood pressure alone is not sufficient.[9, 10]

Studies from our group showed that the level of the endothelium-derived peptide ET1 is increased in several organs during the development of hypertension in SHR, importantly the levels of ET1 is increased in several organs.[11] Apart from being a potent vasoconstrictor ET1 is also a potent growth promoting and pro-inflammatory agent.[12-16] Because of these actions, ET1 is of interest in the development of endothelial dysfunction and hypertension-related arterial remodeling. ET1 can be formed through cleavage of big-ET1 by endothelin converting enzyme (ECE). Alternatively big-ET1 can be hydrolyzed by chymase or matrix metalloproteinase 2 (MMP2) to form ET1 (1-31) or ET1 (1-32), respectively. Both are further processed into ET1 by neutral endopeptidase (NEP).[17-19] Thus a dual NEP/ECE inhibitor, for example the novel compound SOL1, reduces ET1 production by inhibiting all three pathways.[20] Recently, Kalk et al.[21] reported that the dual NEP/ECE inhibitor daglutril (SLV338, an analogue of SOL1) reduced cardiomyocyte hypertrophy, interstitial fibrosis and perivascular fibrosis in the 2-kidney 1-clip model of hypertension.

Here, we tested the hypothesis that ET1 contributes to endothelial dysfunction, arterial remodeling and hypertension in established essential hypertension. We therefore compared the effects of chronic treatment with the vasodilator hydralazine, the $\mathrm{AT}_{1}$ 
receptor antagonist losartan or the dual NEP/ECE inhibitor SOL1 on functional and structural properties of mesenteric resistance arteries from chronically hypertensive (32 week old) SHR.

\section{Materials and Methods}

\section{Animals, model and surgery}

28 week-old male SHR rats were obtained from Charles River (Maastricht, NL). All experiments were performed in accordance with the ethical committee for animal welfare of Maastricht University. The rats were anesthetized with isoflurane (1-4\%) and osmotic minipumps (2ML4 pumps, Alzet, Cupertino, CA, USA) were implanted subcutaneously for chronic continuous drug treatment during the next 4 weeks. Preliminary dose-finding experiments were carried out to identify an appropriate dose of the dual NEP/ECE inhibitor SOL1 (2-\{[1-(\{[(3S)-1-(carboxymethyl-2-oxo-2,3,4,5tetrahydro-1H-1-benzazepin-3-yl]amino carbonyl)cyclopentyl]methyl\}-4-[[3-

methylamino)propyl](methyl)amino]-4-oxobutanoic acid; Abbott). $50 \mathrm{mg} / \mathrm{kg}$.day decreased urinary ET1 content (from $32.89 \pm 3.91$ to $1.35 \pm 0.25 \mathrm{pg} / \mathrm{ml}, \mathrm{p}<0.001$ ). Losartan and hydralazine were administered at $20 \mathrm{mg} / \mathrm{kg}$.day and $9 \mathrm{mg} / \mathrm{kg}$.day, respectively. Additional hydralyzine was added to the drinking water because the maximal solubility of hydralazine was reached in saline, in order to keep the dose at 20 $\mathrm{mg} / \mathrm{kg}$.day. In untreated SHR, a dummy device (polyethylene (PE) tube of the same size as the 2ML4 pumps) was implanted subcutaneously.[22] Animals were randomly assigned to the treatment groups $(\mathrm{n}=8$ each).

At the end of the drug treatment blood pressure was measured in conscious unrestrained rats via a heparinized $(5 \mathrm{U} / \mathrm{ml})$ indwelling PE catheter that was introduced into the left femoral artery 2 days before measurement. The arterial catheter was connected to a pressure transducer (Micro Switch $150 \mathrm{PC}$ ) and its output was sampled at $2.5 \mathrm{kHz}$. Mean arterial pressure (MAP) was calculated using the IDEEQ data-acquisition system (instrument services, Maastricht University). All animals were euthanized with isoflurane $(>4 \%)$.

\section{Arterial pressure/diameter relationships}

Animals were euthanized and $1^{\text {st }}$ order mesenteric arteries were isolated. Arteries were mounted on two glass micropipettes in an organ chamber filled with Ca-free Krebs Ringer solution (144 mM NaCl, $4.7 \mathrm{mM} \mathrm{KCl}, 1.2 \mathrm{mM} \mathrm{MgSO}_{4}, 1.2 \mathrm{mM} \mathrm{KH_{2 }} \mathrm{PO}_{4}, 14.9$ $\mathrm{mM}$ HEPES, and $5.5 \mathrm{mM}$ glucose; $37^{\circ} \mathrm{C}, \mathrm{pH}$ 7.4). $10 \mu \mathrm{M}$ Na-nitroprusside (SNP) was added to ensure maximal vasodilatation. A pressure-diameter relationship was established by recording the lumen diameter while gradually increasing the distending pressure (20-120 mmHg, $10 \mathrm{mmHg}$ steps).[23] After the experiment, vessels were fixed 
at $80 \mathrm{mmHg}$ in $4 \%$ phosphate buffered formaldehyde solution for 1 hour at $37^{\circ} \mathrm{C}$ and stored in $70 \%$ ethanol.

\section{Wire Myography}

Third order mesenteric resistance arterial segments of approximately $2 \mathrm{~mm}$ in length were isolated and mounted in wire myographs for the recording of isometric force development.[24] From a portion of the arterial segments the endothelium was mechanically removed.[25] Each experiment started by progressively stretching the arterial segment to the diameter at which the largest contractile response to $10 \mu \mathrm{M}$ noradrenaline (NA) could be obtained (optimal diameter).

To prevent the sensory nerves from releasing calcitonin gene-related peptide (CGRP) when stimulated during potassium induced depolarizations, all arterial segments were exposed to capsaicin (1 $\mu \mathrm{M}$, during $20 \mathrm{~min})$.[26, 27] Viability of the endothelium was tested by measuring acetylcholine- $(\mathrm{ACh})(10 \mu \mathrm{M})$ induced relaxation during PHEinduced contraction. Contractile responses to increasing concentrations of $\mathrm{K}^{+}$(5.9-40 $\mathrm{mM})$ and PHE $(0.16-20 \mu \mathrm{M})$ and relaxing responses to increasing concentrations of ACh (0.01-10 $\mu \mathrm{M})$ were recorded. The effects of nitric oxide synthase inhibition (L-N $\mathrm{N}_{-}$ nitroarginine methyl ester [L-NAME], $100 \mu \mathrm{M}$ ), cyclo-oxygenase inhibition (indomethacin [INDO], $1 \mu \mathrm{M}$ ) and a non-selective ET-receptor antagonist (bosentan [BOS] $10 \mu \mathrm{M})$, were evaluated.

After these experiments, vessels were fixed in $4 \%$ phosphate buffered formaldehyde solution for 1 hour at $37^{\circ} \mathrm{C}$ and stored in $70 \%$ ethanol.

\section{Histological and morphometric analysis}

Fixed $1^{\text {st }}$ and $3^{\text {rd }}$ order arteries were embedded in paraffin and cross-sections $(4 \mu \mathrm{m})$ were cut. All vessels were stained with Lawson's solution (Boom, Meppel, The Netherlands) to visualize the internal and external elastic laminae. The cross-sectional area of the media (mCSA) was determined from the circumferences of the internal and external elastic laminae. The average number of nuclear profiles in the media was determined by counting on haematoxylin-eosin stained cross-sections. Media thickness and media to lumen ratio were calculated as previously described.[23]

\section{Physiological solutions and drugs}

The Krebs Ringer bicarbonate-buffered physiological salt solution (Krebs Ringer buffer [KRB]) that was continuously aerated with $95 \% \mathrm{O}_{2} / 5 \% \mathrm{CO}_{2}$ and maintained at $37^{\circ} \mathrm{C}$ contained (in $\mathrm{mM}$ ): $118.5 \mathrm{NaCl}, 4.7 \mathrm{KCl}, 2.5 \mathrm{CaCl}_{2}, 1.2 \mathrm{MgSO}_{4}, 1.2 \mathrm{KH}_{2} \mathrm{PO}_{4}, 25.0$ $\mathrm{NaHCO}_{3}$ and 5.5 glucose. Bosentan was obtained from Actelion Pharmaceuticals (Allschwil, Switzerland) and was dissolved in DMSO. Capsaicin and INDO were purchased from Sigma Aldrich (Zwijndrecht, the Netherlands) and dissolved in ethanol. 
ACh, NA and PHE were purchased from Sigma and dissolved in KRB. High $\mathrm{K}^{+}-\mathrm{KRB}$ solution was $\mathrm{KRB}$ in which all $\mathrm{NaCl}$ was replaced by $\mathrm{KCl}$. Solutions containing 10-40 $\mathrm{mM} \mathrm{K}{ }^{+}$were prepared by mixing volumes of $\mathrm{KRB}$ and $\mathrm{K}^{+}-\mathrm{KRB}$.

\section{Statistical analysis}

All contractile responses were expressed as a percentage of the maximal NA response prior to the administration of any pharmacological inhibitor. Individual concentrationresponse curves were fitted to a non-linear sigmoid regression curve (Graphpad Prism 5.0; La Jolla, CA, USA). Sensitivity $\left(\mathrm{pEC}_{50}\right)$ and maximal effect $\left(\mathrm{E}_{\max }\right)$ are shown as mean \pm SEM. Two-way ANOVAs were used to compare $\mathrm{pEC}_{50}$ or $\mathrm{E}_{\max }$. A Bonferroni post-test was used to compare multiple groups. Morphology and pressure-diameter relations are expressed as means \pm SEM. Statistical significance of differences between groups was evaluated by ANOVA (for consecutive measurements in pressure-diameter curves) or 1-way ANOVA followed by Bonferroni or paired t-test (Graphpad Prism 5.0). A value of $P<0.05$ was considered to denote a statistically significant difference.

\section{Results}

\section{General and arterial structural characteristics}

Body weights were not significantly altered by any treatment. MAP was significantly reduced by losartan and hydralazine treatment. It tended to be reduced by SOL1 but this did not reach statistical significance (Table 7.1).

Lumen diameter at $80 \mathrm{mmHg}$ and $\mathrm{mCSA}$ of $1^{\text {st }}$ order mesenteric resistance arteries were comparable in vehicle, SOL1, losartan and hydralazine treated animals. Media to lumen ratio of $1^{\text {st }}$ order mesenteric arteries was not altered in the SOL1 and hydralazine groups and was significantly decreased in the losartan group (Table 7.1). Optimal diameter of $3^{\text {rd }}$ order MrAs was reduced by chronic treatment with losartan but was not affected by the other drugs. mCSA and media to lumen ratio of $3^{\text {rd }}$ order mesenteric resistance arteries were comparable in vehicle, SOL1, losartan and hydralazine treated animals. The maximal contractile response to NA was not altered in the losartan and hydralazine groups and tended to be increased in the SOL1 treated group (Table 7.1). 


\begin{tabular}{|c|c|c|c|c|}
\hline & Vehicle & SOL1 & Losartan & Hydralazine \\
\hline Body weight (g) & $353 \pm 7$ & $362 \pm 8$ & $366 \pm 6$ & $356 \pm 9$ \\
\hline MAP (mmHg) & $191 \pm 7$ & $172 \pm 3$ & $125 \pm 5 *$ & $113 \pm 14 *$ \\
\hline $\begin{array}{c}\text { Diameter } 1^{\text {st }} \text { order } \\
(\mu \mathrm{m})\end{array}$ & $373 \pm 21$ & $369 \pm 17$ & $397 \pm 19$ & $398 \pm 14$ \\
\hline $\operatorname{mCSA}\left(10^{3} \mu \mathrm{m}^{2}\right)$ & $30 \pm 3$ & $26 \pm 2$ & $24 \pm 3$ & $28 \pm 3$ \\
\hline Media to lumen ratio & $\begin{array}{c}0.184 \pm \\
0.014\end{array}$ & $\begin{array}{c}0.164 \pm \\
0.006\end{array}$ & $\begin{array}{c}0.144 \pm 0.008 \\
*\end{array}$ & $\begin{array}{c}0.150 \pm \\
0.012\end{array}$ \\
\hline $\mathrm{NCC}$ & $55 \pm 3$ & $47 \pm 2$ & $49 \pm 1$ & $52 \pm 3$ \\
\hline $\begin{array}{c}\text { Diameter } 3^{\text {rd }} \text { order } \\
(\mu \mathrm{m})\end{array}$ & $273 \pm 8$ & $282 \pm 10$ & $244 \pm 10 *$ & $288 \pm 7$ \\
\hline Active Tension $(\mathrm{N} / \mathrm{m})$ & $4.91 \pm 0.43$ & $5.55 \pm 0.45$ & $4.65 \pm 0.22$ & $4.44 \pm 0.37$ \\
\hline $\operatorname{mCSA}\left(10^{3} \mu \mathrm{m}^{2}\right)$ & $13 \pm 1$ & $14 \pm 1$ & $11 \pm 1$ & $13 \pm 1$ \\
\hline Media to lumen ratio & $\begin{array}{c}0.115 \pm \\
0.005\end{array}$ & $0.140 \pm 0.02$ & $0.109 \pm 0.004$ & $\begin{array}{c}0.109 \pm \\
0.004\end{array}$ \\
\hline
\end{tabular}

Table 7.1: General and arterial structural characteristics of $1^{\text {st }}$ and $3^{\text {rd }}$ order mesenteric resistance arteries. Abbreviations: MAP, mean arterial pressure; mCSA, Cross sectional area of the media; NCC, cell count of the media (nuclear profiles). Results are depicted as mean \pm SEM. *: $P<0.05$ treatment versus Vehicle.

\section{Effects of chronic treatments on $K^{+}$-induced arterial contractions}

In $3^{\text {rd }}$ order mesenteric arteries, the $\mathrm{pEC}_{50}$ and $\mathrm{E}_{\max }$ of $\mathrm{K}^{+}$-induced contraction did not differ between treatment groups (Figure 7.1, Table 7.2). L-NAME did not modify the $\mathrm{pEC}_{50}$ but increased $\mathrm{E}_{\max }$ in all groups (saline: $72.3 \pm 3.8 \%$ to $83.3 \pm 3.0 \%$; SOL1: 61.7 $\pm 5.5 \%$ to $78.9 \pm 4.4 \%$; losartan: $67.9 \pm 4.1 \%$ to $77.3 \pm 3.0 \%$; hydralazine: $66.3 \pm 2.2 \%$ to $84.7 \pm 4.8 \%$ ).

Endothelial denudation or bosentan $\left(10 \mu \mathrm{M}\right.$, non-selective $\mathrm{ET}_{\mathrm{A} / \mathrm{B}}$ antagonist $)$ did not alter $\mathrm{K}^{+}$-induced contractile responses (Table 7.2). In denuded arteries of all four treatment groups, L-NAME did not increase $\mathrm{K}^{+}$-induced contractions either (Figure 7.1, Table 7.2). 

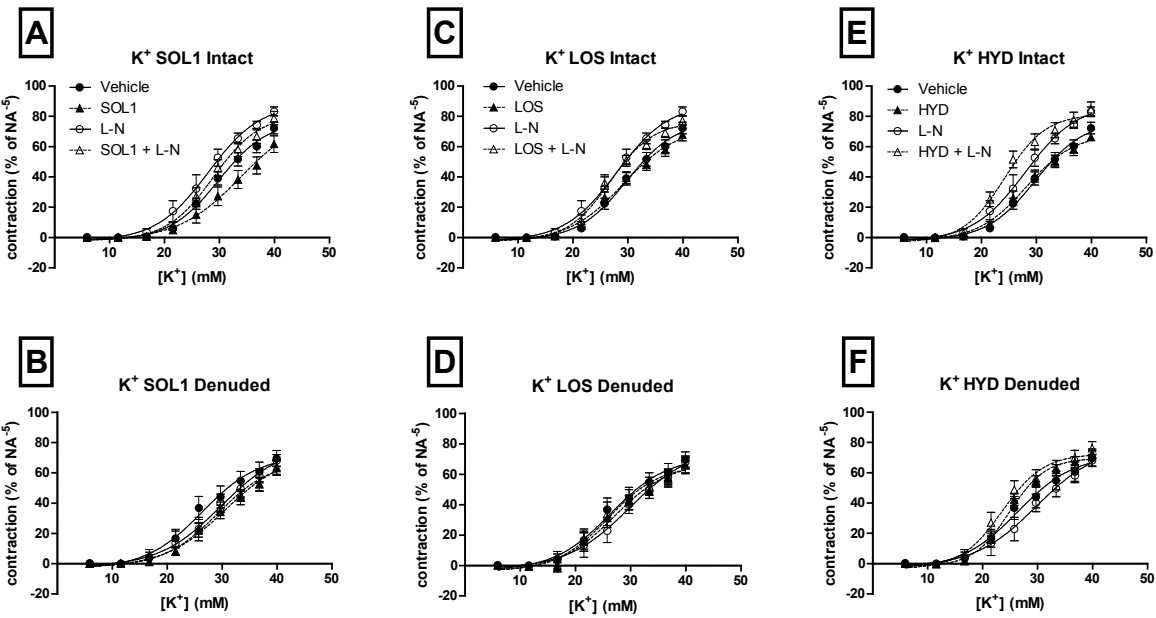

Figure 7.1: $\mathbf{K}^{+}$-induced contractile responses in intact $(\mathrm{A}+\mathrm{C}+\mathrm{E})$ and denuded $(\mathrm{B}+\mathrm{D}+\mathrm{F})$ arteries in presence of vehicle (all panels, solid lines and closed circles), SOL1 (A + B, dotted lines and closed triangles), losartan $(\mathrm{C}+\mathrm{D}$, dotted lines and closed triangles) or hydralazine $(\mathrm{C}+\mathrm{D}$, dotted lines and closed triangles). Open symbols: in the presence of L-NAME (L-N).

\begin{tabular}{cccccc}
\hline & & Vehicle & SOL-1 & Losartan & Hydralazine \\
\hline \multirow{2}{*}{ Control } & $\mathrm{pEC}_{50}$ & $1.52 \pm 0.03$ & $1.43 \pm 0.10$ & $1.52 \pm 0.03$ & $1.53 \pm 0.03$ \\
\cline { 2 - 6 } & $\mathrm{E}_{\max }$ & $72.3 \pm 3.8$ & $61.7 \pm 5.5$ & $67.9 \pm 4.1$ & $66.3 \pm 2.2$ \\
\hline \multirow{2}{*}{+ L-NAME } & $\mathrm{pEC}_{50}$ & $1.55 \pm 0.02$ & $1.53 \pm 0.02$ & $1.57 \pm 0.01$ & $1.60 \pm 0.01$ \\
\cline { 2 - 6 } & $\mathrm{E}_{\max }$ & $83.3 \pm 3.0 \#$ & $78.9 \pm 4.4 \#$ & $77.3 \pm 3.0$ & $84.71 \pm 4.8 \#$ \\
\hline
\end{tabular}

Table 7.2: Amplitude of contraction is expressed as \% of the maximal response to NA. Results are shown as mean \pm SEM. *: $P<0.05$ without versus with $L-N A M E$.

\section{Effects of chronic treatments on phenylephrine-induced contractile responses}

Sensitivity to PHE was significantly reduced by treatment with SOL1 or losartan ( $\mathrm{pEC}_{50}$, vehicle: $5.69 \pm 0.03$, SOL1: $5.53 \pm 0.02$; losartan: $5.50 \pm 0.05$ ) but increased by treatment with hydralazine $\left(\mathrm{pEC}_{50}\right.$ : hydralazine: $\left.5.90 \pm 0.03\right)$. L-NAME significantly increased the sensitivity to PHE in intact arteries of SOL1 treated animals $(5.75 \pm 0.02)$ but had no effect in arteries from vehicle, losartan or hydralazine treated groups. Similarly, mechanical removal of the endothelium increased the sensitivity to PHE in SOL1 treated animals $\left(\mathrm{pEC}_{50}: 5.68 \pm 0.07\right)$ but not in the vehicle, losartan or hydralazine treated groups. L-NAME had no effects in denuded arteries (Figure 7.2, Table 7.3). 
Bosentan decreased the sensitivity to PHE in arteries of SOL1 treated SHR in absence and presence of L-NAME (-L-NAME: $5.35 \pm 0.03$; + L-NAME: $5.65 \pm 0.02$ ). No effects of bosentan on PHE-induced contractile responses were observed in the vehicle, losartan or hydralazine treated groups. Maximal responses to PHE were not modified by the chronic drug treatments and were not altered by L-NAME, bosentan or endothelium removal (Figure 7.2, Table 7.3).
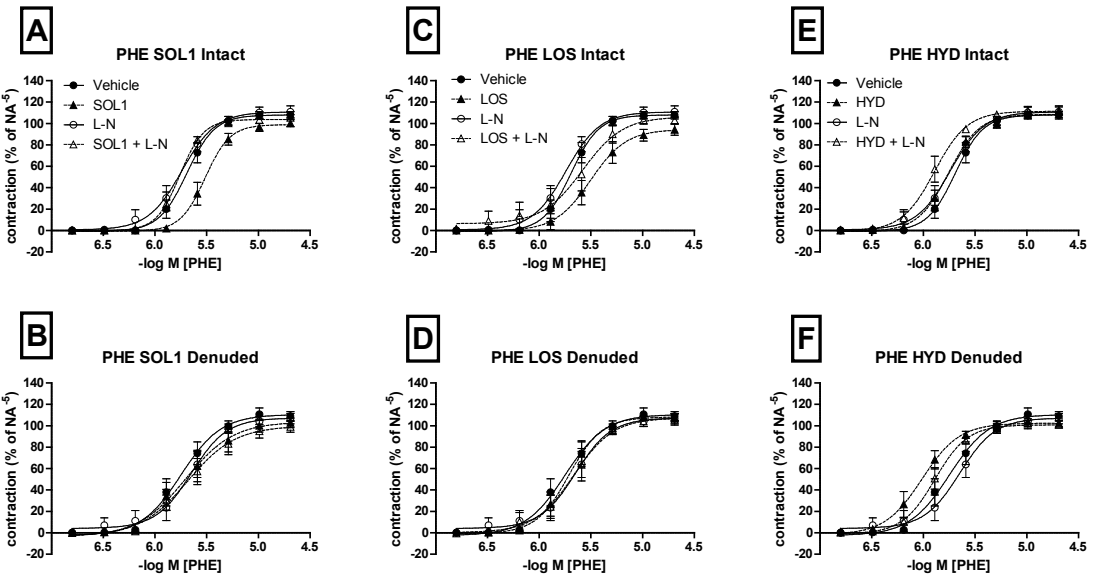

Figure 7.2: Contractile responses to PHE in intact $(\mathrm{A}+\mathrm{C}+\mathrm{E})$ and denuded $(\mathrm{B}+\mathrm{D}+\mathrm{F})$ arteries with vehicle (all panels, solid lines and closed circles), SOL1 (A + B, dotted lines and closed triangles), losartan $(C+D$, dotted lines and closed triangles) or hydralazine $(C+D$, dotted lines and closed triangles). Open symbols: in presence of L-NAME (L-N).

\begin{tabular}{cccccc}
\hline & & Vehicle & SOL-1 & Losartan & Hydralazine \\
\hline \multirow{2}{*}{ Control } & $\mathrm{pEC}_{50}$ & $5.69 \pm 0.02$ & $5.54 \pm 0.03 *$ & $5.50 \pm 0.05 *$ & $5.90 \pm 0.03 *$ \\
\cline { 2 - 6 } & $\mathrm{E}_{\max }(\%)$ & $107.9 \pm 3.5$ & $100.3 \pm 3.2$ & $94.3 \pm 5.3$ & $110.9 \pm 2.7$ \\
\hline \multirow{2}{*}{+ L-NAME } & $\mathrm{pEC}_{50}$ & $5.71 \pm 0.04$ & $5.75 \pm 0.02 \#$ & $5.58 \pm 0.08$ & $5.75 \pm 0.02$ \\
\cline { 2 - 6 } & $\mathrm{E}_{\max }(\%)$ & $111.0 \pm 5.5$ & $105.4 \pm 3.2$ & $103.0 \pm 3.3$ & $112.0 \pm 3.3$ \\
\hline
\end{tabular}

Table 7.3: $\mathrm{pEC}_{50}$ and $\mathrm{E}_{\max }$ as measured during PHE-induced contractile responses. Results are depicted as mean \pm SEM. * $\mathrm{P}<0.05$ treatment versus Vehicle, \# : $\mathrm{P}<0.05$ without versus with $\mathrm{L}-\mathrm{NAME}$.

\section{Effects of chronic NEP/ECE inhibition and anti-hypertensive treatments on arterial responses to acetylcholine}

To assess endothelium-dependent responses, arteries were contracted with PHE and exposed to increasing concentrations of ACh $(0.001-10 \mu \mathrm{M})$. In $3^{\text {rd }}$ order mesenteric resistance arteries of 32 week old $\mathrm{SHR}, \mathrm{pEC}_{50}$ and $\mathrm{E}_{\max }$ to $\mathrm{ACh}$-induced relaxations did 


\section{Chapter 7}

not differ significantly between treatment groups (Figure 7.3A). Notable, $\mathrm{E}_{\max }$ tended to be decreased by chronic hydralazine treatment and tended to be increased by chronic losartan and SOL1 treatment. Maximal responses to ACh were not modified by acute bosentan administration (slight increase) (Figure $7.3 \mathrm{~A}, \mathrm{~B}$ ). However, $\mathrm{E}_{\max }$ to ACh induced relaxations were significantly increased in all groups by acute INDO administration (Figure 7.3 A, B, C, D). This effect is due to reduction by the COX inhibitor of the contractile response observed with high concentrations of ACh. 
凹

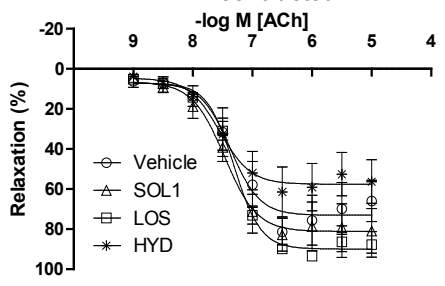

c

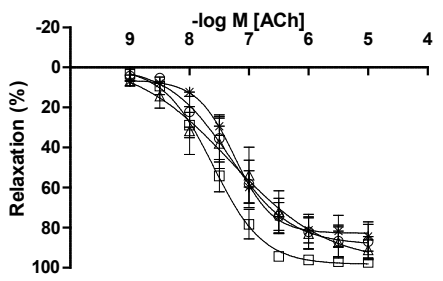

E PHE contracted + INDO + L-NAME

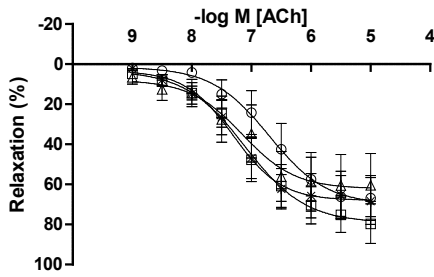

G

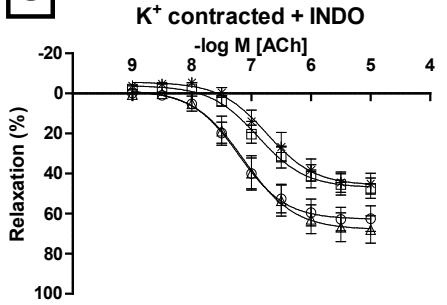

B

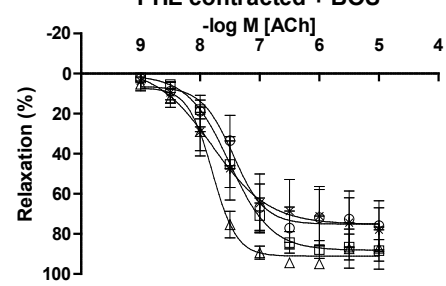

D

PHE contracted + INDO + BOS

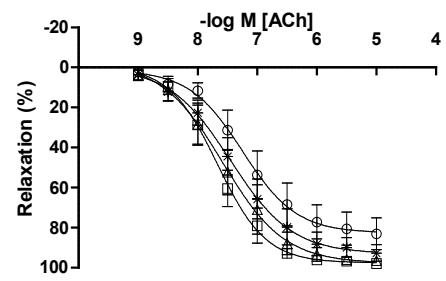

$F$

FHE contracted + INDO + L-NAME + BOS

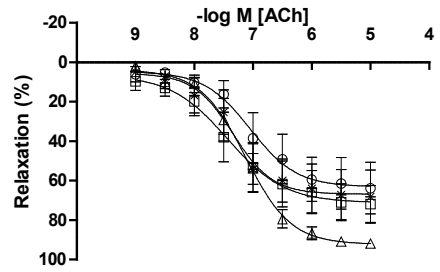

$\mathrm{H}$

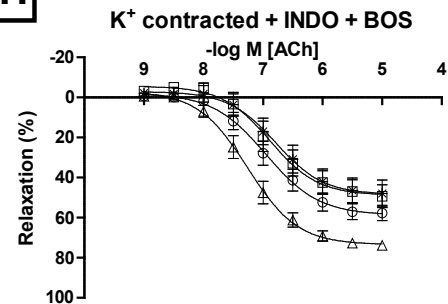

Figure 7.3: Relaxing responses of mesenteric resistance arteries of SHR to ACh in absence or presence of INDO. The top panels depict responses in absence and presence of INDO and absence $(A, C)$ and presence (B, D) of bosentan (BOS) with vehicle (open circles), SOL1 (open triangles), losartan (open squares) or hydralazine (open diamonds). The middle panels depict responses to ACh during PHEinduced contractions in presence of INDO and L-NAME (EDHF-related responses) in absence (E) and presence (F) of bosentan The bottom panels depict responses to $\mathrm{ACh}$ during $\mathrm{K}^{+}$-induced contraction in presence of INDO, in absence $(G)$ and presence $(\mathrm{H})$ of bosentan (EDNO-related responses). 


\begin{tabular}{|c|c|c|c|c|c|c|}
\hline & & & Vehicle & SOL1 & Losartan & Hydralazine \\
\hline \multirow{4}{*}{ EDNO } & \multirow{2}{*}{ Control } & $\mathrm{pEC}_{50}$ & $7.18 \pm 0.15$ & $7.11 \pm 0.18$ & $6.89 \pm 0.12$ & $6.71 \pm 0.13$ \\
\hline & & $E_{\max }(\%)$ & $62.6 \pm 6.4$ & $68.0 \pm 6.8$ & $47.4 \pm 5.1$ & $45.1 \pm 5.2$ \\
\hline & \multirow{2}{*}{ Bosentan } & $\mathrm{pEC}_{50}$ & $6.95 \pm 0.11$ & $7.22 \pm 0.08$ & $6.88 \pm 0.15$ & $6.78 \pm 0.20$ \\
\hline & & $\mathrm{E}_{\max }(\%)$ & $58.4 \pm 4.3$ & $71.0 \pm 3.4 *$ & $49.4 \pm 5.7$ & $48.0 \pm 6.7$ \\
\hline \multirow{4}{*}{ EDHF } & \multirow{2}{*}{ Control } & $\mathrm{pEC}_{50}$ & $6.72 \pm 0.28$ & $7.14 \pm 0.39$ & $7.04 \pm 0.19$ & $7.31 \pm 0.25$ \\
\hline & & $E_{\max }(\%)$ & $66.9 \pm 11.2$ & $60.43 \pm 15.8$ & $79.8 \pm 8.9$ & $68.4 \pm 11.7$ \\
\hline & \multirow{2}{*}{ Bosentan } & $\log \mathrm{EC}_{50}$ & $7.04 \pm 0.27$ & $7.13 \pm 0.10$ & $7.43 \pm 0.31$ & $7.31 \pm 0.25$ \\
\hline & & $\mathrm{E}_{\max }(\%)$ & $63.9 \pm 13.1$ & $91.86 \pm 2.0 *$ & $71.9 \pm 9.4$ & $68.1 \pm 13.1$ \\
\hline
\end{tabular}

Table 7.4: $\mathrm{pEC}_{50}$ and $\mathrm{E}_{\max }$ of the relaxing response induced by increasing concentrations of acetylcholine. Abbreviations: EDNO, endothelium-derived nitric oxide (precontraction with $40 \mathrm{mM}$ $\mathrm{K}^{+}$); EDHF, endothelium-derived hyperpolarizing factor (precontraction with $20 \mu \mathrm{M} \mathrm{PHE}$ in presence of L-NAME). Results are depicted as mean \pm SEM. *: $\mathrm{P}<0.05$ treatment versus Vehicle.

\section{Effects of chronic NEP/ECE inhibition and anti-hypertensive treatments on EDHF- related arterial responses}

To assess the contribution of EDHF to $\mathrm{ACh}(0.001-10 \mu \mathrm{M})$ induced relaxing responses, arteries were contracted with PHE $(20 \mu \mathrm{M})$ in presence of INDO (to prevent formation of vasodilator and vasoconstrictor prostaglandins) and L-NAME (to prevent involvement of NO). Obviously, the remaining ACh-induced response was mediated by EDHF.

Sensitivity and maximal responses did not differ significantly between groups. Bosentan significantly increased maximal EDHF-type responses in SOL1 treated $(57.0 \pm 13.1 \%$ to $91.9 \pm 2.0 \%$ ) but not vehicle, losartan or hydralazine treated animals. In presence of bosentan maximal EDHF-type responses were significantly larger in SOL1 treated animals compared to vehicle $(63.9 \pm 13.1 \%$ to $91.9 \pm 2.0 \%)$ (Figure $7.3 \mathrm{E}$ and F; Table 7.4).

\section{Effects of chronic NEP/ECE inhibition and anti-hypertensive treatments on arterial responses to endothelium-derived $\mathrm{NO}$}

To investigate the contribution of $\mathrm{NO}$ to ACh-induced $(0.001-10 \mu \mathrm{M})$ relaxing responses, arteries contracted with $40 \mathrm{mM} \mathrm{K}^{+}$in presence of INDO (to prevent formation of vasodilator and vasoconstrictor prostaglandins). A high extracellular $\mathrm{K}^{+}$ concentration effectively prevents EDHF-related responses.[28] The remaining AChinduced response was abolished in presence of L-NAME and was thus considered to be due to endothelium-derived NO (EDNO). Sensitivity and maximal responses did not 
differ significantly between groups. The maximal ACh-induced EDNO response in presence of bosentan was increased in SOL1-treated versus vehicle-treated animals $(58.4 \pm 4.2 \%$ to $71.0 \pm 3.4 \%)$ and unaltered in losartan or hydralazine treated groups (Figure $7.3 \mathrm{G}$ and $\mathrm{H}$; Table 7.4).

\section{Discussion}

This study demonstrates that chronic SOL1 treatment can restore several aspects of endothelial function, even though an effect on blood pressure was minimal. In contrast more classic antihypertensive drugs such as losartan or hydralazine were both effective in lowering blood pressure but had little to no effect on endothelial dysfunction even though losartan succeeded in partly reversing the resistance artery structural changes associated with hypertension.

ET1 is involved in the pathophysiology of experimental and clinical pulmonary hypertension, chronic renal failure and heart failure. The situation in essential hypertension is, however, less clear.[29] In SHR, the role of the renin-angiotensin system is well established.[30] A potential role of the endothelin system in the arterial functional and structural changes is, however, less clear.[31] Montagnani et al. reported that while there is no difference in ET1-induced contractions between 5 week old SHR and WKY, they noted a marked increase in ET1-induced contractile responses in 12 week old SHR.[32] Furthermore, our group reported increased levels of ET1 in several organs of 8 and 12 week old SHR.[11] This points to a transient upregulation of the endothelin system during the development of hypertension. ET1 is not only a very potent vasoconstrictor[12] but is also a pro-inflammatory agent[15], has mitogenic effects on vascular smooth muscle cells[13], is pro-angiogenic[16], pro-oxidant[33] and promotes fibrosis.[14] Moreover, endothelium restricted overexpression of ET1 causes vascular remodeling and endothelial dysfunction in the absence of a hemodynamic effect.[33] The pro-oxidant and pro-inflammatory functions might, at least in some forms of hypertension, be more important than the pressor effect. Because of the aforementioned functions, the ET1 system emerges as a potential target for normalizing functional and structural arterial properties associated with hypertension.

We tested the hypothesis that ET1 contributes to endothelial dysfunction, arterial remodeling and hypertension in 32 week-old SHR. To evaluate this we treated adult SHR with the dual NEP/ECE inhibitor SOL1 that effectively decreases big-ET1 to ET1 conversion[34] and compared the effects with a four week treatment with an AT1 receptor antagonist (losartan) and a four week treatment with a vasodilator (hydralazine). Decreasing ET1 production might be helpful in conditions where either the intravascular levels of ET1 and/or the vascular effects of the peptide are increased.[32, 35-37] Moreover, inhibiting NEP might have added beneficial value by chronically inhibiting breakdown of other vasoactive peptides such as natriuretic 
peptides and CGRP.[38-41] We investigated both structural and functional effects of SOL1 in mesenteric resistance arteries.

ET1 has been shown to contribute to remodeling of large and small arteries in hypertension. Hypertrophic remodeling rather than eutrophic remodeling of resistance arteries seems to occur in models associated with an upregulated ET system suggesting that ET1 system upregulation leads to vascular hypertrophy.[42]

In the current study we observed no significant change in diameter, media thickness, cross sectional area of the media, nuclear cell count or media to lumen ratio in $1^{\text {st }}$ order mesenteric resistance arteries of 32 week old SHR caused by reducing blood pressure by means of a 4 week treatment with a vasodilator (hydralazine). This means that a decrease in blood pressure alone cannot reverse structural changes in these arteries. These observations are in line with earlier reports.[43-45]

Chronic losartan treatment did not cause a significant increase in diameter or decrease in cross sectional area of the media, nuclear cell count in $1^{\text {st }}$ order mesenteric arteries of SHR. These arteries do however show a decrease in media to lumen ratio. Despite differences in experimental design and treatment timing our findings are similar to earlier reports from other groups.[8, 43, 44, 46] Studies with chronic AT1 receptor antagonists have shown that treatment for a longer period than four weeks are superior in establishing beneficial effects on vascular remodeling.[47]

In contrast to chronic losartan treatment SOL1 treatment was not successful in reducing blood pressure or arterial structural changes. The absence of an anti-hypertensive effect is in line with observations made by Kalk et al. who did not observe a blood pressure reduction with daglutril (SLV338; a SOL1 analogue)[21] in the 2-kidney 1-clip model. Similarly Sharkovska et al. did not observe a blood pressure reduction with daglutril in rats chronically treated with L-NAME.[48] Also, as with losartan, a 4 week treatment with the NEP/ECE inhibitor might have been too short to fully correct structural changes in resistance arteries.

To assess arterial and endothelial function and the effects of a chronic SOL1 treatment we investigated $3^{\text {rd }}$ order mesenteric resistance arteries in vitro. Functional properties of resistance sized arteries are often altered in hypertension in relation to dysfunctional endothelium. Endothelial dysfunction is frequently regarded as a reduced bioavailability or function of EDNO, blunted EDHF responses and hypersensitivity to vasoconstrictors.[49] In SHR, specifically EDCFs are described as a manifestation of endothelial dysfunction and these EDCF-mediated contractions in response to stimulation of the artery with ACh are fully inhibited by a cyclo-oxygenase inhibitor (INDO). In 32 week old SHR investigated in this study, a moderate EDCF component was observed. The prostanoids $\mathrm{PGH}_{2}, \mathrm{PGI}_{2}$ and thromboxane $\mathrm{A}_{2}\left(\mathrm{TXA}_{2}\right)$ have been suggested to be responsible for increased vascular tone in hypertension. [50] Recently Spijkers et al. reported endothelium-dependent contractions due to increased $\mathrm{TXA}_{2}$ 
release in arteries of SHR. Moreover they observed an increased expression of COX-1 in smooth muscle cells of SHR compared to Wister Kyoto rats (WKY) and an increased expression of $\mathrm{iPLA}_{2}$ (substrate delivery to COX-1) and $\mathrm{TXA}_{2}$-synthase in the endothelium of SHR compared to WKY.[22, 51] In the present study, the EDCF response (indicated by a reduced maximal relaxing response to $\mathrm{ACh}$ ) was abolished by cyclo-oxygenase inhibition and moderately inhibited by acute ET-receptor antagonism and by chronic losartan or SOL1 treatment.

No effects of hydralazine, losartan or SOL1 were observed on arterial smooth contractile responses to $\mathrm{K}^{+}$-induced depolarization. Sensitivity to smooth muscle activation was similar in all groups. Except for the hydralazine treated animals there was no effect of L-NAME on $\mathrm{pEC}_{50}$ or $\mathrm{E}_{\max }$. Normally $\mathrm{NO}$ synthase inhibition causes a leftward shift in the concentration-response curve and an increased maximal response.[52] These effects are absent in the arteries investigated in this study, meaning that the NO production under basal conditions (e.g. without agonist-induced stimulation) is blunted. None of the treatments could restore the L-NAME induced leftward shift and only hydralazine restored the increase in maximal contraction induced by L-NAME.

A similar L-NAME-induced leftward shift can be expected on PHE-induced concentration-response curves.[25, 52] Again, this shift was completely absent in vehicle, losartan or hydralazine treated groups. After 4 weeks of chronic dual NEP/ECE inhibition, however, L-NAME caused a significant leftward shift. This can be considered an improvement of basal endothelial function because to some extent chronic SOL1 treatment succeeds in restoring basal NO production. The molecular mechanism of this effect of 4 week treatment with the NEP/ECE inhibitor might involve changes in the dimerization and phosphorylation of endothelial NO synthase, but this remains to be established.[53]

In this study, the agonist-induced EDNO-type responses were not significantly altered by any of the chronic treatments. Surprisingly, acute administration of the non selective $\mathrm{ET}_{\mathrm{A} / \mathrm{B}}$ receptor antagonist bosentan improved the maximal EDNO-type responses in SOL1 treated animals. This might indicate that intra-arterial production of ET1 is rapidly restored in vitro after wash out of the ECE/NEP inhibitor that had been administered for 4 weeks. Another EDRF, EDHF causes endothelial hyperpolarization with subsequent vascular smooth muscle cell hyperpolarization. The contribution of EDHF is most marked in small arteries.[24, 54] In mesenteric resistance arteries this response is blocked by depolarization with high extracellular $\left[\mathrm{K}^{+}\right]$or inhibitors of endothelial small- and intermediate-conductance calcium-activated $\mathrm{K}^{+}$channels. [24, 28 , 55, 56] EDHF-type responses were not significantly affected by SOL1, losartan or hydralazine treatment. Acute administration of the non selective $\mathrm{ET}_{\mathrm{A} / \mathrm{B}}$ receptor antagonist bosentan improved the maximal EDHF-type relaxing responses in SOL1 treated animals. This means that both EDNO- and EDHF-type responses in the SOL1 
treated group were improved by acute ET-receptor antagonism. Because SOL1 is easily removed from organs,[20] conversion of big-ET1 to ET1 may recommence before endothelial function is investigated. Subsequently, ET1 might impair endotheliumderived relaxing responses through a similar myo-endothelial coupling mechanism as proposed by Hilgers and De Mey.[25] This might explain the acute bosentan effect on the EDHF response in the SOL1-treated animals.

In conclusion, chronic treatment with an $\mathrm{AT}_{1}$ receptor antagonist in 32 week old SHR caused regression of the changes in arterial structure and a significant lowering of the blood pressure. Chronic dual NEP/ECE inhibition, on the other hand, caused an improvement of several aspects of endothelial function. While the effects of losartan and SOL1 are different, they could be considered beneficial in both instances. A combination of an $\mathrm{AT}_{1}$ receptor antagonist, or alternatively an $\mathrm{ACE}$ inhibitor, with a dual NEP/ECE inhibitor could provide superior results and might be subject of future studies. Triple vasopeptidase (ACE/ECE/NEP) inhibitors are becoming available (for review [57]) and deserve detailed investigation in terms of anti-hypertensive effects and restoration of structural and endothelial properties in resistance arteries. 
Arterial Function and Structure in 32 Week old SHR

\section{Sources of funding:}

This study was performed within the framework of the Dutch Top Institute Pharma project: T2-108; Metalloproteases and Novel Targets in Endothelial Dysfunction 


\section{References}

[1] Vanhoutte PM, Shimokawa H, Tang EH, Feletou M. Endothelial dysfunction and vascular disease. Acta Physiol (Oxf) 2009; 196: 193-222.

[2] Furchgott RF, Vanhoutte PM. Endothelium-derived relaxing and contracting factors. FASEB J 1989; 3: 2007-18.

[3] Tang EH, Vanhoutte PM. Endothelial dysfunction: a strategic target in the treatment of hypertension? Pflugers Arch 2010; 459: 995-1004.

[4] Heagerty AM, Aalkjaer C, Bund SJ, Korsgaard N, Mulvany MJ. Small artery structure in hypertension. Dual processes of remodeling and growth. Hypertension 1993; 21: 391-7.

[5] Gluais P, Lonchampt M, Morrow JD, Vanhoutte PM, Feletou M. Acetylcholine-induced endothelium-dependent contractions in the SHR aorta: the Janus face of prostacyclin. Br J Pharmacol 2005; 146: 834-45.

[6] Mulvany MJ. Resistance vessel growth and remodelling: cause or consequence in cardiovascular disease. J Hum Hypertens 1995; 9: 479-85.

[7] Martinez-Lemus LA, Hill MA, Meininger GA. The plastic nature of the vascular wall: a continuum of remodeling events contributing to control of arteriolar diameter and structure. Physiology (Bethesda) 2009; 24: 45-57.

[8] Bellien J, Iacob M, Gutierrez L, et al. Crucial role of NO and endotheliumderived hyperpolarizing factor in human sustained conduit artery flowmediated dilatation. Hypertension 2006; 48: 1088-94.

[9] Sun D, Huang A, Yan EH, et al. Reduced release of nitric oxide to shear stress in mesenteric arteries of aged rats. Am J Physiol Heart Circ Physiol 2004; 286: H2249-56.

[10] Nelissen J, Heijnen B, Lemkens P, et al. Endothelin-1 and Calcitonin GeneRelated Peptide contribute to the developing hypertension in young spontaneously hypertensive rats. The FASEB Journal 2011; 25: 823.2.

[11] Yanagisawa M, Kurihara H, Kimura S, et al. A novel potent vasoconstrictor peptide produced by vascular endothelial cells. Nature 1988; 332: 411-5.

[12] Donckier JE, Michel L, Van Beneden R, Delos M, Havaux X. Increased expression of endothelin-1 and its mitogenic receptor ETA in human papillary thyroid carcinoma. Clin Endocrinol (Oxf) 2003; 59: 354-60.

[13] Ammarguellat F, Larouche I, Schiffrin EL. Myocardial fibrosis in DOCA-salt hypertensive rats: effect of endothelin ET(A) receptor antagonism. Circulation 2001; 103: 319-24.

[14] Saleh MA, Boesen EI, Pollock JS, Savin VJ, Pollock DM. Endothelin-1 increases glomerular permeability and inflammation independent of blood pressure in the rat. Hypertension 2010; 56: 942-9.

[15] Boldrini L, Pistolesi S, Gisfredi S, et al. Expression of endothelin 1 and its angiogenic role in meningiomas. Virchows Arch 2006; 449: 546-53.

[16] Sawamura T, Kimura S, Shinmi O, et al. Purification and characterization of putative endothelin converting enzyme in bovine adrenal medulla: evidence for a cathepsin D-like enzyme. Biochem Biophys Res Commun 1990; 168: 12306. 
[17] Nakano A, Kishi F, Minami K, et al. Selective conversion of big endothelins to tracheal smooth muscle-constricting 31-amino acid-length endothelins by chymase from human mast cells. J Immunol 1997; 159: 1987-92.

[18] Fernandez-Patron C, Radomski MW, Davidge ST. Vascular matrix metalloproteinase-2 cleaves big endothelin-1 yielding a novel vasoconstrictor. Circ Res 1999; 85: 906-11.

[19] Nelissen J, Lemkens P, Sann H, et al. Pharmacokinetic and pharmacodynamic properties of SOL1: A novel dual inhibitor of neutral endopeptidase and endothelin converting enzyme. Life Sci 2012.

[20] Kalk P, Sharkovska Y, Kashina E, et al. Endothelin-Converting Enzyme/Neutral Endopeptidase Inhibitor SLV338 Prevents Hypertensive Cardiac Remodeling in a Blood Pressure-Independent Manner. Hypertension 2011; 57: 755-63.

[21] Ceiler DL, De Mey JG. Chronic N(G)-nitro-L-arginine methyl ester treatment does not prevent flow-induced remodeling in mesenteric feed arteries and arcading arterioles. Arterioscler Thromb Vasc Biol 2000; 20: 2057-63.

[22] Buus CL, Pourageaud F, Fazzi GE, et al. Smooth muscle cell changes during flow-related remodeling of rat mesenteric resistance arteries. Circ Res 2001; 89: 180-6.

[23] Hilgers RH, Todd J, Jr., Webb RC. Regional heterogeneity in acetylcholineinduced relaxation in rat vascular bed: role of calcium-activated $\mathrm{K}+$ channels. Am J Physiol Heart Circ Physiol 2006; 291: H216-22.

[24] Wang Y, Wang DH. Prevention of endothelin-1-induced increases in blood pressure: role of endogenous CGRP. Am J Physiol Heart Circ Physiol 2004; 287: H1868-74.

[25] De Mey JG, Megens R, Fazzi GE. Functional antagonism between endogenous neuropeptide $\mathrm{Y}$ and calcitonin gene-related peptide in mesenteric resistance arteries. J Pharmacol Exp Ther 2008; 324: 930-7.

[26] Adeagbo AS, Triggle CR. Varying extracellular $[\mathrm{K}+]$ : a functional approach to separating EDHF- and EDNO-related mechanisms in perfused rat mesenteric arterial bed. J Cardiovasc Pharmacol 1993; 21: 423-9.

[27] Pourageaud F, De Mey JG. Structural properties of rat mesenteric small arteries after 4-wk exposure to elevated or reduced blood flow. Am J Physiol 1997; 273: H1699-706.

[28] Unthank JL, Nixon JC, Burkhart HM, Fath SW, Dalsing MC. Early collateral and microvascular adaptations to intestinal artery occlusion in rat. Am J Physiol 1996; 271: H914-23.

[29] Rizzoni D, Porteri E, Piccoli A, et al. Effects of losartan and enalapril on small artery structure in hypertensive rats. Hypertension 1998; 32: 305-10.

[30] Schiffrin EL. Vascular endothelin in hypertension. Vascul Pharmacol 2005; 43: 19-29.

[31] Montagnani M, Vulpis V, Nazzaro P, et al. Endothelin-1-receptor-mediated responses in resistance vessels of young and adult spontaneously hypertensive rats. J Hypertens 2000; 18: 893-900.

[32] Amiri F, Virdis A, Neves MF, et al. Endothelium-restricted overexpression of human endothelin-1 causes vascular remodeling and endothelial dysfunction. Circulation 2004; 110: 2233-40. 
[33] Touyz RM, Lariviere R, Schiffrin EL. Endothelin receptor subtypes in mesenteric vascular smooth muscle cells of spontaneously hypertensive rats. Can J Physiol Pharmacol 1995; 73: 1262-73.

[34] Dohi Y, Hahn AW, Boulanger CM, Buhler FR, Luscher TF. Endothelin stimulated by angiotensin II augments contractility of spontaneously hypertensive rat resistance arteries. Hypertension 1992; 19: 131-7.

[35] Kenny AJ, Bourne A, Ingram J. Hydrolysis of human and pig brain natriuretic peptides, urodilatin, C-type natriuretic peptide and some C-receptor ligands by endopeptidase-24.11. Biochem J 1993; 291 ( Pt 1): 83-8.

[36] Yandle TG, Brennan SO, Espiner EA, Nicholls MG, Richards AM. Endopeptidase-24.11 in human plasma degrades atrial natriuretic factor (ANF) to ANF(99-105/106-126). Peptides 1989; 10: 891-4.

[37] Katayama M, Nadel JA, Bunnett NW, et al. Catabolism of calcitonin generelated peptide and substance $\mathrm{P}$ by neutral endopeptidase. Peptides 1991; 12: 563-7.

[38] Harrap SB, Mirakian C, Datodi SR, Lever AF. Blood pressure and lifespan following brief ACE inhibitor treatment in young spontaneously hypertensive rats. Clin Exp Pharmacol Physiol 1994; 21: 125-7.

[39] Mulvany MJ. Resistance vessel abnormalities in spontaneously hypertensive rats. J Cardiovasc Pharmacol 1984; 6 Suppl 4: S656-65.

[40] Fu-Xiang D, Jameson M, Skopec J, Diederich A, Diederich D. Endothelial dysfunction of resistance arteries of spontaneously hypertensive rats. J Cardiovasc Pharmacol 1992; 20 Suppl 12: S190-2.

[41] Sharkovska Y, Kalk P, von Websky K, et al. Renoprotective effects of combined endothelin-converting enzyme/neutral endopeptidase inhibitor SLV338 in acute and chronic experimental renal damage. Clin Lab 2011; 57 : 507-15.

[42] Singh M, Mensah GA, Bakris G. Pathogenesis and clinical physiology of hypertension. Cardiol Clin 2010; 28: 545-59.

[43] Feletou M, Verbeuren TJ, Vanhoutte PM. Endothelium-dependent contractions in SHR: a tale of prostanoid TP and IP receptors. Br J Pharmacol 2009; 156: 563-74.

[44] Spijkers LJ, Janssen BJ, Nelissen J, et al. Antihypertensive treatment differentially affects vascular sphingolipid biology in spontaneously hypertensive rats. PLoS One 2011; 6: e29222.

[45] Spijkers LJ, van den Akker RF, Janssen BJ, et al. Hypertension is associated with marked alterations in sphingolipid biology: a potential role for ceramide. PLoS One 2011; 6: e21817.

[46] Luscher TF, Vanhoutte PM. Endothelium-dependent contractions to acetylcholine in the aorta of the spontaneously hypertensive rat. Hypertension 1986; 8: 344-8.

[47] Hoeffner U, Vanhoutte PM. Increases in flow reduce the release of endothelium-derived relaxing factor in the aorta of normotensive and spontaneously hypertensive rats. Am J Hypertens 1989; 2: 762-7.

[48] Yang D, Feletou M, Levens N, Zhang JN, Vanhoutte PM. A diffusible substance(s) mediates endothelium-dependent contractions in the aorta of SHR. Hypertension 2003; 41: 143-8. 
[49] Parsons SJ, Hill A, Waldron GJ, Plane F, Garland CJ. The relative importance of nitric oxide and nitric oxide-independent mechanisms in acetylcholineevoked dilatation of the rat mesenteric bed. Br J Pharmacol 1994; 113: 1275 80 .

[50] Hilgers RH, Janssen GM, Fazzi GE, De Mey JG. Twenty-four-hour exposure to altered blood flow modifies endothelial $\mathrm{Ca} 2+$-activated $\mathrm{K}+$ channels in rat mesenteric arteries. J Pharmacol Exp Ther 2010; 333: 210-7.

[51] Edwards G, Dora KA, Gardener MJ, Garland CJ, Weston AH. K+ is an endothelium-derived hyperpolarizing factor in rat arteries. Nature 1998; 396: 269-72.

[52] Ghiadoni L, Magagna A, Versari D, et al. Different effect of antihypertensive drugs on conduit artery endothelial function. Hypertension 2003; 41: 1281-6.

[53] Rehman A, Schiffrin EL. Vascular effects of antihypertensive drug therapy. Curr Hypertens Rep 2010; 12: 226-32.

[54] Agabiti-Rosei E, Porteri E, Rizzoni D. Arterial stiffness, hypertension, and rational use of nebivolol. Vasc Health Risk Manag 2009; 5: 353-60.

[55] Kitta Y, Obata JE, Nakamura T, et al. Persistent impairment of endothelial vasomotor function has a negative impact on outcome in patients with coronary artery disease. J Am Coll Cardiol 2009; 53: 323-30.

[56] Modena MG, Bonetti L, Coppi F, Bursi F, Rossi R. Prognostic role of reversible endothelial dysfunction in hypertensive postmenopausal women. $\mathrm{J}$ Am Coll Cardiol 2002; 40: 505-10.

[57] Bonetti PO, Lerman LO, Lerman A. Endothelial dysfunction: a marker of atherosclerotic risk. Arterioscler Thromb Vasc Biol 2003; 23: 168-75.

[58] Taddei S, Virdis A, Ghiadoni L, Sudano I, Salvetti A. Effects of antihypertensive drugs on endothelial dysfunction: clinical implications. Drugs 2002; 62: 265-84.

[59] Versari D, Daghini E, Virdis A, Ghiadoni L, Taddei S. Endothelial dysfunction as a target for prevention of cardiovascular disease. Diabetes Care 2009; 32 Suppl 2: S314-21.

[60] Gao YJ, Yang LF, Stead S, Lee RM. Flow-induced vascular remodeling in the mesenteric artery of spontaneously hypertensive rats. Can J Physiol Pharmacol 2008; 86: 737-44.

[61] Langille BL. Arterial remodeling: relation to hemodynamics. Can J Physiol Pharmacol 1996; 74: 834-41.

[62] Davies PF. Flow-mediated endothelial mechanotransduction. Physiol Rev 1995; 75: 519-60.

[63] Mulvany MJ. Small artery remodeling and significance in the development of hypertension. News Physiol Sci 2002; 17: 105-9.

[64] Bakker EN, van der Meulen ET, van den Berg BM, et al. Inward remodeling follows chronic vasoconstriction in isolated resistance arteries. J Vasc Res 2002; 39: 12-20.

[65] Bakker EN, Sorop O, Spaan JA, VanBavel E. Remodeling of resistance arteries in organoid culture is modulated by pressure and pressure pulsation and depends on vasomotion. Am J Physiol Heart Circ Physiol 2004; 286 : H2052-6.

[66] Martinez-Lemus LA, Hill MA, Bolz SS, Pohl U, Meininger GA. Acute mechanoadaptation of vascular smooth muscle cells in response to continuous 
Chapter 7

arteriolar vasoconstriction: implications for functional remodeling. FASEB J 2004; 18: 708-10.

[67] Rudic RD, Shesely EG, Maeda N, et al. Direct evidence for the importance of endothelium-derived nitric oxide in vascular remodeling. J Clin Invest 1998; 101: 731-6.

[68] Tronc F, Wassef M, Esposito B, et al. Role of NO in flow-induced remodeling of the rabbit common carotid artery. Arterioscler Thromb Vasc Biol 1996; 16: 1256-62.

[69] De Mey JG, Schiffers PM, Hilgers RH, Sanders MM. Toward functional genomics of flow-induced outward remodeling of resistance arteries. Am J Physiol Heart Circ Physiol 2005; 288: H1022-7. 


\section{Chapter 8 \\ General Discussion}




\section{General discussion}

High blood pressure can be due to an increase in cardiac output, peripheral resistance or both. In most cases of human and experimental established hypertension cardiac output is unaltered and therefore peripheral resistance is the main contributor to the high blood pressure $[1,2]$. Because of its specific ability to produce several vasoactive compounds, the endothelium is an important regulator of vascular function and structure especially in resistance sized arteries, the main arteries that determine peripheral resistance [3, 4]. The 21 amino acid bicyclic peptide endothelin-1 (ET1) is one of these endotheliumderived vasoactive compounds that can also be produced by a variety of other cell types under pathological conditions [5]. The endothelin axis has been implicated in several forms of human and experimental hypertension [6-10]. Apart from being a potent vasoconstrictor, ET1 is also a potent growth promoting and pro-inflammatory agent [5, 11-14]. These functions provide several paths to an increase in vascular resistance for example by persistent vasoconstriction, hypersensitization to other vasoconstrictor systems, inward remodeling, increased arterial stiffness, inflammation, etc. ET1 can be formed through cleavage of big-ET1 (ET1 (1-38)) by endothelin converting enzyme (ECE). Alternatively big-ET1 can be hydrolyzed by chymase or MMP2 to form ET1 (131) and ET1 (1-32) respectively. Both are further processed into ET1 by neutral endopeptidase (NEP) [15-17]. Thus a dual NEP/ECE inhibitor potentially reduces ET1 production by inhibiting all three pathways.

Vascular (endothelial) function and structure in experimental hypertension were the subject of this thesis. We focused on the endothelin system in resistance arteries and investigated dual NEP/ECE inhibition as a treatment option.

\section{Endothelial dysfunction}

In Chapter 2 we studied vasomotor responses to monitor activity of components of the eNOS/sGC/PKG pathway in 6 week old WKY and SHR. At this age no statistically significant changes in vasomotor responses to NO-synthase blockade, an endothelium dependent vasodilator and a NO-donor were observed between mesenteric resistance arteries of the hypertensive (HT) and the normotensive (NT) strain. In 12 week old SHR, vasomotor responses were significantly altered compared to age-matched NT WKY (Chapter 6). This is in line with observations of others [18, 19]. The dysfunction is most apparent in the upregulation of the EDCF (endothelium-derived contractile factor) response and an impairement of the EDHF (endothelium-derived hyperpolarizing factor) response. The EDNO (endothelium-derived nitric oxide) function is largely unaffected (Chapters 6 and 7) as reported earlier [20-22]. The major portion of the blood pressure increase in SHR occurs between 8 and 12 weeks of age [23-25]. Interestingly, ET1 levels are also elevated in several organs at 8 and 12, but not 6 weeks of age [26] suggesting that ET1 contributes to the development of high blood pressure and endothelial dysfunction in these rats. In 32 weeks old SHR (Chapter 7) 
largely similar observations were made. One peculiar observation in this study was that NO synthase inhibition did not cause a leftward shift of the concentration response curves for contractile stimuli. The lack of a leftward shift as observed in 32 week old SHR was not observed in 6 week (Chapter 2) and 12 week (Chapter 6) old SHR. Although these arteries did not show an impairment of the ACh-induced relaxation responses, the myoendothelial activation of the NO system, observed with contractile stimuli in NT animals, was severely impaired in HT SHR.

We also investigated endothelium-dependent vasomotor function in a non genetic model of hypertension, the DOCA-salt HT rat (Chapter 4). While this model is generally described as a model showing increased endothelin levels [27-29] we did not observe increases in ET1 content in the thoracic aorta, the epigastric artery or mesenteric arteries. Also no significant changes in ACh-induced relaxing responses were observed. Similar to the old SHR (Chapter 7) we did observe a decreased effect of NO synthase inhibition on PHE-induced contractions. An even more striking observation is that the effect of arterial smooth muscle activation is partially inhibited by the dual $\mathrm{ET}_{\mathrm{A} / \mathrm{B}}$ receptor antagonist bosentan. A large portion of this effect could be mimicked by inhibiting ET1 production through NEP/ECE inhibition. These effects were absent after mechanical removal of the endothelium and are thus endothelium-dependent. This implies that activating the arterial smooth muscle prompts (possibly through myoendothelial gap junctions) the endothelium to produce and release ET1 which will further activate the arterial smooth muscle. With a radio immuno assay we showed that stimulation of the smooth muscle with high potassium, increased ET1 levels in mesenteric resistance arteries of DOCA-salt HT but not NT animals. Moreover the effects of ET receptor antagonism and NEP/ECE inhibitors on arterial smooth muscle activation were not observed in normotensive rats nor SHR (Chapter 2, 6 and 7), so they appear to be specific to the DOCA-salt hypertension.

The existence of heterocellular myoendothelial gap-junctions is well described [30-33]. Through these gap-junctions small ions and molecules can travel from endothelial cells to vascular smooth muscle cells and vice versa. One example is the conductance of endothelium derived hyperpolarizing factors through these myoendothelial gapjunctions $[34,35]$. Our group previously reported that even during vasoconstriction, a signal can originate in the vascular smooth muscle cells and prompt the endothelium to synthesize endothelium derived vasoactive factors [35, 36]. The report of Hilgers and De Mey strongly suggested that arterial smooth muscle can promote endotheliumdependent contraction through gap junctions and ET1, especially when endothelial nitric oxide synthesis is impaired or inhibited [35]. Our results show that in DOCA-salt HT rats, inhibition of NO synthase is not necessary to promote the release of ET1 from the endothelium (Chapter 4). 


\section{Resistance artery remodeling}

In arteries, wall shear stress and circumferential wall stress are homeostatically controlled by vasomotor and structural changes of lumen diameter and wall thickness [37-39]. For example, the acute response to an increase in shear stress consists of a reduction of the contractile activity of the vascular smooth muscle cells (vasodilatation; [40-42]). The response to a chronic increase in blood flow involves increases of the structural lumen diameter and of the arterial wall mass (outward hypertrophic remodeling; [38, 43-45]). Flow-induced vasodilatation and remodeling are both endothelium-dependent $[37,43,46]$. The transition from the acute vasomotor responses to the chronic structural responses is poorly understood. Also the effect of endothelial dysfunction (in hypertension) on the ability of mesenteric resistance arteries to respond to changes in shear stress is poorly characterized.

In this thesis two different types of arterial remodeling were addressed. First we will discuss the arterial remodeling in hypertension (hypertension-related arterial remodeling). Next we will discuss arterial remodeling as caused by flow modifying surgery (flow-related arterial remodeling).

\section{Hypertension-related resistance artery remodeling}

In Chapter 2 we concentrated on the possible effects on arterial structure of a HT genotype before high blood pressure develops (6 week old SHR). At this age the lumen diameters of mesenteric arteries of SHR and WKY were nearly identical.

In Chapter 6 we described that the diameter and the cross sectional area of $1^{\text {st }}$ order mesenteric resistance arteries of 12 week old SHR and age matched WKY are comparable. These findings are similar to the findings of Gao et al. [47]. They are however at variance with observation made by Mulvany et al. [48]. This group did however use $3^{\text {rd }}$ order mesenteric arteries from 20 week old SHR which might explain the discrepancy. Although arterial structure in 12 week old SHR is not changed we did observe a significant increase in blood pressure. In other words, in these rats, HT had no major effects on arterial structure of $1^{\text {st }}$ order mesenteric arteries. We do however observe a substantial increase in resistance arterial stiffness in the HT compared to the NT animals. The arterial stiffness could easily contribute to the high blood pressure. Several groups report no change in arterial stiffness in 6 week old SHR and increased arterial stiffness at 12 and 20 weeks [49-53] and that at least in the aorta, hypertension is preceded by increased arterial stiffness [51].

In Chapter 5 we observed hypertension related hypertrophic arterial remodeling after 3 and 6 weeks of DOCA-salt HT and an increase in arterial stiffness similar to the arterial stiffness observed in SHR (Chapter 6). An increase in lumen diameter was observed after 3 weeks of HT but not after 6 weeks. Reports from other groups lean more to an unaltered or decreased diameter in this model.[29, 54] This discrepancy might be 
because of differences in experimental design and strain differences. A possible explanation for the increase in diameter after 3 weeks of HT is that in this experimental model a rise in blood pressure might be preceded or accompanied by an increase in blood flow in certain arterial beds. Shimamoto et al. described that blood flow in the superior mesenteric artery of DOCA-salt HT rats increased $70 \%$ [55]. The combination of increased shear stress caused by increased blood flow and increased circumferential wall stress caused by increased blood pressure might explain the unusual structural adaptation.

While outward remodeling is generally not observed in models of hypertension, hypertrophic remodeling is often witnessed especially in models of secondary hypertension [56]. ET1 has been shown to contribute to the hypertension-related remodeling of large and small arteries[57, 58]. Hypertrophic remodeling rather than eutrophic inward remodeling of resistance arteries seems to occur in models associated with an upregulated endothelin system suggesting that ET1-system upregulation leads to vascular hypertrophy [29]. Moreover we observed a clear and transient inflammation in arteries of DOCA-salt HT rats (Chapter 5). The important role of inflammation in remodeling of resistance arteries in this model of hypertension has been previously described by Ko et al.[59] and is probably a consequence of the pro-inflammatory action of ET1 $[60,61]$. It is however striking that while we did measure an important endothelin component in SHR within the timeframe we investigated as evidenced by tissue content [26], no hypertrophic or pro-inflammatory effects were observed. We suspect that in these animals counterbalancing vasoactive systems (for example CGRP) are able to 'mask' or counteract at least the hypertrophic and pro-inflammatory effects of ET1 (Figure 8.1).
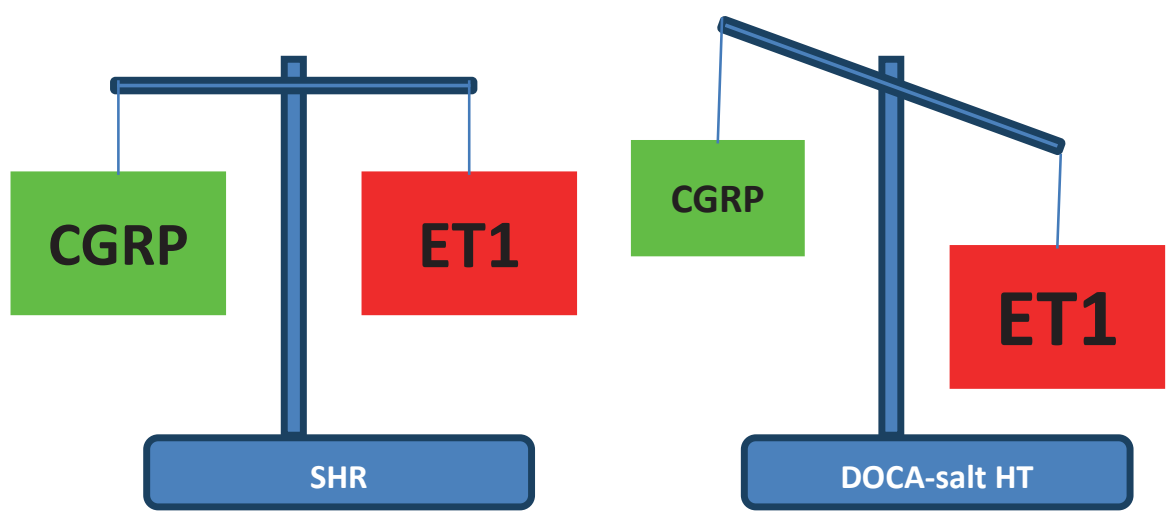

Figure 8.1: Representation of a possible balance for vasoactive peptides in SHR (left) and DOCA-salt HT. 


\section{Flow related resistance artery remodeling}

Because the endothelium functions as an important shear stress sensor, and shear stress is one of the driving forces in arterial structural responses [37-39, 43, 62, 63], it may be hypothesized that in arteries that show endothelial dysfunction, flow related arterial remodeling is modified as well. At least in two different experimental models (SHR [47] and obese Zucker rats [64]) this proposal was previously confirmed. In another experimental model (chronic L-NAME treatment, [65]) flow related arterial remodeling was, however, unaltered.

In Chapters 2, 5 and 6 we applied a widely used mesenteric resistance artery ligation model in order to impose increased or decreased shear stress levels on these arteries in vivo.

In both young WKY and young SHR, increased (HF) and reduced (LF) blood flow ultimately lead to outward hypertrophic and inward hypotrophic remodeling, respectively [38, 44, 45, 63, 65-69]. Both structural responses involve marked changes in gene expression and in cellular turnover and differentiation [63,69] which are preceded by a rapid and transient transcriptional response of a comparatively small number of genes [68].

In mesenteric resistance arteries of young WKY rats we observed a concurrent down regulation of eNOS, sGC $\alpha 1$ and PKG1 $\beta$ gene expressions in arteries exposed to reduced blood flow and in arteries exposed to increased blood flow for 24 hours (Chapter 2). This suggests a more general response aiming to create an intermediate state to facilitate the tissue to restore stresses independent of the direction of the remodeling. Protein expression of TSP1 was increased in LF mesenteric arteries. Observations in young SHR were largely similar to those made in WKY.

The upregulation of TSP1 in LF mesenteric arteries of both WKY and SHR suggests that TSP1 contributes to a de-adhesive state facilitating structural changes. TSP1 is a large matricellular protein with many functions. The ability of the hepI peptide sequence of TSP1 to signal cellular de-adhesion is in this instance particularly interesting [70]. This sequence of TSP1 binds to the receptor co-complex of calreticulin/LRP1 and stimulates focal adhesion disassembly and increased cell migration [70-73]. To evaluate a possible contribution of TSP1 to small artery remodeling, arteries were exposed to the hepI peptide sequence in vitro [74]. A distending pressure, but no vasomotor tone was present during culture allowing the hepI induced de-adhesive state to result in outward arterial remodeling. That 3 days of exposure to hepI increased diameter without altering arterial distensibility contributes to the suggestion that the remodeling resulted from a de-adhesive state rather than from major changes in the extracellular matrices. 
Mesenteric resistance arteries of 12 week old WKY respond to increases and decreases in blood flow, by outward hypertrophic and inward hypotrophic remodeling, respectively (Chapter 6). This is in line with several earlier reports, [38, 44, 45, 63, 65 69]. Mesenteric arteries of 12 week old SHR however show significantly different flow related arterial remodeling responses (Chapter 6). The response to a decrease in flow is comparable to the response observed in WKY. Mesenteric arteries of SHR however show an impaired outward remodeling response when subjected to increased flow in vivo.

Outward remodeling as a response to increased flow was also impaired in DOCA-salt HT rats (Chapter 5). The inward remodeling response when subjected to decreased flow was preserved in this model. The pro-inflammatory phenotype however did in some instances lead to massive hypertrophy and hyperplasia in these arteries. After six weeks of hypertension this was accompanied by formation of vasa vasorum-like structures in the adventitial layer proximal to the suture.

While arterial remodeling responses in different rat models cannot be generalized, common observations in both hypertension models are an impaired outward remodeling response and an increase in arterial stiffness. Restoring the ability to respond to increased shear stress and reducing arterial stiffness might be of (pharmaco-)therapeutic significance. In Chapters 5, 6 and 7 we evaluated the potential usefulness of dual $\mathrm{NEP} / \mathrm{ECE}$ inhibition in this respect.

\section{Effects of dual NEP/ECE inhibition}

In Chapter 3 we describe the peculiar molecular pharmacology of the ET receptor type $\mathrm{A}\left(\mathrm{ET}_{\mathrm{A}}\right)$. ET1 binds tightly to the $\mathrm{ET}_{\mathrm{A}}$ receptor and causes long-lasting effects. In resistance arteries, the long-lasting contractile effects can only be partly and reversibly relaxed by low-molecular-weight $\mathrm{ET}_{\mathrm{A}}$ antagonists (ERAs). This provides an explanation as to why clinical trials with ERAs were not as successful as anticipated [75-77].

A different approach to prevent ET1-induced effects is by preventing the production of ET1. As mentioned before dual NEP/ECE inhibition has the potential to effectively reduce ET1 levels by inhibiting several pathways of ET1 production (Figure 8.2). Both enzymes are structurally similar matrix metalloproteases with diverse effects on several vasoactive compounds (see Figure 1.6). Reducing active ET1 levels has potential beneficial effects on endothelial (arterial) function as well as on arterial structure. 


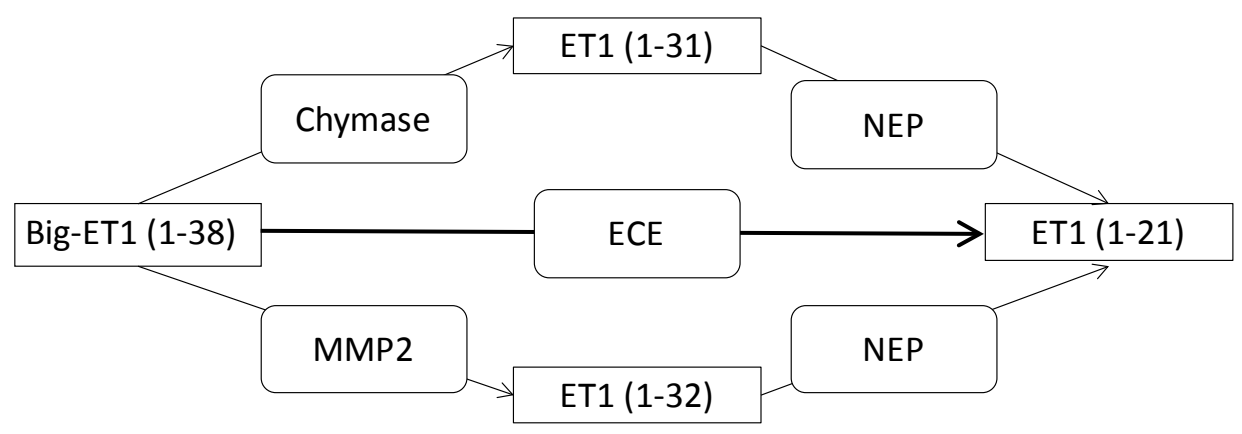

Figure 8.2: Biosynthesis of ET1.

\section{Effects of dual NEP/ECE inhibition on arterial ET1.}

In Chapter 4 we tested the potential of SOL1 to inhibit ET1 production/release. To this end we performed a radio immuno assay where we stimulated mesenteric resistance arteries with thrombin, which can induce ET1 production and release from isolated arteries [78], and high potassium buffer which as we mentioned before specifically stimulates myo-endothelial coupling, especially in DOCA-salt HT animals (Chapter 4). Phosphoramidon as well as SOL1 significantly reduced the amount of ET1 in mesenteric resistance arteries produced by thrombin stimulation as well as the ET1 production in mesenteric resistance arteries of DOCA salt-HT rats. These results validate the use of SOL1 to reduce ET1 production.

\section{Effects of dual NEP/ECE inhibition on blood pressure}

Chronic SOL1 treatment had no effect on blood pressure in SHR independent of their age (Chapters 6 and 7). In DOCA-salt HT rats, however, chronic SOL1 treatment significantly reduced blood pressure (Chapter 5). These effects are similar to the effects observed by Li et al. with ET-receptor antagonists in these experimental models [29, 79-81]. Recently Kalk et al. observed no effect of SLV338, a dual NEP/ECE inhibitor that is chemically related to SOL1, in the 2 kidney 1 clip model of hypertension [82] and Sharkovska et al. reported no effect of SLV338 on blood pressure in L-NAME treated rats [83].

\section{Effects of dual NEP/ECE inhibition on endothelium-dependent arterial reactivity}

In Chapter 6 we studied effects of a chronic treatment with SOL1 on acute endothelial function in mesenteric resistance arteries of 12 week old SHR. An early (SOL1 administration from week 4 to week 8) and a late (SOL1 administration from week 8 to week 12) intervention were studied. In both the early and the late SOL1 intervention groups EDCF-reactivity was abolished by the drug treatment. EDNO was not affected 
but endothelium-derived hyperpolarizing factor (EDHF) was significantly improved by an early SOL1 intervention and even more so by the late SOL1 intervention. This indicates that chronically reducing ET1 production has a positive effect on preserving endothelial function. Even at this age, reducing ET1 production restores or improves the (im)balance between EDCFs and EDRFs.

In Chapter 7 we compared the effects on acute endothelial function of mesenteric resistance arteries for 4 weeks treatment with SOL-1, losartan (AT1-receptor antagonist), hydralazine (direct vasodilator) or vehicle in 32 weeks old SHR. In these animals, the leftward shift of the concentration response curve of phenylephrine, caused by a NO synthase inhibitor, was restored by chronic SOL1 treatment. Similar to the younger SHR, SOL1 treatment completely abolished the typical EDCF response. Again in line with the observations in the 12 week old SHR, EDNO responses were largely unaffected and the EDHF response was improved. The latter was however only observed after acute bosentan administration. This means that even though these animals have established high blood pressure and pronounced endothelial dysfunction, again chronically reducing ET1 production ameliorates the (im)balance between EDCFs and EDRFs.

\section{Effects of dual NEP/ECE inhibition on resistance artery remodeling}

In Chapters 6 and 7 we observed no effect of the NEP/ECE inhibitor SOL1 on resistance artery structure in 12 week old and 32 week old SHR. Chronic losartan treatment, however, significantly decreased the media to lumen ratio in 32 week old SHR as previously described [84-87].

In Chapter 5 we studied the effects on arterial remodeling of chronic 3 week administration of SOL1 during the development of DOCA-salt hypertension. A 3 week SOL1 treatment reduced the media cross-sectional area of arteries of DOCA-salt HT rats, restored outward remodeling and reduced the infiltration of monocyte/macrophages, but arterial stiffness was not affected by the treatment.

Overall the effects of chronic SOL1 treatment on blood pressure and vascular structure are very modest in the SHR. In the DOCA-salt HT rats both aspects are improved by chronic SOL1 treatment. Observations made with SOL1 especially in DOCA-salt HT support roles of ET1 and inflammation in the development of a hypertrophic phenotype. Arterial stiffening, as observed in both hypertension models cannot be resolved by chronic NEP/ECE treatment. Improvement of endothelial function with this treatment was however consistent. In two other models of non-genetic hypertension, a similar therapy also failed to at least reduce blood pressure $[82,83]$. In these two reports as well as in our studies, diverse beneficial effects on several aspects of the pathology were observed despite the lack of a blood pressure lowering effect. Although blood pressure reduction is better handled with other drugs, SOL1 might provide an added value in the treatment of vascular disease. 


\section{Perspective}

Endothelial function is often altered in hypertension. Normal endothelial function is dependent on a balance between relaxing and contractile factors. This thesis shows that in the experimental models that we investigated, ET1 can be the disrupting factor, flipping the balance and causing a dysfunctional endothelium. Since its discovery, the endothelin system has been regarded as a potential target for pharmacotherapy. However clinical trials with ET-receptor antagonists have not been as successful as expected [75-77] which might well be due to the atypical pharmacology of ET1 (Chapter 3). In this view we considered the possibility that preventing the production of ET1 (by inhibiting ECE and NEP) might be more effective than trying to prevent ET1 from binding to its receptor. The findings in this thesis show that this approach showed good results in restoring endothelial function in both SHR and DOCA-salt HT rats. SOL1 was not evenly effective in lowering blood pressure or restoring arterial structure. It might be worthwhile considering combining NEP/ECE inhibition with ACE inhibition or angiotensin II receptor antagonism. Experimental compounds are being developed for these purposes [76, 88]. 


\section{References}

[1] Folkow B. "Structural factor" in primary and secondary hypertension. Hypertension 1990; 16: 89-101.

[2] Folkow B. Physiological aspects of primary hypertension. Physiol Rev 1982; 62: 347-504.

[3] Vanhoutte PM, Shimokawa H, Tang EH, Feletou M. Endothelial dysfunction and vascular disease. Acta Physiol (Oxf) 2009; 196: 193-222.

[4] Furchgott RF, Vanhoutte PM. Endothelium-derived relaxing and contracting factors. FASEB J 1989; 3: 2007-18.

[5] Yanagisawa M, Kurihara H, Kimura S, et al. A novel potent vasoconstrictor peptide produced by vascular endothelial cells. Nature 1988; 332: 411-5.

[6] Epstein BJ, Anderson S. Endothelin receptor antagonists as antihypertensives: the next frontier. Expert Rev Cardiovasc Ther 2009; 7: 675-87.

[7] Prasad VS, Palaniswamy C, Frishman WH. Endothelin as a clinical target in the treatment of systemic hypertension. Cardiol Rev 2009; 17: 181-91.

[8] Schiffrin EL. Vascular endothelin in hypertension. Vascul Pharmacol 2005; 43: 19-29.

[9] Dhaun N, Goddard J, Kohan DE, et al. Role of endothelin-1 in clinical hypertension: 20 years on. Hypertension 2008; 52: 452-9.

[10] Touyz RM, Schiffrin EL. Role of endothelin in human hypertension. Can J Physiol Pharmacol 2003; 81: 533-41.

[11] Donckier JE, Michel L, Van Beneden R, Delos M, Havaux X. Increased expression of endothelin-1 and its mitogenic receptor ETA in human papillary thyroid carcinoma. Clin Endocrinol (Oxf) 2003; 59: 354-60.

[12] Ammarguellat F, Larouche I, Schiffrin EL. Myocardial fibrosis in DOCA-salt hypertensive rats: effect of endothelin ET(A) receptor antagonism. Circulation 2001; 103: 319-24.

[13] Saleh MA, Boesen EI, Pollock JS, Savin VJ, Pollock DM. Endothelin-1 increases glomerular permeability and inflammation independent of blood pressure in the rat. Hypertension 2010; 56: 942-9.

[14] Boldrini L, Pistolesi S, Gisfredi S, et al. Expression of endothelin 1 and its angiogenic role in meningiomas. Virchows Arch 2006; 449: 546-53.

[15] Sawamura T, Kimura S, Shinmi O, et al. Purification and characterization of putative endothelin converting enzyme in bovine adrenal medulla: evidence for a cathepsin D-like enzyme. Biochem Biophys Res Commun 1990; 168: 12306.

[16] Nakano A, Kishi F, Minami K, et al. Selective conversion of big endothelins to tracheal smooth muscle-constricting 31-amino acid-length endothelins by chymase from human mast cells. J Immunol 1997; 159: 1987-92.

[17] Fernandez-Patron C, Radomski MW, Davidge ST. Vascular matrix metalloproteinase-2 cleaves big endothelin-1 yielding a novel vasoconstrictor. Circ Res 1999; 85: 906-11.

[18] Ito S, Carretero OA. Impaired response to acetylcholine despite intact endothelium-derived relaxing factor/nitric oxide in isolated microperfused afferent arterioles of the spontaneously hypertensive rat. J Cardiovasc Pharmacol 1992; 20 Suppl 12: S187-9. 
[19] Jameson M, Dai FX, Luscher T, et al. Endothelium-derived contracting factors in resistance arteries of young spontaneously hypertensive rats before development of overt hypertension. Hypertension 1993; 21:280-8.

[20] Bernatova I, Conde MV, Kopincova J, et al. Endothelial dysfunction in spontaneously hypertensive rats: focus on methodological aspects. J Hypertens Suppl 2009; 27: S27-31.

[21] Nava E, Farre AL, Moreno C, et al. Alterations to the nitric oxide pathway in the spontaneously hypertensive rat. J Hypertens 1998; 16: 609-15.

[22] Radaelli A, Mircoli L, Mori I, Mancia G, Ferrari AU. Nitric oxide dependent vasodilation in young spontaneously hypertensive rats. Hypertension 1998; 32: 735-9.

[23] Pfeffer MA, Frohlich ED. Hemodynamic and myocardial function in young and old normotensive and spontaneously hypertensive rats. Circ Res 1973; 32 : Suppl 1:28-38.

[24] Cunha RS, Dabire H, Bezie I, et al. Mechanical stress of the carotid artery at the early phase of spontaneous hypertension in rats. Hypertension 1997; 29: 992-8.

[25] Okamoto K, Aoki K. Development of a strain of spontaneously hypertensive rats. Jpn Circ J 1963; 27: 282-93.

[26] Nelissen J, Heijnen B, Lemkens P, et al. Endothelin-1 and Calcitonin GeneRelated Peptide contribute to the developing hypertension in young spontaneously hypertensive rats. The FASEB Journal 2011; 25: 823.2.

[27] Lariviere R, Thibault G, Schiffrin EL. Increased endothelin-1 content in blood vessels of deoxycorticosterone acetate-salt hypertensive but not in spontaneously hypertensive rats. Hypertension 1993; 21: 294-300.

[28] Lariviere R, Day R, Schiffrin EL. Increased expression of endothelin-1 gene in blood vessels of deoxycorticosterone acetate-salt hypertensive rats. Hypertension 1993; 21: 916-20.

[29] Li JS, Lariviere R, Schiffrin EL. Effect of a nonselective endothelin antagonist on vascular remodeling in deoxycorticosterone acetate-salt hypertensive rats. Evidence for a role of endothelin in vascular hypertrophy. Hypertension 1994; 24: $183-8$.

[30] Xia J, Little TL, Duling BR. Cellular pathways of the conducted electrical response in arterioles of hamster cheek pouch in vitro. Am J Physiol 1995; 269: H2031-8.

[31] Segal SS, Duling BR. Conduction of vasomotor responses in arterioles: a role for cell-to-cell coupling? Am J Physiol 1989; 256: H838-45.

[32] Little TL, Xia J, Duling BR. Dye tracers define differential endothelial and smooth muscle coupling patterns within the arteriolar wall. Circ Res 1995; 76: 498-504.

[33] Xia J, Duling BR. Electromechanical coupling and the conducted vasomotor response. Am J Physiol 1995; 269: H2022-30.

[34] Dora KA, Doyle MP, Duling BR. Elevation of intracellular calcium in smooth muscle causes endothelial cell generation of NO in arterioles. Proc Natl Acad Sci U S A 1997; 94: 6529-34.

[35] Hilgers RH, De Mey JG. Myoendothelial coupling in the mesenteric arterial bed; segmental differences and interplay between nitric oxide and endothelin1. Br J Pharmacol 2009; 156: 1239-47. 
[36] Dora KA, Hinton JM, Walker SD, Garland CJ. An indirect influence of phenylephrine on the release of endothelium-derived vasodilators in rat small mesenteric artery. Br J Pharmacol 2000; 129: 381-7.

[37] Davies PF. Flow-mediated endothelial mechanotransduction. Physiol Rev 1995; 75: 519-60.

[38] Pourageaud F, De Mey JG. Structural properties of rat mesenteric small arteries after 4-wk exposure to elevated or reduced blood flow. Am J Physiol 1997; 273: H1699-706.

[39] Langille BL. Morphologic responses of endothelium to shear stress: reorganization of the adherens junction. Microcirculation 2001; 8: 195-206.

[40] Smiesko V, Lang DJ, Johnson PC. Dilator response of rat mesenteric arcading arterioles to increased blood flow velocity. Am J Physiol 1989; 257: H195865 .

[41] Bevan JA, Laher I. Pressure and flow-dependent vascular tone. FASEB J 1991; 5: 2267-73.

[42] Bevan JA, Henrion D. Pharmacological implications of the flow-dependence of vascular smooth muscle tone. Annu Rev Pharmacol Toxicol 1994; 34: 17390 .

[43] Langille BL, O'Donnell F. Reductions in arterial diameter produced by chronic decreases in blood flow are endothelium-dependent. Science 1986; 231: 405-7.

[44] Unthank JL, Fath SW, Burkhart HM, Miller SC, Dalsing MC. Wall remodeling during luminal expansion of mesenteric arterial collaterals in the rat. Circ Res 1996; 79: 1015-23.

[45] Dumont O, Loufrani L, Henrion D. Key role of the NO-pathway and matrix metalloprotease-9 in high blood flow-induced remodeling of rat resistance arteries. Arterioscler Thromb Vasc Biol 2007; 27: 317-24.

[46] Tohda K, Masuda H, Kawamura K, Shozawa T. Difference in dilatation between endothelium-preserved and -desquamated segments in the flowloaded rat common carotid artery. Arterioscler Thromb 1992; 12: 519-28.

[47] Gao YJ, Yang LF, Stead S, Lee RM. Flow-induced vascular remodeling in the mesenteric artery of spontaneously hypertensive rats. Can J Physiol Pharmacol 2008; 86: 737-44.

[48] Mulvany MJ, Baandrup U, Gundersen HJ. Evidence for hyperplasia in mesenteric resistance vessels of spontaneously hypertensive rats using a threedimensional disector. Circ Res 1985; 57: 794-800.

[49] Mizutani K, Ikeda K, Kawai Y, Yamori Y. Biomechanical properties and chemical composition of the aorta in genetic hypertensive rats. J Hypertens 1999; 17: 481-7.

[50] Boonen HC, Daemen MJ, Eerdmans PH, et al. Mesenteric small artery changes after vasoconstrictor infusion in young rats. J Cardiovasc Pharmacol 1993; 22: 388-95.

[51] van Gorp AW, Schenau DS, Hoeks AP, et al. In spontaneously hypertensive rats alterations in aortic wall properties precede development of hypertension. Am J Physiol Heart Circ Physiol 2000; 278: H1241-7.

[52] Izzard AS, Horton S, Heerkens EH, Shaw L, Heagerty AM. Middle cerebral artery structure and distensibility during developing and established phases of hypertension in the spontaneously hypertensive rat. J Hypertens 2006; 24: 87580 . 
[53] Intengan HD, Thibault G, Li JS, Schiffrin EL. Resistance artery mechanics, structure, and extracellular components in spontaneously hypertensive rats : effects of angiotensin receptor antagonism and converting enzyme inhibition. Circulation 1999; 100: 2267-75.

[54] Schiffrin EL, Lariviere R, Li JS, Sventek P, Touyz RM. Endothelin-1 gene expression and vascular hypertrophy in DOCA-salt hypertension compared to spontaneously hypertensive rats. Clin Exp Pharmacol Physiol Suppl 1995; 22: S188-90.

[55] Shimamoto H, Iriuchijima J. Hemodynamic characteristics of conscious deoxycorticosterone acetate hypertensive rats. Jpn J Physiol 1987; 37: 243-54.

[56] Heagerty AM, Aalkjaer C, Bund SJ, Korsgaard N, Mulvany MJ. Small artery structure in hypertension. Dual processes of remodeling and growth. Hypertension 1993; 21: 391-7.

[57] Amiri F, Virdis A, Neves MF, et al. Endothelium-restricted overexpression of human endothelin-1 causes vascular remodeling and endothelial dysfunction. Circulation 2004; 110: 2233-40.

[58] Fukuda G, Khan ZA, Barbin YP, et al. Endothelin-mediated remodeling in aortas of diabetic rats. Diabetes Metab Res Rev 2005; 21: 367-75.

[59] Ko EA, Amiri F, Pandey NR, et al. Resistance artery remodeling in deoxycorticosterone acetate-salt hypertension is dependent on vascular inflammation: evidence from m-CSF-deficient mice. Am J Physiol Heart Circ Physiol 2007; 292: H1789-95.

[60] Leibovitz E, Ebrahimian T, Paradis P, Schiffrin EL. Aldosterone induces arterial stiffness in absence of oxidative stress and endothelial dysfunction. J Hypertens 2009.

[61] Amiri F, Paradis P, Reudelhuber TL, Schiffrin EL. Vascular inflammation in absence of blood pressure elevation in transgenic murine model overexpressing endothelin-1 in endothelial cells. J Hypertens 2008; 26: 1102-9.

[62] Ward MR, Pasterkamp G, Yeung AC, Borst C. Arterial remodeling. Mechanisms and clinical implications. Circulation 2000; 102: 1186-91.

[63] Buus CL, Pourageaud F, Fazzi GE, et al. Smooth muscle cell changes during flow-related remodeling of rat mesenteric resistance arteries. Circ Res 2001; 89: 180-6.

[64] Bouvet C, Belin de Chantemele E, Guihot AL, et al. Flow-induced remodeling in resistance arteries from obese Zucker rats is associated with endothelial dysfunction. Hypertension 2007; 50: 248-54.

[65] Ceiler DL, De Mey JG. Chronic N(G)-nitro-L-arginine methyl ester treatment does not prevent flow-induced remodeling in mesenteric feed arteries and arcading arterioles. Arterioscler Thromb Vasc Biol 2000; 20: 2057-63.

[66] Tuttle JL, Hahn TL, Sanders BM, et al. Impaired collateral development in mature rats. Am J Physiol Heart Circ Physiol 2002; 283: H146-55.

[67] Tuttle JL, Sanders BM, Burkhart HM, et al. Impaired collateral artery development in spontaneously hypertensive rats. Microcirculation 2002; 9: 343-51.

[68] De Mey JG, Schiffers PM, Hilgers RH, Sanders MM. Toward functional genomics of flow-induced outward remodeling of resistance arteries. Am J Physiol Heart Circ Physiol 2005; 288: H1022-7. 
[69] Wesselman JP, Kuijs R, Hermans JJ, et al. Role of the Rhoa/Rho kinase system in flow-related remodeling of rat mesenteric small arteries in vivo. $\mathrm{J}$ Vasc Res 2004; 41: 277-90.

[70] Murphy-Ullrich JE, Pallero MA, Boerth N, et al. Cyclic GMP-dependent protein kinase is required for thrombospondin and tenascin mediated focal adhesion disassembly. J Cell Sci 1996; 109 ( Pt 10): 2499-508.

[71] Orr AW, Elzie CA, Kucik DF, Murphy-Ullrich JE. Thrombospondin signaling through the calreticulin/LDL receptor-related protein co-complex stimulates random and directed cell migration. J Cell Sci 2003; 116: 2917-27.

[72] Orr AW, Pedraza CE, Pallero MA, et al. Low density lipoprotein receptorrelated protein is a calreticulin coreceptor that signals focal adhesion disassembly. J Cell Biol 2003; 161: 1179-89.

[73] Murphy-Ullrich JE. The de-adhesive activity of matricellular proteins: is intermediate cell adhesion an adaptive state? J Clin Invest 2001; 107: 785-90.

[74] Dey NB, Boerth NJ, Murphy-Ullrich JE, et al. Cyclic GMP-dependent protein kinase inhibits osteopontin and thrombospondin production in rat aortic smooth muscle cells. Circ Res 1998; 82: 139-46.

[75] Hynynen MM, Khalil RA. The vascular endothelin system in hypertension-recent patents and discoveries. Recent Pat Cardiovasc Drug Discov 2006; 1 : 95-108.

[76] Kirkby NS, Hadoke PW, Bagnall AJ, Webb DJ. The endothelin system as a therapeutic target in cardiovascular disease: great expectations or bleak house? Br J Pharmacol 2008; 153: 1105-19.

[77] Schneider MP, Boesen EI, Pollock DM. Contrasting actions of endothelin ET(A) and ET(B) receptors in cardiovascular disease. Annu Rev Pharmacol Toxicol 2007; 47: 731-59.

[78] Boulanger C, Luscher TF. Release of endothelin from the porcine aorta. Inhibition by endothelium-derived nitric oxide. J Clin Invest 1990; 85: 587-90.

[79] Li JS, Schiffrin EL. Effect of chronic treatment of adult spontaneously hypertensive rats with an endothelin receptor antagonist. Hypertension 1995; 25: 495-500.

[80] Li JS, Schiffrin EL. Chronic endothelin receptor antagonist treatment of young spontaneously hypertensive rats. J Hypertens 1995; 13: 647-52.

[81] Schiffrin EL, Sventek P, Li JS, Turgeon A, Reudelhuber T. Antihypertensive effect of an endothelin receptor antagonist in DOCA-salt spontaneously hypertensive rats. Br J Pharmacol 1995; 115: 1377-81.

[82] Kalk P, Sharkovska Y, Kashina E, et al. Endothelin-Converting Enzyme/Neutral Endopeptidase Inhibitor SLV338 Prevents Hypertensive Cardiac Remodeling in a Blood Pressure-Independent Manner. Hypertension 2011; 57: 755-63.

[83] Sharkovska Y, Kalk P, von Websky K, et al. Renoprotective effects of combined endothelin-converting enzyme/neutral endopeptidase inhibitor SLV338 in acute and chronic experimental renal damage. Clin Lab 2011; 57: 507-15.

[84] Soltis EE. Alterations in vascular structure and function after short-term losartan treatment in spontaneously hypertensive rats. J Pharmacol Exp Ther 1993; 266: 642-6. 
General Discussion

[85] Pu Q, Brassard P, Javeshghani DM, et al. Effects of combined AT1 receptor antagonist/NEP inhibitor on vascular remodeling and cardiac fibrosis in SHRSP. J Hypertens 2008; 26: 322-33.

[86] Schiffrin EL, Park JB, Intengan HD, Touyz RM. Correction of arterial structure and endothelial dysfunction in human essential hypertension by the angiotensin receptor antagonist losartan. Circulation 2000; 101: 1653-9.

[87] Morton JJ, Beattie EC, MacPherson F. Angiotensin II receptor antagonist losartan has persistent effects on blood pressure in the young spontaneously hypertensive rat: lack of relation to vascular structure. J Vasc Res 1992; 29: 264-9.

[88] Davenport AP, Hyndman KA, Dhaun N, et al. Endothelin. Pharmacol Rev 2016; 68: 357-418. 


\section{Chapter 9}

Summary 
Endothelial dysfunction and arterial remodeling contribute to the pathophysiology of hypertension. It is unclear whether hypertension affects the ability to respond to imposed changes in shear stress and circumferential wall stress.

Endothelin-1 (ET1) is a potent vasoconstrictor, a potent growth promoting and proinflammatory agent. These functions make the endothelin system a prone target in reversing arterial remodeling, preventing endothelial dysfunction and treatment of hypertension.

In Chapter 2 we evaluated the effects of altered blood flow on the mRNA and protein expression in 6 week old WKY and 6 week old SHR. We observed a rapid and concurrent downregulation of eNOS, sGC and PKG mRNA and upregulation of TSP1 mRNA expressions at the initiation of flow-related remodeling. The results for mRNA as well as protein were however largely similar in both strains suggesting that the pathways investigated are not likely involved in the inward remodeling of resistance arteries that contributes to the elevated total peripheral vascular resistance and blood pressure in SHR. Furthermore we reported the ability of the calreticulin/LRP1 binding sequence (hep1) of TSP1 to promote a de-adhesive state and reverse the inward remodeling of mesenteric resistance arteries observed in 12 week old SHR.

In Chapter 3 we give an overview of the peculiar interaction of ET1 with the $\mathrm{ET}_{\mathrm{A}}$ receptor. We elaborated on why current treatments targeting ET1/ET-receptor interacting have been less successful than anticipated.

In Chapter 6 we reported that chronic NEP/ECE inhibition with SOL1 has no effects on blood pressure nor on structure of mesenteric resistance arteries from young (12 week old) SHR. Dysfunction is most apparent in the upregulation of the EDCF (endotheliumderived contractile factor) response and an impairement of the EDHF (endotheliumderived hyperpolarizing factor) response. Despite the lack of structural effects in these animals, chronic SOL1 administration does improve endothelial function and may thus be a valuable (supplementary) treatment option for this pathology.

Similar results as regards to EDCF and EDHF as well as structure were obtained in 32 week old SHR (Chapter 7), although the improvement of EDHF was only observed after a pretreatment with the non-selective $\mathrm{ET}_{\mathrm{A} / \mathrm{B}}$ antagonist bosentan. Chronic treatment with the angiotensin II antagonist losartan or the vasodilator hydralazine did not result in an improvement of endothelial function. Contrary to the lack of effect of SOL1 on arterial structure and blood pressure, chronic losartan administration succeeded in significantly reducing blood pressure and decreasing wall to lumen ratios. A combination of an angiotensin II receptor antagonist, or alternatively an ACE inhibitor, and a dual NEP/ECE inhibitor could be an interesting option to look in to.

In Chapter 4 we confirmed that SOL1 is able to reduce ET1 peptide levels in mesenteric resistance arteries. Subsequently we established potassium induced activation of vascular 
smooth muscle as a stimulus for endothelin-1 production and release in DOCA-salt HT, but not NT rats. In line with this observation, ET1 potentiated contractile responses during potassium induced activation of vascular smooth muscle in mesenteric resistance arteries of DOCA-salt HT rats. A similar effect was not observed in NT. The endothelin-1 effects could be completely inhibited by mechanical removal of the endothelium and by the non selective ET-receptor antagonist bosentan, and partly by inhibiting the synthesis pathways with the dual NEP/ECE inhibitors phosphoramidon and SOL1. These observations suggest that a pronounced feedback mechanism exists stimulating endothelin-1 release from the endothelium after potassium induced activation of vascular smooth muscle specifically in DOCA-salt HT rats.

Structural properties and the effect of SOL1 administration were described in Chapter 5.

We showed that mesenteric resistance arteries of DOCA salt HT rats show transient infiltration of monocyte/macrophages, hypertrophy, increased arterial stiffness, impaired outward remodeling in response to an increase in flow and inward remodeling as a response to decreased flow. While the can be by chronic NEP/ECE inhibitor treatment (partly) reversed hypertrophy and improved the impaired outward remodeling. Arterial stiffness was not affected by the chronic SOL1 administration. Furthermore we observed that mesenteric resistance arteries exposed to low flow conditions also showed transient infiltration of monocyte/macrophages which was more pronounced in DOCA-salt hypertensive arteries. After 6 weeks of DOCA-salt hypertension, vasa vasorum-like structures formed in the adventitial layer proximal to the suture. The region and severity of the inflammation was greatly reduced by chronic SOL1 administration.

Chapter 8 provides a general discussion of this dissertation. 



\section{Chapter 10}

Samenvatting 
Endotheel dysfunctie en arteriële remodelering dragen bij tot de pathofysiologie van hypertensie. Het is niet duidelijk als hypertensie de mogelijkheid van bloedvaten om te reageren op opgelegde veranderingen in schuifspanning en wandspanning, beïnvloed.

Endotheline-1 (ET1) is een krachtige vaatvernauwend, celgroei stimulerend en een ontstekings-inducerend eiwit. Deze eigenschappen maken van het endotheline systeem een uitstekend aangrijppunt voor het omkeren van arteriële remodelering, het voorkomen van endotheel-dysfunctie en de behandeling van hypertensie.

In Hoofdstuk 2 evalueren we de effecten van gewijzigd bloedstroomdebiet op de mRNA en eiwit expressie in 6 weken oude WKY en SHR. We zagen een snelle en gelijktijdige "neerwaartse regulering" van eNOS, sGC en PKG mRNA en een "opwaartse regulatie" van TSP1 mRNA expressie bij het initiëren van stroom-gerelateerde remodelering. De resultaten wat betreft mRNA en eiwit waren gelijkaardig wat suggereert dat de onderzochte mechanisme waarschijnlijk niet betrokken zijn bij het proces van inwaarts remodeleren van weerstandsvaten, wat bijdraagt tot de totale verhoogde perifere vasculaire weerstand en bloeddruk kenmerkend voor de SHR. Voorts zagen we dat de calreticulin/LRP1 bindings sequentie (hep1) van TSP1 de de-adhesieve staat en de omgekeerde remodelering van mesenterische weerstandsvaten van 12 weken oude SHR bevorderde.

Hoofdstuk 3 biedt een overzicht van de opmerkelijke interacties van ET1 met de ETA receptor. We gaan in op mogelijke redenen waarom de huidige behandelingen die zich richten op de ET1/ET-receptor interacties minder succesvol zijn dan verwacht.

In Hoofdstuk 6 wordt beschreven dat chronische inhibitie van NEP/ECE met SOL1 geen effecten had op bloeddruk of de structuur van mesenterische weerstandsvaten van jonge (12 weken oude) SHR. De Dysfunctie in deze dieren uit zich het meest prominent als een opregulatie van de EDCF en een verzwakking van de EDHF respons. Ondanks het gebrek aan structuur effecten in deze dieren verbetert het chronisch toedienen van SOL1 de endotheel functie en zou dus een waardevolle (additionele) behandelingsmogelijkheid zijn voor deze pathologie.

Gelijkaardige resultaten wat betreft zowel EDVF en EDHF als vaatstructuur werden waargenomen in 32 weken oude SHR (Hoofdstuk 7), hoewel dat de verbetering van EDHF enkel werd waargenomen na voorbehandeling met de niet-selevtieve ETA/B receptor antagonist bosentan. Chronische behandeling met de angiotensine II antagonist losartan of de vaatverwijderaar hydralazine resulteerden niet in een verbetering van endotheel functie. In tegenstelling tot het gebrek aan effect van SOL1 op arteriële structuur en bloeddruk was chronische losartan behandeling wel succesvol in het verlagen van de bloeddruk en de wand vs lumen ratio. Een combinatie van een angiotensin II receptor antagonsit, of een ACE inhibitor en een NEP/ECE inhibitor zou een interessant agens kunnen zijn om in deze optiek te bekijken. 
In Hoofdstuk 4 bevestigden we dat SOL1 in staat is om de ET petide niveaus in mesenterische weerstandsvaten te verminderen. Vervolgens toonden we aan dat Kalium geinduceerde activatie van vasulaire gladde spier een stimulans is voor ET1 productie en vrijzetting in DOCA zout hypertensieve maar niet in notmotensieve ratten. Volgend op deze observatie konden we vaststellen dat ET1 de contractorische responses door Kalium geinduceerde activatie van vasculaire gladde spier versterkte in DOCA zout hypertensieve ratten. Een gelijkaardig effect werd niet waargenomen in normotensieve ratten. De ET1 effecten konden volledig geinhibeerd worden door de mechanische verwijdering van het endotheel en door de niet selectieve ET-receptor antagonist bosentan, en ook deels door het inhiberen van de synthese route met de dubbele NEP/ECE inhibitoren phosphoramidon en SOL1. Deze observaties suggereren dat er een uitgesproken terugkoppelingsmechanisme bestaat dat ET vrijzetting stimuleerd uit het endotheel na Kalium geinduceerde activatie van vasculaire gladde spier specifiek in DOCA zout hypertensieve ratten.

Structurele eigenschappen en het effect van SOL1 administatie werden beschreven in Hoofdstuk 5.

We toonden aan dat mesenterische weerstandsvaten van DOCA zout hypertensieve ratten een transiente infiltratie van monocyte/macrofagen, verhoogde arteriele stijfheid, en vermindering van de uitwaartste remodelering als antwoord op een verhoogde stroom en inwaartse remodelering als antwooord op een verlaagde stroom vertonen. Arteriele stijfheid werd niet beinvloed door chronische SOL1 behandeling. Voorts konden we vaststellen dat mesenterische weerstandsvaten, blootgesteld aan verlaagde bloedstroom, een transiente infiltratie van monocyte/macrofagen vertoond die meer uitgesproken was in arterien van DOCA zout hypertensieve dieren. Na 6 weken DOCA zout hypertensie vormden zich vasa-vasorum structuren in de adventitia laag dicht bij de hechting. De betrokken regio en de ernst van de infflamatie werden sterk verminderd door chorinsche SOL1 toediening.

Hoofdstuk 8 voorziet een algemene discussie van dit proefschrift. 



\section{Appendix \\ Valorisatie addendum \\ Dankwoord \\ Curriculum Vitae \\ List of publications}




\section{Valorisatie addendum}

Hypertensie of hoge bloeddruk is een aandoening waaraan meer dan 1 miljard mensen wereldwijd leiden. Zowat 95\% van de patiënten met hoge bloeddruk worden beschouwd als leidend aan primaire of essentiële hypertensie, omdat er geen specifieke oorzaak kon geïdentificeerd worden voor hun aandoening. Hoge bloeddruk wordt geassocieerd met een verhoogd risico voor mortaliteit en morbiditeit door cardiovasculaire ziektes, het laatste stadium van nierziektes, en cerebrovasculaire accidenten. De voordelen van het verminderen van de risico's door middel van het verlagen van de bloeddruk met antihypertensieve therapieën is reeds overtuigend aangetoond in een aanzienlijke hoeveelheid klinische studies. Ondanks de geboekte vooruitgang in recente jaren in de preventie, de detectie en de behandeling van hoge bloeddruk, blijft hypertensie een belangrijke uitdaging voor de volksgezondheid. Op basis van de vaststellingen dat de bevolking almaar ouder wordt en de toename van andere risicofactoren zoals obesitas, diabetes en een dieet dat overmatig zout bevat kan voorspeld worden dat het aantal patiënten dat leidt aan een te hoge bloeddruk zal blijven toenemen. Hoewel er meer dan 75 antihypertensieve geneesmiddelen, behorende tot verschillende klassen, voorhanden zijn blijkt dit onvoldoende om bloeddruk onder controle te krijgen (houden). Het aantal patiënten met een verhoogde bloeddruk bij wie de verhoogde bloeddruk behandeld en onder controle kan gehouden worden is aanzienlijk gestegen, maar naar schatting 1/3 van de patiënten met hoge bloeddruk wordt niet behandeld en bij $1 / 4$ van de patiënten met een hoge bloeddruk leidt de behandeling niet tot een verlaging van de bloeddruk. Dit geeft aan dat er nood is aan nieuwe anti-hypertensieve therapieën (klassen).

Doorgaans is het hoofddoel van anti-hypertensieve therapieën het verlagen van de bloeddruk op zich, maar omdat een verhoogde perifere vaatweerstand kan beschouwd worden als de belangrijkste oorzaak van permanente hoge bloeddruk, worden niet zozeer de oorzaken maar de symptomen van hoge bloeddruk aangepakt. Het is daarom belangrijk om niet enkel de bloeddruk te verlagen maar om ook de structurele en functionele veranderingen in de arteriën die bijdragen tot de perifere weerstand, te verlichten. Het is dus belangrijk om de veranderingen in arteriële structuur om te keren en de endotheel functie te normaliseren.

Neutral endopeptidase (NEP) en endothelin converting enzyme (ECE) zijn structureel zeer gelijkende metalloproteases die beide betrokken zijn bij de productie en de afbraak van verschillende vasoactieve peptiden zoals bradykinine, Ang I, Ang II, natriuretic peptides (ANP,BNP and CNP), substance P, CGRP en endothelin-1 (ET1). Endothelin-1 (ET1), is een zeer krachtige vasoconstrictor die tevens de groei van cellen en ontstekings reacties bevordert.

Het doel van het onderzoek in dit proefschrift was het (i) karakteriseren van de endotheel dysfunctie en de impact op vasculaire remodelering in diermodellen (met name ratten) 
voor hoge bloeddruk en (ii) het onderzoeken van het potentieel van NEP/ECE inhibitie als een bijkomende behandelingsoptie met toegevoegde waarde in hypertensie.

Preklinische studies met ECE-inhibitoren vertoonden wel wat potentieel maar in andere werd vastgesteld dat een vermindering van ECE activiteit een accumulatie van amyloid $\beta$-peptide tot gevolge had wat kan leiden tot neurotoxiciteit. Candoxatril, een krachtige, oraal beschikbare NEP inhibitor bleek effectief in het voorkomen van de afbraak van natriuretische peptides, maar de effecten op de bloeddruk van hypertensieve patiënten was niet klinisch betekenisvol. Integendeel, in normotensieve patiënten werd een verhoogde bloeddruk gemeld, waarschijnlijk toe te schrijven aan een verhoogde activiteit van ET1 en Ang II. Met de combinatie NEP/ECE inhibitor SLV306 werd een verlaging van de ambulante bloeddruk vastgesteld in een patiëntenpopulatie die zeer vaak resistent bleek voor andere therapieën.

In de toekomst zouden NEP/ECE inhibitors verder ontwikkeld moeten worden en zouden patiëntstudies in therapie-resistente populaties van patienten met hoge bloeddruk meer inzicht kunnen verschaffen. Bovendien zou het onderzoeken van het potentieel van triple inhibitoren (angiotensin-converting enzyme/NEP/ECE) een toegevoegde waarde kunnen bieden voor patiënten die niet reageren op de therapieën die reeds voorhanden zijn. 


\section{Dankwoord}

Vooreerst wil ik Jo bedanken om me de kans te geven om te promoveren. Bedankt voor al het geduld, al de input en deskundigheid. Bedankt om me blijvend nieuwschierig te houden en me af en toe weer in de juiste richting te duwen.

Mijn co-promotor Paul. Je hebt al die jaren naast me gestaan als een rots. Je hebt je praktische en inhoudelijke kennis altijd enorm goed weten over te brengen, en vooral ik wist van de eerste dag dat ik altijd en voor alles op jou kon rekenen.

Rob, jij stond tijdens mijn eerste jaren nagenoeg altijd naast me experimenten uit te voeren. Bedankt voor de inspiratie, de vele koffie momentjes, en alle interessante gesprekken. Ik heb er veel van geleerd.

Merlijn, wat dat betreft opvolger van Rob. Bureau-genoot en TIP collega. On the fly advies of hulp vragen, ik wist altijd wat ik aan je had. Bedankt voor de interessante discussies en kritische lezingen van manuscripten.

Bart, Léon, en Jelly, oofk TIP collegas, bedankt voor de bergen in vivo werk waar ik van mocht meeprofiteren. Zonder jullie had ik niet veel gehad om over te schrijven. Ben en Thijs, bedankt voor alle input in mijn experimenten en manuscripten.

Jet, Ger, en Gregorio. Weinigen zullen ooit beseffen hoe immens veel werk jullie voor mij verzet hebben. Uit de grond van mijn hart, bedankt voor het geduld, de leuke gesprekken, en uiteraard al het experimentele werk!

Mijn andere TIP collegas, het was erg stimulerend om tweejaarlijks jullie resultaten naast de mijne te leggen en te zoeken naar rakpunten.

Daniela, een wijs man zei me ooit "aan een dood paard moet je niet blijven sleuren", maar dat moet de afgelopen jaren vaak het gevoel zijn geweest dat jij hebt gehad. Bedankt voor de onvoorwaardelijke steun, de peptalks, en het geloof in mij. Ik had dit met niemand anders naast me willen doen.

Maria-Laura, Elisa, en Anna, lieve kinderen, ooit zullen jullie beseffen hoe belangrijk jullie voor mij zijn. Veel sombere dagen hebben jullie opgevrolijkt met een lach, een knuffel of een kusje. Ik zie jullie doodgraag!

Yazmin en Danilo, bedankt om me in jullie gezin te ontvangen alsof ik jullie eigen kind was. Ook heel erg bedankt voor het opvolgen van mijn promotie en het deskundige advies. 
Ten slotte, moeke en papa, jullie hebben er altijd alles aan gedaan om er voor te zorgen dat ik überhaupt kon beginnen aan een promotietraject. Dank voor alle steun, alle geloof in mij en het feit dat jullie altijd voor mij klaar staan! 
Appendix

\section{Curriculum Vitae}

Pieter Lemkens werd geboren op 31 December 1980 te Leuven (België), groeide op in Genk (België) waar hij afstuurdeerde van het Sint-Jan Bergmans college in 1999.

$\mathrm{Na}$ een periode in de opleiding bio-ingenieur begon hij aan een bachelor opleiding Scheikunde. Na het behalen van de bachelor titel in 2004 begon hij aan een master opleiding Biochemie die hij succesvol beëindigde in 2006.

In 2007 begon hij met een promotietraject bij de afdeling Farmacologie (toen nog Farmacologie en Toxicologie) die onderdeel is van het Cardiovascular Research Institute Maastricht (CARIM). Tijdens zijn promotietraject presenteerde hij zijn werk op verschillende nationale en internationale congressen.

Sinds 2012 is hij aan de slag als medical writer bij SGS LS, mechelen, België 


\section{List of publications}

P. Lemkens, G.E.M. Boari, G.E. Fazzi, G. Janssen, J.E. Murphy-Ullrich, P.M.H. Schiffers and J.G.R. De Mey: NO Synthase and Thrombospondin-1 in the Initiation of Flow- Related Remodeling of Mesenteric Resistance Arteries from Young Normotensive and Spontaneously Hypertensive Rats. Open Cardiovasc Med J. $2012 ; 6: 50-9$

P. Lemkens, J. Nelissen, M.J.P.M.T Meens, G.E. Fazzi, G.J.M. Janssen, J.J.M. Debets, B. Janssen, P.M.H. Schiffers, J.G.R. De Mey. Impaired Flow-Induced Arterial Remodeling in DOCA-Salt Hypertension. Hypertens Res. 2012 Nov;35(11):1093-101

P. Lemkens, J. Nelissen, M.J.P.M.T Meens, B.J.A. Janssen, P.M.H. Schiffers, J.G.R. De Mey. Dual neutral endopeptidase/endothelin-converting enzyme inhibition improves endothelial function of mesenteric resistance arteries in young SHR. $J$ Hypertens. 2012 Sep;30(9):1799-808

P Lemkens, LJ Spijkers, MJ Meens, J Nelissen, B Janssen, SL Peters, PM Schiffers, JG De Mey. Dual NEP/ECE inhibition improves endothelial function in mesenteric resistance arteries of 32-week-old SHR. Hypertens Res. 2017 Aug;40(8):738-745

MJPMT Meens, NJA Mattheij, J Nelissen, P Lemkens, MG Compeer, BJA Janssen, JGR De Mey. CGRP terminates long-lasting vasopressor responses to endothelin-1 in vivo. Hypertension. $2011 \mathrm{Jul} ; 58(1)$

Jo GR De Mey, Matthijs G Compeer, Pieter Lemkens, Merlijn JPMT Meens. ETAreceptor antagonists or allosteric inhibitors? Trends in pharmacology. 2011 Jun;32(6)

Merlijn Meens, Nadine Mattheij, Pieter van Loenen, Léon Spijkers, Pieter Lemkens, Jelly Nelissen, Astrid Alewijnse, Jo De Mey. G protein $\beta \gamma$ subunits in vasorelaxing and anti-endothelinergic effects of calcitonin gene-related peptide. Br J Pharmacol. 2012 May;166(1):297-308

Nelissen J, Lemkens P, Sann H, Bindl M, Bassissi F, Jasserand D, De Mey JG, Janssen BJ. Pharmacokinetic and pharmacodynamic properties of SOL1: a novel dual inhibitor of neutral endopeptidase and endothelin converting enzyme. Life Sci. 2012 Oct $15 ; 91(13-14): 587-92$ 
